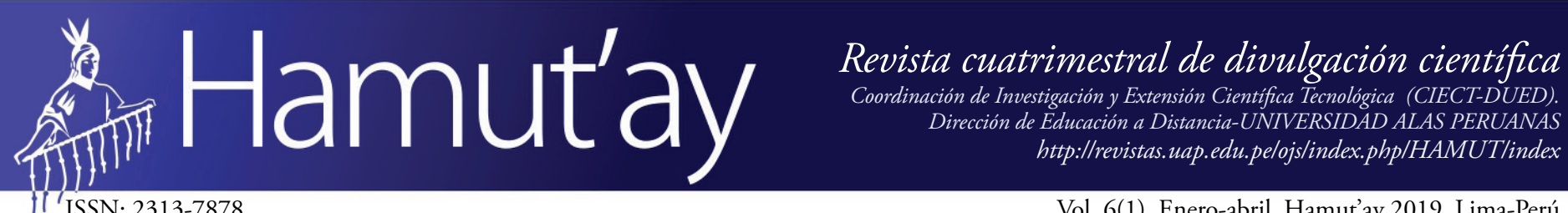

Vol. 6(1). Enero-abril. Hamut’ay 2019. Lima-Perú

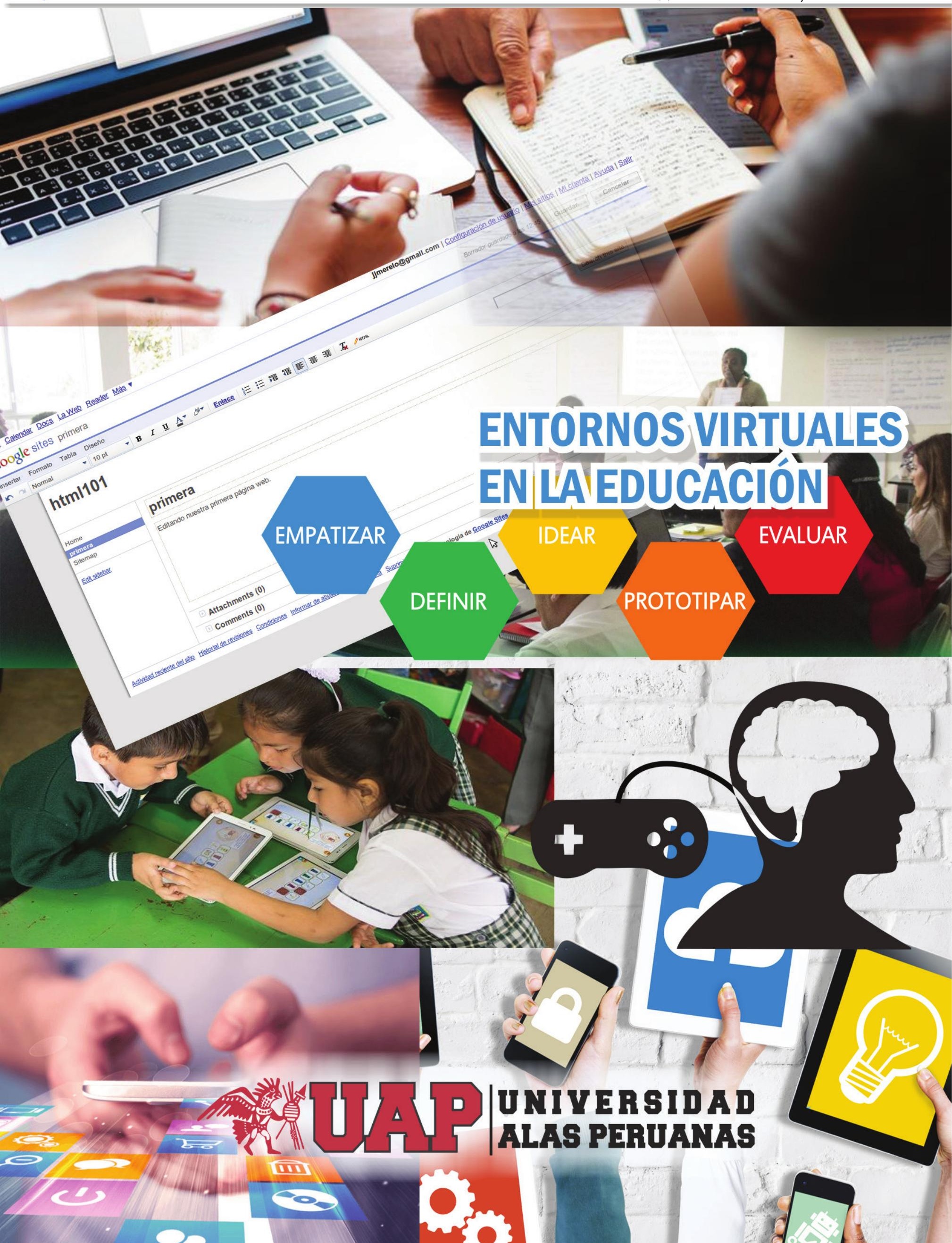




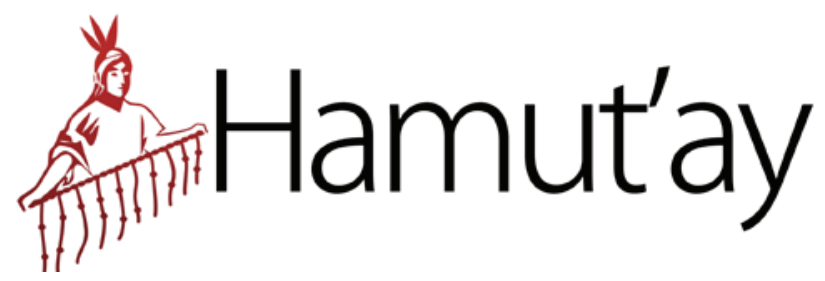

Revista cuatrimestral de divulgación científica publicada por la Coordinación de Investigación y Extensión Científica Tecnológica (CIECT-DUED) de la Dirección de Educación a Distancia. Universidad Alas Peruanas. Lima, Perú.

ISSN 2313-7878

Título clave: Hamut'ay

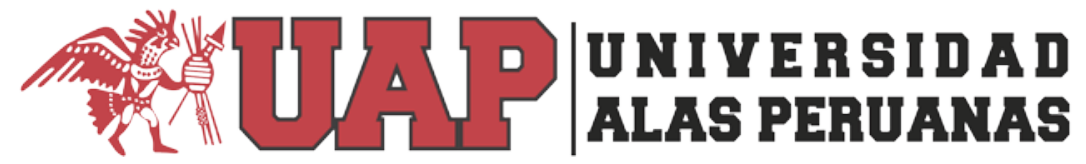

DUED

http://revistas.uap.edu.pe/ojs/index.php/HAMUT/index correo electrónico: revistahamutay@uap.edu.pe 
UNIVERSIDAD ALAS PERUANAS

Dr. José María Viaña Pérez Rector (i)

Ignacio A. Ramírez Vallejo M.V.,Ph. D. Vicerrector Académico

Dr. Manuel Coronado Aguilar

Vicerrector Administrativo

Dr. Ricardo Díaz Bazán

Vicerrector de Investigacion, Innovación y Emprendimiento

Dra. Rosabel Alarcón Ramírez

Directora, Dirección de Educación a Distancia

Directora General Revista Hamut'ay

\section{EDITOR EN JEFE}

Dra. Cleofé Genoveva Alvites Huamaní

Universidad Alas Peruanas, Perú

\section{CONSEJO EDITORIAL}

Dra. Constanza Abadia Garcia

Universidad Nacional Abierta a Distancia, Colombia

Dr. Agustín Jaime Negrete Cortés Universidad Autónoma de Baja California, México

Dr. Ramfis Miguelena

Universidad Tecnológica de Panamá

Dr. José Ernesto Mancera Pineda

Universidad Nacional de Colombia

Dr. Pedro Agustín Pernías Peco

Universidad de Alicante, España

Ing. David Antonio Franco Borré

Universidad de Cartagena, Colombia

Ricardo Filipe Martins, PhD

Grupo PEDAGO, Instituto Superior de Ciências

Educativas ISCE / ISCE Douro, Portugal

Lilian R. Daset, Ph.D.

Universidad Católica del Uruguay

Ing. Katia Ruiz

Universidad Alas Peruanas, Perú

Mag. Liliana Larrea

Universidad Alas Peruanas, Perú

Lic. Luis Molina Almanza

Universidad Alas Peruanas, Perú
Vol. 6(1). Enero-abril. Hamut’ay 2019. Lima-Perú

\section{COMITÉ CIENTÍFICO}

Dr. Pere Marqués Graells

Universidad Autónoma de Barcelona, España

Dr. José Antonio Caride Gómez

Universidade de Santiago de Compostela, España

Dr. Philip Desenne

Harvard University, EE. UU.

M.Sc. Plinio Puello Marrugo

Universidad de Cartagena, Colombia

Dr. Pedro Martínez Geijo

Universidad Nacional de Educación a Distancia, España

Miguel Ángel García-Ruiz, PhD.

Algoma University, Canadá

Adriana P. Herrera. PhD.

Universidad de Cartagena, Colombia

Dra. Sonia Concari

Universidad Nacional de Rosario, Argentina

Dr. Omar O. López Sinisterra

Universidad de Panamá, Panamá

Dr. Enrique Berra Ruíz

Universidad Autónoma de Baja California, México

Maestro Óscar Pérez Mora

Universidad de Guadalajara, México

M.D.C. Martha Amalia Ávalos Medina

Universidad Tecnológica de Morelia

Dr. Miguel Angel Vargas-Lombardo

Universidad Tecnológica de Panamá

\section{SOPORTE TÉCNICO}

Ing. Pedro Aguirre Apaza

\section{DIAGRAMACIÓN Y ARTES FINALES}

Ing. Víctor Raúl Millán Salazar

\section{CORRECCIÓN DE ESTILO}

Dr. José Bernardo Peńa Arcila

TRADUCCIÓN

Mg. Magaly Ugarte Sebastián

\section{DIRECCIÓN}

Av. Guillermo Prescott 520, San Isidro, Lima, Perú. Teléfono 4714545

http://revistas.uap.edu.pe/ojs/index.php/HAMUT/issue/archive Email: revistahamutay@uap.edu.pe

\section{REVISTA ARBITRADA}

Se permite la copia y distribución por cualquier medio siempre que se mantenga el reconocimiento de los autores y no se realice modificaciones.

Los artículos publicados expresan las opiniones personales de sus autores y no necesariamente las de la Universidad Alas Peruanas. 


\section{Índice}

Editorial:

Las tecnologías en el rol de los docentes, estudiantes y padres de familia

Technology in the role of teachers, students and parents

Percepción del alumnado universitario sobre su grado de competencia

digital

Perception of university students about their level of digital competence

La formación digital del estudiante universitario digital: competencias, necesidades y pautas de actuación

Digital literacy of university digital students: competences, needs and action guidelines

Google sites como herramienta didáctica online en el aprendizaje

significativo del área de ciencia, tecnología y ambiente en estudiantes de cuarto grado de educación secundaria

Google sites as an online teaching tool for meaningful learning in the area of science, technology and environment in fourth grade students of secondary education

Competencia digital y desarrollo profesional de los docentes de dos instituciones de educación básica regular del distrito de Los Olivos, Lima-Perú

Digital competence and professional development of teachers from two institutions of regular basic education of Los Olivos district, Lima-Peru

Plataforma de recursos educativos abiertos para la formación de capital humano en pymes

Platform of open educational resources for the formation of human capital in small and medium enterprises

Innovación Educativa en el Aula mediante Design Thinking y Game

Thinking

Educational innovation in the classroom through Design Thinking and

Game Thinking

Educomunicación y buenas prácticas en los nuevos escenarios tecnológicos: análisis del caso Gallego (España)

Educommunication and good practices in the new technological scenarios: analysis of the Gallego case (Spain)

La escuela en la sociedad red: un espacio de encuentro con los valores

The school in the network society: a meeting place with values

La tablet en la escuela: revisión bibliográfica en Scopus

The tablet in schools: a bibliographic review from Scopus 


\section{Editorial}

Cita recomendada: Alvites-Huamaní, C. (2018) Las tecnologías en el rol de los docentes, estudiantes y padres de familia. Hamut'ay 6(1) 5-6. http://dx.doi.org/10.21503/hamu.v6i1.1570

\section{LAS TECNOLOGÍAS EN EL ROL DE LOS DOCENTES, ESTUDIANTES Y PADRES DE FAMILIA}

Las constantes innovaciones en los dispositivos móviles de uso personal y su conectividad; además de la diversidad de aplicaciones enmarcadas en la tendencia hacía la informática para la gente, han despertado interés en su utilización en muchas áreas; es así como la educación como una acción social no escapa de ese interés, lo que ha generado un cambio sustancial en los roles de los docentes, estudiantes y padres de familia, no solo como medios de comunicación, sino también como recursos para el aprendizaje, debido entre otras cosas al aumento constante en su uso y cada vez más a temprana edad.

Para los profesores de todos los niveles educativos ha sido y sigue siendo un reto el poder adquirir competencias idóneas para el uso y aplicación de las tecnologías en el aula y extra muros, el poder manejar, utilizar y aplicar estos recursos enfocándose en el beneficio para sus estudiantes; así como el poder comprenderlos, decodificarlos y situarlos en sus sesiones de aprendizaje para la enseńanza de los cursos que imparte a sus estudiantes, reto éste en constante evolución y que ha orientado un gran número de investigaciones.

Pero en el caso de los estudiantes, pertenecientes a la generación tecnológica, el uso habitual y cotidiano de esas herramientas crea, en ese sentido, una diferencia abismal en relación a las destrezas para su uso, llevándolos a una mayor complacencia al interactuar con estos medios para realizar sus tareas; más aún si esto implica trabajar en equipo, de manera colaborativa y con metodologías innovadoras, utilizando inteligencia artificial, realidad aumentada, juegos en $2 \mathrm{D}$ y $3 \mathrm{D}$ y otros tipos de estrategias tecnológicas usando la Tablet, el teléfono móvil u otro tipo de equipo que les permiten sentir la educación-inmersión.

\section{TeCHNOLOgIES IN THE ROLE OF TEACHERS, STUDENTS AND PARENTS}

The constant innovations in mobile devices for personal use and their connectivity as well as the diversity of applications framed within the trend, computing for people, have aroused interest in its use in many areas; this is how education as a social action does not escape from this interest, which has generated a substantial change in the roles of teachers, students and parents; not only as means of communication, but also as resources for learning, due among other things to the constant increase in their use and at an increasingly young age.

For teachers of all educational levels, it is still is a challenge to be able to acquire suitable competences for the use and application of technologies in and outside the classroom, to be able to manage, use and apply these resources focusing on the benefit for their students; as well as being able to understand, decode and include them in their learning sessions to teach their corresponding subjects. This is a challenge, in constant evolution that has directed a large number of researches.

But in the case of the students, belonging to the technological generation, the habitual and daily use of these tools, creates in that sense an abysmal difference in relation to the skills for their use, leading them to feel a greater complacency when interacting with these media to do their homework; even more if this means working as a team, collaboratively and with innovative methodologies, using artificial intelligence, augmented reality, $2 \mathrm{D}$ and $3 \mathrm{D}$ games and other types of technological strategies using Tablets, mobile phone or other type of equipment that allows them feel the education immersion. 
Considerando que los estudiantes de este siglo XXI han adquirido nuevas competencias que van vinculadas con las tecnologías en su formación académica, esto ha implicado también que la familia este dentro de este contexto, viéndose obligado los padres de familia, de la generación del siglo XX en su mayoría, a cumplir nuevos roles como orientadores de sus hijos, sobre todo en aquellos estudiantes que todavía cursan la educación básica, proceso de orientación que en muchos casos se torna bastante frustrante al tener que sumergirse en la omnipotencia de las tecnologías, pero esto no significa que no lo hayan hecho, sino por el contrario, están en todo el proceso de adquirir competencias digitales, que les permitan ayudar a sus menores hijos y poder incidir en el uso correcto de estos medios, no solo como recursos académicos, sino incentivar valores, necesarios en estos tiempos en el que la violencia en las redes e internet se han proliferado.
Considering that students of this XXI century have acquired new competences that are linked with technologies in their academic formation, it has also implied that the family is within this context, parents, who mostly belong to the XX generation, are being forced to fulfill new roles as counselors of their children, especially of those students who still attend basic education. This guidance process that in many cases has become quite frustrating, immersing themselves in the omnipotence of technologies, does not mean they have not done it yet, but on the contrary, they are in the whole process of acquiring digital skills, which will allow them to help their younger children and be able to influence the correct use of these media, not only as academic resources, but to encourage values, necessary in these times in which violence in social networks and the internet have spread.

\section{Dra. Cleofé Genoveva Alvites Huamani Editor Jefe de la revista cientifica Hamut'ay I Editor in Chief of the Hamutay journal \\ DUED}




\title{
Percepción del alumnado universitario sobre su grado de competencia digital
}

\section{Perception of university students about their level of digital competence}

\author{
Víctor Manuel Hernández Rivero ${ }^{1}$ \\ http://orcid.org/0000-0001-5551-463X \\ María Belén San Nicolás Santos ${ }^{2}$ \\ http://orcid.org/0000-0002-8884-638X
}

Universidad de La Laguna, España

\section{Cita Recomendada}

Hernández, V. \& San Nicolás, M. (2019). Percepción del alumnado universitario sobre su grado de competencias digital. Hamut'ay, 6(1), 7-18. http://dx.doi.org/10.21503/hamu.v6i1.1571

\section{RESUMEN}

La competencia digital es clave para el desempeño profesional de todos los profesionales, por ello es importante desarrollar una formación que tenga en cuenta el desarrollo de estas habilidades. Concretamente en el ámbito educativo las tecnologías han tenido un gran impacto, modificando las prácticas docentes. Por ello es especialmente importante conocer la competencia digital de los estudiantes y ayudarles a desarrollarla, preparándolos para afrontar su futuro profesional. El estudio que se presenta es de tipo cuantitativo, con un diseño descriptivo que trata de conocer el uso que el alumnado realiza de los recursos TIC, su frecuencia y la autopercepción de este sobre sus competencias digitales básicas. Para ello se empleó un cuestionario basado en la propuesta de Roig \& Pascual (2012). El planteamiento inicial hace pensar que el alumnado hace un uso frecuente de la tecnología, sin embargo, no tienen un alto grado de desarrollo de las competencias digitales básicas. Algunos de los resultados más destacables muestran que el teléfono móvil es uno de los dispositivos más utilizados por ellos, el 47,7 \% del alumnado lo usa más de 7 horas diarias. Además, las principales actividades a las que dedican su tiempo están relacionadas con el trabajo en grupo, el $42 \%$ del alumnado trabaja de esta forma con mucha frecuencia.

Se planteó al alumnado que respondiera el grado de frecuencia de uso de diferentes herramientas TIC en una escala de 1 a 6 , las más utilizadas fueron los entornos colaborativos 4.83, y los recursos para procesar información y comunicarse 4.97.

En general, la autopercepción del alumnado sobre su competencia digital es alta, exceptuando al-

1 Profesor de Didáctica y Organización Escolar de la Universidad de La Laguna (España). Sus principales líneas de investigación están relacionadas con las TIC en educación, el asesoramiento y los sistemas de apoyo, y la innovación educativa. Miembro del grupo de investigación Laboratorio de Educación y Nuevas Tecnologías (EDULLAB) y de la Red de Excelencia en Investigación e Innovación Educativa REUNI+D. E-mail: vhernan@ull.edu.es

2 Profesora de la Universidad de La Laguna (España), área de Métodos de Investigación y Diagnóstico en Educación. Sus principales líneas de investigación están relacionadas con el e-learning en la universidad, las TIC en el sistema escolar y evaluación de Materiales Didácticos Digitales. Miembro del grupo de investigación competitivo Laboratorio de Educación y Nuevas Tecnologías (Edullab) y de la Red de Excelencia en Investigación e Innovación Educativa REUNI+D. E-mail: bsannico@ull.edu.es 
gunas actividades de carácter más complejo con las que no están tan familiarizados como son la programación, los juegos, el análisis estadístico, la edición de imágenes o la creación de vídeos.

Palabras Clave: Competencia digital, alumnado universitario, competencias profesionales, docencia universitaria.

\section{Abstract}

Digital competence is the key for professional performance of all professionals, so it is important to develop a training that takes into account the development of these skills. Specifically, in the educational field, technologies have had a great impact, modifying teaching practices. Therefore, it is especially important to know the digital competence of students and help them to develop it, preparing them to face their professional future. The following study is quantitative, with a descriptive design that aims to know the use that students make of ICT resources, their frequency and their self-perception of their basic digital skills. For this, a questionnaire based on the proposal of Roig $\&$ Pascual (2012) was used. The initial approach suggests that students make frequent use of technology; however, they do not have a high degree of development of their basic digital skills. Some of the most remarkable results show that the mobile phone is one of the devices most used by them, $47.7 \%$ of the students use it more than 7 hours a day. In addition, the main activities to which they dedicate their time are related to group work, $42 \%$ of students work in groups very often.

The students were asked to answer the degree of frequency of use of different ICT tools on a scale of 1 to 6 , the most used were the collaborative environments 4.83 , and the resources to process information and communicate 4.97.

In general, students' self-perception of their digital competence is high, except for some more complex activities, which they are not very familiar with, such as programming, games, statistical analysis, image editing or video creation.

Keywords: Digital competence, university students, professional competences, university teaching.

\section{INTRODUCCIÓN}

El desarrollo de la competencia digital es un aspecto clave para todos los profesionales en el momento histórico en el que nos encontramos, es por ello que la formación en estas competencias forma parte de los planes de estudios de las universidades. Es innegable el auge que la tecnología ha tenido concretamente en el ámbito educativo y esto ha requerido no solo la actualización del profesorado, sino también la dedicación de esfuerzos a la formación en competencias digitales de los futuros profesionales de la educación (Area, 2008; Area, Hernández \& Sosa, 2018).
En el Libro Blanco de la titulación del Grado en Pedagogía publicado por la ANECA (Vila, 2004) se contemplan las tecnologías como uno de los contenidos clave que han tenido un impacto importante en el ámbito educativo, por lo que el alumnado debe conocerlas, aplicarlas y valorarlas de forma crítica para su aplicación en las funciones profesionales. Por otro lado, la legislación educativa vigente en España recoge no sólo la importancia de las TIC, sino el compromiso que el profesorado debe tener en la aplicación y aprovechamiento de los recursos tecnológicos en el ejercicio docente (Ley Orgánica 8/2013, de 9 de diciembre, para la Mejora de la Calidad Educativa, Espańa). 
La Comisión Europea publicó el informe "DIGCOMP: A Framework for Developing and Understanding Digital Competence in Europe", en el que se describe un marco para el desarrollo y comprensión de la competencia digital en Europa (Ferrari, 2013). En Espańa se ha desarrollado y actualizado en los últimos ańos un informe similar en el que se identifican las áreas y competencias que el profesorado debe desarrollar para afrontar los nuevos retos educativos relacionados con la tecnología (INTEF, 2017).

Paralelamente el Informe Horizon Educación Superior (Becker et al., 2017) y el Informe Horizon Primaria y Secundaria (Freeman et al., 2017) identifican cuáles son las nuevas tendencias en educación relacionadas con la tecnología.

Por lo antes expuesto, en esta investigación los objetivos se han centrado en:

- Identificar el tipo de recurso digital que utiliza el alumnado en sus tareas académicas, el tiempo que dedican a su uso y tipo de conectividad a la que tienen acceso.

- Analizar en las actividades académicas que realiza el alumnado, la frecuencia de uso de los recursos TIC y el tipo de herramientas más comunes que emplea.

- Conocer la competencia digital del alumnado para su uso en las actividades académicas y profesionales propias de su perfil.

Asimismo, es importante indicar que este alumnado no ha cursado con anterioridad asignaturas relacionadas con el uso de las TIC en la titulación, sin embargo, hace un uso frecuente de las tecnologías en sus actividades académicas y para su uso personal por lo que, hipotéticamente, se presupone cierto nivel de competencia digital.

\section{Conceptualizando la competencia digital}

Lo que entendíamos por alfabetización hasta hace algunas décadas ya no es válido, ser competente digitalmente pasa a ser una necesidad para poder interactuar con el mundo que nos rodea, con el mundo digital en este caso, y podemos afirmar que forma parte de nuestro día a día como ciudadanos y ciudadanas (Castellanos, Sánchez \& Calderero, 2017).
Cuando hablamos de competencia nos referimos a la habilidad de una persona para realizar una actividad concreta. Cuando hablamos de competencia digital es aquella que está relacionada con el uso de las TIC, pero cuando nos acercamos al ámbito educativo esta competencia no se centra solo en el uso de la tecnología sino también en su uso creativo, crítico y seguro en las actividades docentes. En el Marco Común de la Competencia Digital Docente (INTEF, 2017) se concretan cinco áreas de esta competencia: información y alfabetización informacional, comunicación y colaboración, creación de contenidos digitales, seguridad y resolución de problemas.

Gisbert, González \& Esteve (2016) diferencian entre el concepto de competencia digital del estudiante y competencia digital docente, indicando que el primero tiene que ver con las capacidades para interactuar en la Sociedad de la Información y el segundo con ser competente para uso de la tecnología en la práctica docente.

Uno de los argumentos clave que justifica el desarrollo de planes de formación orientados al desarrollo de la competencia digital en el alumnado universitario, se basa en las demandas sociales y del mercado de trabajo, que exige a los profesionales en general y a los titulados universitarios en particular, contar con la competencia digital necesaria aplicada al ámbito de conocimiento correspondiente para el desempeño adecuado de las funciones profesionales, sin embargo existen diferencia entre el nivel de autopercepción de la competencia digital del alumnado y del mercado de trabajo (Torres-Coronas \& Vidal-Blasco, 2015).

\section{Evaluación de la competencia digital}

Guzmán \& Gisbert (2008) en su estudio realizado en México para evaluar las competencias digitales y para recopilar información han utilizado como instrumento el cuestionario, para conocer sobre la utilización de las tecnologías de la información y comunicación en el aprendizaje universitario sobre aspectos relacionados al uso del ordenador, frecuencia de uso, utilidad, dominio de las TIC y competencia básica en TIC. Además del caso de la Universidad Autónoma de Querétaro, México, este estudio se ha aplicado también 
en la Universidad de Alicante, Espańa, (Roig \& Pascual, 2012).

Otros autores han desarrollado instrumentos con el objetivo de analizar la competencia digital del alumnado universitario. Es el caso del Cuestionario para el estudio de la Competencia Digital del Alumnado de Educación Superior (CDAES) elaborado por Gutiérrez, Cabero \& Estrada (2016) en el que se recogen un total de seis dimensiones: alfabetización tecnológica (funcionamiento y concepto de las TIC); búsqueda y tratamiento de la información (investigación y manejo de la información); pensamiento crítico, solución de problemas y toma de decisiones; comunicación y colaboración; ciudadanía digital; y por último, creatividad e innovación.

La formación de los futuros maestros y maestras en las competencias digitales es una estrategia clave para el desarrollo de procesos de innovación en los centros. En el estudio realizado por Roblizo \& Cózar (2015) se evalúa la formación recibida en este sentido, valorando la adecuación de la misma a las demandas del contexto profesional. Los aspectos analizados se centran en seis grupos de herramientas: creación de documentos y objetos multimedia, información, comunicación y colaboración, herramientas educativas y tecnologías emergentes.

\section{Competencia digital en el alumnado universitario}

En relación a los resultados obtenidos en algunos estudios sobre la competencia digital del alumnado universitario y más concretamente del alumnado de las facultades de educación podemos destacar:

Carrasco, Sánchez \& Carro (2015) realizan un estudio con el alumnado de posgrado en educación e identifican que no existen diferencias significativas entre los alumnos y las alumnas en cuanto al acceso a dispositivos y conectividad, aunque el tiempo de dedicación a determinadas tareas si difieren, ellas dedican más tiempo al desarrollo de actividades académicas en la red. En general, la valoración de la competencia digital del alumnado se sitúa en un nivel medio, aunque este nivel competencial disminuye cuando se trata de abor- dar tareas más complejas.

Roblizo \& Cózar (2015) realizaron un estudio sobre los usos y competencias TIC del alumnado de Educación Infantil y Primaria, en este caso, como en el anterior no se identificaron diferencias significativas en el uso de la tecnología por parte de las alumnas y los alumnos.

García-Valcárcel \& Martín (2016) utilizan el modelo TPACK basado en el análisis del conocimiento pedagógico, conocimiento tecnológico y conocimiento disciplinar para el análisis de las competencias digitales de los graduados de las titulaciones de maestro de 14 universidades. En este caso algunos de los resultados más destacados indicaron que el alumnado se siente preparado para la búsqueda de información y uso de programas para la elaboración de presentaciones y recurso para la organización de la información. Sin embargo, se sienten más inseguros en actividad relacionadas con el uso didáctico de tabletas, pizarras digitales o recursos para la creación de videojuegos.

\section{Materiales Y Métodos}

\section{Participantes}

La población a la que hace referencia el estudio que se presenta es de un total de 126 estudiantes, en el cuestionario participaron un total de 99 estudiantes y se mantuvieron 89 respuestas debido a la duplicidad de respuestas de algunos participantes. La muestra es aleatoria dado que no se realizó una selección previa, por lo que se facilitó el acceso al cuestionario en línea a todo el alumnado de tercer curso de Pedagogía participante en las asignaturas del primer cuatrimestre del curso académico 2018-2019, de tercero del Grado en Pedagogía de la Universidad de La Laguna (España).

El análisis se ha realizado a través del programa SPSS utilizando principalmente análisis estadísticos descriptivos para conocer las características de la población de referencia. La media de edad del alumnado es de 22 años. El 85.2\% son alumnas y el $14.5 \%$ son alumnos, lo que supone una distri- 
bución heterogénea, pero que a la vez es representativa de los que sucede en muchas facultades de Educación y en los estudios de Grado en Pedagogía, cuyos estudios están claramente feminizados.

\section{Tabla 1}

Distribución de la muestra

\begin{tabular}{llrr}
\hline \multirow{2}{*}{ Edad } & \multicolumn{1}{c}{ İ́tem } & \multicolumn{1}{c}{$f$} & \multicolumn{1}{c}{$\%$} \\
\hline & $21-25$ & 80 & 90.9 \\
& $26-31$ & 6 & 6.8 \\
& $32-35$ & 1 & 1.1 \\
& $36-41$ & 1 & 1.1 \\
\hline Sexo & Hombre & 13 & 14.8 \\
\cline { 2 - 4 } & Mujer & 75 & 85.2 \\
\hline Conexión a & ADSL & 15 & 17 \\
\cline { 2 - 4 } Internet & Fibra & 63 & 71.6 \\
\cline { 2 - 4 } & Conexión de datos & 10 & 11.4 \\
& móviles & & \\
\hline Desde dónde & Desde casa & 44 & 50 \\
\cline { 2 - 4 } sueles conectarte & Desde la Facultad & 12 & 13.6 \\
\cline { 2 - 4 } & En cualquier sitio (con & 32 & 36.4 \\
& el móvil) & & \\
\hline
\end{tabular}

Elaboración propia (2019)

\section{Instrumento}

El cuestionario se ha basado en la propuesta de Roig \& Pascual (2012), en el que se recogen las siguientes dimensiones: uso del ordenador, frecuencia de uso de recursos TIC y competencia básica en TIC. Para cada uno de los ítems se ha usado una escala Likert de seis niveles en la que los participantes han respondido sobre su frecuencia de uso o nivel competencial otorgando los siguientes valores 1 , nunca, nada hasta 6 , siempre, mucho. Los ítems utilizados han sido los siguientes:

\section{Tabla 2}

Dimensiones del cuestionario

\begin{tabular}{ll}
\hline Dimensiones & \multicolumn{1}{c}{ Ítems } \\
\hline Uso del ordenador & ¿Qué dispositivos sueles usar? \\
& ¿Cuántas horas diarias utilizas los \\
siguientes dispositivos? & ¿Qué conexión a Internet tienes? \\
& ¿Desde dónde sueles conectarte?
\end{tabular}

Frecuencia de uso de recursos TIC
Se plantean una serie de recursos y actividades para que los participantes valoren su grado de uso en una escala de 1 (nada) a 6 (mucho): investigación y búsqueda de

\begin{tabular}{ll}
\hline Dimensiones & \multicolumn{1}{c}{ Ítems } \\
\hline Frecuencia de uso de & información, navegar por internet, \\
recursos TIC & gestión, foros, multimedia, hojas de \\
& cálculo, presentaciones, procesador \\
& de textos, correo electrónico, bases \\
& de datos, autoformación, blogs, \\
& redes sociales, tutoría profesora- \\
& do-alumnado, videoconferencia, \\
chat, trabajo en grupo, análisis esta- & dístico, edición de imagen, creación \\
& de vídeos, listas de distribución, \\
& programación, jugar. \\
& Grado de alfabetización tecnológica \\
Gompetencia básica & Grado de uso de las TIC para el de- \\
en TIC & sarrollo de actividades académicas \\
& Actividades de tratamiento y difu- \\
& sión de información \\
& Uso de herramientas de comuni- \\
& cación \\
\hline
\end{tabular}

Elaboración propia (2019)

Para calcular la fiabilidad de los ítems de escala se ha utilizado el coeficiente de Alpha de Cronbach que en este estudio ha sido de 0.932 por lo que podemos garantizar la fiabilidad del instrumento (Merino \& Lautenschlager, 2003).

\section{Tipo y diseño de estudio}

Se trata de un estudio de tipo cuantitativo basado en la investigación de Roig \& Pascual (2012). La muestra está formada por 88 alumnos y alumnas. El estudio tiene un diseńo descriptivo que trata de conocer el uso que el alumnado realiza de los recursos TIC, su frecuencia y la autopercepción del alumnado sobre sus competencias digitales básicas. El planteamiento inicial hace pensar que el alumnado hace un uso frecuente de la tecnología, pero que sin embargo las competencias digitales básicas no tienen un alto grado de desarrollo.

\section{Procedimiento}

Para el desarrollo del estudio se siguió el siguiente procedimiento que se desarrolla en cuatro fases:

- Fase 1: Adaptación del instrumento al momento actual y al caso de la Universidad de La Laguna. El desarrollo de este estudio surge como una necesidad del análisis de las competencias digitales del alumnado que inicia el 
tercer curso de la titulación y que tendrá que desarrollar actividades relacionadas con las competencias digitales, para ello se seleccionó el instrumento presentado con anterioridad y se elaboró una propuesta en línea a través de los formularios de Google en la que se incorporaron y modificaron algunas preguntas con el ánimo de adaptar al contexto y momento actual.

- Fase 2: Aplicación del cuestionario al alumnado. Se destinó una sesión a la presentación del objetivo del estudio, del instrumento y a la solicitud de participación y respuesta del cuestionario, garantizando la confidencialidad de las respuestas. Este procedimiento se realizó a comienzo de curso con el objetivo de conocer el punto de partida del alumnado en relación a su grado de competencia digital. Al tratarse de dos grupos de alumnado, correspondientes a dos turnos, se replicó el mismo procedimiento en ambos casos.

- Fase 3: Recogida de datos. Una vez completada la recogida de datos se procedió al análisis de los mismos para lo que previamente fue necesario realizar un procedimiento de depuración y normalización de los datos, evitando respuestas duplicadas o incongruencias.

- Fase 4: Análisis e interpretación de los datos. $\mathrm{El}$ análisis de los datos se ha realizado con el paquete estadístico SPSS 22.

\section{Resultados}

En relación al primer objetivo de este estudio, orientado a identificar los dispositivos tecnológicos que utiliza el alumnado en sus tareas académicas, el tiempo que dedican a su uso y tipo de conectividad a la que tienen acceso, los resultados indican que el $88.6 \%$ del alumnado no usa nunca el ordenador de sobremesa, sin embargo, podemos observar un aumento considerable del tiempo dedicado al uso de dispositivos móviles como el smartphone, utilizado por el $47.7 \%$ del alumnado durante más de 7 horas diarias. El portátil se emplea entre 1 y 3 horas por el $27.3 \%$; entre 3 y 5 horas por el $23.9 \%$; entre 5 y 7 horas por el 26.1
\% y más de 7 horas por el 19.3\%. En cambio, las tabletas tienen muy poco uso en el aula: el alumnado afirma no usarlas nunca en el $72.7 \%$ de los casos en la Figura 1.

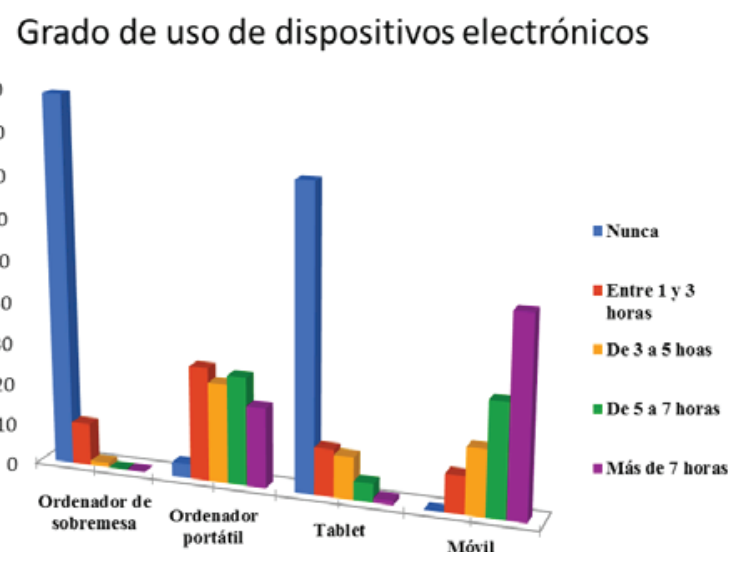

Figura 1

Grado de uso de dispositivos electrónicos. Elaboración propia (2019)

Según la figura 1 la mayoría del alumnado no utiliza un único dispositivo, por ejemplo, el 50\% utiliza el ordenador portátil y móvil de forma combinada. La calidad de la conectividad es un elemento clave que condiciona notablemente las actividades que es posible realizar por ello se ha preguntado sobre esto al alumnado. El 71.6\% dispone de fibra óptica, el 17\% ADSL y el 11.4\% se conecta normalmente a través de datos móviles. El lugar desde el que suelen conectarse es en el 50\% de los casos desde su casa, el 36\% utiliza los datos móviles, por lo que pueden conectarse desde cualquier lugar y solo el $13.6 \%$ utiliza la conectividad a la que tienen acceso desde la Universidad.

En relación al segundo objetivo de este estudio, centrado en el análisis de las actividades académicas que realiza el alumnado con TIC, la frecuencia de uso y el tipo de herramientas más comunes que emplea, los resultados indican que, en las actividades relacionadas con la búsqueda de información o navegación, las actividades de ofimática, de comunicación y otras actividades relacionadas con las tareas académicas. Para valorar su grado de uso se planteó al alumnado que hiciera una valoración de cada una de ellas utilizando una escala de seis niveles donde 1 equivale a nunca y 6 a siempre.

En la figura 2 se observa que las actividades que el 
alumnado realiza con mayor frecuencia otorgando una puntuación de seis puntos en la escala, son las de uso del correo electrónico $56.8 \%$ y desarrollo de trabajos en grupo $42 \%$. Con un menos grado de frecuencia, otorgando 5 puntos en la escala realizan actividad de investigación y búsqueda de información 39.8\%, navegar por internet 37.5\%. Estas actividades tienen relación con el trabajo académico desarrollado por el alumnado.

\section{Frecuencia de uso de recursos de información y gestión}

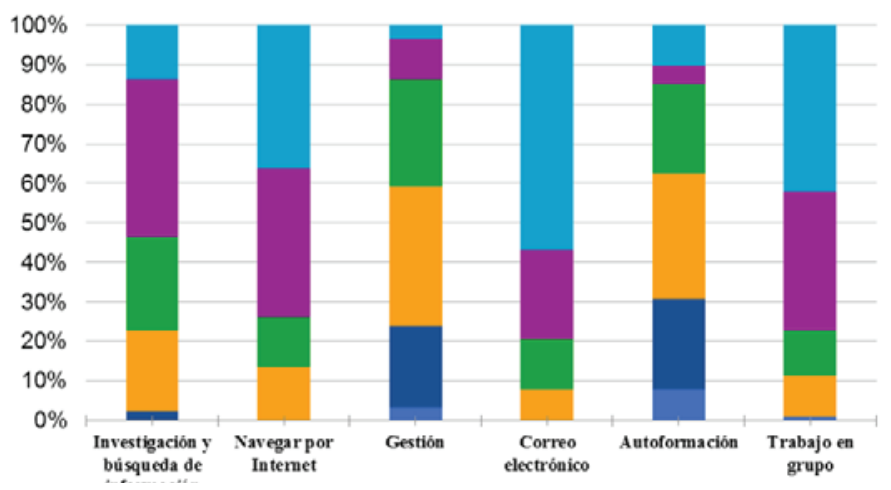

Figura 2

Frecuencia de uso de recursos de información y gestión. Elaboración propia (2019)

Las actividades menos realizadas en este bloque son las de autoformación, el 31.8\% del alumnado le asigna un nivel intermedio-bajo de frecuencia en la escala. Lo mismo ocurre con la utilización de las TIC para el desarrollo de actividades de gestión, el 35.2\% del alumnado afirma usarlo con escasa frecuencia.

Los recursos de comunicación utilizados con mayor frecuencia, según la figura 3, son las redes sociales y el chat, se trata de aquellos recursos a los que el alumnado ha otorgado un nivel de frecuencia de cinco y seis puntos en la escala. Las redes sociales son utilizadas por un $19.3 \%$ del alumnado con mucha frecuencia y un por un $58 \%$ del alumnado siempre. El chat es usado por un $25 \%$ con mucha frecuencia y por el $21 \%$ del alumnado siempre.

En la figura 3, también se recogen los datos relativos al uso de recursos de comunicación. Los menos utilizados son los sistemas de videoconferencia, el 36.4\% del alumnado afirma no usarlos nunca; las listas de distribución, el 27.3\% afirma no usarlas nunca y el $43.2 \%$ las con poca frecuen-

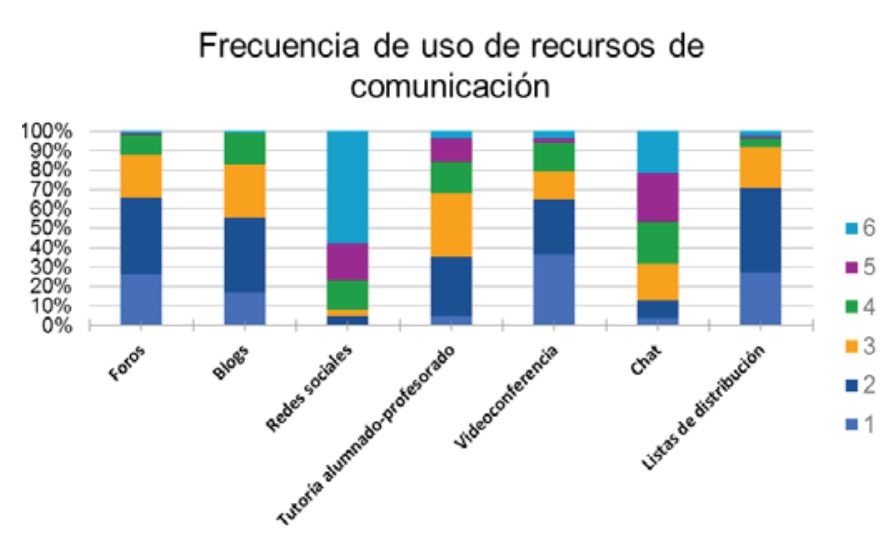

Figura 3

Frecuencia de uso de recursos de comunicación.

Elaboración propia (2019)

cia y por últimos los blogs, el $17 \%$ no los usa nunca y el $38.6 \%$ los usa muy poco.

El uso de programas de ofimática forma parte del día a día de muchas actividades académicas y profesionales.

En la figura 4 se observa como el alumnado usa con mayor frecuencia aquellos programas para el desarrollo de presentaciones, el $27.3 \%$ del alumnado los utiliza con mucha frecuencia y el $17 \%$ del alumnado afirma usarlos siempre. Los procesadores de textos son usados por el $22.7 \%$ del alumnado con mucha frecuencia.

Frecuencia de uso de programas de ofimática

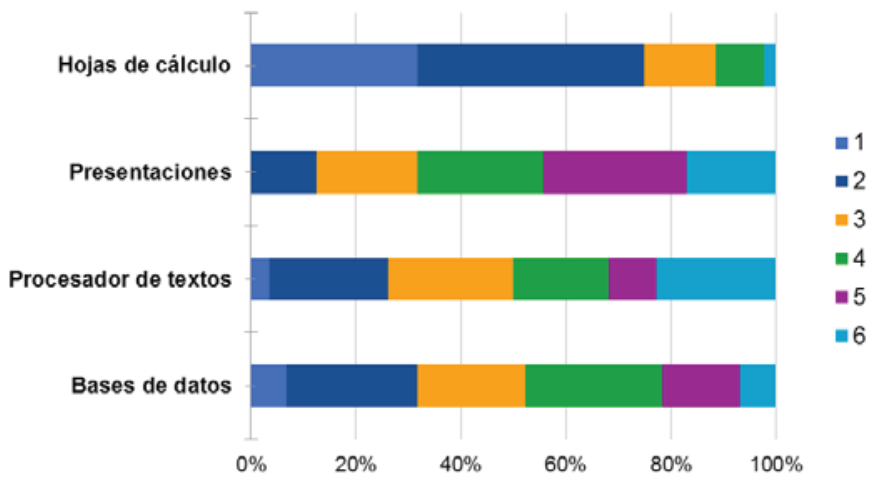

Figura 4

Frecuencia de uso de programas de ofimática. Elaboración propia (2019)

Las hojas de cálculo son usadas mucho menos, el $31.8 \%$ del alumnado no las usa nunca y el $43.2 \%$ las usa con muy poca frecuencia.

En la figura 5 se presentan los datos correspondientes a otros recursos digitales como por ejemplo 
recursos multimedia, edición de imagen y vídeo, programación, juegos y recursos para análisis estadístico. Se trata del desarrollo de actividades complejas que no están asociadas específicamente a las actividades académicas o profesionales propias de la titulación, pero que cada vez más forman parte de competencias transversales a adquirir.

\section{Recursos digitales avanzados}

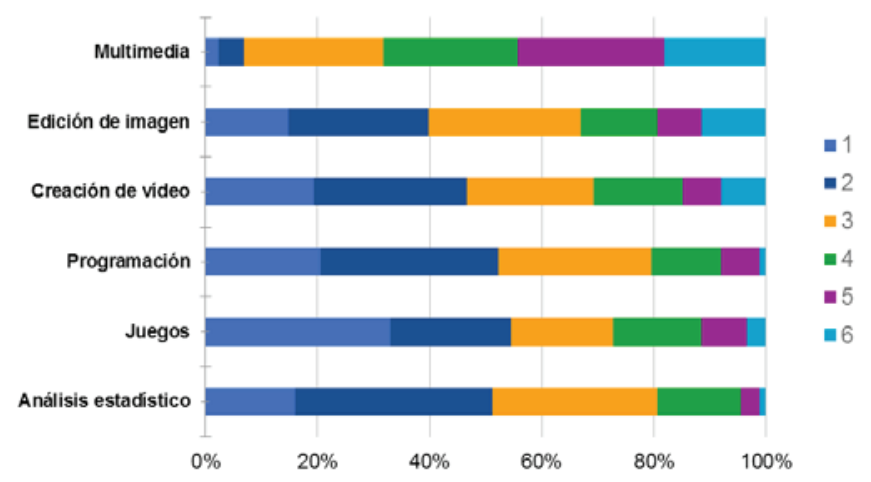

Figura 5

Uso de recursos digitales avanzados.

Elaboración propia (2019)

Todas las actividades y recursos planteados en la Figura 5 tienen una escasa frecuencia de uso. Las actividades que el alumnado realiza con menos frecuencia son las de juegos, el 33\% no los usa nunca y el $21.6 \%$ los usa con muy poca frecuencia; programación, $20.5 \%$ del alumnado no realiza nunca este tipo de actividades y el $31.8 \%$ las realiza con escasa frecuencia $y$, por último, las actividades de análisis estadístico, el 15.9\% del alumnado no realiza nunca este tipo de actividades y el $35.2 \%$ las realiza con muy poca frecuencia.

En relación con el tercer objetivo del estudio dirigido a conocer la competencia digital del alumnado para su uso en las actividades académicas y profesionales propias de su perfil, los resultados muestran que en la figura 6 , cuál es la autopercepción del alumnado sobre su grado de alfabetización tecnológica, uso de las TIC para el desarrollo de actividades de carácter académico o intelectual y por último uso de las TIC para el tratamiento y difusión de la información. En todos los casos se plantean una serie de afirmaciones que el alumnado debe valorar usando una escala de seis niveles tipo Likert.

A continuación, se presentan las medias obtenidas para cada una de ellas.
En relación al apartado de alfabetización tecnológica se plantean tres afirmaciones: logra autonomía frente a problemas técnicos cotidianos 4.27, muestra interés por actualizar sus conocimientos tecnológicos 4.35, aprovecha el uso de entornos virtuales de aprendizaje 4.34. En los tres casos la media de las respuestas está por encima de los cuatro, lo que indica cierta autopercepción de autonomía por parte del alumnado a la hora de afrontar tareas que implica el uso de la tecnología.

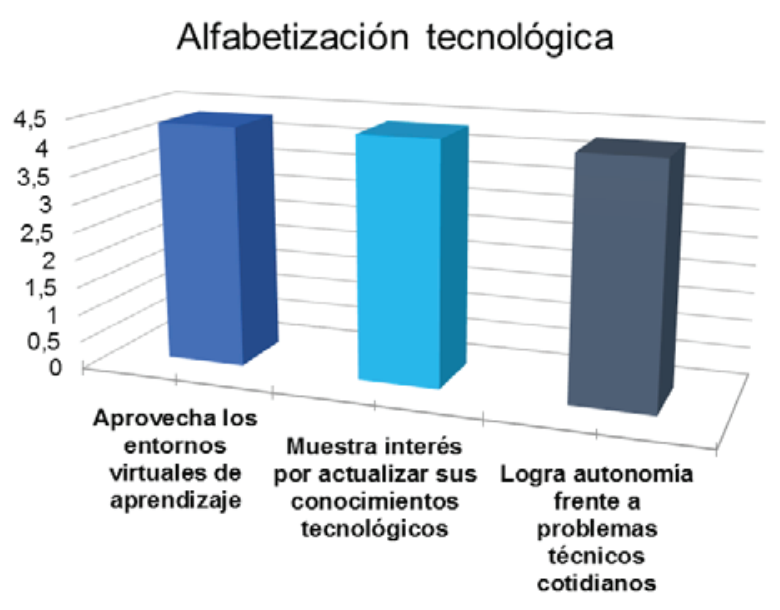

Figura 6

Autopercepción del grado de alfabetización tecnológica. Elaboración propia (2019)

Para valorar el desarrollo de las tareas de carácter intelectual se plantean los siguientes aspectos recogidos en la figura 7: emplea las TIC para buscar, localizar, evaluar y recuperar información 4.82; aprende a trabajar en equipo a través de entornos colaborativos 4.58, descarga de archivos 4.95, analizar y comentar críticamente páginas web 3.34, crear un documento incorporando textos e imágenes 4.26, usar buscadores especializados 4.42, evaluar recursos educativos 3.45, trabajo individual 4.49 y trabajo colaborativo 5.11. Las actividades más frecuentes están relacionadas con el trabajo colaborativo, la descarga de archivos y la búsqueda de información.

La Figura 8 muestra los datos de tratamiento y difusión de información. Se obverva el grado de autopercepción del alumnado sobre las siguientes afirmaciones: evalúa de manera crítica y responsable la información recogida 4.43 , contrasta la validez y actualidad de la información localizada 4.53 , respeta las fuentes de autoría de la información buscada y tratada 4.76, aprovecha nuevas 
fuentes de información y recursos para el aprendizaje 4.55, presenta y difunde con la ayuda de los medios TIC trabajos y conclusiones obtenidas (4).

\section{Trabajo académico e intelectual}

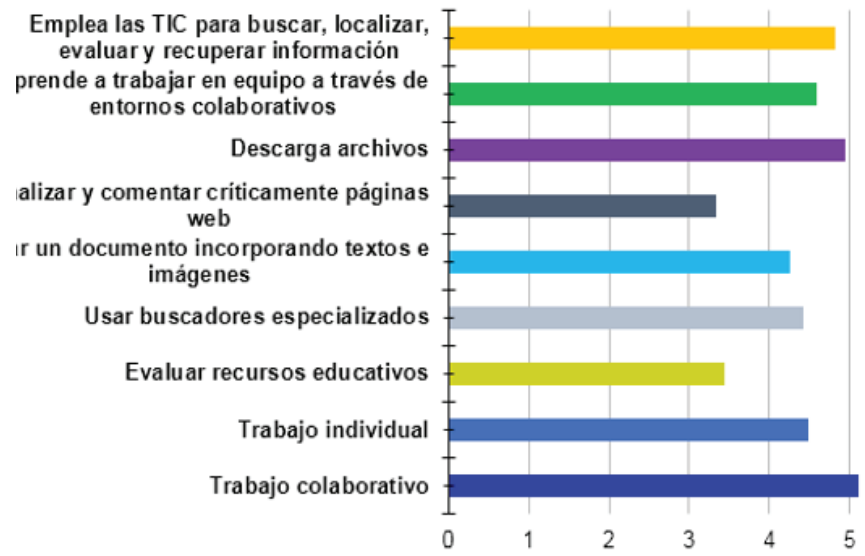

\section{Figura 7}

Uso de las TIC para el desarrollo de las tareas de carácter intelectual.

Elaboración propia (2019)

\section{Tratamiento y difusión de la información}

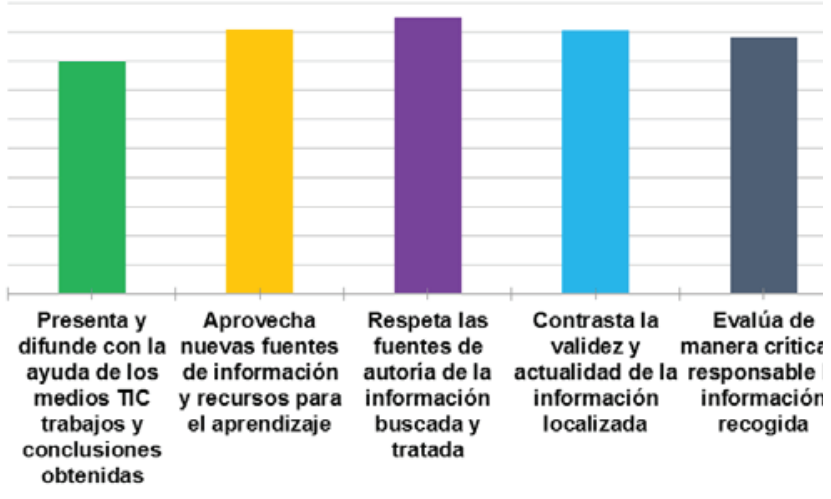

Figura 8

Tratamiento y difusión de la información.

Elaboración propia (2019)

Uno de los aspectos clave de la competencia digital tienen que ver con las habilidades comunicativas a través de la tecnología, para valorar estos aspectos se plantean las siguientes cuestiones recogidas en la figura 8: participa en actividades en grupo en entornos colaborativos 4.83 , es consciente del estilo comunicativo y actuaciones adecuadas en los foros 3.95; comprende y utiliza un entorno de trabajo colaborativo 4.81, utiliza los medios TIC para trabajar, procesar la información y comunicarse 4.97 y por último interactúa con el profeso- rado y atiende sus indicaciones 4.23.

En la figura 9 se observa que el ítem con menos puntuación media es el que tiene que ver con el estilo comunicativo y el uso de normas de netiqueta, sin embargo, tal y como se ha reflejado con anterioridad, uno de los aspectos más destacables es el trabajo colaborativo y el uso de recursos digitales que apoyan este tipo de procesos de trabajo.

\section{Uso de herramientas de comunicación}

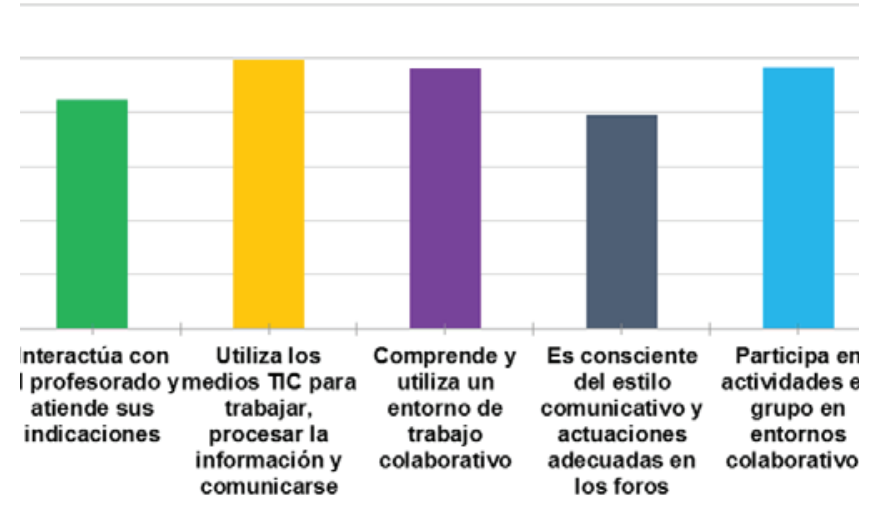

Figura 9

Uso de herramientas de comunicación.

Elaboración propia (2019)

El análisis ANOVA permite identificar si existen diferencias entre las puntuaciones obtenidas por las alumnas y los alumnos. En la mayoría de los ítems analizados en el estudio no se identifican diferencias significativas.

La Tabla 3 presentada en la página siguiente muestra los ítems en los que se han hallado diferencias significativas: número de horas diarias dedicadas al uso de teléfono móvil, contrastar la validez y actualidad de la información localizada, conciencia del estilo comunicativo en la red e interacción con el profesorado. 
Tabla 3

ANOVA

\begin{tabular}{|c|c|c|c|c|c|c|}
\hline & & $\begin{array}{l}\text { Suma } \\
\text { de cua- } \\
\text { drados }\end{array}$ & $\mathrm{GI}$ & $\begin{array}{l}\text { Media } \\
\text { cua- } \\
\text { drática }\end{array}$ & $F$ & Sig. \\
\hline \multirow{3}{*}{$\begin{array}{l}\text { ¿Cuántas } \\
\text { horas diarias } \\
\text { utilizas los } \\
\text { siguientes } \\
\text { dispositivos? } \\
\text { [Móvil] }\end{array}$} & $\begin{array}{l}\text { Entre } \\
\text { grupos }\end{array}$ & 5.453 & 1 & 5.453 & 5.796 & 0.018 \\
\hline & $\begin{array}{l}\text { Dentro de } \\
\text { grupos }\end{array}$ & 80.911 & 86 & 0.941 & & \\
\hline & Total & 86.364 & 87 & & & \\
\hline \multirow{3}{*}{$\begin{array}{l}\text { Contrasta } \\
\text { la validez y } \\
\text { actualidad de } \\
\text { la información } \\
\text { localizada }\end{array}$} & $\begin{array}{l}\text { Entre } \\
\text { grupos }\end{array}$ & 4.495 & 1 & 4.495 & 4.138 & 0.045 \\
\hline & $\begin{array}{l}\text { Dentro de } \\
\text { grupos }\end{array}$ & 93.403 & 86 & 1.086 & & \\
\hline & Total & 97.898 & 87 & & & \\
\hline \multirow{3}{*}{$\begin{array}{l}\text { Es consciente } \\
\text { del estilo } \\
\text { comunicativo } \\
\text { y actuaciones } \\
\text { adecuadas } \\
\text { en los foros }\end{array}$} & $\begin{array}{l}\text { Entre } \\
\text { grupos }\end{array}$ & 11.748 & 1 & 11.748 & 7.768 & 0.007 \\
\hline & $\begin{array}{l}\text { Dentro de } \\
\text { grupos }\end{array}$ & 130.070 & 86 & 1.512 & & \\
\hline & Total & 14.818 & 87 & & & \\
\hline \multirow{3}{*}{$\begin{array}{l}\text { Interactúa } \\
\text { con el } \\
\text { profesorado } \\
\text { y atiende sus } \\
\text { indicaciones }\end{array}$} & $\begin{array}{l}\text { Entre } \\
\text { grupos }\end{array}$ & 17.576 & 1 & 17.576 & 10.361 & 0.002 \\
\hline & $\begin{array}{l}\text { Dentro de } \\
\text { grupos }\end{array}$ & 145.879 & 86 & 1.696 & & \\
\hline & Total & 163.455 & 87 & & & \\
\hline
\end{tabular}

Elaboración propia (2019)

Tabla 4

Medias por género.

\begin{tabular}{|c|c|c|c|c|c|}
\hline & & & Media & $\begin{array}{l}\text { Des- } \\
\text { viación } \\
\text { están- } \\
\text { dar }\end{array}$ & $\begin{array}{c}\text { Error } \\
\text { están- } \\
\text { dar }\end{array}$ \\
\hline \multirow{3}{*}{$\begin{array}{l}\text { ¿Cuántas horas } \\
\text { diarias utilizas } \\
\text { los siguientes } \\
\text { dispositivos? } \\
\text { [Móvil] }\end{array}$} & Hombre & 13 & 3.54 & 1.266 & 0.351 \\
\hline & Mujer & 75 & 4.24 & 0.913 & 0.105 \\
\hline & Total & 88 & 4.14 & 0.996 & 0.106 \\
\hline \multirow{3}{*}{$\begin{array}{l}\text { Interactúa con } \\
\text { el profesorado } \\
\text { y atiende sus } \\
\text { indicaciones }\end{array}$} & Hombre & 13 & 5.08 & 0.862 & 0.239 \\
\hline & Mujer & 75 & 4.44 & 1.068 & 0.123 \\
\hline & Total & 88 & 4.53 & 1.061 & 0.113 \\
\hline \multirow{3}{*}{$\begin{array}{l}\text { Es conscien- } \\
\text { te del estilo } \\
\text { comunicativo } \\
\text { y actuaciones } \\
\text { adecuadas en } \\
\text { los foros }\end{array}$} & Hombre & 13 & 3.08 & 1.038 & 0.288 \\
\hline & Mujer & 75 & 4.11 & 1.258 & 0.145 \\
\hline & Total & 88 & 3.95 & 1.277 & 0.136 \\
\hline \multirow{3}{*}{$\begin{array}{l}\text { Interactúa con } \\
\text { el profesorado } \\
\text { y atiende sus } \\
\text { indicaciones }\end{array}$} & Hombre & 13 & 3.15 & 1.214 & 0.337 \\
\hline & Mujer & 75 & 4.41 & 1.316 & 0.152 \\
\hline & Total & 88 & 4.23 & 1.371 & 0.146 \\
\hline
\end{tabular}

Elaboración propia (2019)

\section{Discusión y Conclusiones}

Con el paso del tiempo el perfil de los estudiantes ha ido cambiando, el consumo de la tecnología va variando, cada vez más prevalece la movilidad, usabilidad y accesibilidad de los dispositivos. Como hemos podido observar en relación con el primer objetivo, identificar el tipo de recurso digital que utiliza el alumnado en sus tareas académicas, el tiempo que dedican a su uso y tipo de conectividad a la que tienen acceso, el alumnado no utiliza un único dispositivo, los más habitual es usar el ordenador portátil y móvil de forma combinada $50 \%$. Otros estudios ratifican esta tendencia en la que predomina el uso del portátil $73 \%$ sobre el resto de dispositivos, o la conectividad desde casa y Facultad (Cózar \& Roblizo, 2014).

Las conclusiones obtenidas en este estudio con respecto al segundo objetivo, que explora la frecuencia de uso de los recursos TIC y el tipo de herramientas más comunes que emplea, apuntan a que el alumnado da especial importancia a la capacidad de trabajo en equipo, este puede ser uno de los motivos por lo que los ítems relacionados con el trabajo colaborativo destacan especialmente, por ejemplo, el ítem aprende a trabajar en equipo en entornos colaborativos 4.58 de media; trabaja de manera colaborativa 5.11 puntos de media; participa en actividades en grupo en entornos colaborativos en línea, 4.83 puntos de media. Sin embargo, en otras facultades de educación en las que se han realizado estudios similares no se identifican las TIC como un elemento favorecedor del trabajo cooperativo o en grupo (Cózar \& Roblizo, 2014).

De la misma forma, en la elaboración de actividades académicas se realizan con frecuencia presentaciones, 4.17 puntos de media y en menor medida trabajos por escrito, 3.75 puntos de media.

Las actividades de búsqueda de información son realizadas por $39.8 \%$ del alumnado con mucha frecuencia o navegación en la red, el $36.4 \%$ la realiza siempre y el $37.5 \%$ la realiza con mucha frecuencia. Estas actividades son la base para el desarrollo de otras áreas de la competencia digital y son realizadas frecuentemente por el alumnado, tal y como hemos observado. En el estudio reali- 
zado por Gisbert, Espuny \& González (2011) la puntuación media fue de 3.93 en nuestro caso ha sido de 4.42 sobre 6 .

Dentro de las funciones de los profesionales de la pedagogía se encuentra los procesos de elaboración de planes de actuación en organizaciones educativas que respondan a las necesidades. La tecnología forma parte de las organizaciones y la presencia de estas en los centros va más allá de la disponibilidad de los recursos. En los Informes Horizon (Becker et al., 2017; Freeman et al., 2017) tanto en la versión sobre los niveles de primaria y secundaria, como en el de educación superior, se plantean nuevas tendencias educativas para cuya puesta en marcha será necesario desarrollar planes de formación que permitan adquirir las competencias necesarias. En nuestro caso el alumnado presenta en general una media que oscila entre los cuatro y los cinco puntos sobre 6 en las competencias digitales básicas, sin embargo, en las actividades más complejas como por ejemplo en el desarrollo de actividades programación 2.57, juegos 2.55 o recursos audiovisuales 2.88 , que serían algunas de las tendencias recogidas en los informes citados anteriormente, la media baja considerablemente de dos a tres puntos sobre seis.

En relación al tercer objetivo, conocer la competencia digital del alumnado para su uso en las actividades académicas y profesionales propias de su perfil, habría que comentar que este tipo de competencia va más allá del uso de los dispositivos, tanto para el desarrollo académico como profesional, tal y como se recoge en el Libro Blanco de la titulación (Vila, 2004), en el Marco Común de la Competencia Digital Docente (INTEF, 2017) o en la Legislación Educativa Española (Ley Orgánica 8/2013, de 9 de diciembre, para la Mejora de la Calidad Educativa). El alumnado debe adquirir habilidades de aprendizaje continuo y familiarizarse con las nuevas tendencias en educación, especialmente aquellas relacionadas con el desarrollo tecnológico. Este estudio nos muestra algunos puntos fuertes y débiles sobre los que es necesario trabajar. La Facultad de Educación de la Universidad de La Laguna está inmersa en un proceso de modificación de títulos, en los que será posible integrar asignaturas que desarrollen las competencias digitales de los estudiantes, no solo para su desarrollo académico, sino también para su desarrollo profesional, integrando los recursos tecnológicos en el desarrollo de las funciones profesionales.

\section{REFERENCIAS BIBLIOGRÁFICAS}

Area, M. (2008). La innovación pedagógica con TIC y el desarrollo de las competencias informacionales y digitales. Revista de Investigación en la Escuela, 64, 5-17.

Area, M., Hernández, V. \& Sosa, J. J. (2018). Leadership and school integration of ICT. Tearchers perceptions in Spain. Education and Information Technologies, 24(1), 549-565. https://doi.org/10.1007/s10639-018-9789-0

Cantón-Mayo, I., Cañón-Rodríguez, R. \& Grande-de-Pedro, M. (2016). La comunicación como subdimensiones de la competencia digital en futuros maestros de primaria. Pixel-Bit. Revista de Medios y Educación, 50, 33-47.

Carrasco, M.E.E., Sánchez, C., \& Carro, A. (2015). Las competencias digitales en estudiantes del posgrado en educación. Revista Lasallista de Investigación, 12(2), 10-18. Recuperado: https://www.redalyc.org/pdf/695/69542291002. pdf

Cascales, A., Martínez, M.J. \& Gomariz, M.A. (2016). Competencia tecnológica y trabajo colaborativo en las prácticas curriculares del Grado en Pedagogía en la Universidad de Murcia. Revista de Investigación en Educación, 14(1), 31-52. Recuperado de: http://reined.webs.uvigo.es/index. $\mathrm{php} / \mathrm{reined} /$ article/download/223/243

Castellanos, A., Sánchez, C. \& Calderero, J. F. (2017). Nuevos modelos tecnopedagógicos. Competencia digital de los alumnos universitarios. Revista Electrónica de Investigación Educativa, 19(1), 1-9. https://doi.org/10.24320/ redie.2017.19.1.1148

Cózar, R. \& Roblizo, M. J. (2014). La competencia digital en la formación de los futuros maestros: percepciones de los futuros maestros: percepciones de los alumnos de los Grados de Maestro de la Facultad de Educación de Albacete. Revista Latinoamérica a de Tecnología Educativa. 13 (2), 119-133. Recuperado de: https://dialnet.unirioja.es/descarga/articulo/4912059.pdf

Fernández Cruz, F. J. \& Fernández Díaz, M. J. (2016). Los docentes de la Generación $\mathrm{Z}$ y sus competencias digitales. Revista Comunicar 46(24), 97-105. https://doi. org/10.3916/C46-2016-10

Ferrari, A. (2013). DIGCOMP: A Framework for Developing and Understanding Digital Competence in Europe. Luxemburgo: Comisión Europea. Journal Research Centre. European Commission. Recuperado de: http://publications.jrc.ec.europa.eu/repository/bitstream/JRC83167/lbna-26035-enn.pdf

Freeman, A., Adams, S., Cummins, M., Davis, A., \& 
Hall Giesinger, C. (2017). NMC/CoSN Horizon Report: 2017 K-12 Edition. Austin, Texas: The New Media Consortium. Recuperado de https://intef.es/wp-content/ uploads/2017/12/2017_1105_Horizon2017_Prim_Secund_INTEF.pdf

García-Valcárcel, A. \& Martín, M. (2015). Análisis de las competencias digitales de los graduados en titulaciones de maestro. Paper presented at the XXIII Jornadas Universitarias de Tecnología Educativa, Badajoz. http://eventos.unex. es/file_manager/get_paper/2232

Gisbert, M.; González, J. \& Esteve, F. (2016). Competencia digital y competencia digital docente: una panorámica sobre el estado de la cuestión. Revista Interuniversitaria de Investigación en Tecnología Educativa, 0, 74-83. https:// doi.org/10.6018/riite2016/257631

González, M. C., Martín, S. C., \& Llorente, A. M. P. (2014). Percepción de los alumnos de Educación Primaria de la Universidad de Salamanca sobre su competencia digital. EDUTEC. Revista Electrónica de Tecnología Educativa, 48, 1-14. Recuperado de http://www.edutec.es/revista/ index.php/edutec-e/article/download/156/21/

Gutiérrez, J. J., \& Cabero, J. (2016). Estudio de caso sobre la autopercepción de la competencia digital del estudiante universitario de las titulaciones de grado de Educación Infantil y Primaria. Profesorado. Revista de Currículum y Formación del Profesorado, 20 (2), 180-199. Recuperado de https://recyt.fecyt.es/index.php/profesorado/article/ view/52098/31782

Gutiérrez, J. J., Cabero, J., \& Estrada, L. I. (2017). Diseño y validación de un instrumento de evaluación de la competencia digital del estudiante universitario. Revista Espacios, 38(10), 1-27. Recuperado de https://idus.us.es/xmlui/ bitstream/handle/11441/54725/Dise\%C3\%B1o_y_validacion_de_un_instrumento_de_evaluacion_de_la_competencia_digital_del_estudiante.pdf?sequence=1

Gutiérrez, R. C., \& Colmenero, M. J. R. (2014). La competencia digital en la formación de los futuros maestros: percepciones de los alumnos de los Grados de Maestro de la Facultad de Educación de Albacete. RELATEC: Revista Latinoamericana de Tecnología Educativa, 13(2), 119-133.

Guzmán, T., \& Gisbert, M. (2008). Competencias TIC de los estudiantes de la Universidad Autónoma de Querétaro (UAQ): Un estudio de caso. Portal Educativo de las Américas. Recuperado de http://recursos.portaleducoas.org/publicaciones/competencias-tic-de-los-estudiantes-de-la-universidad-aut-noma-de-quer-taro-uaq-un

Herrero, R. M. (2014). El papel de las TIC en el aula universitaria para la formación en competencias del alumnado. Píxel-Bit. Revista de Medios y Educación, 45, 173-188.

INTEF (2017). Marco Común de Competencia Digital Docente. Madrid: Ministerio de Educación, Cultura y Deporte. Recuperado de https://aprende.intef.es/sites/ default/files/2018-05/2017_1020_Marco-Com\%C3\%BAn-de-Competencia-Digital-Docente.pdf

Matilla, M., Sayavedra, C., \& Alfonso, V.C. (2014). Com- petencias TIC en alumnos universitarios: Dimensiones y Categorías para su análisis. Ponencia presentada en Congreso iberoamericano de Ciencia, Tecnología, Innovación y Educación. Buenos Aires. Recuperado de https://www.oei. es/historico/congreso2014/memoriactei/1534.pdf

Merino, C., \& Lautenschlager, G. (2003). Comparación Estadística de la Confiabilidad Alfa de Cronbach: Aplicaciones en la Medición Educacional y Psicológica. Revista de Psicología, 12(2), 127-136. https://doi.org/10.5354/07190581.2012 .17668

Roblizo, M. J., \& Cózar, R. (2015). Usos y competencias en TIC en los futuros maestros de educación infantil y primaria: hacia una alfabetización tecnológica real para docentes. Píxel-Bit. Revista de Medios y Educación, 47, 23-39. https://doi.org/10.12795/pixelbit.2015.147.02

Roig, R. \& Pascual, A. M. (2012). Las competencias digitales de los futuros docentes. Un análisis con estudiantes de Magisterio de Educación Infantil de la Universidad de Alicante. Revista d'innovació educativa. Universitat de Valéncia, 9, 52-60. https://doi.org/10.7203/attic.9.1958

Torres-Coronas, T., \& Vidal-Blasco, M. A. (2015). Percepción de estudiantes y empleadores sobre el desarrollo de competencias digitales en la Educación Superior: Students and employers perception about the development of digital skills in Higher Education. Revista de Educación, 367, 6390.

Vila, A. (2004). Libro Blanco. Título de Grado en Pedagogía y Educación Social. Agencia Nacional de Evaluación de la Calidad y Acreditación (ANECA). Universidad Deusto. 


\title{
La formación digital del estudiante universitario digital: competencias, necesidades y pautas de actuación
}

\section{Digital literacy of university digital students: competences, needs and action guidelines}

\author{
Alba María Hernández-Sánchez ${ }^{1}$ \\ https://orcid.org/0000-0002-3245-6868 \\ Consejería de Educación de la Junta de Andalucía, España \\ Rocío Quijano López ${ }^{2}$ \\ https://orcid.org/0000-0002-6989-3244 \\ Miguel Pérez Ferra ${ }^{3}$ \\ https://orcid.org/0000-0002-3580-6472 \\ Universidad de Jaén, España
}

Recibido: 05-01-2019

Aceptado: 20-03-2019

\section{Cita Recomendada}

Hernández-Sánchez, A., Quijano, R. \& Pérez, M. (2019). La formación digital del estudiante universitario digital: competencias, necesidades y pautas de actuación. Hamut'ay, 6(1), 19-32. http://dx.doi.org/10.21503/hamu.v6i1.1572

\section{RESUMEN}

El presente estudio pretende identificar el nivel de competencia digital del estudiante universitario al inicio de su formación como futuro maestro o maestra, así como comprender las necesidades de formación digital en coherencia con su futuro desempeño profesional. De manera que se contraste que el desempeño de la competencia digital es heterogéneo y carente en función a las habilidades que implican pensamiento de orden superior.

La población de estudio se compone de 559 estudiantes de primer curso de magisterio de las universidades de Granada, Jaén y Oviedo que han cumplimentado un cuestionario "ad hoc" validado por jueces expertos con un alfa de Cronbach de 0.791 de 51 ítems con respuesta graduada tipo Likert sobre la competencia digital.

El estudio descriptivo evidencia la falta de homogeneidad competencial dentro del grupo de nativos y nativas digitales. Observándose un buen desempeño generalizado en torno a actividades como el almacenamiento, la recuperación, la presencia, la participación, el mantenimiento y el potencial creativo. Mientras que, por el contrario, se muestra un desempeño con claras carencias a nivel de evaluación y gestión de la información, filtrado y uso crítico, aplicación de disposiciones legales, creación de materiales y autonomía en la resolución de problemas.

Con todo, el perfil competencial que demuestran los resultados de investigación requiere de una

1 Es maestra funcionaria facilitadora de la inclusión, licenciada en Psicopedagogía y doctora en CC. de la Educación. Líneas de investigación: inclusión educativa, discapacidad y enseñanza a distancia. E-mail: albamaria@ugr.es

2 Es profesora en el Departamento de Didáctica de las Ciencias de la Universidad de Jaén, Catedrática de Escuela Universitaria. Líneas de investigación: formación del profesorado, desarrollo de competencias, enseñanza de las ciencias. E-mail: rquijano@ujaen.es.

3 Es maestro, licenciado en Pedagogía y en Filosofía, doctor en CC.de la Educación, con mención de Premino Extraordinadio, Catedrático de Universidad. Líneas de investigación: Asesoramiento Curricular, formación en competencias e identidad profesional docente. E-mail: mperez@ujaen.es 
necesidad formativa procesual, práctica, transversal, significativa y contextualizada inminente que desarrolle las habilidades de pensamiento de orden superior de los futuros docentes.

Palabras Clave: Educación Superior, nativo digital, competencia digital, tecnologías.

\section{Abstract}

The present study aims to identify the level of digital competence of university students at the beginning of their training as future teachers; as well as to understand the needs of digital training in coherence with their future professional performance. In such a way as to contrast that the performance of digital competence is heterogeneous and devoid in relation to the abilities that involve high order thinking skills.

The study population consists of 559 first-year pedagogy students from the universities of Granada, Jaén and Oviedo who have completed an "ad hoc" questionnaire validated by expert judges with a Cronbach's alpha of 0.791 out of 51 items with a Likert type graded answer about digital competence.

The descriptive study shows the lack of competence homogeneity within the group of digital natives. We observed a good generalized performance regarding activities such as storage, recovery, presence, participation, maintenance and creative potential. While, on the other side, it shows a performance with clear deficiencies at the level of evaluation and information management, filtering and critical use, application of legal provisions, creation of materials and autonomy in problem solving.

Therefore, the competence profile shown by the research results requires a procedural, practical, transversal, significant and contextualized imminent formative training that foster high order thinking skills of future teachers.

Keywords: Higher education, digital native, digital competence, technologies.

\section{INTRODUCCIÓN}

El presente estudio es parte de una investigación de $\mathrm{I}+\mathrm{D}+\mathrm{i}$, denominada: "Evaluación y desarrollo de dos competencias genéricas en estudiantes de primer año del grado de Maestro en Educación Primaria, con referencia: EDU2015-70491-R". El mismo pretende profundizar en la formación actual del estudiante universitario desde una visión de "nativo digital" y cuáles son sus necesidades de formación, con respecto a las TIC, como estudiante del Título de Grado de Magisterio en Educación Primaria. La importancia del presente trabajo surge desde la relevancia que se le confiere a las competencias transversales en la Declaración de Bolonia (1999), redefiniendo los espacios de logro a adquirir por los futuros profesionales.

En el presente siglo la evolución tecnológica ha repercutido de forma significativa en todas las áreas de la sociedad, concretamente en la Educación Superior, tanto a nivel de institución educativa como en las características de los estudiantes (Gisbert \& Esteve, 2011). Bajo este marco se han generado nuevas modalidades de formación que redefinen los fines formativos. Estas circunstancias auspician procedimientos que permiten a los estudiantes generar conocimiento a partir de la información previa. Ello sitúa a la competencia digital más allá de acciones que la reduzcan a la búsqueda y difusión de información. Por el contrario, también aborda el desarrollo de la 
capacidad de seleccionar la información, entenderla, procesarla, organizarla y transformarla en conocimiento, aplicándola a diferentes situaciones y contextos (Gewerc \& Montero-Mesa, 2015; Pérez-Ferra, Quijano-López, \& Ocaña-Moral, 2013). Por lo que la competencia digital constituye un eje transversal necesario en la formación de los universitarios (Gabarda, Rodríguez-Martín \& Moreno-Rodríguez, 2017), razón por la que la situación actual de la formación de los futuros profesionales de la docencia está mediada por el uso de la competencia digital (Sandoval, Rodríguez-Alveal \& Maldonado, (2017), ya que promueve el desarrollo de la empatía, la escucha activa, la asertividad o la capacidad persuasiva (Núñez-López, Ávila-Palet \& Olivares-Olivares, 2018). Ello comporta: obtener información, gestionar, generar y difundir conocimiento. Además, de ser un recurso que articula procesos metodológicos en la formación.

Cabría preguntarse cómo afecta a nuestros estudiantes de magisterio la irrupción de las tecnologías en la formación y aprendizaje de los mismos, así como el hecho de que sean o no capaces de desenvolverse con ellas (Snell-Siddle, Snell \& Fisher, 2017). Desde 1998 Tapscott utilizó, por primera vez, la expresión "Generación NET", desde entonces han surgido numerosas definiciones o términos que denominan a los individuos nacidos después de 1982 (considerada la primera generación que ha crecido en un entorno completamente tecnológico) y, según diversos autores como Gasser \& Palfrey (2008) estas generaciones poseen unas características diferentes a las de las generaciones anteriores y características comunes entre ellos mismos (Pedró, 2009). Posteriormente surgieron denominaciones como "inmigrantes digitales", donde no solo se diferencian los estudiantes en su forma de vestir o de hablar, sino en su forma de procesar la información y a estos nuevos estudiantes se les denomina "nativos digitales", que se caracterizan porque su lenguaje es el digital pero el sistema educativo no fue diseñado para ellos, lo que conlleva repercusiones en el sistema de formación de Educación Superior, razón por la que los docentes deben aprender a trabajar con un lenguaje digital, que no es el suyo y deben reconsiderar las metodologías y el contenido a desarrollar en las aulas en función de los nuevos recursos que tienen a su disposición. La cuestión no es que las metodologías cambian en la medida que se utilizan, sino que se articulan y adicionan a nuevos métodos que se pueden llevar a cabo mediante recursos y materiales de esta naturaleza.

Pero la formación de los futuros docentes no puede quedar reducida a la mera adquisición de destrezas tecnológicas, que siendo necesarias, debe transcender y abordar la aplicación didáctica de las mismas (Apple, 2018). Ello supone que los futuros docentes deben planificar, llevar a cabo procesos didácticos, tutorizar, etc. Son todas ellas acciones y procesos en las que la competencia digital es necesaria para gestionar los recursos digitales, aunque frecuentemente, las evidencias ponen de manifiesto que el nivel de fracaso en la gestión de los cursos en línea es elevado, superando el 60\%.

El avance hacia el nuevo rol docente urge a profundizar en la selección, organización y distribución de los recursos de información que proporciona la propia red. La competencia comunicativa y digital surgen de la integración de entornos virtuales y personales (Salinas, De Benito \& Lizana, 2014), que deben conducir hacia un Humanismo cívico. Dicho lo cual, la alfabetización digital, considerada en su más amplia realidad, integra todas las competencias que un futuro maestro necesita para desenvolverse de modo efectivo en la sociedad de la información y el conocimiento (García-Ávila, 2017).

En este sentido se orienta la definición sobre competencia digital que aporta la Comisión Europea (European Parlament and the Council, 2006), que define la competencia digital como "el uso seguro y crítico de las tecnologías de la sociedad de la información para el trabajo, el ocio y la comunicación", que se manifiesta en la utilización de ordenadores para evaluar, guardar e intercambiar información, entre otros aspectos, así como participar en redes de colaboración a través de Internet. Atendiendo a ello, se asume la alfabetización digital, que comprende el uso adecuado de la tecnología, la comprensión crítica de la información y la creación y comunicación de contenido digital que, relacionados con la competencia comunicativa, constituyen la base para aplicarlos al desempeño didáctico. 
Con todo, el presente estudio pretende arrojar luz en torno a los siguientes objetivos:

- Identificar el nivel de competencia digital del estudiante universitario al inicio de su formación como futuro maestro o maestra.

- Comprender las necesidades de formación digital del estudiante en cuestión en coherencia con su futuro desempeño profesional.

Fines de investigación que parten de la hipótesis de que el estudiante universitario digital, objeto de estudio, (como representantes de la generación de nativos y nativas digitales) muestra un desempeño de la competencia digital heterogéneo y carente en función al dominio de las subcompetencias que la definen (navegación y resolución de problemas técnicos, disposiciones legales reguladoras de los derechos de autor, desarrollo, integración y estructuración de contenidos e interacción a través de medios digitales y gestión de la identidad digital).

Por lo expuesto es relevante describir en la revisión de la literatura las cuatro dimensiones surgida del análisis factorial, que conforman 4 subcompetencias integradas por diferentes variables que correlacionan en torno a una misma dimensión, y aunque responde a una realidad epistemológicamente contextualizada, tienen como referente al Institute for Prospective Technological Studies (IPTS), uno de los centros de investigación de la Comisión Europea, y responden a los resultados del Proyecto DIGCOMP (Ferrari, 2013), así como el "Proyecto Marco común de competencia digital docente" del Instituto Nacional de Tecnologías Educativas y de Formación del Profesorado (2017). Se definen cuatro subcompetencias: "navegación y resolución de problemas técnicos", "disposiciones legales reguladoras de los derechos de autor", "desarrollo, integración y estructuración de contenidos" e "interacción a través de medios digitales y gestión de la identidad digital" (Cabero-Almenara \& Llorente-Cejudo, 2008).

\section{La competencia digital desde una visión holística}

El Marco Común de Competencia Digital Docente (INTEF, 2017) ofrece una visión amplia de la complejidad que entrańa el aprendizaje de la competencia digital, estableciendo una estructura general que incluye las diferentes áreas o subcompetencias que precisa la figura docente actual.

La subcompetencia "navegación y resolución de problemas técnicos”, alude a la habilidad para identificar necesidades y recursos digitales, tomar decisiones a la hora de elegir la "herramienta" digital apropiada, acorde a la finalidad o necesidad y resolver problemas (Aranda, Martínez, Faraci \& Cechich, 2013). Podemos considerar esta área, junto con la de seguridad, las dos áreas que son transversales a las áreas de la Información, la Comunicación y la Creación de contenidos. La resolución de problemas técnicos alude a las siguientes unidades de competencia:

- Resolución de problemas técnicos a través de su identificación.

- Identificación de necesidades y respuestas tecnológicas: uso de recursos, herramientas...

- Innovación y uso de la tecnología digital de forma creativa.

- Identificación de lagunas en la competencia digital.

La seguridad como protección de información y datos personales se encuentra muy ligada al dominio instrumental para poder llevar a cabo las medidas correctas de protección (Solarte, Enriquez \& Benavides, 2015). Y lo mismo ocurre con la transversalidad de la competencia en resolución de problemas en lo relacionado con la navegación, que permite buscar información digital en red, aspectos que han sido detectados como elementos de mejora en la formación de los estudiantes de primer curso del grado de maestros y maestras (Castellanos, Sánchez-Romero y Calderero, 2017; Napal, Peñalva.Vélez \& Mendióroz, 2018). Otros estudios valoran las competencias técnicas que tienen los futuros docentes (Tondeur et al., 2015), que se definen como la combinación de habilidades técnico-procesales, cognitivas y socio-emocionales, necesarias para vivir, aprender y trabajar en la sociedad digital (Fraser, Atkins \& Richard, 2013; Nawaz \& Kundi, 2010; Eshet-Alkalai, 2012).

Especial relevancia adquiere la subcompetencia "disposiciones legales reguladoras de los derechos de autor y licencias de uso". Los derechos de au- 
tor responden a uno de los aspectos más interesantes de la propiedad intelectual, en la medida que aportan soluciones a posibles conflictos que pudieran surgir en las relaciones entre autores, los editores y usuarios. Se considera relevante que los estudiantes muestren interés por su conocimiento; en aspectos relativas al conocimiento de los procedimientos por los cuales se puede liberalizar su obra o hacerla de dominio público, así como una preocupación por cumplir las normas legales cuando emite o recibe mensajes digitales ( $\mathrm{Ra}$ mírez \& Arellano, 2015).

La tercera subcompetencia es de vital importancia debido a que se vincula con otras subcompetencias de la competencia comunicativa, tales como la morfosintáctica, el registro lingüístico o la sociolingüística, en concreto se hace referencia al "desarrollo, integración y estructuración de contenidos", de vital importancia para la construcción del discurso didáctico. La subcompetencia de referencia permite elaborar materiales dedicados a la formación de futuros profesionales de la educación, atendiendo a diferentes ámbitos de la tecnología educativa, así como a la formación de futuros profesionales de la educación (Cabero, Marín-Díaz e Infante, 2011). Facilitar esa formación, es oportuno poner a disposición de los profesionales y futuros profesionales de la educación un entorno formativo telemático para la adquisición de diferentes capacidades y competencias que permitan la utilización de las TIC.

En diferentes investigaciones se ha estudiado, no solo las carencias que tienen los estudiantes respecto a la unidad de competencia "desarrollo, integración y estructuración de contenidos", a fin de poder gestionar la competencia digital en contextos educativos, sino también el "hándicap" inicial que supone el desconocimiento de principios elementales de la ciencia didáctica en el primer año en el que se cursa la carrera (Colomer, Saiz \& Bel, 2018). De modo que la mejora de la competencia digital precisa del desarrollo de las habilidades de pensamiento de orden superior que son habitualmente relegadas a un segundo plano de actuación.

Con todo y a pesar de las evidencias científicas que demuestra la potencialidad de los contenidos digitales educativos, es necesario "reajustar el sentido de la formación para los mismos en la misma dirección del desarrollo profesional, tanto a través de la formación inicial como la formación continua para su logro" (Tejada \& Pozos, 2018, p. 28).

En último lugar, se aborda la "interacción a través de medios digitales y gestión de la identidad digital", subcompetencia "que permite definir nuevos escenarios, entornos y posibilidades para la educación, formación profesional y capacitación laboral" (Velázquez-Sortino, Gómez-Zermeño \& Alemán de la Garza, 2017, p. 151).

Las posibilidades de la metodología didáctica aconsejan que los futuros maestros aprendan a utilizar "herramientas" digitales distintas para interactuar con los demás, como el correo electrónico, WhatsApp, redes sociales, etc., que incremente el potencial de uso de las TIC en el ámbito educativo, interacción que compromete a cuidar la imagen en línea de quienes utilizan los recursos telemáticos y la identidad digital, en la medida que la interacción digital favorece el incremento considerable de datos personales en el entorno digital, coincidiendo, o no, la identidad personal con la analogía (Giones-Valls \& Serrat-Brustenga, 2010).

Los datos que compartimos en los medios, en las redes digitales, condicionan nuestra vida e incluso nuestra vida social y laboral. Esta subcompetencia integra la capacidad de los estudiantes de trabajar en entornos virtuales y personales, en aspectos como utilizar herramientas digitales diferentes para interactuar, que abordan en el ámbito de la Didáctica el conocimiento de las interacciones que ha de establecerse entre diferentes fuentes de información digitales, atendiendo a la actividad docente que ha de planificar.

\section{Materiales Y Métodos}

\section{Participantes}

El presente estudio estuvo conformado por una población de 559 estudiantes. Los criterios de inclusión para participar en el estudio era pertenecer a las universidades de Granada, Jaén y Oviedo, así como ser estudiante de primer curso del 
título de Grado de Educación Primaria. Se parte de una población inicial de mil cuatrocientos treinta estudiantes, siendo la muestra mínima representativa de 304 estudiantes, según la fórmula "Sample Size Calculator for a proportion (absolute margin). El perfil de la población participante se concreta en torno a la siguiente información:

Tabla 1

Distribución de la muestra

\begin{tabular}{|c|c|c|c|}
\hline Ítem & Elección & $\begin{array}{l}\text { Núme- } \\
\text { ro }\end{array}$ & $\%$ \\
\hline \multirow[t]{3}{*}{$\begin{array}{l}\text { Universidad de } \\
\text { procedencia }\end{array}$} & $\begin{array}{l}\text { Universidad de } \\
\text { Granada }\end{array}$ & 65 & 11.6 \\
\hline & Universidad de Jaén & 297 & 53.1 \\
\hline & Universidad de Oviedo & 197 & 35.2 \\
\hline \multirow[t]{2}{*}{ Sexo } & Mujeres & 424 & 75.8 \\
\hline & Hombre & 135 & 24.2 \\
\hline \multirow{3}{*}{$\begin{array}{l}\text { Estudios de Bachi- } \\
\text { llerato o Formación } \\
\text { Profesional }\end{array}$} & Centro público & 463 & 82.8 \\
\hline & Centro concertado & 62 & 11.11 \\
\hline & Centro privado & 34 & 6.1 \\
\hline \multirow{7}{*}{$\begin{array}{l}\text { Titulación } \\
\text { académica de los } \\
\text { padres, madres o } \\
\text { tutores legales }\end{array}$} & Educación Primaria & 176 & 31.5 \\
\hline & Bachillerato & 103 & 18.4 \\
\hline & Formación Profesional & 152 & 27.2 \\
\hline & Diplomatura & 19 & 3.4 \\
\hline & Licenciatura & 91 & 16.3 \\
\hline & Maestría & 11 & 2 \\
\hline & Doctorado & 7 & 1.3 \\
\hline \multirow{2}{*}{$\begin{array}{l}\text { Titulación previa a } \\
\text { Magisterio }\end{array}$} & Sí & 113 & 20.2 \\
\hline & No & 446 & 79.8 \\
\hline \multirow{2}{*}{$\begin{array}{l}\text { Estudios previos } \\
\text { en un centro ins- } \\
\text { crito al Programa } \\
\text { de Tecnologías de } \\
\text { la Información y la } \\
\text { Comunicación }\end{array}$} & Sí & 361 & 64.6 \\
\hline & No & 198 & 35.4 \\
\hline \multirow[t]{5}{*}{$\begin{array}{l}\text { Destreza tecno- } \\
\text { lógica }\end{array}$} & $\begin{array}{l}\text { Aprendizaje en la } \\
\text { familia }\end{array}$ & 49 & 8.8 \\
\hline & $\begin{array}{l}\text { Aprendizaje en el } \\
\text { centro que estudió }\end{array}$ & 111 & 19.9 \\
\hline & $\begin{array}{l}\text { Aprendizaje en otras } \\
\text { instituciones }\end{array}$ & 32 & 5.7 \\
\hline & Autoaprendizaje & 361 & 64.6 \\
\hline & Otros & 6 & 1.1 \\
\hline \multirow{2}{*}{$\begin{array}{l}\text { Formación especí- } \\
\text { fica previa en TIC }\end{array}$} & Sí & 253 & 45.3 \\
\hline & No & 306 & 54.7 \\
\hline \multirow{2}{*}{$\begin{array}{l}\text { Modalidad de la } \\
\text { formación TIC } \\
\text { recibida }\end{array}$} & Presencial & 347 & 62.1 \\
\hline & Virtual & 206 & 36.9 \\
\hline
\end{tabular}

Elaboración propia (2019)

\section{Instrumento}

La investigación ha utilizado un instrumento de medida "ad hoc" con escalas aditivas tipo Likert, consistente en 51 ítems sobre los rasgos de la competencia digital. Las opciones de respuesta utilizadas han sido: "Nunca=1", "Casi nunca=2", "En algunas ocasiones=3", "Casi siempre $=4$ ", "Siempre=5" y "No sabe/No contesta".

La fiabilidad del instrumento se realizó mediante el Alfa de Cronbach respecto a la totalidad de la escala es de 0.791. La eliminación de cada ítem respecto a la totalidad, aporta los siguientes datos (ítem no $33=0.770<0.789=1$ tem no 22 ). No se suprime ningún ítem, ya que al eliminar respectivamente cada uno de los ítems, el resultado no aporta un alfa superior al de la totalidad de la escala; es decir 0.791. Se aplica el alfa de las dos mitades para conocer el nivel de consistencia entre las dos partes del cuestionario; en los ítems impares se obtuvo un alfa $=0.6785$; en los ítems pares un alfa $=0.740$; por consiguiente, hay una consistencia razonable en la fiabilidad de los ítems pares respecto a los impares.

En la validez de constructo se utilizan los mismos procedimientos estadísticos que en la validez del cuestionario de competenciales digitales, con resultados mostrados en la tabla 2 . La medida de adecuación muestral aporta un KMO 0.867, mientras que la prueba de esfericidad de Bartlett confirma la existencia de factores subyacentes en la matriz de datos, siendo $\alpha=0.000$ y el índice de discriminación de 0.5 , partiendo para realizar la validez de constructo de 51 ítems. La solución del análisis factorial, define 4 factores, que integran 21 de los ítems originalmente propuestos (tabla 3) explicativos del $41.316 \%$ de la varianza, con un índice mínimo de discriminación de 0.5.

Tabla 2

Resumen estadístico del análisis factorial-competencia digital.

\begin{tabular}{llc}
\hline $\begin{array}{c}\text { Medida de adecuación } \\
\text { muestral }\end{array}$ & \multicolumn{1}{c}{$\begin{array}{c}\text { Kaiser.Meyer-Ol- } \\
\text { kin }\end{array}$} & 0.867 \\
\hline Prueba de esfericidad & Chi- cuadrado & 7260.477 \\
de Bartlett & Gl. & 1275 \\
& Sig. & 0.000 \\
\hline
\end{tabular}

Elaboración propia (2019) 
Tabla 3

Varianza explicada y agrupación de los ítems en factores (rotación varimax) - competencia digital.

\begin{tabular}{lcc}
\hline \multicolumn{1}{c}{ Factores } & $\begin{array}{c}\text { Varianza expli- } \\
\text { cada por factor } \\
(\%)\end{array}$ & $\begin{array}{c}\text { Ítem que inte- } \\
\text { gran cada factor }\end{array}$ \\
\hline $\begin{array}{l}\text { F-1:Subcompetencia, } \\
\text { navegación y resolución } \\
\text { de problemas técnicos }\end{array}$ & 16.978 & $1,10,37,38,44$, \\
$\begin{array}{l}\text { F-2:Subcompetencia, } \\
\text { disposiciones legales }\end{array}$ & 15.508 & 45,47 \\
reguladoras de los & & $34,21,22,23,35$ \\
derechos de autor y de & & \\
las licencias de uso. & & \\
$\begin{array}{l}\text { F-3:Subcompetencia,- } \\
\text { desarrollo, integración }\end{array}$ & 5.031 & $27,29,31,32$ \\
y estructuración de \\
contenidos \\
$\begin{array}{l}\text { F-4: Subcompetencia, } \\
\text { interacción a través } \\
\text { de medios digitales y } \\
\text { gestión de la identidad } \\
\text { digital. } \\
\text { Varianza total explicada } \\
\text { Número de factores }\end{array}$ \\
\hline
\end{tabular}

Elaboración propia (2019)

Tipo y diseño de estudio

Se aplica el cuestionario "ad hoc" diseñado desde una metodología de corte cuantitativo con un análisis descriptivo dentro de un estudio más amplio pretest-postest que evalúe la aplicación de un programa formativo a medida, tal y como aplican e investigan otros autores y autoras como González, Román \& Prendes (2018).

\section{Confidencialidad}

El grupo de estudiantes participa de forma voluntaria, garantizándose la protección de la identidad de la población de estudio respeto a sus derechos individuales.

\section{Procedimiento}

El presente trabajo se redacta a partir de las fases I, II, III y IV del proyecto I+D+i del que nace. Siendo la estructura general de las fases del proyecto las que se detallan a continuación:
Fase I: Determinación de los grupos de estudiantes participantes en la investigación.

Fase II: Diagnóstico preliminar de las necesidades formativas: Análisis y valoración de los programas ordinarios de formación en los grupos docentes relacionados con las competencias clave del estudio y las muestras de estudiantes seleccionadas.

Fase III: Construcción y validación del instrumento de evaluación: cuestionario ad hoc.

Fase IV: Aplicación del pretest.

Fase V: Diseño y validación de un programa formativo en línea

Fase VI: Aplicación y evaluación del programa formativo.

Fase VII: Aplicación del postest.

\section{Resultados}

La presentación y análisis de los resultados se disponen en torno a la estructura del cuestionario de competencia digital diseñado en coherencia con las subcompetencias digitales de estudio ya explicitadas. De modo que la información se organiza alrededor de los siguientes apartados, aglutinando y relacionando los desempeños que los componen (tabla 4):

\section{Tabla 4}

Desempeños que componen las subcompetencias de la competencia digital.

\begin{tabular}{|c|c|}
\hline Elección & Número \\
\hline \multirow[t]{3}{*}{$\begin{array}{l}\text { Acceso a la } \\
\text { información }\end{array}$} & $\begin{array}{l}\text { Navegación, búsqueda y filtrado de informa- } \\
\text { ción. }\end{array}$ \\
\hline & Evaluación de la información. \\
\hline & $\begin{array}{l}\text { Almacenamiento y recuperación de informa- } \\
\text { ción. }\end{array}$ \\
\hline \multirow{6}{*}{$\begin{array}{l}\text { Comunica- } \\
\text { ción }\end{array}$} & Interacción a través de medios digitales \\
\hline & Compartir información y contenidos \\
\hline & Participación ciudadana en línea \\
\hline & Colaboración mediante medios digitales \\
\hline & Netiqueta. \\
\hline & Gestión de la identidad digital. \\
\hline \multirow{4}{*}{$\begin{array}{l}\text { Creación } \\
\text { de conteni- } \\
\text { dos }\end{array}$} & Desarrollo de contenidos. \\
\hline & Integración y reestructuración de contenidos. \\
\hline & Derechos de autor y licencias. \\
\hline & Programación. \\
\hline
\end{tabular}




\begin{tabular}{|c|c|}
\hline Elección & Número \\
\hline \multirow[t]{4}{*}{ Seguridad } & Protección de dispositivos. \\
\hline & $\begin{array}{l}\text { Protección de datos personales e identidad } \\
\text { digital. }\end{array}$ \\
\hline & Protección de la salud. \\
\hline & Protección del entorno. \\
\hline \multirow{4}{*}{$\begin{array}{l}\text { Resolución } \\
\text { de proble- } \\
\text { mas }\end{array}$} & Resolución de problemas técnicos. \\
\hline & $\begin{array}{l}\text { Identificación de necesidades y respuestas } \\
\text { tecnológicas. }\end{array}$ \\
\hline & $\begin{array}{l}\text { Innovación y uso de la tecnología de forma } \\
\text { creativa. }\end{array}$ \\
\hline & $\begin{array}{l}\text { Identificación de lagunas en la competencia } \\
\text { digital. }\end{array}$ \\
\hline
\end{tabular}

Elaboración propia (2019)

\section{El acceso a la información}

El estudiantado universitario digital que forma parte de la presente investigación dista de tener una competencia digital efectiva en términos de acceso a la información. Por un lado, se observa que las habilidades a nivel técnico relacionadas con el almacenamiento y la recuperación de la información tienen una tendencia mayoritaria positiva. De manera que en las respuestas de los ítems de la Tabla 5 visualiza una tendencia general a poner en prácticas estas actividades de manera habitual en su mayoría.

Tabla 5

Competencia digital efectiva en términos de acceso a la información (\%).

\begin{tabular}{lccc}
\hline & $\begin{array}{c}\text { Nunca } \\
\text { o casi } \\
\text { nunca }\end{array}$ & $\begin{array}{c}\text { En } \\
\text { algunas } \\
\text { ocasio- } \\
\text { nes }\end{array}$ & $\begin{array}{c}\text { Casi } \\
\text { siempre } \\
\text { o siem- } \\
\text { pre }\end{array}$ \\
\hline $\begin{array}{l}\text { Guardas información en di- } \\
\text { ferentes formatos clasificán- } \\
\text { dola de forma que la puedas } \\
\text { recuperar fácilmente }\end{array}$ & 11.8 & 23.3 & 64.6 \\
$\begin{array}{l}\text { Realizas copias de seguri- } \\
\text { dad de la información que } \\
\text { consideras relevante }\end{array}$ & 26 & 21.1 & 51.9 \\
$\begin{array}{l}\text { Utilizas espacios de almace- } \\
\text { namiento externo con ese fin }\end{array}$ & 20.8 & 23.8 & 52.2 \\
\hline
\end{tabular}

Elaboración propia (2019)

Sin embargo, los datos informan de un bajo desempeño a nivel de la evaluación y la gestión de la información. Las acciones de evaluación en la Tabla 6 muestran que el acceso crítico a la información no se sitúa en una posición prioritaria a la hora de acceder a la misma.

\section{Tabla 6}

Evaluación y la gestión de la información (\%).

\begin{tabular}{lccc}
\hline & $\begin{array}{c}\text { Nunca } \\
\text { o casi } \\
\text { nunca }\end{array}$ & $\begin{array}{c}\text { En } \\
\text { algunas } \\
\text { ocasio- } \\
\text { nes }\end{array}$ & $\begin{array}{c}\text { Casi } \\
\text { siempre } \\
\text { o siem- } \\
\text { pre }\end{array}$ \\
\hline $\begin{array}{l}\text { Tienes en cuenta las } \\
\text { restricciones de los recursos } \\
\text { educativos publicados con } \\
\text { derechos de autor }\end{array}$ & 38.1 & 23.4 & 29.7 \\
$\begin{array}{l}\text { Utilizas recursos educativos } \\
\text { disponibles en Internet en } \\
\text { función de las demandas que } \\
\text { te plantean las asignaturas }\end{array}$ & 8.4 & 40.3 & 48.2 \\
$\begin{array}{l}\text { Evalúas críticamente la } \\
\text { información que localizas }\end{array}$ & 20.5 & 37.9 & 39.9 \\
en Internet posicionándote \\
sobre su enfoque
\end{tabular}

Elaboración propia (2019)

La gestión de la navegación, la búsqueda y el filtrado de la información son desempeńos poco asimilados en la población participante (Tabla 7):

\section{Tabla 7}

Gestión de la navegación, la búsqueda y el filtrado de la información (\%).

\begin{tabular}{lccc}
\hline & $\begin{array}{c}\text { Nunca } \\
\text { o casi } \\
\text { nunca }\end{array}$ & $\begin{array}{c}\text { En } \\
\text { algunas } \\
\text { ocasio- } \\
\text { nes }\end{array}$ & $\begin{array}{c}\text { Casi } \\
\text { siempre } \\
\text { o siem- } \\
\text { pre }\end{array}$ \\
\hline $\begin{array}{l}\text { Configuras el navegador web } \\
\text { de tu ordenador cuando lo } \\
\text { consideras necesario }\end{array}$ & 41.5 & 27 & 26.6 \\
$\begin{array}{l}\text { Seleccionas fuentes de infor- } \\
\text { mación de interés profesional }\end{array}$ & 24.3 & 47.6 & 26.4 \\
$\begin{array}{l}\text { Localizas información digi- } \\
\text { talizada utilizando palabras } \\
\text { clave y filtros para ajustar y } \\
\text { limitar tu búsqueda }\end{array}$ & 27.4 & 28.1 & 42.5 \\
$\begin{array}{l}\text { Usas distintos buscadores } \\
\text { para localizar información y } \\
\text { recursos }\end{array}$ & 37.2 & 23.1 & 39.5 \\
\hline
\end{tabular}

Elaboración propia (2019) 


\section{La comunicación}

La participación en línea y la interacción a través de los medios digitales son acciones que, popularmente, se presuponen intrínsecas a la propia idiosincrasia de los nativos y las nativas digitales.

En este sentido, el análisis de la información arroja un apoyo claro a esta premisa a través de los siguientes resultados:

\section{Tabla 8}

Participación en línea y la interacción a través de los medios digitales $(\%)$.

\begin{tabular}{lccc}
\hline & $\begin{array}{c}\text { Nunca o casi } \\
\text { nunca }\end{array}$ & $\begin{array}{c}\text { En } \\
\text { algunas } \\
\text { ocasio- } \\
\text { nes }\end{array}$ & $\begin{array}{c}\text { Casi } \\
\text { siempre } \\
\text { o siem- } \\
\text { pre }\end{array}$ \\
\hline $\begin{array}{l}\text { Utilizas al menos tres } \\
\text { herramientas digitales } \\
\text { distintas para interactuar } \\
\text { con los demás }\end{array}$ & 0.7 & 8.4 & 90.7 \\
$\begin{array}{l}\text { Cuando navegas, inte- } \\
\text { raccionas con diferentes } \\
\text { fuentes de información } \\
\text { digital }\end{array}$ & 5 & 19.1 & 76.4 \\
$\begin{array}{l}\text { Participas activamen- } \\
\text { te en al menos dos } \\
\text { comunidades virtuales y } \\
\text { redes sociales }\end{array}$ & & & \\
$\begin{array}{l}\text { Aprovechas las posibi- } \\
\text { lidades que te ofrecen } \\
\text { los medios digitales } \\
\text { incluyendo a las redes } \\
\text { sociales para promover } \\
\text { la participación social de } \\
\text { la ciudadanía }\end{array}$ & & & \\
\hline
\end{tabular}

Elaboración propia (2019)

Aunque en la mayoría de los ítems hay un alto porcentaje de la población que siempre o casi siempre participa e interacciona de forma activa en línea, el uso concreto de la red para la participación social de la ciudadanía no es una actividad que se practique con tanta frecuencia; infiriéndose así que el perfil de estudiantes digital se identifica de forma clara con la presencia y la participación digital pero no tan nítidamente con el uso crítico y social del medio.

En la línea de la inferencia anterior, se observa que el desempeńo relacionado con compartir información y colaborar mediante medios digitales presenta carencias significativas en el estudiante digital ( Tabla 9).

Tabla 9

Compartir información y colaborar mediante medios digitales (\%).

\begin{tabular}{|c|c|c|c|}
\hline & $\begin{array}{c}\text { Nunca o casi } \\
\text { nunca }\end{array}$ & $\begin{array}{l}\text { En } \\
\text { algunas } \\
\text { ocasio- } \\
\text { nes }\end{array}$ & $\begin{array}{l}\text { Casi } \\
\text { siempre } \\
\text { o siem- } \\
\text { pre }\end{array}$ \\
\hline $\begin{array}{l}\text { Cuando compartes in- } \\
\text { formación o contenidos } \\
\text { obtenidos en línea, citas } \\
\text { al autor y a la fuente, } \\
\text { siguiendo las normas } \\
\text { existentes }\end{array}$ & 31.8 & 33.3 & 32.5 \\
\hline $\begin{array}{l}\text { Seleccionas para com- } \\
\text { partir en red, noticias y } \\
\text { recursos localizados en } \\
\text { diversas páginas web, } \\
\text { foros y otras comunida- } \\
\text { des en línea }\end{array}$ & 33 & 35.2 & 30 \\
\hline $\begin{array}{l}\text { Utilizas programas y } \\
\text { aplicaciones para crear } \\
\text { presentaciones digitales } \\
\text { proyectables }\end{array}$ & 31.3 & 28.6 & 37.8 \\
\hline $\begin{array}{l}\text { Difundes en línea las } \\
\text { presentaciones digitales } \\
\text { creadas a través de } \\
\text { envío por correo, redes } \\
\text { sociales, subida a repo- } \\
\text { sitorios, etc }\end{array}$ & 48.3 & 28.1 & 18.8 \\
\hline $\begin{array}{l}\text { Usas herramientas de } \\
\text { trabajo colaborativo en } \\
\text { línea para crear conoci- } \\
\text { miento compartido }\end{array}$ & 32.6 & 40.8 & 32.7 \\
\hline
\end{tabular}

Elaboración propia (2019)

El análisis de las normas de comportamiento a través de Internet (netiqueta) muestra que la consulta de las disposiciones legales que regulan los derechos y los deberes de quienes emitimos y recibimos mensajes digitales no suele ser una actividad que se tenga presente en la comunicación en línea del estudiante digital, "nunca o casi nunca" $65.5 \%$.

Así mismo, aunque los porcentajes sean algo más alentadores, el resto de ítems relacionados no resuelven un desempeño generalizado de esta unidad competencial (Tabla 10). 


\section{Tabla 10}

Disposiciones legales que regulan los derechos y los deberes $(\%)$.

\begin{tabular}{lccc}
\hline & $\begin{array}{r}\text { Nunca } \\
\text { o casi } \\
\text { nunca }\end{array}$ & $\begin{array}{c}\text { En } \\
\text { algunas } \\
\text { ocasio- } \\
\text { nes }\end{array}$ & $\begin{array}{c}\text { Casi } \\
\text { siempre } \\
\text { o siem- } \\
\text { pre }\end{array}$ \\
\hline $\begin{array}{l}\text { La consulta de las disposicio- } \\
\text { nes legales que regulan los } \\
\text { derechos y los deberes de } \\
\text { quienes emitimos y recibimos } \\
\text { mensajes digitales }\end{array}$ & & 17.4 & 10.2 \\
$\begin{array}{l}\text { Cuando emites y recibes } \\
\text { mensajes digitales cumples }\end{array}$ & 24.9 & 25.6 & 32.3 \\
las normas legales que & & & \\
regulan tal transferencia de & & & \\
información & & & \\
$\begin{array}{l}\text { Tienes presente las carac- } \\
\text { terísticas socioculturales de }\end{array}$ & 25.7 & 27.6 & 35.3 \\
las audiencias hacia los que \\
diriges tus mensajes digitales \\
que creas para difundirlos a \\
través de internet
\end{tabular}

Elaboración propia (2019)

La gestión de la identidad digital en torno a las interacciones y participación en el medio muestra que un $79.8 \%$ cuida la información que se hace pública "casi siempre o siempre". Sin embargo, el acto de revisión que precisa la gestión de la identidad digital no se completa en un alto porcentaje del estudiante digital, observándose que el rastreo de la huella digital en Internet no es un proceso primordialmente asumido (Tabla 11).

Tabla 11

Gestión de la identidad digital (\%).

\begin{tabular}{lccc}
\hline & $\begin{array}{c}\text { Nunca } \\
\text { o casi } \\
\text { nunca }\end{array}$ & $\begin{array}{c}\text { En } \\
\text { algunas } \\
\text { ocasio- } \\
\text { nes }\end{array}$ & $\begin{array}{c}\text { Casi } \\
\text { siempre } \\
\text { o siem- } \\
\text { pre }\end{array}$ \\
\hline $\begin{array}{l}\text { Gestión de la identidad digital } \\
\text { que se realiza en torno a las } \\
\text { interacciones y participación } \\
\text { en el medio } \\
\text { Gestión de la identidad digital }\end{array}$ & 5 & 14.3 & 79.8 \\
\hline
\end{tabular}

Elaboración propia (2019)

\section{Creación de contenidos}

El perfil de estudiante digital generalizado infunde una visión de competencia creativa de material digital prácticamente intrínseca a la participación en el medio. Sin embargo, el análisis de los resultados obtenidos muestra que la creación de audios digitales mezclando voz y música además de la creación de vídeos propios insertando fotografías, gráficos, fragmentos de películas y textos tienen un desempeño bajo en un amplio número de participantes. En sincronía con los análisis anteriores, se observa que el uso de programas de edición digital para modificar contenidos propios o ajenos es un desempeńo poco asumido por la mayoría de los estudiantes. Incluso la creación de presentaciones digitales combinando imágenes, gráficos y textos presenta un porcentaje inferior a la mitad de personas que lo valoran como una actividad que siempre o casi siempre realizan, como se presenta en la Tabla 12

Tabla 12

Competencia creativa de material digital(\%).

\begin{tabular}{lccc}
\hline & $\begin{array}{c}\text { Nunca o casi } \\
\text { nunca }\end{array}$ & $\begin{array}{c}\text { En } \\
\text { algunas } \\
\text { ocasio- } \\
\text { nes }\end{array}$ & $\begin{array}{c}\text { Casi } \\
\text { siempre } \\
\text { o siem- } \\
\text { pre }\end{array}$ \\
\hline $\begin{array}{l}\text { La creación de audios } \\
\text { digitales mezclando voz } \\
\text { y música }\end{array}$ & 63.4 & 21.1 & 12.9 \\
$\begin{array}{l}\text { La creación de vídeos } \\
\text { propios insertando } \\
\text { fotografías, gráficos, } \\
\text { fragmentos de películas } \\
\text { y textos }\end{array}$ & 45.8 & 28.6 & 24.2 \\
$\begin{array}{l}\text { El uso de programas } \\
\text { de edición digital para } \\
\text { modificar contenidos } \\
\text { propios o ajenos } \\
\text { Creación de presen- } \\
\text { taciones digitales } \\
\text { combinando imágenes, } \\
\text { gráficos y textos }\end{array}$ & 49.4 & 27.5 & 20.1 \\
\hline
\end{tabular}

Elaboración propia (2019)

El desempeño que más carencias presenta es el referente al conocimiento, valoración y aplicación de los derechos de autor y las licencias en la creación, integración, reestructuración y gestión de materiales en línea (Tabla 13).

Tabla 13

Conocimiento, valoración y aplicación de los derechos de autor $(\%)$. 


\begin{tabular}{lccc}
\hline & $\begin{array}{c}\text { Nunca } \\
\text { o casi } \\
\text { nunca }\end{array}$ & $\begin{array}{c}\text { En } \\
\text { algunas } \\
\text { ocasio- } \\
\text { nes }\end{array}$ & $\begin{array}{c}\text { Casi } \\
\text { siempre } \\
\text { o siem- } \\
\text { pre }\end{array}$ \\
\hline $\begin{array}{l}\text { Te preocupas de conocer las } \\
\text { normativas que regulan los } \\
\text { derechos de autor según el } \\
\text { tipo de licencia elegida para }\end{array}$ & 60.5 & 19.9 & 15.2 \\
protegerlos & & & \\
$\begin{array}{l}\text { Respetas las obligaciones } \\
\text { y derechos previstos en }\end{array}$ & 32.7 & 25.2 & 30.4 \\
las normativas que regulan \\
las licencias de uso de los \\
materiales creados por los \\
$\begin{array}{l}\text { autores } \\
\begin{array}{l}\text { Te preocupas por conocer los } \\
\text { procedimientos por los cua- } \\
\text { les un autor puede liberalizar } \\
\text { sus derechos para hacer su } \\
\text { obra de dominio público y }\end{array} \\
\text { gratuito }\end{array}$ & & & \\
\hline
\end{tabular}

Elaboración propia (2019)

\section{Seguridad}

Se observa una visión positiva del desempeño de acciones para proteger la seguridad en línea en términos de protección de dispositivos y de datos personales e identidad digital. El perfil de estudiantes digital (Tabla 14) realiza operaciones básicas de mantenimiento y protección de los dispositivos que utiliza de forma mayoritaria "casi siempre o siempre" $59.4 \%$ y sabe actuar cuando detecta amenazas de seguridad. Es conveniente señalar que un grupo importante no tiene la competencia para autogestionar la protección.

\section{Tabla 14}

Operaciones básicas de mantenimiento y protección de los dispositivos (\%).

\begin{tabular}{lccc}
\hline & $\begin{array}{c}\text { Nunca } \\
\text { o casi } \\
\text { nunca }\end{array}$ & $\begin{array}{c}\text { En } \\
\text { algunas } \\
\text { ocasio- } \\
\text { nes }\end{array}$ & $\begin{array}{c}\text { Casi } \\
\text { siempre } \\
\text { o siem- } \\
\text { pre }\end{array}$ \\
\hline $\begin{array}{l}\text { Realiza operaciones básicas } \\
\text { de mantenimiento y protec- } \\
\text { ción de los dispositivos que } \\
\text { utiliza de forma mayoritaria }\end{array}$ & 10.7 & 28.8 & 59.4 \\
$\begin{array}{l}\text { Sabe actuar cuando detecta } \\
\text { amenazas de seguridad en } \\
\text { sus dispositivos en muchos } \\
\text { casos }\end{array}$ & 26.3 & 25 & 45 \\
\hline
\end{tabular}

Elaboración propia (2019)

La autoprotección de los datos personales, mos- trados en la Tabla 15, se erige como un desempeño mayoritariamente asumido, observándose que se protegen los datos personales sensibles "casi siempre o siempre" $74.6 \%$ y la identidad digital propia y de los demás "casi siempre o siempre" $75.7 \%$.

\section{Tabla 15}

Autoprotección (\%).

\begin{tabular}{lccc}
\hline & $\begin{array}{c}\text { Nunca } \\
\text { o casi } \\
\text { nunca }\end{array}$ & $\begin{array}{c}\text { En } \\
\text { algunas } \\
\text { ocasio- } \\
\text { nes }\end{array}$ & $\begin{array}{c}\text { Casi } \\
\text { siempre } \\
\text { o siem- } \\
\text { pre }\end{array}$ \\
\hline $\begin{array}{l}\text { Autoprotección de los datos } \\
\text { personales } \\
\begin{array}{l}\text { La identidad digital propia y } \\
\text { de los demás }\end{array}\end{array}$ & 5.4 & 16.6 & 74.6 \\
\hline
\end{tabular}

Elaboración propia (2019)

\section{Resolución de problemas}

La autonomía del estudiantes digital en la resolución de problemas técnicos es mayoritariamente baja, observándose que la identificación de problemas técnicos explicando con claridad en qué consiste en mal funcionamiento en cuestión es poco desarrollada "nunca o casi nunca" $41.2 \%$ y que la resolución de los problemas técnicos no complejos relacionados con los dispositivos y el entorno digital habitual con la ayuda manual o la información técnica disponible, tampoco es una acción que se suela abordar de manera generalizada, se muestra en la Tabla 16

\section{Tabla 16}

Resolución de problemas (\%).

\begin{tabular}{lccc}
\hline & $\begin{array}{c}\text { Nunca } \\
\text { o casi } \\
\text { nunca }\end{array}$ & $\begin{array}{c}\text { En } \\
\text { algunas } \\
\text { ocasio- } \\
\text { nes }\end{array}$ & $\begin{array}{c}\text { Casi } \\
\text { siempre } \\
\text { o siem- } \\
\text { pre }\end{array}$ \\
\hline $\begin{array}{l}\text { Identificación de problemas } \\
\text { técnicos explicando con cla- } \\
\text { ridad en qué consiste en mal } \\
\text { funcionamiento en cuestión }\end{array}$ & 41.2 & 30.8 & 22.8 \\
$\begin{array}{l}\text { Resolución de los problemas } \\
\text { técnicos no complejos rela- } \\
\text { cionados con los dispositivos }\end{array}$ & 37.1 & 31.8 & \\
$\begin{array}{l}\text { y el entorno digital habitual } \\
\text { con la ayuda manual o la in- } \\
\text { formación técnica disponible }\end{array}$ & & & \\
\hline
\end{tabular}

Elaboración propia (2019) 
Por su parte, los datos del desempeńo de acciones relacionadas con la resolución de problemas a través del uso de la tecnología de forma creativa y la identificación de lagunas en la competencia digital, muestran que hay un porcentaje alentador de personas que asumen un perfil activo de cambio hacia la mejora.

Tabla 17

Uso de la tecnología de forma creativa (\%).

\begin{tabular}{lccc}
\hline & $\begin{array}{c}\text { Nunca o casi } \\
\text { nunca }\end{array}$ & $\begin{array}{c}\text { En } \\
\text { algunas } \\
\text { ocasio- } \\
\text { nes }\end{array}$ & $\begin{array}{c}\text { Casi } \\
\text { siempre } \\
\text { o siem- } \\
\text { pre }\end{array}$ \\
\hline $\begin{array}{l}\text { Utilizas las tecnolo- } \\
\text { gías en tu actividad }\end{array}$ & 6.4 & 28.1 & 64.6 \\
académica para buscar & & & \\
soluciones alternativas & & & \\
e innovadoras que & & & \\
faciliten las áreas de & & & \\
aprendizaje & & & \\
Utilizas las tecnologías \\
en tu labor diaria para \\
gestionar soluciones \\
innovadoras y participar \\
en proyectos creativos \\
$\begin{array}{l}\text { Reconoces las } \\
\text { carencias en el uso de } \\
\text { medios digitales con } \\
\text { fines de aprendizaje } \\
\text { profesional docente }\end{array}$ \\
$\begin{array}{l}\text { Experimentas con } \\
\text { nuevas tecnologías } \\
\text { digitales que te ayudan } \\
\text { a cubrir posibles lagu- } \\
\text { nas en la competencia } \\
\text { digital, necesaria para tu } \\
\text { aprendizaje }\end{array}$ & & & \\
\hline
\end{tabular}

Elaboración propia (2019)

\section{Discusión y Conclusiones}

Los resultados de investigación obtenidos respaldan la hipótesis de trabajo, poniendo de relieve la gran heterogeneidad competencial digital que tiene el estudiante universitario. Aunque se pueden sacar conclusiones que explican la capacidad o falta de la misma para desarrollar la competencia digital en su futura labor como docentes, se observa que el hecho de compartir un momento histórico concreto caracterizado por el predominio de un lenguaje digital, no significa que los maestros y las maestras estén previamente preparados y preparadas para aplicar y valorar la competencia digital en su ideario y práctica docente.

La reflexión en torno a los resultados compartidos permite afirmar que hay una clara tendencia del estudiante digital que presenta un desempeño que implica habilidades de pensamiento de orden inferior, focalizados en el almacenamiento, recuperación, presencia y participación en línea y mantenimiento y protección. Mientras que, por el contrario, las habilidades de orden superior relacionadas con la evaluación y la gestión de la información, el filtrado, la creación y el uso crítico, la valoración de derechos y la autonomía en la resolución de problemas, se aplican con menos asiduidad (González, Cárdenas \& Arellano, 2017; Moreno-Rodríguez, Gabarda \& Rodríguez-Martín, 2016; Rangel, 2018; Torres \& Jaimes, 2015). De manera que, en coherencia con investigaciones previamente citadas dentro del presente artículo, los denominados nativos y nativas digitales no muestran un perfil unificado que incluya una competencia digital efectiva que les permita adaptarse a situaciones y contextos diversos a través de la selección, entendimiento, procesamiento, crítica y transformación de la información digital. Estos datos obtenidos podrían adaptarse a la propuesta establecida por Churches (2009) donde configura y distribuye las habilidades digitales en torno al pensamiento de orden superior e inferior.

Evidenciándose que la incorporación del lenguaje digital y sus aplicaciones no son un factor determinante y definitorio para el necesario cambio hacia el desarrollo y asimilación de habilidades de pensamiento de orden superior dentro de la tradicional taxonomía de Bloom. Siendo necesario que el potencial creativo que se observa en el análisis de los resultados, se oriente más allá de la presencia y la participación superficial en línea, hacia una participación crítica y significativa donde los futuros maestros y maestras se empoderen digitalmente desde la interiorización y práctica de habilidades de pensamiento de orden superior.

Con todo, se estima la concreción de pautas de actuación en torno al empoderamiento y mejora de la competencia digital de los futuros maestros 
y maestras requiere de un proceso longitudinal personalizado, donde se interrelacionan todas las propuestas de manera progresiva:

- Itinerario formativo trasversal de la competencia digital que aborde el desarrollo de los desempeños que implican habilidades de pensamiento de orden superior.

- La formación tiene que ser comprendida como un proceso paulatino que parte de las experiencias, estilos y ritmos de aprendizaje diversos de los diferentes grupos de estudiantes.

- La adquisición de la competencia digital requiere de una práctica constante retroalimentada que cuestiona los modelos tradicionales de enseńanza y sitúa al alumnado en el centro de su propio proceso de aprendizaje. De manera que es necesario tutorizar desde la Universidad el proceso de adquisición de desempeños digitales desde la práctica y la experimentación, desde el aprendizaje del grupo natural y el análisis metacognitivo de la individualidad de cada estudiante.

\section{Agradecimiento}

A la fuente de financiación de la investigación I+$\mathrm{D}+\mathrm{i}$ de donde se extrae la presente información de estudio, denominada: "Evaluación y desarrollo de dos competencias genéricas en estudiantes de primer año del grado de Maestro en Educación Primaria”, con referencia: EDU2015-70491-R”.

\section{REFERENCIAS BIBLIOGRÁFICAS}

Apple, M., W. (2018). Curricular form and the logic of technical control: building the possessive individual. En M. W. Apple (editor). Cultural and Economic Reproduction in Education (pp. 8 - 28). London: Routledge.

Aranda, G. A., Martínez, N. Faraci, P. \& Cechich, A. (2013). Hacia un framework de evaluación de calidad de información en foros de discusión técnicos. Argentine Symposium on Software Engineering. Recuperado de http://42jaiio.sadio.org.ar/proceedings/simposios/Trabajos/ASSE/01.pdf

Cabero, J. \& Llorente, M. C. (2008). La alfabetización digital de los alumnos. Competencias digitales para el siglo XXI. Revista Portuguesa de Pedagogía, 36 (1). Recuperado de https://impactum-journals.uc.pt/rppedagogia/article/ view/1234/682
Cabero J., Marín, V., \& Infante, A. (2011). Creación de un entorno personal para el aprendizaje: desarrollo de una experiencia. Edutec. Revista Electrónica de Tecnología Educativa, 38, 1-13. Recuperado de http://rabida.uhu.es/dspace/ bitstream/handle/10272/10798/Creacion_de_un_entorno_personal.pdf?sequence $=2$

Castellanos, A.; Sánchez-Romero, C. \& Calderero, J.F. (2017). Nuevos modelos tecnopedagógicos. Competencia digital de los alumnos universitarios. Revista Electrónica de Investigación Educativa, 19 (1), 1-9. https://doi. org/10.24320/redie.2017.19.1.1148

Churches, A. (2009). Taxonomía de Bloom para la era digital. Eduteka.org. Recuperado de http://www.eduteka.org/ TaxonomiaBloomDigital.php

Colomer, J.C., Sáiz, J. \& Bel, J.C. (2018). Competencia digital en futuros docentes de Ciencias Sociales en Educación Primaria: análisis desde el modelo TPACK. Educatio Siglo XXI, 36 (1),107-128. https://doi.org/10.6018/j/324191

Declaración de Bolonia (1999). Declaración conjunta de los ministros europeos de enseńanza, Bolonia, 12 de junio de 1999. Recuperado de https://www.google. com/ search? source=hp\&ei=EJk6W6K2MYOusAHPh63QCw\&q=Declaraci\%C3\%B3n+de+Bolonia.\&oq=Declaraci\%C3\%B3n+de+Bolonia.\&gs_l=psy-ab.3..0i22i$30 \mathrm{k} 1110.1257 .7016 .0 .7434 .25 .18 .0 .0 .0 .0 .963 .2304$. 0j4j6-2.7.0...0...1c.1.64.psy-ab..18.6.2302.0..0.106. eG5H5axpQ8A

Gabarda, V., Rodríguez-Martín, A. \& Moreno-Rodríguez, M. D. (2017). La competencia digital en estudiantes de magisterio. Análisis competencial y percepción personal del futuro maestro. Educatio Siglo XXI, 35(2), 253-274, 253274. https://doi.org/10.6018/j/298601

Gasser, U. \& Palfrey, J. (2008). Born digital: Understanding the first generation of digital natives. New York: Basic Books.

Gewerc, A. \& Montero-Mesa, L. (2015). Conocimiento profesional y competencia digital en la formación del profesorado. En caso del Grado de Maestro en Educación Primaria. Revista latinoamericana de tecnología educativa. 14(1), 31-43. Recuperado de http://dehesa.unex.es/bitstream/ handle/10662/3369/1695-288X_14_1_31.pdf?sequence $=1$ \&isAllowed $=y$

Giones-Valls, A. \& Serrat-Brustenga, M. (2010). La gestión de la identidad digital: una nueva habilidad informacional y digital. BiD: textos de información y documentación, 24. http://dx.doi.org/10.1344/105.000001545

Gisbert, M. \& Esteve, F. (2011). Digital Leaners: la competencia digital de los estudiantes universitarios. La cuestión universitaria, 7, 48-59. Recuperado de http://polired.upm.es/index.php/lacuestionuniversitaria/article/ view/3359/3423

González, V., Román, M., \& Prendes, M. (2018). Formación en competencias digitales para estudiantes universitarios basada en el modelo DigComp. Edutec. Revista Electrónica De Tecnología Educativa, (65), 1-15 (391). 
https://doi.org/10.21556/edutec.2018.65.1119

González, L. A., Cárdenas, J. A. \& Arellano, J. C. (2017). Desarrollo de habilidades del pensamiento de orden superior a través de actividades de desempeńo. Anfei Digital, 6, 1-9. Recuperado de http://www.anfei.org.mx/ revista/index. php /revista/article/view/360/1002

INTEF (2017). Marco Común de Competencia Digital Docente. Madrid: Ministerio de Educación, Cultura y Deporte.

Moreno-Rodríguez, M.D.; Gabarda, V. \& Rodríguez-Martín, A.M. (2016). Alfabetización informacional y competencia digital en estudiantes de magisterio. Profesorado. Revista de currículum y formación del profesorado, 22, (3), 253269. Recuperado de http://revistaseug.ugr.es/index.php/ profesorado/article/view/8001. https://doi.org/10.30827/ profesorado.v22i3.8001

Napal, M.; Peñalva-Vélez, A. \& Mendióroz, A.M. (2018). Development of Digital Competence in Secondary Education Teachers' Training. Education Sciences, 8 (104), 1-12. https://doi.org/10.3390/educsci8030104

Núñez-López, S., Ávila-Palet, J. E., \& Olivares-Olivares, S. L., (2018). El desarrollo del pensamiento crítico en estudiantes universitarios por medio del aprendizaje basado en problemas. Revista Iberoamericana de Educación Superior, 8(23), 126-138. https://doi.org/10.22201/iisue.20072872e.2017.23.3012

Snell-Siddle, C., Sarah, S \& Fisher, D. (2017). Tools of the trade: can mobile technologies enhance the learning experience in a tertiary environment? MIER Journal of Educational Studies, Trends \& Practices, 7(1), 14-23. Recuperado de http://www.mierjs.in/ojs/index.php/mjestp/article/ view/138/123

Pedró, F. (2009). New millennium learners in higher education: evidence and policy implications. Paris: Centre for Educational Research and Innovation (CERI). OECD.

Pérez-Ferra, M., Quijano-López, R. \& Ocaña-Moral, Ma. T. (2013). El profesorado universitario ante el Espacio Europeo de Educación Superior: dos años después. Educatio Siglo XXI, 31 (2), 235-253. Recuperado de http://revistas. um.es/educatio/article/view/187611

Ramírez, D. \& Arellano, L. (2015). Problemáticas legales de la gestión cultural en la era digital. II Encuentro de Gestión Cultural. Tlaquepaque, (Jalisco), 14 L 17 de octubre. Recuperado de http://observatoriocultural. udgvirtual.udg.mx/ repositorio/ handle/123456789/285

Rangel, A. (2018). Tecnologías de la Información y la Comunicación en la Educación Superior: una revisión documental. Pixel Bit, 52, 125-137. https://doi.org/10.12795/ pixelbit.2018.i52.09

Sandoval, P.; Rodríguez-Alveal, F. \& Maldonado, A.C. (2017). Evaluation of digital and pedagogical literacy in ICT based on the opinions of Initial Teacher Education students. Educ. Pesqui., 43, (1), 127-143. https://doi.org/10.1590/ s1517-9702201701154907

Solarte, F. N. J., Enriquez, E. R. \& Benavides, M del C.
(2015). Metodología de análisis y evaluación de riesgos aplicados a la seguridad informática y de información bajo la norma ISO/IEC 27001. Revista Tecnológica ESPOL, 28 (5), 492-507. Recuperado de http://www.rte.espol.edu.ec/ index.php/ tecnologica/article/view/456/321

Tejada, J. \& Pozos, K. (2018). Nuevos escenarios y competencias digitales docentes: hacia la profesionalización docente con TIC. Revista de currículo y profesorado, 22, (1), 25-51. Recuperado de https://recyt.fecyt.es/index.php/ profesorado/ article/view/ 63620/38691

Tondeur, J., Aesaert, K., Pynoo, B., van Braak, J, Fraeyman, N. \& erstad, Ol (2015). Developing a validated instrument to measure preservice teachers' ICT competencies: Meeting the demands of the 21 st century. British Journal of Educational Technology, 50(1), 23 - 39. Recuperado de https:// onlinelibrary.wiley.com/journal/14678535

Torres, S. A. \& Jaimes, K. (2015). Producción de conocimiento mediado por TIC: cuerpos académicos de tres universidades Públicas estatales de México. Revista Electrónica Sinéctica (44). Recuperado de http://www.redalyc.org/articulo.oa?id=99832951002

Velázquez-Sortino, M., Gómez-Zermeño, M. \& Alemán de la Garza, L. (2017). Interacciones en un curso en línea, abierto y masivo para docentes. Propuesta para un modelo de análisis. Digital Education Review, 31, 149-175. 


\section{Google Sites como herramienta didáctica online en el aprendizaje significativo del área de ciencia, tecnología y ambiente en estudiantes de cuarto grado de educación secundaria}

\section{Google Sites as an online teaching tool for meaningful learning in the area of science, technology and environment in fourth grade students of secondary education}

Oscar Melanio Dávila Rojas ${ }^{1}$

https://orcid.org/0000-0001-6915-8373

Carmen Rosa Gutiérrez Pantoja ${ }^{2}$

https://orcid.org/0000-0001-9817-9405

Universidad Católica Sedes Sapientiae, Perú

Recibido: 05-01-2019

Aceptado: 21-03-2019

\section{Cita Recomendada}

Dávila, O. \& Gutiérrez, C. (2019). Google Sites como herramienta didáctica online en el aprendizaje significativo del área de Ciencia, Tecnología y Ambiente en estudiantes de cuarto grado de Educación Secundaria. Hamut'ay, 6(1), 33-53.

http://dx.doi.org/10.21503/hamu.v6i1.1573

\section{RESUMEN}

Esta investigación abordó la importancia del Google Sites como herramienta didáctica online. Buscó respuesta a la pregunta: ¿Cuál es la influencia del Google Sites como herramienta didáctica online en el aprendizaje significativo en el área de Ciencia, Tecnología y Ambiente, en estudiantes del cuarto grado del nivel secundaria de la Institución Educativa Publica No 3056 "Gran Bretaña" Lima, 2017? Como respuesta a dicha pregunta, se planteó la hipótesis de que Google Sites como herramienta didáctica online influye significativamente en el aprendizaje significativo. El trabajo se desarrolló con un enfoque cuantitativo, de alcance explicativo y diseńo cuasi-experimental, modelo pre test - post test, con dos grupos: uno experimental y otro de control. Se ejecutó en una muestra no probabilística de 46 estudiantes (22 del grupo de control y 24 del grupo experimental). El instrumento utilizado fue la prueba diagnóstica regional 2017 para el área de CTA utilizada por el Ministerio de Educación de Perú para evaluar a estudiantes del cuarto grado de educación secundaria. Los resultados del contraste permitieron verificar la hipótesis planteada, con un nivel de significancia $\operatorname{de} p=, 000<, 001$.

Palabras Clave: Google Sites, herramienta tecnológica, portafolio, archivador digital, blog, web, Ciencia, Tecnología.

\footnotetext{
1 Doctor en Ciencias de la Educación por la Universidad Nacional de Educación Enrique Guzmán y Valle, Magíster en Docencia y Gestión Educativa en la Universidad César Vallejo, Licenciado en Lengua y Literatura en la Universidad Nacional Federico Villarreal, Abogado titulado por la Universidad Nacional Mayor de San Marcos, Docente-Investigador especialista en Metodología de la Investigación. E-mail: oscarmelanio@yahoo.es

2 Licenciada en Educación, con especialidad en Biología - Química por la Universidad Nacional Mayor de San Marcos, con estudios concluidos en Maestría por la Universidad Católica Sedes Sapientiae y Especialización en Educación y Tecnologías de la Información y Comunicación (TIC) por la Universidad Antonio Ruiz de Montoya. E-mail: gutierrezcarmen45@gmail.com
} 


\section{Abstract}

This research addressed the importance of Google Sites as an online teaching tool. We tried to answer the question: What is the influence of Google Sites as an online teaching tool in meaningful learning in the area of Science, Technology and Environment, in fourth grade students of the secondary level at No. 3056 "Gran Bretaña" Public School - Lima, 2017? In response to this question, we formulated the hypothesis that Google Sites as an online teaching tool significantly influences meaningful learning. The work was developed with a quantitative approach, an explanatory scope and a quasi-experimental design. We used a pre-test / post-test model, with two groups: an experimental and a control group. It was executed with a non-probabilistic sample of 46 students ( 22 from the control group and 24 from the experimental group). The instrument we used was the 2017 Regional Diagnostic Test for the Science area applied by the Ministry of Education of Peru to evaluate fourth grade students of secondary education. The results of the contrast allowed us to verify the stated hypothesis, with a level of significance of $p=, 000<, 001$.

Keywords: Google Sites, technological tool, portfolio, digital folder, blog, web, science, technology.

\section{INTRODUCCIÓN}

Resulta evidente que, en pleno siglo XXI, las Tecnologías de la Información y Comunicación (TIC) impactan en diferentes aspectos de la vida y la sociedad, en especial en el campo educativo, al que la tecnología proporciona distintos recursos y herramientas útiles para mejorar los aprendizajes. Por ende, es innegable que, para participar en la sociedad tecnológica actual, el individuo requiere acceder a las TIC y las plataformas virtuales e iniciar así el proceso de rompimiento de las brechas digitales (Hernández, 2017). Pese al avance dinámico del desarrollo tecnológico en el mundo, muchos individuos todavía no se adaptan a los cambios que la realidad les presenta. Resulta indispensable que el sistema educativo integre las TIC en la escuela, use las plataformas virtuales $y$, desde ese espacio, se acorten las brechas digitales. Esto implica el necesario desarrollo de competencias tecnológicas en los docentes, sobre quienes pesa la responsabilidad de ayudar a los estudiantes a adaptarse al enfoque tecnológico que define a la sociedad del nuevo milenio.

El reto de la educación actual exige dejar de lado los modelos tradicionales, ya que en estos tiempos los docentes no pueden decir a los estudiantes qué y cómo aprender, sino que se necesita nuevas formas de aprender en las que los estudiantes interactúen en un clima de confianza y respeto mutuo hacia sus pares y hacia el docente. En España, Campos (2014) comprobó que los padres de familia y docentes de educación primaria percibían como negativa a la metodología de enseñanza tradicional y esto se debería a desacuerdos entre la presión académica y la falta de comunicación entre la escuela y la familia, como también a la falta de adaptación a los ritmos de aprendizaje y a las necesidades emocionales de los estudiantes. Los docentes y padres de familia apuestan por una atención más individualizada y el uso de métodos activos para superar las dificultades actuales. En México, Azamar-Alonso (2015, p. 139) analizó los modelos educativos tradicionales y concluyó que están temporalmente desfasados $y$, frente a los nuevos paradigmas, tienen una utilidad nula; por consiguiente, son incapaces de atender las demandas de la sociedad actual que se torna cada vez más exigente.

En la educación interactiva, a la que se refiere esta investigación, los estudiantes asumen el control de su aprendizaje, autorregulan el proceso y con- 
siguen logros más duraderos. Por esa razón, el paso de una educación tradicional a una sociedad fundamentada en la adquisición de conocimiento implica que los docentes, además de introducir cambios necesarios en sus prácticas metodológicas, cambien de mentalidad y vuelquen su mirada hacia entornos de aprendizaje distintos a los conocidos y exploren las posibilidades educativas de estos (Hernández, 2017, p. 333). La transición requiere de un cambio de roles en los actores del proceso educativo, los docentes ya no pueden continuar administrando o impartiendo conocimientos (CEPLAN, 2014, p. 38). Les corresponde procurar que los estudiantes autogestionen su proceso de aprendizaje y sean capaces de buscar, seleccionar, procesar y utilizar la información de manera independiente, de manera que enfrenten los cambios que experimenta el mundo actual. Necesitan un mayor dominio de las herramientas digitales y usarlas para autosatisfacer sus necesidades de aprendizaje. El docente, media entre los discentes y tales herramientas apostando por el uso responsable y el máximo aprovechamiento de sus beneficios. En este panorama, el aprendizaje se distancia cada vez más de la limitante pizarra tradicional y de los pupitres estáticos y navega en la telarańa de la red, donde la información está disponible para quienes la requieran y sepan usarla y se actualiza y cambia cada segundo.

Estas consideraciones gestaron el interés de los investigadores por recurrir a una herramienta didáctica online que favoreciera el aprendizaje significativo en el área de Ciencia, Tecnología y Ambiente (CTA). Por ello se formuló la pregunta: ¿Cuál es la influencia del Google Sites como herramienta didáctica online en el aprendizaje significativo en el área de Ciencia, Tecnología y Ambiente en estudiantes del cuarto grado del nivel secundaria de la Institución Educativa Publica No 3056 "Gran Bretaña" - Lima, 2017?. Y se desarrolló teniendo como objetivo general determinar la influencia del Google Sites como herramienta didáctica online en el aprendizaje significativo en CTA.

\section{Las TIC en educación}

El ejercicio de la docencia reclama una actuali- zación y promoción de prácticas de enseñanza novedosas, sobre todo la apropiación de nuevas e innovadoras concepciones y tecnologías orientadas a la eficacia y eficiencia del servicio educativo. El uso pedagógico de las TIC impacta de forma positiva en el aprendizaje. Los estudiantes, como nativos digitales, mantienen una estrecha relación con dichas tecnologías. Con ellas amplían su vida social; las usan como herramientas indispensables en los nuevos escenarios de aprendizaje. Las nuevas tecnologías brindan nuevas posibilidades para aprender a aprender y conducir el propio aprendizaje; pero su implantación en un sistema educativo depende de buenas decisiones político-educativas, que son responsabilidad de los gobiernos de turno. Estas decisiones implican una valoración reflexiva de las políticas, estrategias y herramientas a utilizarse en dicho proceso, así como de las prácticas escolares que se sustenten en el uso de las TIC (Colás, De Pablos \& Ballesta, 2018). El proceso tiene un enfoque constructivista: el docente (facilitador) prioriza la participación activa del estudiante en su aprendizaje, lo inserta en la sociedad del conocimiento, que no existe sin la tecnología. La gestión del conocimiento obliga al sujeto a valerse de la tecnología disponible.

Un óptimo sistema educativo debe ser relevante, pertinente y darse en un marco de equidad, eficiencia y eficacia (UNESCO, 2013). Es relevante si desarrolla las competencias necesarias para que el individuo se involucre y participe en actividades humanas afrontando cualquier desafío y desarrollando su proyecto de vida. Es pertinente si permite la apropiación de contenidos provenientes de distintas culturas locales e internacionales, y si esta se desarrolla en forma autónoma y con identidad propia; lo que implica transitar de una pedagogía de la homogeneidad a otra de la diversidad. La educación de calidad se da en un contexto de equidad cuando ofrece al sujeto la oportunidad de ejercer sus derechos a la educación y disfrutar de las mismas oportunidades educativas en igualdad de condiciones. La educación es eficaz si permite el acceso de toda la población a un servicio de calidad y eficiente cuando permite el respeto al derecho del ciudadano a dicho servicio y le reconoce y retribuye el esfuerzo realizado. Lograr la calidad educativa involucra "Mejorar todos los aspectos cualitativos de la educación, 
garantizando los parámetros más elevados, para conseguir resultados de aprendizaje reconocidos y mensurables, especialmente en lectura, escritura, aritmética y competencias prácticas esenciales" (UNESCO, 2014, p. 94).

Las TIC aportan a una educación relevante si: (i) permiten que el sujeto aprenda a conocer, aprenda a ser, aprenda a hacer y aprenda a vivir en comunidad; (ii) ofrecen múltiples alternativas o soportes para el desarrollo de propuestas pedagógicas y la diversificación de la enseñanza y aprendizaje; (iii) el acceso a ellas es equitativo, con disponibilidad de recursos de calidad que permitan alcanzar resultados de aprendizaje óptimos (UNESCO, 2013). Es deber de los docentes prepararse para enseñar y gestionar el aprendizaje de los estudiantes utilizando recursos didácticos pertinentes y relevantes (Ministerio de Educación del Perú, 2012). Esta preparación incluye la búsqueda y selección de herramientas didácticas que faciliten el proceso de aprendizaje-enseñanza. Las TIC, como herramientas didácticas, apoyan la labor docente; motivan al estudiante y hacen más entretenido el aprendizaje, gracias a la dinamización de Internet y la tecnología y la cobertura mundial que tienen estas, en especial en favor de la educación, donde abren espacios para el debate e interacción entre los sectores interesados. Pero es necesario que los avances científicos y tecnológicos marchen a la par con las necesidades humanas (Palacio \& Cabrera, 2017).

La presencia de las TIC en las aulas constituye un tránsito significativo del texto impreso al soporte digital. Esto disminuye de forma considerable el consumo de bosques y la conservación de la salud del planeta. El proceso requiere de la capacidad analítica de los estudiantes, quienes deben: (i) evaluar la necesidad y pertinencia los dispositivos para elegir aquellos que resulten más convenientes a sus necesidades de aprendizaje, (ii) aprender a usarlos en forma responsable y, sobre todo, (iii) apoderarse de la mejor información que estos les pueden proporcionar para utilizarla en la comprensión de nueva información o solucionar situaciones problemáticas relacionadas con las actividades que realiza. Por su parte, los docentes son responsables de formar personas que: autorregulan su comportamiento, muestran una actitud crítica, analítica y reflexiva, aprovechan las herramientas en beneficio de su aprendizaje y dejan de usarlas en actividades inocuas. En ese sentido, el trabajo con Google Sites brinda la oportunidad de acercar a los estudiantes a las plataformas virtuales para desarrollar sus destrezas tecnológicas de la mano con el aprendizaje de alguna materia.

\section{Google Sites como herramienta didáctica online}

Está claro entonces que la tecnología digital interviene en todas las actividades humanas; incide en los cambios educativos, familiares y laborales (UNESCO, 2013). No se puede concebir la vida humana desvinculada de la tecnología, pues esta no solo trae comodidad a la vida del hombre, sino que facilita muchas de sus actividades y modifica sus destrezas cognitivas. Por ende, la incorporación de la tecnología a la escuela implica digitalizar las aulas incorporando dispositivos (pc, Tablet, celular) para el acceso a información variada y pertinente en el aprendizaje. Estos valiosos recursos complementan la labor del docente y sirven para que el estudiante se adapte al entorno cada vez más cambiante, siendo capaz de adquirir y construir conocimiento (Hernández, 2017).

En ese contexto surge Google Sites (GS), como aplicación online gratuita creada en el año 2008 por la empresa estadounidense Google. Esta plataforma facilita la recepción de actividades, la producción de textos, la difusión de tareas y productos de aprendizaje, así como la incorporación de distintos ritmos de trabajo y la individualización en la revisión de tareas y comentarios a estas (Ambròs \& Ramos, 2017). Como herramienta didáctica, GS permite que el docente planifique las actividades didácticas, convirtiéndolas en experiencias motivadoras y entretenidas que favorecen la construcción del aprendizaje.
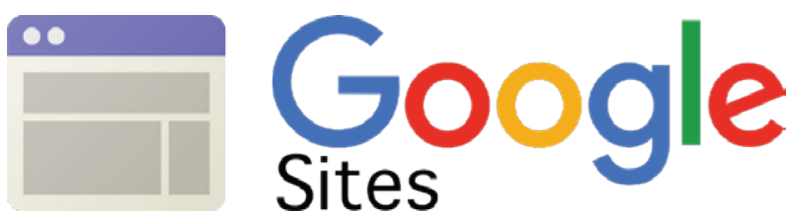

Figura 1.

Logo de Google Sites (GS).

Fuente: https://www.cookman.edu/cit/webservices/googlesites.html 
Las características, funciones y utilidad de Google Sites

La plataforma Google Sites se caracteriza porque en ella la información y comunicación fluyen sin parar. Permite la creación de sitios web personalizados y páginas web prescindiendo de HTML u otros lenguajes de programación complejos (Wojcicki, Izumi, Chang, Parisi \& Silerman, 2016). Su uso no requiere descarga ni instalación de algún software o programa, tampoco exige conocimiento o aplicación de complejos lenguajes de programación. Su diseño y construcción es intuitivo, amigable, ameno y fácil de manejar. Se accede a esta plataforma desde cualquier ordenador o equipo tecnológico y solo se necesita una conexión a Internet. Una vez que el propietario diseña el sitio web con GS, él y los usuarios reunirán en un solo lugar información variada de distintas áreas del conocimiento. Como vídeos, imágenes, mapas, calendarios, presentaciones, hojas de cálculo, archivos adjuntos y de texto, registrar enlaces, entre otros. Algo a tener en cuenta es el espacio limitado del que dispone un usuario de la versión gratuita (hasta $100 \mathrm{MB}$ ), a diferencia del uso por suscripción de la plataforma, que garantiza un espacio más amplio.

Son funciones de Google Sites (Wojcicki et al., 2016):

a. Crear y actualizar en forma personalizada el sitio.

b. Crear subpáginas para mantener el sitio organizado en torno a ideas concretas.

c. Elegir el tipo de página más conveniente: página web (la más simple), anuncios (muestran las entradas publicadas) o archivos.

d. Determinar la ubicación central para el sitio web y los archivos que se alojarán en este.

e. Decidir si el mantenimiento del sitio es público o privado.

f. Buscar en el contenido del sitio a través del Google Search o buscador.

Google Sites es una herramienta útil en la labor docente. Facilita la creación de páginas web con contenido multimedia, a partir de la selección de plantillas predeterminadas. Permite recopilar la información en un solo lugar (funciona como repositorio digital), almacenar material impor- tante, de interés para los usuarios y en formatos distintos. El administrador controla quién puede ver y editar la información; si esta será de dominio público (ubicado y accedido por cualquier usuario de Internet) o privado (solo accesible por aquellas personas a las que se les permite explícitamente hacerlo). Inclusive, se puede invitar a otros usuarios y permitirles editar los contenidos o sólo verlos. Gracias a esta posibilidad de interacción, GS tiene un poderoso impacto en el trabajo colaborativo, pues los miembros del grupo pueden ver el trabajo de los demás integrantes y aporta a la mejora del producto. Además, GS admite la retroalimentación.

Las características, funciones y utilidad de Google Sites antes reseñados se tuvieron en cuenta al emplear dicha plataforma para desarrollar el aprendizaje significativo en CTA.

\section{Aplicación de Google Sites en las aulas}

En la sociedad del siglo XXI, caracterizada por una serie de retos, GS permite la construcción compartida de conocimiento (Ambròs \& Ramos, 2017). El aprendizaje y el conocimiento no pueden estar desligados de la tecnología. Se trata de saber buscar información, procesarla, seleccionar la más importante y aplicarla en la solución de problemas académicos, sociales, laborales o familiares. Por tanto, las personas son competentes si utilizan herramientas tecnológicas para acceder a esa información, apoderársela y aplicarla en la superación de las dificultades que se les presenten.

Si bien hay otras plataformas que ofrecen servicios parecidos y con aplicaciones educativas que conducen a resultados semejantes (Entorno de Aprendizaje Virtual - Virtual learning environment (VLE), Sistema de Gestión de Aprendizajes - Learning Management System (LMS), Sistema de Gestión de Cursos - Course Management System (CMS), Entorno de Gestión de Aprendizajes - Managed Learning Environment (MLE), Sistema Integrado de Aprendizajes - Integrated learning system (ILS), Plataforma de Aprendizajes - Learning Plataform (LP), Campus Virtual (CV), Aula Virtual (AV)...) en esta investigación se optó por Google Sites debido a la familiaridad que los estudiantes tenían con el navegador Goo- 
gle. Es importante que aprendan a ver a Google no como un simple navegador, sino como una gran plataforma que les brinda, además, otras herramientas útiles para su aprendizaje.

El uso adecuado de la plataforma GS en educación brinda la oportunidad de crear un sitio web para realizar un trabajo colaborativo efectivo, dentro y fuera de las aulas, (Gonzáles, 2014). Permite al usuario:

- Creación de libros o apuntes digitales. El docente, como propietario y según las unidades didácticas, asigna a las páginas actividades que los estudiantes pueden desarrollar en un determinado periodo lectivo.

- Compilación de trabajos producidos por los discentes. En función de proyectos o temas específicos. La plataforma funciona como portafolio digital de los productos de aprendizaje.

- Configuración de una biblioteca o repositorio digital. Docente y estudiantes proponen un listado de recursos (audios, videos, imágenes, documentos de variados formatos, entre otros) disponibles mediante links o enlaces a páginas web.

- Creación de listas de tareas o proyecto pedagógicos a desarrollar. El docente indica las pautas a seguir, las fases a desarrollarse durante la realización del proyecto y publica la rúbrica que se empleará en la evaluación.

- Realización de blogging. El docente y los estudiantes difunden información de interés, exponiendo sus puntos de vista con respecto a esta.

El aprendizaje significativo en el área de Ciencia, Tecnología y Ambiente (CTA)

Enfoques del área de CTA. La alfabetización, la cultura científica y tecnológica, asi como la educación en Ciencia, Tecnología y Sociedad (CTS) se han convertido en demandas latentes de todos los pueblos del mundo (Ministerio de Educación de Perú, 2015). La enseñanza de las ciencias promueve y promociona los conocimientos cientificos y tecnologicos como parte de la educación básica para todos, con una perspectiva global y vinculados a los problemas de desarrollo social. Se tiene una orientación humanista impregnada de valores que ayudan en la resolución y superación de los problemas de salud, energéticos y ambientales latentes.

El Ministerio de Educación de Perú (2013) señala que el área de CTA tiene dos enfoques: El de la indagación científica y el de la alfabetización científica y tecnológica, que se detallan a continuación.

El enfoque de indagación científica. Comprende el conjunto de procesos que permiten habilidades científicas. A partir de su relación con el mundo natural, el estudiante construye conocimientos y comprende el mundo circundante. El término indagación no solo se utiliza dentro del contexto educativo y para la enseńanza de las ciencias, se aplica también en la vida cotidiana, porque todos de alguna forma buscan explicaciones o respuestas para preguntas relacionadas con lo que viven a diario. La indagación permite a los estudiantes lograr aprendizajes cientificos (Ministerio de Educación de Perú, 2015), les fija la idea de hacer ciencia; es decir, no basta "saber algo", sino que es necesario conocerlo científicamente. Con este nivel de comprensión, nadie puede ser engañado por ciertos acontecimientos de la realidad o pronunciamientos públicos.

Pero hay que distinguir entre la indagación como objetivo de aprendizaje y la indagación como método didáctico. La primera es un componente del conocimiento acerca de la naturaleza propia de la ciencia; la segunda permite obtener conocimiento en la clase de ciencias (Caamaño, Cañal \& De Pro, 2012). El docente que enseña ciencias define con claridad el tipo de indagación que los estudiantes realizarán en una actividad, conociendo que los seres humanos son curiosos por naturaleza. Desde pequeños se formulan preguntas sobre distintos fenómenos naturales. El buen docente aprovecha esta característica y diseña actividades indagatorias que requieren de un trabajo científico, colaborativo, con demanda de habilidades sociales, lingüísticas y de comunicación. (Tabla 1)

El enfoque de la indagación científica es formativo, privilegia el desarrollo de las competencias, reconoce al docente como guía en los procesos de indagación y promueve el uso adecuado de recursos y materiales didácticos, estrategias e instru- 
mentos de evaluación. Además, se da una mirada humana a la naturaleza, la ciencia y el trabajo científico (Ministerio de Educación de Perú, 2013).

Tabla 1

Propuesta metodológica para el desarrollo de la indagación

- Generar un escenario práctico para la enseñanza y el aprendizaje, donde el estudiante plantee preguntas y obtenga respuestas desde el análisis de información.

- Otorgar al estudiante un rol activo para que, gracias a su protagonismo, actitud y motivación por el trabajo en equipo, pueda incluso decidir el tema a trabajar.

- Enfatizar que el docente solo guía y facilita la indagación.

- Organizar la indagación y guiar a los estudiantes por cinco etapas: (i) motivar-enganchar-involucrar, (ii) explorar-investigar, (iii) explicar, (iv) extender-elaborar y (v) evaluar.

Fuente: Ministerio de Educación de Perú (2015a)

Enfoque de la alfabetización científica. Al enseñar ciencia se generan situaciones de aprendizaje que relacionan los saberes previos y los fenómenos naturales de manera que el sujeto se interrogue y elabore explicaciones según modelos formales y generalizadores propios de las ciencias naturales (Ministerio de Educación de Perú, 2013). En virtud de este enfoque, los estudiantes adquieren elementos para leer y comprender el entorno. La alfabetización científica y tecnológica aspira a que los estudiantes se desenvuelvan en el mundo, conozcan la importancia de aquellas en su vida personal y social y, como ciudadanos, reflexionen y tomen decisiones informadas. En virtud de la alfabetización científica, los estudiantes comprenden ideas clave para explicar científicamente lo que observan. La alfabetización conlleva al fomento de actitudes favorables y positivas hacia la ciencia (Garmendia \& Guisasola, 2015).

\section{Competencias del área de Ciencia, Tecnología y Ambiente}

Las competencias son facultades de la persona para saber actuar de manera pertinente en un determinado contexto usando de manera flexible y creativa todas sus capacidades y recursos. Estas capacidades son conocimientos, habilidades, valores y actitudes de los que dispone el sujeto para alcanzar un objetivo o solucionar un problema del entorno (Ministerio de Educación de Perú, 2015a y 2015c). Una persona competente ha logrado aprendizajes complejos de carácter longitudinal, alcanzan niveles cada vez más altos de desempeño y, en razón de esto, actúan en un contexto particular. Según objetivos o la solución de un problema, movilizan los saberes adquiridos en diferentes situaciones, dentro y fuera de la escuela. En el marco de Pisa 2015 (Ministerio de Educación de Perú, 2015b) se explica que las "competencias se articulan mediante una serie de términos que definen la demanda cognitiva a través del uso de capacidades como reconocer, interpretar, analizar y evaluar" (p. 18). Pero las referidas competencias no señalan ningún orden jerárquico, sino que la respuesta a las demandas cognitivas depende de los conocimientos requeridos.

Las competencias científicas permiten hacer ciencia, aplicar la ciencia y la tecnología para explicar el mundo; propician la convivencia pacífica, en armonía con el ambiente físico. Su desarrollo se relaciona con la indagación, el manejo de conceptos, teorías, principios, leyes y modelos de las ciencias naturales que permiten entender y explicar el mundo (Ministerio de Educación de Perú, 2015b); también con el impulso de formas de vida sanas, la innovación del diseño y producción de prototipos tecnológicos para solucionar problemas, reflexionar, emitir juicios de valor y convivir en forma pacífica y respetuosa. La figura 2 muestra las cuatro competencias señaladas en Rutas de Aprendizaje de CTA (Ministerio de Educación, de Perú, 2015c, p. 10).

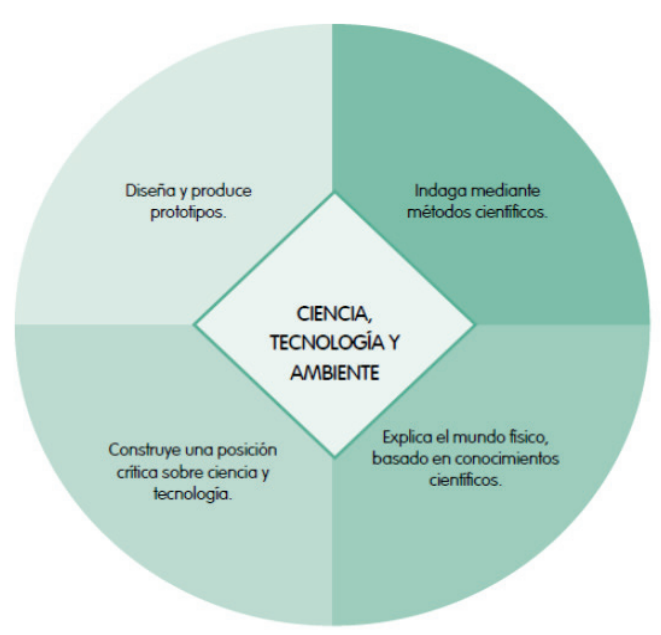

Figura 2

Competencias de Ciencia, Tecnología y Ambiente. Fuente: Rutas del Aprendizaje. Área Ciencia, Tecnologia y Ambiente (2015c, p. 10). 
Google Sites como herramienta didáctica online en el aprendizaje significativo del área de ciencia, tecnología y ambiente en estudiantes de cuarto grado de educación secundaria

El Ministerio de Educación de Perú (2017) define a la competencia como "la facultad que tiene una persona de combinar un conjunto de capacidades a fin de lograr un propósito específico en una situación determinada, actuando de manera pertinente y con sentido ético" (p. 29). Es decir, la persona competente usa de forma articulada, deliberada y consciente las capacidades que posee para enfrentarse situaciones nuevas y resolver los retos o situaciones problemáticas de su realidad personal, familiar o social.

En la Tabla 2 se observa que, en Rutas de Aprendizaje (Ministerio de Educación de Perú, 2015c, p. 10), se consideraban cuatro competencias, a diferencia de PISA, que solo trabajó con tres. Sin embargo, en el Currículo Nacional de la Educación Básica (Ministerio de Educación de Perú, 2017, pp. 33-34) se fijan solo tres competencias. De estas, la primera y la segunda son muy parecidas a sus homólogas en PISA, pero la tercera difiere. PISA considera la competencia "Interpretar datos y pruebas científicamente" y el Currículo Nacional establece la competencia "Indaga mediante métodos científicos para construir conocimientos" (Ministerio de Educación de Perú (2015a, p. 17; 2015b, p 32).

La competencia científica requiere que las personas con conocimientos de ciencia y tecnología juzguen la importancia de las investigaciones previas y conozcan el valor de las nuevas investigaciones científicas. Si bien la tecnología se basa en la ciencia, ambas tienen claras diferencias en cuanto a objetivos, propósitos y productos. La ciencia busca respuestas a preguntas específicas, mientras que la tecnología persigue soluciones para los problemas. Sin embargo, hay entre ellas vinculaciones estrechas.

La presente investigación asumió las competencias de Rutas de Aprendizaje para CTA, versión 2015 (Ministerio de Educación de Perú, 2015c), indicadas en la tabla 1 , por ser estas las que estuvieron vigentes durante el año escolar en el cual se desarrolló el trabajo experimental. Estas competencias son:

Indaga, mediante métodos científicos, situaciones que pueden ser investigadas por la ciencia. El desarrollo de esta competencia está asociado a cinco capacidades:

\section{Tabla 2}

Las competencias científicas según PISA 2015 y Rutas de Aprendizaje de CTA y el Currículo Nacional de Educación Básica

\begin{tabular}{|c|c|c|}
\hline PISA 2015 & $\begin{array}{c}\text { Rutas de Aprendi- } \\
\text { zaje de CTA }\end{array}$ & $\begin{array}{l}\text { En el Currículo } \\
\text { Nacional de la Edu- } \\
\text { cación Básica }\end{array}$ \\
\hline $\begin{array}{l}\text { Explicar fenóme- } \\
\text { nos científica- } \\
\text { mente }\end{array}$ & $\begin{array}{l}\text { Explica el mundo } \\
\text { físico, basado en } \\
\text { conocimientos } \\
\text { científicos. }\end{array}$ & $\begin{array}{r}\text { Explica el mundo } \\
\text { físico basándose en } \\
\text { conocimientos so- } \\
\text { bre los seres vivos; } \\
\text { materia y energía; } \\
\text { biodiversidad, } \\
\text { Tierra y universo }\end{array}$ \\
\hline \multirow[t]{2}{*}{$\begin{array}{l}\text { Evaluar y diseñar } \\
\text { la investigación } \\
\text { científica }\end{array}$} & $\begin{array}{l}\text { Diseña y produce } \\
\text { prototipos tec- } \\
\text { nológicos para re- } \\
\text { solver problemas } \\
\text { de su entorno. }\end{array}$ & $\begin{array}{r}\text { Diseña y construye } \\
\text { soluciones tecnoló- } \\
\text { gicas para resolver } \\
\text { problemas de su } \\
\text { entorno }\end{array}$ \\
\hline & $\begin{array}{l}\text { Construye una } \\
\text { posición crítica } \\
\text { sobre la ciencia y } \\
\text { la tecnología en } \\
\text { sociedad. }\end{array}$ & \\
\hline $\begin{array}{l}\text { Interpretar datos } \\
\text { y pruebas científi- } \\
\text { camente. }\end{array}$ & $\begin{array}{l}\text { Indaga, mediante } \\
\text { métodos científi- } \\
\text { cos, situaciones } \\
\text { que pueden ser } \\
\text { investigadas por } \\
\text { la ciencia }\end{array}$ & $\begin{array}{r}\text { Indaga mediante } \\
\text { métodos científicos } \\
\text { para construir } \\
\text { conocimientos }\end{array}$ \\
\hline
\end{tabular}

Fuente: Ministerio de Educación de Perú (2015a; 2015b, pp. 32-33; 2015c, p. 10 y 2017, pp. 33-34).)

(i) problematiza situaciones, (ii) diseña estrategias para hacer una indagación, (iii) genera y registra datos e información, (iv) analiza datos o información y (v) evalúa y comunica (Ministerio de Educación de Perú, 2015c, p. 12 y 2017, p. 120).

La indagación científica es "un proceso reflexivo de exploración, planificación, comunicación, construcción y re-construcción" del conocimiento (González-Weil et al. 2012, p. 101). Al indagar, los estudiantes producen nuevos conocimientos que puede enriquecer con la experimentación y respaldarlos con experiencias, conocimientos previos y evidencias obtenidas. Usan métodos científicos e indagan en situaciones problemáticas del entorno; generan información, la registran, analizan, evalúan y comunican el resultado del análisis reflexivo. La indagación científica, más que una simple recepción y trasmisión de conocimientos, 
es una excelente alternativa para la apropiación y uso de métodos en la construcción conocimiento (Flórez-Nisperuza \& De la Ossa, 2018, p. 63).

En PISA 2015, la competencia científica "explicar fenómenos científicamente" (Ministerio de Educación, 2015b, p. 34) exige que, en determinadas situaciones, se utilicen conocimientos apropiados para generar hipótesis explicativas donde no hay conocimientos o datos. En el proceso, no solo se recuerdan y aplican los conocimientos, sino que se emplean modelos para formular hipótesis, realizar predicciones y explicar las implicancias del conocimiento científico. La enseñanza en ciencia garantiza que docentes y estudiantes usen estrategias para apropiarse de conocimientos científicos y tecnológicos imprescindibles para interpretar cuanto acontecen en el mundo natural (Caamaño et al., 2012). Así pues, el reto para ambos consiste en modernizar los conocimientos existentes.

Explica el mundo físico, basado en conocimientos científicos. Esta competencia combina dos capacidades: “(i) Comprende y usa conocimientos sobre los seres vivos, materia y energía, biodiversidad, Tierra y universo y (ii) Evalúa las implicancias del saber y del quehacer científico y tecnológico" (Ministerio de Educación de Perú, 2015c, p. 27 y 2017, p. 125). En la primera, el estudiante establece relaciones entre conceptos; construye representaciones del mundo mediante explicaciones, ejemplificaciones, aplicaciones, justificaciones, comparaciones, contextualizaciones y generalizaciones al aplicar los conceptos a otras situaciones. En la segunda, asume posturas críticas o toma decisiones según sus saberes locales, evidencias empíricas y científicas para la conservación del ambiente (local y global) y mejorar su calidad de vida.

Diseña y produce prototipos tecnológicos para resolver problemas de su entorno. $\mathrm{El} \mathrm{CN}$ de $\mathrm{EB}$ (Ministerio de Educación de Perú, 2015c, pp. 44-45 y 2017, p. 128) señala que, para el logro de la competencia diseńa y produce prototipos tecnológicos, los estudiantes combinan e integran cuatro capacidades: "(i) determina una alternativa de solución tecnológica, (ii) diseña alternativas de solución tecnológica, (iii) implementa la alternativa de solución tecnológica y (iv) evalúa y comunica el funcionamiento y los impactos de su alternativa de solución tecnológica” (p. 128).

Gracias a la tecnología, el hombre ha creado muchas cosas artificiales, pero su accionar tecnológico pone en riesgo al medio ambiente, inclusive la existencia y supervivencia humana. Ante esto, corresponde considerar a la tecnología como parte del sistema ecológico, al que necesita conocer, comprender y entender. Solo así se maximizarán los beneficios, se minimizarán los riesgos y podría hablarse de una cultura tecnológica.

La tecnología está en todos lados, en cada actividad humana. Si bien en la escuela los estudiantes aprenden acerca del funcionamiento, comportamiento y composición del mundo natural mediante el aporte de distintas disciplinas científicas, necesitan conocer los fundamentos científicos, los principios que rigen el funcionamiento y el comportamiento de los objetos que integran el mundo artificial. La tecnología, utilizada en la práctica educativa, integra la teoría con la práctica. La enseñanza de las ciencias pretende que los egresados lleven consigo conocimientos básicos, ideas, conceptos y procedimientos para conocer la ciencia y aplicarla en la solución de problemas relacionados con la naturaleza circundante (UNESCO, 2016).

La educación enfrenta el reto de solucionar problemas medioambientales mundiales. Esta preocupación global apunta al desarrollo de una actitud preventiva respecto al deterioro del planeta, así como al control de lo que lo genera y los efectos que el cambio climático produce en la humanidad (UNESCO, 2014). El camino para lograrlo está en la mejora de los conocimientos, el fomento de valores, el afianzamiento de convicciones sobre la necesidad de prevenir y evitar la destrucción, la modificación de comportamientos nocivos para la salud del planeta. Hablar de calidad de vida es pensar en una educación ambiental que despierta conciencias y avidez por la generación de conocimientos para resolver los problemas que afectan al ambiente local y globa, la cual está ligada a la innovación tecnológica; es una alternativa para enfrentar los problemas medioambientales. Por lo que hay necesidad de mejorar las políticas de innovación tecnológica, pues, además de sus aplicaciones al campo de la educación, está vinculada 
Google Sites como herramienta didáctica online en el aprendizaje significativo del área de ciencia, tecnología y ambiente en estudiantes de cuarto grado de educación secundaria

al crecimiento económico de una nación. En investigaciones bien documentadas se ha comprobado que las variables tecnológicas impactan en el crecimiento de la economía de las naciones (Velazquez \& Salgado, 2016).

Construye una posición crítica sobre la ciencia y la tecnología en sociedad. Hay una serie de capacidades que permitirán alcanzar el desarrollo de esta competencia. Estas son: "(i) evalúa las implicancias del saber y del quehacer científico y tecnológico y (ii) toma una posición crítica frente a situaciones socio científicas. Los estudiantes establecen relaciones entre ciencia, tecnología y sociedad" (Ministerio de Educación de Perú, 2015c, pp. 58-59). Estas relaciones se manifiestan en el ámbito social y tienen implicancias paradigmáticas originadas en el saber científico. La adopción de una postura crítica supone plantear alternativas de solución efectivas y sostenibles que mejoren la calidad de vida del individuo. Como estrategia recomendada para el logro de esta competencia se propone, evaluar los conocimientos previos para conocer la posición inicial de los estudiantes frente a un determinado problema y, a partir de estos, plantearles dilemas sociocientíficos, en los que, desde el análisis y reflexión, se llegue a conclusiones individuales, de grupos de trabajo o a nivel de toda la clase.

\section{El programa experimental Google Sites}

Conforme a la tabla 3, el trabajo utilizando Google Sites como herramienta didáctica online en el aprendizaje significativo en el área de CTA estuvo integrado por 12 sesiones de aprendizaje. En cada sesión se usó la plataforma GS, de manera que el aprendizaje previsto fuera un producto de la interacción entre el estudiante y la herramienta tecnológica elegida. La ejecución de las sesiones de aprendizaje se basó en un enfoque formativo y el desarrollo de las competencias científicas, como parte de la formación integral de los estudiantes de educación secundaria.
Tabla 3

Distribución de la muestra

\begin{tabular}{|c|c|c|}
\hline & Título de la sesión & Componente de GS \\
\hline 1 & Extinciones masivas & Sitio Web/Blog \\
\hline 2 & Evolución humana & Sitio Web/Wiki \\
\hline 3 & Química de los seres vivos & Sitio Web/Archivador digital \\
\hline 4 & $\begin{array}{l}\text { Los glúcidos, moléculas } \\
\text { energéticas }\end{array}$ & Sitio Web/Archivador digital \\
\hline 5 & $\begin{array}{l}\text { Los lípidos, moléculas ener- } \\
\text { géticas }\end{array}$ & Sitio Web/Archivador digital \\
\hline 6 & $\begin{array}{l}\text { Vitaminas, moléculas regula- } \\
\text { doras }\end{array}$ & Sitio Web/Portafolio digital \\
\hline 7 & Agua, molécula de vida & Sitio Web/Blog \\
\hline 8 & Los minerales en nuestra vida & Sitio Web/Wiki \\
\hline 9 & $\begin{array}{l}\text { Desentrañando los misterios de } \\
\text { le célula }\end{array}$ & Sitio Web/Archivador digital \\
\hline 10 & Mundo microscópico & Sitio Web/Portafolio digital \\
\hline 11 & $\begin{array}{l}\text { Ciclo celular, garantizando la } \\
\text { supervivencia }\end{array}$ & Sitio Web/Portafolio digital \\
\hline 12 & $\begin{array}{l}\text { Los procesos para obtener } \\
\text { nutrientes, la digestión }\end{array}$ & Sitio Web/Portafolio digital \\
\hline
\end{tabular}

Fuente: programa experimental, 2017.

La competencia científica prioriza la explicación de los fenómenos, más allá de la simple identificación y utilización de los conocimientos (Turpo, 2016, p. 24). Es decir, se trata de que, a partir de los conocimientos que adquieren sobre los fenómenos observados, los estudiantes expliquen lo que ocurre a su alrededor, teniendo como base los diferentes conocimientos adquiridos durante la clase.

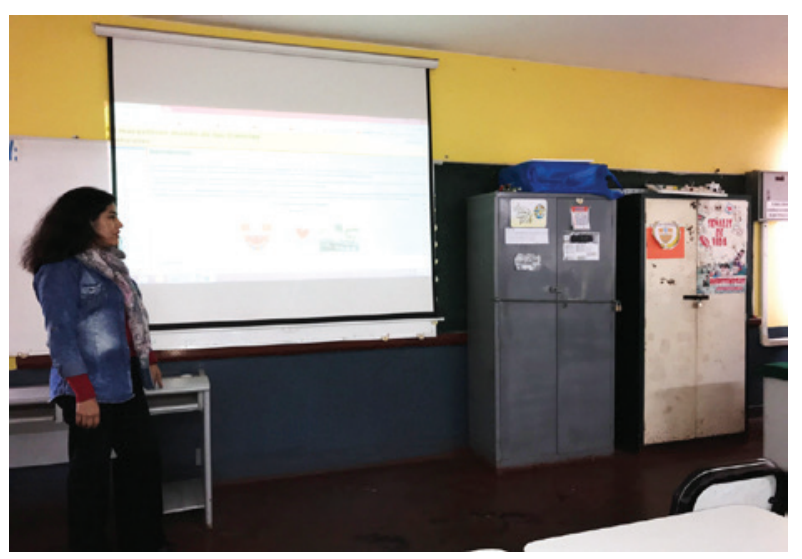

Figura 2

Presentación del programa experimental en el Aula de Innovación Pedagógica (AIP). 


\section{Componentes del programa}

El programa se desarrolló considerando cuatro componentes de la plataforma utilizada para que los estudiantes desarrollen las actividades de aprendizaje propuestas: sitio web, wiki, portfolio digital y archivador digital.

El sitio web (SW). Es el lugar desde donde los estudiantes accedieron a importante y variada información, organizada convenientemente según lo planificado por el docente (Aubry, 2012). Este sitio fue el medio para que el estudiante conociera y resolviera las actividades propuestas según cada propósito de aprendizaje. El SW es el contenedor principal de todo lo planificado. Desde él es posible encontrar los elementos que componen la página principal, los mismos que responden a un diseño y contenido visualmente atractivo para los usuarios. En la creación del SW denominado: El maravilloso mundo de las Ciencias Naturales se utilizó un diseño sencillo y de facil acceso (encabezado, cuadro lateral y cuerpo de la página). El diseño permitió la insercion de textos, imágenes, videos, enlaces, tablas y ofreció la posibilidad de comentar, adjuntar documentos y editarlos. Los usuarios pudieron participar para, con sus aportes, enriquecer el trabajo previo.

La wiki. Wiki es una palabra de origen hawaiano que significa "rápido". La wiki es un espacio de escritura colaborativa (Ramos \& Ramos, 2011). Facilita la creación y modificación de contenidos de manera sencilla, flexible y rápida. El administrador de la wiki fue propietario del espacio, invitó a los estudiantes y les otorgó la posibilidad de editar los materiales publicados. Así se favoreció el trabajo colaborativo y se dio espacio para la retroalimentación por cuenta de todos los participantes. Durante el proceso se desarrollaron las sesiones de aprendizaje que, partiendo del planteamiento de preguntas retadoras, buscaron que los estudiantes respondan y construyan colaborativamente el espacio. Las actividades se vieron enriquecidas por las variadas herramientas de GS, como la inserción de documentos, hipervínculos, imágenes y videos.

El portafolio digital (PD). Fue el espacio para que el estudiante publicara el trabajo realizado en cada actividad propuesta (Cacheiro, Sánchez \& Gon- zález, 2015). El PD conserva evidencias sobre los aprendizajes de los estudiantes. En las sesiones desarrolladas con este componente se pretendió que los estudiantes diseñen y construyan diferentes recursos, almacenados grupalmente en el portafolio. Esto rompió la idea tradicional que se tiene de este, pues se logró la incorporación de diferentes elementos multimedia para que los productos de los estudiantes fueran accesibles, atractivos y estuvieran disponibles para todos los usuarios. El diseño y elaboración de los productos demandó un tiempo y esfuerzo adicional, pero valió la pena pues al final se evidenciaron los resultados.

El archivador digital (AD). También llamado fichero, es un espacio donde se puede almacenar documentos en diferentes formatos, que los estudiantes pueden descargar fácilmente. $\mathrm{El} \mathrm{AD}$ es una herramienta sencilla y segura que facilitó a los estudiantes la ubicación de sus documentos en las páginas creadas para cada sesión de aprendizaje. Los documentos tuvieron nombre propio y la extensión característica que identifica a la aplicación utilizada.

La experiencia pedagógica del docente y la experiencia de aprendizaje de los estudiantes se vieron enriquecidas por el uso de la plataforma GS, que se convirtió en un elemento motivador y de gran utilidad para promover en estos últimos la indagación científica, diseñar y producir prototipos tecnológicos, elaborar una explicación del mundo circundante y dar una mirada crítica a la ciencia y la tecnología en el desarrollo personal, familiar, social, académico y laboral de los estudiantes. Los hallazgos refrendan la hipótesis de investigación y sirven de base para una reflexión acerca del rumbo que debe seguir la práctica pedagógica en la enseñanza de CTA.

\section{Materiales Y Métodos}

\section{Participantes}

El estudio se realizó en la Institución Educativa No 3056 "Gran Bretaña”, ubicada en el distrito de Independencia en Lima Norte. La investigación se ejecutó con una muestra de 88 estudiantes de cuarto grado de Educación Secundaria (46 
Google Sites como herramienta didáctica online en el aprendizaje significativo del área de ciencia, tecnología y ambiente en estudiantes de cuarto grado de educación secundaria

varones y 42 mujeres), distribuidos en cuatro secciones como se muestra en la Tabla 4.

Tabla 4

Distribución poblacional de estudiantes de cuarto grado de educación secundaria de la Institución Educativa No 3056 "Gran Bretaña”

\begin{tabular}{cccc}
\hline Secciones & Varones & Mujeres & Subtotal \\
\hline A & 12 & 10 & 22 \\
B & 13 & 11 & 24 \\
C & 13 & 11 & 24 \\
D & 8 & 10 & 18 \\
\hline Total & 46 & 42 & 88 \\
\hline
\end{tabular}

Fuente: Nomina de matrícula - Sistema de Información de Apoyo a la Gestión de la Institución Educativa SIAGIE (2017).

La muestra no probabilística, de tipo intencional y grupos intactos, estuvo formada por los 46 estudiantes de las secciones A (Grupo de control, con 22 estudiantes) y C (Grupo experimental, con 24 estudiantes). Para elegir los grupos, se tuvo en cuenta la media de las calificaciones en CTA y se eligió a los dos grupos que tenían la media más baja. Se asumió este criterio para tener como referencia común a dos grupos con el rendimiento más bajo y, posteriormente, verificar las probables mejoras en uno de ellos (grupo experimental), como consecuencia del estímulo recibido con la variable independiente.

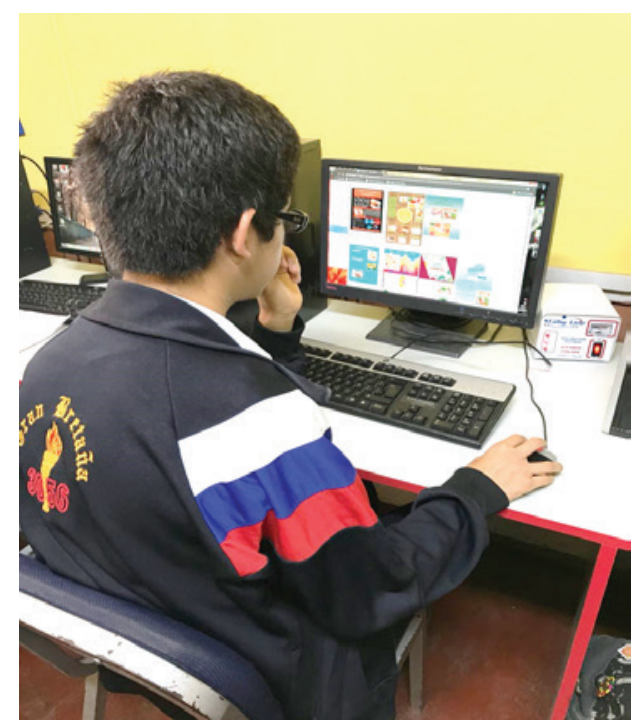

Figura 4

Desarrollo de actividades realizadas por los alumnos del grupo experimental.

\section{Instrumento}

La técnica empleada es la evaluación tipo test, que deriva en valoraciones acerca del aprendizaje de los sujetos evaluados. La finalidad de este tipo de evaluación fue obtener respuestas uniformes que permitieran verificar estadísticamente los objetivos de la investigación (Ministerio de Educación de Perú, 2004).

El instrumento utilizado para evaluar el aprendizaje en el área de CTA fue la Prueba Diagnóstica Regional 2017, elaborada y distribuida por el Ministerio de Educación de Perú para administrarse a estudiantes del cuarto grado de educación secundaria. La prueba evalúa el nivel de logro de los estudiantes en cada una de las competencias de dicha área. A partir de los resultados, los docentes toman decisiones acerca de las situaciones de aprendizaje que deben planificarse en las sesiones de clase, teniendo como base un enfoque formativo y el desarrollo de las competencias del área.

$\mathrm{El}$ instrumento tiene 20 ítems distribuidos en cuatro competencias (Ministerio de Educación de Perú, 2015c, p. 11):

- Indaga, mediante métodos científicos, situaciones que pueden ser investigadas por la ciencia (Ítems 1 al 6).

- Explica el mundo físico, basado en conocimientos científicos (Ítems 7 al 14).

- Diseña y produce prototipos tecnológicos que resuelven problemas de su entorno (Ítems 15 al 18).

- Construye una posición crítica sobre la ciencia y la tecnología en sociedad (Ítems 1 al 19-20).

La prueba diagnóstica se administró en forma individual en un tiempo establecido de 60 minutos. Cada ítem ofrece cuatro alternativas, calificadas con 0 (incorrecto) y 1 (correcto). El puntaje mínimo es 0 y el más alto 20 .

El desarrollo de las sesiones de aprendizaje con ambos grupos se desarrolló según la secuencia temática descrita en la tabla 3 y con intervención de un mismo mediador. Con el grupo de control, el trabajo se desarrolló en la forma convencional, con los materiales y herramientas disponibles en un aula de clase tradicional. Con el grupo experi- 
mental, el desarrollo de las sesiones se dio usando la plataforma GS y los recursos que esta ofrece, desde el Aula de Innovación pedagógica.

\section{Tipo y diseño}

La investigación fue de tipo aplicada y enfoque cuantitativo. Comprendió la recolección numérica de datos que se analizaron mediante estadística descriptiva e inferencial para someter a contraste las hipótesis de investigación (Hernández \& Mendoza, 2018). Es de alcance explicativo, pues tuvo por finalidad explicar la influencia del Google Sites como herramienta didáctica online para el aprendizaje significativo en el área de CTA. Se desarrolló con un diseño cuasiexperimental, modelo preprueba-posprueba y un grupo de control (Hernández \& Mendoza, 2018).

\section{Procedimiento}

La investigación se desarrolló en cuatro fases: planificación, ejecución, análisis de datos y reporte de resultados.

Fase de planificación. Se elaboró el programa experimental, que constó de 12 sesiones incluidas en la tercera unidad didáctica correspondiente al segundo bimestre. La prueba empleada fue elaborada, validada y administrada por el Ministerio de Educación de Perú como parte de la verificación de los aprendizajes de los estudiantes peruanos. En esta etapa se tramitaron las autorizaciones para la ejecución del experimento, recibiendo respuestas favorables.

Fase de ejecución. Completada la planificación del trabajo, se administró el pre test de la prueba a los dos grupos de la muestra (experimental y de control). A continuación, se procedió a desarrollar el programa en 12 sesiones efectivas de trabajo y según los componentes considerados en la variable Google Sites.

En principio, para el mediador, fue importante el aprendizaje mismo de Google Sites, pues dicho conocimiento permitió identificar las opciones de trabajo que ofrece la plataforma para el diseño y construcción de diversas actividades de aprendizaje. Durante el desarrollo de las sesiones, a los estudiantes, como nativos digitales, les resultó bastante natural la interacción con las tecnologías, sobre todo porque les permitió descubrir una nueva forma de aprender en forma colectiva la ciencia, ya que esta herramienta didáctica favorece en gran medida este tipo de trabajo.

Con GS se creó una página web que contiene los recursos propuestos por el mediador para el aprendizaje de los temas. Simultáneamente, los receptores de las actividades de aprendizaje y los trabajos digitales realizados fueron los propios estudiantes, a quienes GS les permitió ejercitarse en la indagaban y acceder a la alfabetización científica y tecnológica.

La plataforma se diseñó para que los estudiantes tuvieran acceso y pudieran editar los contenidos. De esta forma fueron capaces de crear una wiki, a partir de una pregunta generadora o un tema que dieron lugar a un producto de su interés durante la sesión. Se les permitió el diseño, construcción y edición de la misma; desarrollaron un portafolio digital donde publicaron sus producciones. Mediante la búsqueda de información y el uso de herramientas digitales almacenaron y contribuyeron en la conformación de un portafolio, que además les sirvió como archivador digital; en este insertaron sus archivos personales, que podían ser descargados y leídos directamente por todos los estudiantes. Esto facilitó la evaluación por parte del docente. En el caso de los videos, estos podían verse tantas veces como los estudiantes lo necesitaran.

El diseño y elaboración de los diferentes productos, más allá de la inversión de tiempo y esfuerzo adicionales, fue una experiencia satisfactoria y gratificante tanto para el mediador como para los estudiantes. Estos últimos fueron conscientes de la mejora de sus aprendizajes como resultado su compromiso y empoderamiento.

Concluida la fase de estímulo con la variable independiente, se administró el post test de la prueba de CTA. En esta segunda etapa los estudiantes realizaron en forma individual o grupal una serie de actividades y productos en los que se veía reflejado el trabajo con la variable Google Sites.

Fase de análisis. Se prepararon las bases de datos de las mediciones en pre test y post test a los dos 
Google Sites como herramienta didáctica online en el aprendizaje significativo del área de ciencia, tecnología y ambiente en estudiantes de cuarto grado de educación secundaria

grupos de la muestra. Se realizó el análisis para la descripción comparativa de resultados y el análisis estadístico inferencial recurriendo al método hipotético-deductivo para el contraste de las hipótesis de investigación.

Fase de reporte de resultados. Se redactó el informe de la investigación considerando las pautas señaladas en el protocolo institucional y el Manual de Publicaciones (American Psychological Association, 2010). El trabajo final cumplió con todas las exigencias formales, garantizó la reserva de la identidad de los individuos comprendidos en la muestra y respetó el derecho de autor.

Métodos y técnicas de análisis de datos.

Los métodos utilizados fueron el analítico, sintético, comparativo y el hipotético deductivo. Este último implicó someter a contraste las hipótesis de investigación para verificar si el uso de Google Sites influye o no en el aprendizaje significativo de CTA (Hernández \& Mendoza, 2018). Se analizaron los resultados de las mediciones pre test y post test a los grupos de control y experimental y los resultados sirvieron para arribar a las conclusiones del estudio. La técnica empleada es el análisis estadístico, con ayuda del software estadístico SPSS v.22, para calcular las medidas estadísticas: media, mediana, desviación estándar y rango promedio. En el análisis inferencial se utilizó la prueba de Kruskal-Wallis, debido a que no todos los datos tenían una distribución normal (Rial \& Valera, 2008). Los resultados se presentan en tablas (muestran comparativamente las medidas estadísticas y los resultados del contraste de hipótesis) y el diagrama de caja y bigotes (compara la mediana del pre test $y$ post test).

\section{Confidencialidad}

La investigación se desarrolló con respeto estricto de la identidad de los estudiantes comprendidos en la muestra y con la autorización expresa de los padres de familia y el conocimiento de las autoridades de la institución educativa. A los padres de familia se les garantizó que los resultados de las evaluaciones se manejarían de forma anónima y con absoluta reserva de los resultados individuales (American Psychological Association, 2010).

\section{Resultados}

La verificación de las hipótesis se hizo empleando la Prueba U de Mann Whitney. La decisión se tomó considerando un nivel de significancia de 0.05 ( $5 \%$ de error). Por consiguiente: Si $p>0.05$, se concluye con la hipótesis nula $(\mathrm{H} 0)$ y si $p<$ 0.05 , se concluye con la hipótesis alterna $(\mathrm{H} 1)$.

Prueba de hipótesis para el efecto de Google Sites como herramienta didáctica online en el aprendizaje significativo en el área de Ciencia, Tecnología y Ambiente

\section{Hipótesis general}

Ha. Google Sites como herramienta didáctica online influye significativamente en el aprendizaje significativo en el área de Ciencia, Tecnología y Ambiente en estudiantes del cuarto grado del nivel secundaria de la Institución Educativa Publica No 3056 "Gran Bretaña” - Lima.

H0. Google Sites como herramienta didáctica online no influye significativamente en el aprendizaje significativo en el área de Ciencia, Tecnología y Ambiente en estudiantes del cuarto grado del nivel secundaria de la Institución Educativa Publica No 3056 "Gran Bretaña” - Lima.

En el pre test de la variable aprendizaje significativo en el área de Ciencia, Tecnología y Ambiente (tabla 5) la media del grupo de control fue ligeramente mayor $(7.32+2.918)$ que la del grupo experimental $(5.83+1.810)$; mientras que en el post test, la media del grupo experimental (11.21 + 2.284) superó en 3.26 puntos a la media del grupo de control $(7.95+2.903)$.

Los resultados de la prueba de Kruskal-Wallis indicaron que en el pre test de la variable aprendizaje significativo en el área de Ciencia, Tecnología y Ambiente hubo diferencias significativas entre los grupos de control y experimental, pero a favor del primero. Sin embargo, en el post test el grupo experimental obtuvo mejores resultados y la diferencia fue significativa $(p=.000)$ a favor de este. Por tanto, al 0.000 de error, se concluye que Google Sites como herramienta didáctica online influye significativamente en el aprendizaje significativo en el área de CTA. 


\section{Tabla 4}

Medidas estadísticas de la variable aprendizaje significativo en el área de Ciencia, Tecnología y Ambiente en los grupos de control y experimental, pre test y post test.

\begin{tabular}{|c|c|c|c|c|c|}
\hline \multirow[b]{3}{*}{ Fase } & \multirow[b]{3}{*}{ Estadígrafo } & \multicolumn{4}{|c|}{$\begin{array}{l}\text { Aprendizaje significativo en el área } \\
\text { de Ciencia, Tecnología y Ambiente }\end{array}$} \\
\hline & & \multirow[b]{2}{*}{$\begin{array}{l}\text { Grupo } \\
\text { de } \\
\text { control }\end{array}$} & \multirow[b]{2}{*}{$\begin{array}{c}\text { Grupo } \\
\text { Experi- } \\
\text { mental }\end{array}$} & \multicolumn{2}{|c|}{ Kruskal-Wallis } \\
\hline & & & & $\begin{array}{l}\text { Chi- } \\
\text { Cua- } \\
\text { drado }\end{array}$ & $\begin{array}{l}p- \\
\text { valor }\end{array}$ \\
\hline \multirow{4}{*}{$\begin{array}{l}\text { Pre test } \\
p>.05\end{array}$} & Media & 7.32 & 5.83 & 2.956 & .086 \\
\hline & Mediana & 7.50 & 6.00 & & \\
\hline & Desv. típ. & 2.918 & 1.810 & & \\
\hline & Rango prom. & 27.02 & 20.27 & & \\
\hline \multirow{4}{*}{$\begin{array}{l}\text { Post test } \\
p<.01\end{array}$} & Media & 7.95 & 11.21 & 12.956 & .000 \\
\hline & Mediana & 7.50 & 11.50 & & \\
\hline & Desv. típ. & 2.903 & 2.284 & & \\
\hline & Rango prom. & 16.11 & 30.27 & & \\
\hline $\mathrm{N}$ & & 22 & 24 & & \\
\hline
\end{tabular}

Fuente: Base de datos de la prueba diagnóstica regional 2017, área de Ciencia, Tecnología y Ambiente (CTA) para estudiantes del cuarto grado de educación secundaria de menores.

Según la tabla 4 y figura 6, en el pre test de la variable aprendizaje significativo en el área de Ciencia, Tecnología y Ambiente, el grupo de control obtuvo una mediana mayor (7.5) a la del grupo experimental (6). Sin embargo, en el post test, la mediana del grupo experimental (11.5) superó en 4 puntos a la mediana del grupo de control (7.5).

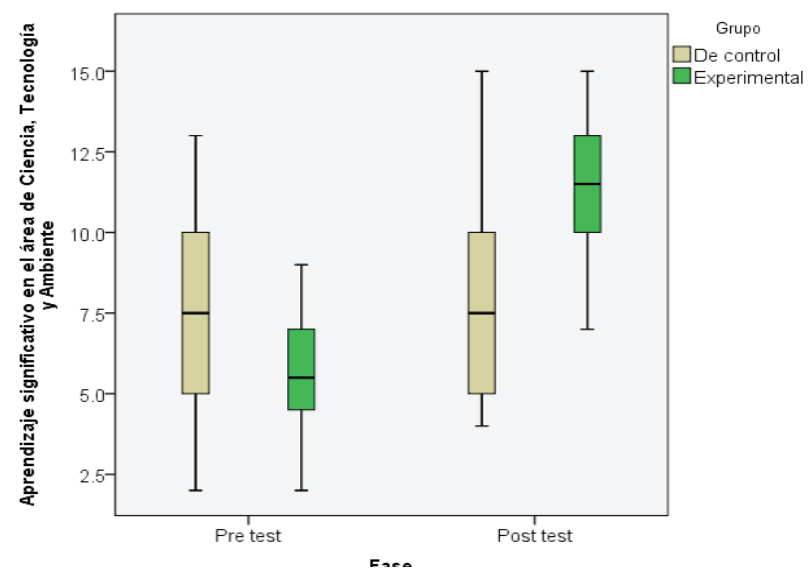

Figura 2

Diagrama de dispersión para la diferencia en el aprendizaje significativo en el área de CTA entre los grupos de control y experimental, pre test $\mathrm{y}$ post test.
Prueba de hipótesis para el efecto de Google Sites en la competencia indaga mediante métodos científicos en situaciones que pueden ser investigadas por la ciencia

\section{Hipótesis especifica 1}

Ha1. Google Sites como herramienta didáctica online influye significativamente en la competencia indaga mediante métodos científicos en situaciones que pueden ser investigadas por la ciencia.

H0. Google Sites como herramienta didáctica online no influye significativamente en la competencia indaga mediante métodos científicos en situaciones que pueden ser investigadas por la ciencia.

En el pre test de la competencia indaga mediante métodos científicos (tabla 6), situaciones que pueden ser investigadas por la ciencia, la media del grupo de control $(2.64+1.177)$ fue bastante similar a la del grupo experimental $(2.25+.676)$; pero en el post test, la media del grupo experimental $(4.00+.885)$ fue 1.18 puntos más que la media del grupo de control $(2.82+1.368)$.

La prueba U de Mann Whitney indicó que, en el pre test de la competencia indaga mediante métodos científicos, no hubo diferencias significativas entre los grupos de control y experimental. En cambio, en el post test, el grupo experimental superó significativamente $(p=.001)$ al grupo de control. Por tanto, al 0.001 de error se concluye que Google Sites como herramienta didáctica online influye significativamente en la competencia indaga mediante métodos científicos en situaciones que pueden ser investigadas por la ciencia.

\section{Tabla 6}

Medidas estadísticas de la competencia indaga mediante métodos científicos en los grupos de control y experimental, pre test y post test.

\begin{tabular}{|c|c|c|c|c|c|}
\hline \multirow[b]{3}{*}{ Fase } & \multirow[b]{3}{*}{ Estadígrafo } & \multicolumn{4}{|c|}{$\begin{array}{l}\text { Indaga mediante métodos } \\
\text { científicos }\end{array}$} \\
\hline & & \multirow[b]{2}{*}{$\begin{array}{c}\text { Grupo } \\
\text { de } \\
\text { control }\end{array}$} & \multirow[b]{2}{*}{$\begin{array}{l}\text { Grupo } \\
\text { Experi- } \\
\text { mental }\end{array}$} & \multicolumn{2}{|c|}{ Kruskal-Wallis } \\
\hline & & & & $\begin{array}{l}\text { Chi- } \\
\text { Cua- } \\
\text { drado }\end{array}$ & $\begin{array}{c}p- \\
\text { valor }\end{array}$ \\
\hline \multirow{3}{*}{$\begin{array}{l}\text { Pre test } \\
p>.05\end{array}$} & Media & 2.64 & 2.25 & 2.956 & .086 \\
\hline & Desv. típ. & 1.177 & .676 & & \\
\hline & Rango prom. & 26.02 & 21.19 & & \\
\hline
\end{tabular}


Google Sites como herramienta didáctica online en el aprendizaje significativo del área de ciencia, tecnología y ambiente en estudiantes de cuarto grado de educación secundaria

\begin{tabular}{|c|c|c|c|c|c|}
\hline \multirow[b]{3}{*}{ Fase } & \multirow[b]{3}{*}{ Estadígrafo } & \multicolumn{4}{|c|}{$\begin{array}{l}\text { Indaga mediante métodos } \\
\text { científicos }\end{array}$} \\
\hline & & \multirow[b]{2}{*}{$\begin{array}{l}\text { Grupo } \\
\text { de } \\
\text { control }\end{array}$} & \multirow[b]{2}{*}{$\begin{array}{c}\text { Grupo } \\
\text { Experi- } \\
\text { mental }\end{array}$} & \multicolumn{2}{|c|}{ Kruskal-Wallis } \\
\hline & & & & $\begin{array}{l}\text { Chi- } \\
\text { Cua- } \\
\text { drado }\end{array}$ & $\begin{array}{c}p- \\
\text { valor }\end{array}$ \\
\hline \multirow{3}{*}{$\begin{array}{l}\text { Post test } \\
p<.01\end{array}$} & Media & 2.82 & 4.00 & 10.348 & .001 \\
\hline & Desv. típ. & 1.368 & .885 & & \\
\hline & Rango prom. & 17.09 & 29.38 & & \\
\hline $\mathrm{N}$ & & 22 & 24 & & \\
\hline
\end{tabular}

Fuente: Base de datos de la prueba diagnóstica regional 2017, área de Ciencia, Tecnología y Ambiente (CTA) para estudiantes del cuarto grado de educación secundaria de menores.

Prueba de hipótesis para el efecto de Google Sites en la competencia explica el mundo físico, basado en conocimientos científicos

\section{Hipótesis especifica 2}

Ha2. Google Sites como herramienta didáctica online influye significativamente en la competencia explica el mundo físico, basado en conocimientos científicos.

H0. Google Sites como herramienta didáctica online no influye significativamente en la competencia explica el mundo físico, basado en conocimientos científicos.

En el pre test de la competencia explica el mundo físico (tabla 7) la media del grupo de control $(2.59+1.297)$ fue ligeramente mayor que la del grupo experimental $(1.92+1.100)$; pero en el post test, la media del grupo experimental (3.5 +1.022 ) fue mayor 0.82 más que la media del grupo de control $(2.68+1.129)$.

La prueba de Kruskal-Wallis indicó en el pre test de la competencia explica el mundo físico hubo diferencias significativas $(p=.053)$ entre los grupos de control y experimental, a favor del primero. Por el contrario, en el post test, el grupo experimental superó significativamente $(p=.015)$ al grupo de control. Por tanto, al 0.015 de error se concluye que Google Sites como herramienta didáctica online influye significativamente en la competencia explica el mundo físico, basado en conocimientos científicos.

\section{Tabla 7}

Medidas estadísticas de la competencia explica el mundo físico en los grupos de control y experimental, pre test y post test.

\begin{tabular}{|c|c|c|c|c|c|}
\hline \multirow[b]{3}{*}{ Fase } & \multirow[b]{3}{*}{ Estadígrafo } & \multicolumn{4}{|c|}{ Explica el mundo físico } \\
\hline & & \multirow[b]{2}{*}{$\begin{array}{l}\text { Grupo } \\
\text { de } \\
\text { control }\end{array}$} & \multirow[b]{2}{*}{$\begin{array}{l}\text { Grupo } \\
\text { Experi- } \\
\text { mental }\end{array}$} & \multicolumn{2}{|c|}{ Kruskal-Wallis } \\
\hline & & & & $\begin{array}{l}\text { Chi- } \\
\text { Cua- } \\
\text { drado }\end{array}$ & $\begin{array}{c}p- \\
\text { valor }\end{array}$ \\
\hline \multirow{3}{*}{$\begin{array}{l}\text { Pre test } \\
p>.05\end{array}$} & Media & 2.59 & 1.96 & 3.729 & .053 \\
\hline & Desv. típ. & 1.297 & 1.083 & & \\
\hline & Rango prom. & 27.30 & 20.02 & & \\
\hline \multirow{3}{*}{$\begin{array}{l}\text { Post test } \\
p<.01\end{array}$} & Media & 2.68 & 3.50 & 5.906 & .015 \\
\hline & Desv. típ. & 1.129 & 1.022 & & \\
\hline & Rango prom. & 18.64 & 27.96 & & \\
\hline $\mathrm{N}$ & & 22 & 24 & & \\
\hline
\end{tabular}

Fuente: Base de datos de la prueba diagnóstica regional 2017, área de Ciencia, Tecnología y Ambiente (CTA) para estudiantes del cuarto grado de educación secundaria de menores.

Prueba de hipótesis para el efecto de Google Sites en la competencia diseńa y produce prototipos tecnológicos para resolver problemas de su entorno

\section{Hipótesis especifica 3}

Ha3. Google Sites como herramienta didáctica online influye significativamente en la competencia diseńa y produce prototipos tecnológicos para resolver problemas de su entorno.

H0. Google Sites como herramienta didáctica online no influye significativamente en la competencia diseña y produce prototipos tecnológicos para resolver problemas de su entorno.

En el pre test de la competencia diseña y produce prototipos tecnológicos para resolver problemas de su entorno (tabla 8), la media del grupo de control $(1.59+.959)$ fue mayor que la del grupo experimental $(1.25+.944)$; pero en el post test, la media del grupo experimental $(2.63+.647)$ fue 0.72 puntos más que la media del grupo de control $(1.91+.750)$.

La prueba de Kruskal-Wallis indicó que en el pre test de la competencia diseña y produce prototipos tecnológicos no hubo diferencias significativas entre los grupos de control y experimental. 
Pero en el post test, el grupo experimental superó significativamente $(p=.001)$ al grupo de control. Por tanto, al 0.001 de error, se concluye que Google Sites como herramienta didáctica online influye significativamente en la competencia diseña y produce prototipos tecnológicos para resolver problemas de su entorno.

\section{Tabla 8}

Medidas estadísticas de la competencia diseña y produce prototipos tecnológicos en los grupos de control y experimental, pre test y post test.

\begin{tabular}{|c|c|c|c|c|c|}
\hline \multirow[b]{3}{*}{ Fase } & \multirow[b]{3}{*}{ Estadígrafo } & \multicolumn{4}{|c|}{$\begin{array}{c}\text { Diseña y produce prototipos } \\
\text { tecnológicos }\end{array}$} \\
\hline & & \multirow[b]{2}{*}{$\begin{array}{l}\text { Grupo } \\
\text { de } \\
\text { control }\end{array}$} & \multirow[b]{2}{*}{$\begin{array}{l}\text { Grupo } \\
\text { Experi- } \\
\text { mental }\end{array}$} & \multicolumn{2}{|c|}{ Kruskal-Wallis } \\
\hline & & & & $\begin{array}{l}\text { Chi- } \\
\text { Cua- } \\
\text { drado }\end{array}$ & $\begin{array}{c}p \text { - } \\
\text { valor }\end{array}$ \\
\hline \multirow{3}{*}{$\begin{array}{l}\text { Pre test } \\
p>.05\end{array}$} & Media & 1.59 & 1.25 & 2.154 & .142 \\
\hline & Desv. típ. & .959 & .944 & & \\
\hline & Rango prom. & 26.36 & 20.88 & & \\
\hline \multirow{3}{*}{$\begin{array}{l}\text { Post test } \\
p<.01\end{array}$} & Media & 1.91 & 2.63 & 11.105 & .001 \\
\hline & Desv. típ. & .750 & .647 & & \\
\hline & Rango prom. & 17.11 & 29.35 & & \\
\hline $\mathrm{N}$ & & 22 & 24 & & \\
\hline
\end{tabular}

Fuente: Base de datos de la prueba diagnóstica regional 2017, área de Ciencia, Tecnología y Ambiente (CTA) para estudiantes del cuarto grado de educación secundaria de menores.

Prueba de hipótesis para el efecto de Google Sites en la competencia construye una posición crítica sobre la ciencia y la tecnología en sociedad

\section{Hipótesis especifica 4}

Ha4. Google Sites como herramienta didáctica online influye significativamente en la competencia construye una posición crítica sobre la ciencia y la tecnología en sociedad.

H0. Google Sites como herramienta didáctica online no influye significativamente en la competencia construye una posición crítica sobre la ciencia y la tecnología en sociedad.

En el pre test de la competencia construye una posición crítica sobre la ciencia y la tecnología en sociedad (tabla 9), la media del grupo de control $(.50+.512)$ fue menor que la del grupo experimental $(.55+.510)$; pero en el post test, la me- dia del grupo experimental $(1.08+.776)$ fue 0.7 puntos mayor que la media del grupo de control $(.38+.495)$.

Los resultados de la prueba de Kruskal-Wallis indicaron que en el pre test de la competencia construye una posición crítica sobre la ciencia y la tecnología en sociedad no hubo diferencias significativas entre los grupos de control y experimental. Pero en el post test, el grupo experimental superó también significativamente $(p=.015)$ al grupo de control. Por tanto, al 0.015 de error, se concluye que Google Sites como herramienta didáctica online influye significativamente en la competencia construye una posición crítica sobre la ciencia y la tecnología en sociedad.

\section{Tabla 9}

Medidas estadísticas de la competencia construye una posición crítica sobre la ciencia y la tecnología en sociedad en los grupos de control y experimental, pre test y post test.

\begin{tabular}{|c|c|c|c|c|c|}
\hline \multirow[b]{3}{*}{ Fase } & \multirow[b]{3}{*}{ Estadígrafo } & \multicolumn{4}{|c|}{$\begin{array}{l}\text { Construye una posición crítica } \\
\text { sobre la ciencia y la tecnología en } \\
\text { sociedad }\end{array}$} \\
\hline & & \multirow[b]{2}{*}{$\begin{array}{c}\text { Grupo } \\
\text { de } \\
\text { control }\end{array}$} & \multirow[b]{2}{*}{$\begin{array}{l}\text { Grupo } \\
\text { Experi- } \\
\text { mental }\end{array}$} & \multicolumn{2}{|c|}{ Kruskal-Wallis } \\
\hline & & & & $\begin{array}{l}\text { Chi- } \\
\text { Cua- } \\
\text { drado }\end{array}$ & $\begin{array}{c}p- \\
\text { valor }\end{array}$ \\
\hline \multirow{3}{*}{$\begin{array}{l}\text { Pre test } \\
p>.05\end{array}$} & Media & .50 & .55 & .714 & .398 \\
\hline & Desv. típ. & .512 & .510 & & \\
\hline & Rango prom. & 25.00 & 22.13 & & \\
\hline \multirow{3}{*}{$\begin{array}{l}\text { Post test } \\
p<.01\end{array}$} & Media & .38 & 1.08 & 5.963 & .015 \\
\hline & Desv. típ. & .495 & .776 & & \\
\hline & Rango prom. & 18.86 & 27.75 & & \\
\hline $\mathrm{N}$ & & 22 & 24 & & \\
\hline
\end{tabular}

Fuente: Base de datos de la prueba diagnóstica regional 2017, área de Ciencia, Tecnología y Ambiente (CTA) para estudiantes del cuarto grado de educación secundaria de menores.

\section{Discusión y Conclusiones}

Los resultados del contraste de la hipótesis general demostraron que, en el post test, hubo diferencias significativas entre los estudiantes del grupo experimental y de control. El Google Sites como herramienta didáctica online influye significativamente $(p=.000)$ en el aprendizaje significativo del área de CTA. Algo similar estableció en Espa- 
Google Sites como herramienta didáctica online en el aprendizaje significativo del área de ciencia, tecnología y ambiente en estudiantes de cuarto grado de educación secundaria

ña Bassas (2013), al utilizar Google Sites para la enseñanza del álgebra a estudiantes con trastornos de déficit de atención e hiperactividad (TDAH). Demostró que el uso de Google Sites mejora el nivel de concentración de los estudiantes, aunque reconoció que no pudo profundizar para averiguar si esta herramienta mejoraba el aprendizaje. En Perú, Alarcón, Ramírez \& Vílchez (2014) también obtuvieron un efecto similar al analizar la relación entre las TIC y el aprendizaje del idioma inglés con estudiantes universitarios de la especialidad ingles - francés, pues verificaron que existe correlación directa entre estas variables, en especial entre los audiovisuales y el aprendizaje significativo de dicho idioma. En España, Acosta, Martín \& Hernández (2015), trabajaron con Google Sites en la aplicación de un modelo de webquest para la enseñanza de geografía en educación secundaria, en donde comprobaron que las herramientas Geoquest y Eartquest son excelentes para mejorar el aprendizaje de geografía. Es preciso resaltar que gran parte del logro de los resultados alcanzados en torno a los aprendizajes significativos se debe a la incorporación de herramientas tecnológicas en el proceso de aprendizaje. En los estudios mencionados se advierte que la aplicación de las TIC en la enseñanza requiere de docentes preparados, capaces de guiar a los estudiantes en el uso eficiente de dichos recursos para la solución de las dificultades que surjan en el proceso de aprendizaje. De forma similar, la presente investigación determinó la influencia del Google Sites como herramienta didáctica online para el aprendizaje significativo en el área de CTA con estudiantes del cuarto grado de educación secundaria de la Institución Educativa Publica No 3056 “Gran Bretaña”. Quiere decir que, utilizada pedagógicamente, Google Sites es una aplicación online que se ha convertido en herramienta didáctica útil para el docente (Barret, 2014). Facilita la enseñanza y mejora los procesos de aprendizaje.

La prueba de hipótesis indicó que, en el post test, la diferencia entre el grupo experimental y de control fue significativa $(p=0.001)$. Los estudiantes mejoraron su aprendizaje en la competencia indaga mediante métodos científicos, siendo capaces de indagar de manera autónoma, identificaron problemas, plantearon preguntas y diseñaron e implementaron estrategias para dar respuesta a sus interrogantes; también analizaron información y reflexionaron sobre la validez de la respuesta obtenida; crearon actividades orientadas a este propósito. Monsalve (2011), en Colombia, dio con un hallazgo semejante, al implementar las herramientas TIC como estrategia didáctica para generar un aprendizaje significativo en estudiantes de sexto grado. Consiguió que los estudiantes se involucren en la indagación científica con ayuda de videos e imágenes interactivas, consultando páginas web y realizando actividades en la sala de informática o desde la casa. También Meléndez (2013), en Lima, llegó a la conclusión de que el uso de la Webquest como recurso mejora la capacidad de comprensión de la información, indagación, experimentación y juicio crítico en estudiantes de quinto grado de educación secundaria. Comprobó que la Webquest, como Google Site, favorece la indagación científica; los estudiantes, además de diseñar estrategias para indagar, generan y registran información, la analizan, evalúan y comunican sus hallazgos.

Según los resultados, en el post test, hubo diferencias significativas $(p=0.015)$ entre el grupo experimental y el grupo de control. En la influencia del Google Sites como herramienta didáctica online en la competencia explica el mundo físico, basado en conocimientos científicos; resultados que se relacionan con los hallazgos de Rodríguez (2016), quien en Santiago de Chucos comprobó que un taller de prototipos tecnológicos influye significativamente $(p<0.01)$ en la competencia explica el mundo físico. Dicho de otro modo, las TIC optimizan el desarrollo de esta competencia. Es preciso destacar que los estudiantes, al explicar científicamente los fenómenos, utilizan conocimientos apropiados para generar hipótesis explicativas en situaciones determinadas en las que no hay conocimientos o datos. Comprenden los conocimientos científicos a partir de sus conocimientos previos sobre el mundo; pueden explicar los fenómenos y resolver situaciones problemáticas de la realidad. Son capaces de conocer, contrastar y comparar los conocimientos alcanzados por los diversos pueblos a lo largo del tiempo y el espacio; construyen argumentos, deliberan, toman decisiones a nivel personal y público, buscan mejorar su calidad de vida y también se interesan por conservar el ambiente (Ministerio de Educa- 
ción de Perú, 2015b, 2015c, 2017).

Con relación a la influencia del Google Sites como herramienta didáctica online en la competencia diseña y produce prototipos tecnológicos para resolver problemas de su entorno, los resultados evidenciaron que, en el post test, hubo diferencias significativas $(p=0.001)$ entre el grupo experimental y el grupo de control. De acuerdo a estos resultados, se corrobora los postulados teóricos que sustentan a la competencia mencionada. Luego del estímulo, los estudiantes diseñaron y construyeron objetos o sistemas basados en conocimientos científicos y tecnológicos, es decir, usaron en forma práctica la tecnología para resolver problemas del contexto y transformar la realidad. De ahí que el logro de esta competencia supone que los estudiantes determinen, diseñen, implementen una alternativa de solución y evalúen y comuniquen los resultados de su funcionamiento, así como los impactos de esta (Ministerio de Educación de Perú, 2015c, 2017). En otras palabras: los estudiantes deben saber aplicar conocimientos básicos y procedimientos en la solución de problemas de su entorno (UNESCO, 2016).

La influencia del Google Sites como herramienta didáctica online en la competencia construye una posición crítica sobre la ciencia y la tecnología en sociedad. Los resultados mostraron que, en el post test, también hubo diferencias significativas $(\mathrm{p}=$ 0.000) entre el grupo experimental y el grupo de control. Este hallazgo se relaciona con el trabajo de Meléndez (2013), quien al estudiar en Lima a la Webquest como recurso de motivación para el aprendizaje de los temas de ciencias con estudiantes del quinto grado de secundaria, comprobó el impacto de esta en la capacidad de juicio crítico; es decir, esta herramienta permite a los estudiantes construir una postura autónoma y crítica frente a situaciones sociocientíficas. A partir de estas situaciones, los estudiantes están en condiciones de participar, deliberar y tomar decisiones en asuntos personales y públicos relacionados con la ciencia y la tecnología (Ministerio de Educación de Perú, 2015c).

Está claro que las TIC favorecen el logro de aprendizajes significativos, siempre y cuando los docentes elijan y utilicen las herramientas que se adapten mejor a las necesidades de cada proceso de aprendizaje (Rojas, 2017). El reto radica en saber integrarlas a las actividades académicas para motivar el entusiasmo de los educandos (Hernández, Gómez \& Balderas, 2014) y conseguir que estos adopten una postura crítica frente a las herramientas tecnológicas que decidan utilizar en su proceso de aprendizaje.

Google Sites es una herramienta de la que pueden disponer libremente los docentes para plantear a los estudiantes actividades atractivas e interesantes que los motiven a involucrarse en el proceso de aprendizaje. Si se pretende que estos logren aprendizajes significativos en alguna materia, las actividades de aprendizaje requieren de estrategias, herramientas y materiales novedosos que propicien la innovación, la creatividad y el desarrollo del pensamiento crítico.

El uso de las TIC, tanto como material concreto y el interactivo, fortalece la labor docente y el trabajo realizado por los estudiantes. Estas herramientas favorecen aprendizajes significativos, pero es necesario que los docentes sepan elegir las herramientas que utilizarán y las adapten a las necesidades de cada proceso de aprendizaje. La correcta integración de las Tic en el proceso de aprendizaje reclama nuevas competencias en los docentes y también mayor responsabilidad de los estudiantes para sujetarse a las reglas de participación en las actividades didácticas propuestas por aquel.

La claridad de los objetivos propuestos en una actividad de aprendizaje orienta la selección de herramientas tecnológicas pertinentes y señala las pautas precisas para la integración de estas en el proceso de aprendizaje. Las actividades en el aula se convierten en novedosas; despiertan el interés de los estudiantes, les dan suficiente espacio para la creatividad y estimulan su participación entusiasta en los retos que plantea el docente.

\section{REFERENCIAS BIBLIOGRÁFICAS}

Acosta, R., Martín, A.V. \& Hernández, A. (2015). Propuesta de un modelo de webquest para la enseńanza de geografía en educación secundaria con la aplicación de google sites. Edutec. Revista Electrónica de Tecnología Educativa, [S.1.], 
Google Sites como herramienta didáctica online en el aprendizaje significativo del área de ciencia, tecnología y ambiente en estudiantes de cuarto grado de educación secundaria

n. 52, p. a302, jun. 2015. ISSN 1135-9250. Recuperado de http://www.edutec.es/revista/index.php/edutec-e/article/ view/296

Alarcón, D., Ramírez, M. \& Vílchez, M. (2014). Las tecnologías de la información y comunicación (TIC) y su relación con el aprendizaje del inglés en los estudiantes de la especialidad de inglés - francés, promoción 2011 de la Universidad Enrique Guzmán y Valle. (Tesis de Licenciatura inédita). Universidad Nacional Enrique Guzmán y Valle: Lima. Recuperado de: http://repositorio.une.edu.pe/bitstream/ handle/UNE/700/T025_09580299_T.pdf?sequence=18isAllowed $=\mathrm{y}$.

Ambròs, A. \& Ramos. J.C. (2017). El uso didáctico de Google Sites en la construcción compartida del conocimiento. Resed, Revista de Estudios Socioeducativos, Nro. 5, pp. 63-74. https://doi.org/10.25267/Rev_estud_socioeducativos.2017.i5.07

American Psychological Association. (2010). Manual de publicaciones de la American Psychological Association (3a ed.) México: El Manual Moderno.

Aubry, C. (2012). Cree su primer sitio web. Del dise-o a la realización. Barcelona: ENI.

Azamar-Alonso, A. (2015). El modelo educativo en México: una revisión de su alcance y una perspectiva para el futuro. Rastros Rostros 17.31: 127-141. http://dx.doi. org/10.16925/ra.v17i31.1094

Barrett, H. C. (2014). ePortfolio Mash Up with GoogleApps. Recuperado de: ePortfolio Mash Up with GoogleApps: http://electronicportfolios.com/google/index.html

Bassas, M. (2013). Uso del Google Sites como herramienta para la enseñanza de álgebra a alumnos con TDAH en el $2^{\circ}$ de la ESO. (Tesis de maestría inédita, Universidad Internacional de la Rioja: Barcelona). Recuperada de http://reunir. unir.net/bitstream/handle/123456789/1801/2013_04_09_ Tfm_Estudio_Del_Trabajo.pdf?sequence=1 2 isAllowed $=y$.

Caamaño, E., Cañal, P. \& De Pro, A. (2012). 11 Ideas clave. El desarrollo de la competencia científica. Barcelona: Graó.

Cacheiro, M.L., Sánchez, C. \& González, J.M (coords.). (2015). Recursos tecnológicos en contextos educativos. Madrid: UNED.

Ampos, E. (2014). Las Metodologías tradicionales de enseñanza desde la perspectiva de los familiares y docentes del Colegio Andolina. (Tesis de licenciatura inédita, Universidad Internacional de La Rioja, España). Recuperada de: https://reunir.unir.net/bitstream/handle/123456789/2236/ Campos-Gutierrez.pdf

Centro Nacional de Planeamiento Estratégico -CEPLAN. (2014). La educación del futuro y el futuro de la educación. Lima: Punto \& Grafía.

Colás, M.P., De Pablos, J. \& Ballesta, J. (2018). Incidencia de las TIC en la enseñanza en el sistema educativo español: una revisión de la investigación. RED. Revista de Educación a Distancia. Núm. 56, Artic. 2, 32-01-2018 https://doi.org/10.6018/red/56/2
Fórez-Nisperuza, E. \& De la Ossa, A.F. (2018). La indagación científica y la transmisión-recepción: una contrastación de modelos de enseńanza para el aprendizaje del concepto densidad. Revista Científica, 31(1), 55-67.

https://doi.org/10.14483/23448350.12452

Garmendia, M. \& Guisasola, J. (2015). Alfabetización científica en contextos escolares: El Proyecto Zientzia Live! Revista Eureka sobre Enseńanza y Divulgación de las Ciencias, 12(2), 294-310.

https://doi.org/10.25267/Rev_Eureka_ensen_divulg_ cienc.2015.v12.i2.05

González, J. (2014). Princippia. Aprendiendo y ense-ando con tecnología. Recuperado de: Princippia. Aprendiendo y enseñando con tecnología. Recuperado de http://blog.princippia.com/2014/04/ideas-y-pautas-para-usar-google-sites. html

González-Weil, C., Cortez, M., Bravo, P., Ibaceta, Y., Cuevas, K., Quiñones, P. et al. (2012). La indagación científica como enfoque pedagógico: estudio sobre las prácticas innovadoras de docentes de ciencia en EM. Estudios Pedagógicos, 38 (2), 85-102. Recuperado de https://doi.org/10.4067/S0718-07052012000200006

Hernández, R.M. (2017). Impacto de las Tic en la educación: Retos y Perspectivas. Propósitos y Representaciones, 5(1), 325-347.

https://doi.org/10.20511/pyr2017.v5n1.149

Hernández, C.A., Gómez, M.G. \& Balderas, M. (2014). Inclusión de las tecnologías para facilitar los procesos de enseñanza - aprendizaje en ciencias naturales. Revista Electrónica "Actualidades Investigativas en Educación", 14 (3), 1-19. Recuperado de http://www.redalyc.org/ pdf/447/44732048010.pdf

Hernández, R. \& Mendoza, C.P. (2018). Metodología de la Investigación. México: McGraw-Hill. https://doi. org/10.17993/CcyLl.2018.15

Meléndez, M. (2013). La Webquest como un recurso de motivación para el aprendizaje de los temas de Ciencias en estudiantes del quinto grado de secundaria de un colegio del Cercado de Lima. (Tesis de licenciatura inédita) Pontifica Universidad Católica del Perú: Lima. Recuperado de http://tesis.pucp.edu.pe/repositorio/bitstream/handle/123456789/5146/Melendez_Campos_Melvin_Webquest_Colegio.pdf?sequence $=1$.

Ministerio de Educación del Perú. (2004). Guía de Evaluación del Aprendizaje. Lima: MINEDU.

Ministerio de Educación del Perú. (2012). Marco del Buen Desempeño Docente. Lima: MINEDU.

Miinisterio de Educación de Perú. (2013). Rutas del Aprendizaje: Ciencia y Tecnología. Fascículo general. Lima: Cimagraf.

Ministerio de Educación de Perú. (2015a). Ciencia, Tecnología y Ambiente 4º. Manual para el docente. Lima: Santillana.

Ministerio de Educación de Perú. (2015b). La competencia científica en el marco de Pisa 2015. Lima: MINEDU. 
Ministerio de Educación. (2015c). Rutas del Aprendizaje. Ciencia, Tecnología y Ambiente VII Ciclo. Lima: Quad/ Graphics Perú S.A.

Ministerio de Educación de Perú. (2017). Currículo Nacional de la Educación Básica. Lima: MINEDU.

Monsalve, M. (2011). Implementación de las TICS como estrategia didáctica para generar un aprendizaje significativo de los procesos celulares en los estudiantes de grado sexto de la Institución educativa San Andrés del Municipio de Girardota. (Tesis de Maestría inédita) Universidad nacional de Colombia - Sede Medellín: Colombia. Recuperado de http://www.bdigital.unal.edu.co/5936/1/43666105.2012. pdf.

Palacio, M. \& Cabrera, K. (2017). La gobernanza de internet como plataforma para impulsar políticas en la educación con TIC. El caso de Colombia. OPERA, (21), 5-23.

https://doi.org/10.18601/16578651.n21.02

Ramos, A. \& Ramos, M.J. (2011). Aplicaciones web. Madrid: Paraninfo.

Rial, A. \& Valera, J. (2008). Estadística práctica para la investigación en ciencias de la salud. La Coruña: Netbiblo.

Rojas, M. (2017) Los recursos tecnológicos como soporte para la enseńanza de las ciencias naturales. Hamut'ay, 4 (1), 85-95. https://doi.org/10.21503/hamu.v4i1.1403

Rodríguez, F.M. (2016). Taller de Prototipos tecnológicos para optimizar la competencia explica el mundo físico del área de Ciencia y Ambiente en estudiantes del sexto grado del distrito de Santiago de Chuco, 2016. (Tesis doctoral inédita). Universidad César Vallejo: Trujillo.

Turpo, O. (2016). El currículo de la competencia científica en Perú y Portugal. Comuni@cción, 7(2), 15-26. Recuperado de http://www.scielo.org.pe/scielo.php?script=sci_arttext\&pid=S2219-71682016000200002\&lng=es\&tlng=es

UNESCO. (2013). Enfoques estratégicos sobre las TICS en Educación en América Latina y el Caribe. Santiago de Chile: OREALC.

UNESCO. (2014). Enseñanza y Aprendizaje: Lograr la calidad para todos. Informe de seguimiento de la EPT en el mundo. París: Ediciones Unesco.

UNESCO. (2016). Aportes para la enseñanza de las Ciencias Naturales. Chile: Ediciones Unesco.

Wojcicki, E., Izumi, L.T., Chang, A., Parisi, E. \& Silerman, A. (2016). Moonshots en la educación: Nuevas tecnologías y aprendizaje mixto en el aula. México: Taurus.

Velazquez, G. \& Salgado J. (2016). Innovación tecnológica: un análisis del crecimiento económico en México (20022012: proyección a 2018). Análisis Económico, 31 (78), 145-170. 


\title{
Competencia digital y desarrollo profesional de los docentes de dos instituciones de educación básica regular del distrito de Los Olivos, Lima-Perú
}

\section{Digital competence and professional development of teachers from two institutions of regular basic education of Los Olivos district, Lima-Peru}

\author{
Felipe Guizado Osco ${ }^{1}$ \\ https://orcid.org/0000-0003-3765-7391 \\ Isabel Menacho Vargas ${ }^{2}$ \\ https://orcid.org/0000-0001-6246-4618 \\ Angel Salvatierra Melgar ${ }^{3}$ \\ https://orcid.org/0000-0003-2817-630X \\ Universidad César Vallejo, Perú
}

Recibido: 30-10-2018

Aceptado: 07-04-2019

\section{Cita Recomendada}

Guizado, F., Menacho, I. \& Salvatierra, A. (2019). Competencia digital y desarrollo profesional de los docentes de dos instituciones de educación básica regular del distrito de Los Olivos, Lima-Perú. Hamut'ay, 6(1), 54-70.

http://dx.doi.org/10.21503/hamu.v6i1.1574

\section{RESUMEN}

El avance y desarrollo vertiginoso de la ciencia y el conocimiento que se evidencia en la evolución de las tecnologías constituye, en estos tiempos, una exigencia al cambio en el perfil del profesional de la educación, quien debe desarrollar las competencias digitales idóneas para implementarlas en su proceso de enseńanza aprendizaje. El objetivo fue determinar la relación entre la competencia digital y el desarrollo profesional de los docentes de Educación Básica Regular. El estudio fue de tipo básico, diseño no experimental, correlacional causal y transversal. La selección de la muestra se realizó en dos instituciones educativas pertenecientes a la Red 08 de la Unidad de Gestión Educativa Local No. 02, en Lima, Perú, ( $\mathrm{n}=100$ docentes). Para la recolección de datos se utilizó dos cuestionarios con escala Likert, cuya validez de contenido fue por juicio de expertos, con un nivel de concordancia superior al 0.75 , y la confiabilidad tuvo un índice de 0.77 y 0.75 . En los resultados se concluye que existe correlación entre las competencias digitales docente y el desarrollo profesional determinado por el Chi cuadrado X2c=18.499 con un 1 grado de libertad y el valor de significación estadística de $p=0.00$ a un nivel de confianza del $95 \%$. Y también se obtuvo que el $24 \%$ del desarrollo profesional es explicado por las competencias digitales de los docentes y el $76 \%$ se debe a otros factores.

1 Licenciado en Educación; Magister en Educación con mención Docencia Universitaria, Doctor en Administración de la Educación, Estudios de Posgrado en la Universidad de Buenos Aires y Universidad Complutense de Madrid, Docente a nivel de pregrado y posgrado. E-mail: fguizadoo@ucv.edu.pe 2 Psicóloga, Educadora, Magister en evaluación y Acreditación de la calidad educativa, Doctora en Educación y Doctora en Gestión Pública y Gobernabilidad. Jefe de Investigación de la Escuela de Posgrado en la Universidad César Vallejo. Investigador por Concytec. E-mail: Regina:16036. imenacho@ucv.edu.pe

3 Licenciado en Matemática, Magister en Tecnologías de la Información, Doctor en Ciencias de la Educación por la Universidad Nacional del Centro del Perú, con estudios de Matemática Estadística por la Universidad Nacional Mayor de San Marcos, diplomatura en: Estadística Aplicada por la Pontificia Universidad Católica del Perú.. docente a nivel de pregrado y posgrado en universidades públicas y privadas. E-mail: smelgara@ucv.edu.pe. 
Palabras Clave: Competencia digital, desarrollo profesional, docente.

\begin{abstract}
The progress and accelerated development of science and knowledge that is evident in the evolution of technologies constitute a demand to change the profile of professionals in the education field. Nowadays, they must develop suitable digital skills to implement them in their teaching-learning process. The objective was to determine the relationship between digital competence and the professional development of teachers working in Regular Basic Education. This was a basic study with a causal cross-sectional correlational non-experimental design. The selection of the sample was carried out in two educational institutions belonging to Network 08 of the Local Educational Management Unit No. 02, in Lima, Peru, ( $\mathrm{n}=100$ teachers). For data collection, two Likert-scale questionnaires were used, whose content validity was obtained by expert judgment, with a level of agreement higher than 0.75 , and its reliability had an index of 0.77 and 0.75 . In the results it is concluded that there is a correlation between the digital competences of teachers and their professional development determined by the Chi square X2c $=18.499$ with 1 degree of freedom and the value of statistical significance of $p=0.00$ at a confidence level of $95 \%$. And it was also obtained that $24 \%$ of the professional development is explained by the digital competences of the teachers while $76 \%$ is due to other factors..
\end{abstract}

Keywords: Digital competence, professional development, teacher.

\section{INTRODUCCIÓN}

El que los docentes desarrollen competencias digitales en su ámbito profesional se ha hecho una necesidad impostergable, debido a los cambios de perfiles de sus estudiantes, a quienes imparten catedra, ya que estos son nativos digitales y están inmersos en estos medios dentro y fuera del aula en cada momento de su vida, por lo que el docente de cualquier nivel educativo no puede estar exento de adquirir y desarrollar estas competencias, como también lo enfatiza Durán, Prendes \& Gutiérrez (2019) al referir que la competencia digital es clave en el perfil profesional docente.

Estudios realizados en Latinoamérica también refieren sobre estos aspectos como es el caso de Osorio (2016) en la investigación realizada en educación básica primaria sobre el desarrollo profesional docente en Colombia; concluye que muchos profesores necesitan apoyo y orientación para ser capaces de enseñar programas de innovación educativa y aplicación de las tecnologías. Por su parte el Ministerio de Educación Nacional de Colombia (2013) sobre el estudio realizado de Competencias TIC para el desarrollo profesional docente, enfatiza el fomento hacia la innovación $y$ en la posibilidad de transformar las practicas educativas con la integración pertinente de las TIC, las cuales consideran como herramientas de gestión del conocimiento y facilitadoras de la comunicación global, las cuales tienen un rol importante en el quehacer educativo, (UNESCO, 2010).

Caudillo (2016) analiza desde otra perspectiva el que el docente deba estar capacitado en el uso y apropiación de las tecnologías como parte de su competencia digital, al resaltar que los estudiantes de educación secundaria en Sonora México siguen mostrando una tendencia confirmatoria con el uso autónomo de las tecnologías, lo cual les 
Competencia digital y desarrollo profesional de los docentes de dos instituciones de educación básica regular del distrito de Los Olivos, Lima-Perú

permiten realizar ciertos logros académicos como una búsqueda y una selección de información hasta cierto punto aceptable. Pero este uso de las tecnologías de la información y comunicación no se observa de la misma manera en los docentes, como lo asevera Colás, De Pablo \& Ballesta (2018) al mencionar que existe una insuficiente preparación del docente para introducir en sus sesiones de aprendizaje la aplicación de las tecnologías, como el uso de Internet y de herramientas informáticas.

En el caso de Perú a partir del 2017 con la implementación del cambio en las competencias del Currículo Nacional de Educación Básica, se mira desde otra perspectiva los aspectos relacionados a las competencias digitales docentes. Vargas-D 'Uniam, Chumpitaz-Campos, Suárez-Díaz \& Badia (2014) en su estudio sobre la relación entre las competencias digitales de docentes de educación básica y el uso educativo de las tecnologías en las aulas, concluyen que se identificaron dos tipos de competencias, las competencias tecnológicas, las cuales comprenden el uso de aplicaciones informáticas, como el procesador de texto, hoja de cálculo y base de datos, aplicaciones y presentaciones multimedia, el software educativo y el uso del Internet para comunicación y navegación; en cuanto a la competencia pedagógica es la que incluye las habilidades en el uso y aplicación de las tecnologías en el proceso de enseñanza aprendizaje. Asimismo, mencionan respecto a las competencias digitales que hay un mayor desarrollo en utilizar las tecnologías para actividades sencillas, al realizar una presentación o localizar recursos útiles para sus asignaturas. En cuanto a las competencias tecnológicas consideran que tienen capacidad para diseñar o modificar paginas web o blog, pero que los docentes hacen un escaso uso de las tecnologías en el aula, por lo que concluyeron que existe una correlación no significativa entre las competencias digitales de los docentes y los usos educativos que realizan en el aula, demostrando los resultados un bajo nivel competencial.

Los autores citados nos orientan a hurgar en la brecha entre las competencias digitales de los docentes y estudiantes la cual presenta un reto para ellos, porque en pleno siglo XXI donde el auge de la innovación educativa ha ido en aumento, toda- vía la labor y la idoneidad en el desempeño de los docentes en apropiarse de las tecnologías es incipiente, situación que se tiene como evidencia en los distintos resultados que arrojan las múltiples evaluaciones de desempeño académico realizadas a estos; ya sea para los ascensos en los distintos niveles como para alcanzar el ingreso a la carrera pública magisterial, (Minedu, 2016). Aunque en menor porcentaje existen instituciones educativas que cuentan con personal docente que tienen altos niveles de desempeño en las distintas áreas que engloban su perfil, y en las que se incluye de manera eficiente y competente el uso y apropiación de las tecnologías, según la evaluación de desempeño realizada por el Minedu (2017).

Por otra parte, el Proyecto Educativo Nacional de educación al 2021, el cual es un referente en el ámbito educativo, destaca que se debe contar con docentes altamente capacitados, con una educación continua y permanente a la par de los avances de las tecnologías, la ciencia y la pedagogía, (CNE, 2006). Al respecto Colomer et al., (2018) refieren que la sociedad en general en estos últimos años ha sufrido una transformación por la influencia de las tecnologías, de la cual no esta exenta la educación, por lo que esta debe estar en sintonía con estos cambios, por ende es cada vez más necesaria la formación y desarrollo profesional de un profesorado que sea competente digitalmente, con capacidad para aprovechar la tecnología ya que el contexto global presenta un avance vertiginoso en el desarrollo de las herramientas de información y comunicación y el conocimiento, en este contexto están incluidos los procesos educativos, los campos educacionales y los distintos espacios donde se promueve el desarrollo de la ciencia.

Es por ello que se presenta la necesidad de realizar una indagación respecto a la competencia digital de los docentes, dentro del contexto de su formación profesional en nuestro país; por lo que en este estudio el objetivo fue determinar la relación entre la competencia digital y el desarrollo profesional de los docentes de Educación Básica Regular, para lo cual se formuló la siguiente hipótesis: existe relación de las competencias digitales y el desarrollo profesional docente y sus dimensiones. 


\section{Competencia digital}

La comunidad europea formula la competencia digital, como una de las competencias básicas y fundamentales, definiéndola como:

El uso crítico y seguro de las tecnologías de la información para el trabajo, el tiempo libre y la comunicación. Apoyándose en habilidades [en el uso] de las Tecnologías de la Información y Comunicación (TIC) básicas: uso de ordenadores para recuperar, evaluar, almacenar, producir, presentar e intercambiar información, y para comunicar y participar en redes de colaboración a través de internet (MECD, 2017, p. 8)

Para el Ministerio de Educación de España (2017) la competencia digital puede definirse "como el uso creativo, crítico y seguro de las tecnologías de información y comunicación para alcanzar los objetivos relacionados con el trabajo, la empleabilidad, el aprendizaje, el tiempo libre, la inclusión y participación en la sociedad" (p.9) así como a la integración sociocultural en un grupo humano digital e imbuido de tecnología. Para Almerich, et al., (2018) las competencias digitales son el conjunto de conocimientos y habilidades que permiten dominar distintos recursos tecnológicos. Desde otra óptica Valdivieso-Guerrero (2013) refiere que es la integración de indicadores de desempeños donde están incluidas las competencias genéricas relacionadas a competencias interpersonales, instrumentales e informacionales y las competencias especificas vinculadas a lo pedagógico-tecnológico y a lo pedagógico-didáctica-disciplinares.

\section{Competencia digital docente}

Un acercamiento a la definición de competencia digital docente lo formulan Zavala et al., (2016, p. 334) al señalar que esta se sustenta en base a su uso de manera creativa, crítica y segura de las tecnologías de información y comunicación como una herramienta para los docentes que les permita llegar a adquirirla como parte de su desarrollo profesional, aprendizaje, entretenimiento, comunicación e información con la sociedad, en el contexto de la escuela. Es esto lo que se pretende develar en el escenario planteado para la localidad en estudio.
La formación profesional docente, por ende, es apostar por asumir la relevancia de la competencia digital bajo el entendimiento de lo que supone ser un docente competente en las diversas esferas de lo educativo; hacer uso de las tecnologías considerando la importancia de saber cómo usar, analizar y reflexionar sobre estas dentro del proceso de enseńanza-aprendizaje, como lo refieren Prendes, Gutiérrez \& Martínez (2018) lo cual hace que tengan un involucramiento pedagógico y social con sus estudiantes.

$\mathrm{Al}$ respecto, Esteve (2015) sostiene que una sociedad globalizada denota cambios a gran velocidad, dentro del marco de la transformación espacio temporal, con una enorme saturación de información, con formas distintas de inteligencia colectiva y en un espacio casi abstracto denominado red, eso supone asumir nuevos retos, que son los desafíos que la educación y las instituciones tienen y están en la necesidad de asumir, dentro del cual el docente es un elemento esencial. En este mismo sentido y expresando la importancia de la competencia digital refieren Sámano et al. (2018) que existe la necesidad de hacer un rediseño curricular con un cambio de fondo en la enseñanza, a la cual se debe incorporar el uso de las tecnologías, haciendo hincapié en la necesidad de plantear la alfabetización digital, como un aprendizaje múltiple, global e integrado de las distintas formas y lenguajes que en la actualidad son importantes en la formación de los docentes, lo cual revertirá en sus estudiantes. Del mismo modo el Ministerio de Educación Nacional de Colombia (2013)refiere que la inclusión de las TIC han influenciado en nuevas didácticas y han potenciado ideales pedagógicos al ofrecer ambientes de aprendizaje ricos en experiencias, recursos y materiales que cautivan el interés del alumnado, permiten libertad de explorar, analizar y construir conocimiento, así como el poseer múltiples fuentes de información actualizadas constantemente.

Es este el cambio que esperamos promover, para que nuestros docentes se incorporen y utilicen la estrategia de enseñanza asistida por herramientas de información y comunicación. 
Competencia digital y desarrollo profesional de los docentes de dos instituciones de educación básica regular del distrito de Los Olivos, Lima-Perú

\section{Dimensiones de la competencia digital}

Según la propuesta referida por Prendes, Gutiérrez \& Martínez (2018) la competencia digital presenta cinco dimensiones, (ver tabla 1)

Tabla 1

Dimensiones de la competencia digital según Prendes, et al.

\begin{tabular}{|c|c|}
\hline Dimensiones & Descripción \\
\hline Técnica & $\begin{array}{l}\text { Permite la capacitación y desarrollo para el } \\
\text { dominio de las tecnologías, la información y la } \\
\text { comunicación, con el manejo de herramien- } \\
\text { tas de edición digital, realizar trabajos con } \\
\text { eficacia en contenidos digitales, en entornos } \\
\text { virtuales de enseñanza- aprendizaje. Incide } \\
\text { en la comprensión y uso eficaz de los siste- } \\
\text { mas informáticos, configuración, instalación } \\
\text { y actualización de software o dispositivos } \\
\text { informáticos }\end{array}$ \\
\hline $\begin{array}{l}\text { Informacional } \\
\text { y comunica- } \\
\text { tiva }\end{array}$ & $\begin{array}{l}\text { Engloba la comunicación interpersonal y } \\
\text { social, obtención, evaluación, organización y } \\
\text { el tratamiento de la información en entornos } \\
\text { digitales, para lo que se requiere, usar siste- } \\
\text { mas informáticos, usar motores de búsqueda, } \\
\text { guardar, archivar y recuperar información en } \\
\text { formato digital, evaluar la calidad y pertinencia } \\
\text { de la información }\end{array}$ \\
\hline Educativa & $\begin{array}{l}\text { Relacionada a la orientación, guía y } \\
\text { evaluación de los procesos de construcción } \\
\text { del conocimiento, así como la colaboración } \\
\text { en entornos digitales, a través de dispositi- } \\
\text { vos digitales, velando por la calidad de los } \\
\text { contenidos }\end{array}$ \\
\hline Analítica & $\begin{array}{l}\text { Tiene como componente la capacidad de } \\
\text { reflexionar de modo crítico sobre nuestra } \\
\text { propia competencia, las posibilidades de } \\
\text { asumir todos los elementos que constituyen el } \\
\text { universo de las tecnologías de comunicación, } \\
\text { para desarrollar los procesos de interacción, } \\
\text { colaboración y evaluación de los aprendizajes }\end{array}$ \\
\hline Social y ética & $\begin{array}{l}\text { Hace referencia a la elaboración en forma } \\
\text { colectiva, trabajando en equipo, en redes } \\
\text { y espacios tele-colaborativos y sobre todo } \\
\text { contribuir al aprendizaje mutuo, al actuar de } \\
\text { forma responsable, seguro y cívico, a través } \\
\text { del respeto a la privacidad, la seguridad de } \\
\text { los datos personales y la información en } \\
\text { internet, con conocimiento de la norma legal } \\
\text { que ampara los derechos de propiedad, } \\
\text { como inicio del ejercicio responsable de la } \\
\text { ciudadanía digital }\end{array}$ \\
\hline
\end{tabular}

Fuente: Prendes et al (2018, p. 9)

Se considera, a su vez el modelo que dimensiona Boris (2009, p. 14) que considera las cinco dimensiones concordantes, (Ver Tabla 2)
Tabla 2

Dimensiones de la competencia digital según Boris.

\begin{tabular}{ll}
\hline Dimensiones & Descripción \\
\hline Aprendizaje & $\begin{array}{l}\text { Referida a la transformación de la información } \\
\text { en conocimiento y su adquisición }\end{array}$ \\
Informacional & $\begin{array}{l}\text { Precisa la obtención, la evaluación y el trata- } \\
\text { miento de la información en entornos digitales. }\end{array}$ \\
Comunicativa & $\begin{array}{l}\text { Abarca la comunicación interpersonal y la } \\
\text { social. }\end{array}$ \\
Cultura digital & $\begin{array}{l}\text { Hace referencia a las prácticas sociales y } \\
\text { culturales de la sociedad del conocimiento y la } \\
\text { ciudadanía digital. }\end{array}$ \\
Tecnológica & $\begin{array}{l}\text { Referida a la alfabetización tecnológica y el co- } \\
\text { nocimiento y dominio de los entornos digitales. }\end{array}$ \\
\hline
\end{tabular}

Fuente: Boris, (2009)

\section{Desarrollo profesional docente.}

El desarrollo docente es un constante aprendizaje y una permanente actualización y renovación de conocimiento, habilidades e innovación, tanto para el uso de estrategias como el mejoramiento de capacidades educativas, como lo señala Osorio (2016)

Existe el constructo en el imaginario de las personas que quienes ostentan estudios de pre y posgrado pueden resolver toda la formación de los profesionales. Sin embargo, lo cierto es que esta formación está limitada hacia los docentes, ya que con supuestos modelos ideales sean aplicados en sesiones [...] la formación docente debe estar orientada a ayudar a superar el desgaste que sufren los profesores, en cuanto a su aprendizaje en su formación inicial y lo nuevo que deben aprender en el desempeño de sus funciones como docente, y que esto les permita estar a la par con la evolución en la sociedad. (p. 41)

Vaillant (2016) refiere que hay un énfasis en mantener la calidad del profesorado, por lo que hay una preocupación en fortalecer el desarrollo profesional del docente, y que este debe estar establecido a través de políticas públicas que aseguren la continuidad y sostenibilidad de procesos que permitan una formación continua de estos. Para Valdivieso \& Ángeles (2016) la formación profesional docente debe ser específica, en el que implique la apropiación y aplicación de las TIC 
para aprovechar las potencialidades de estas en la práctica docente. Asimismo, que durante todo el tiempo que este continúe con su desarrollo profesional y su formación continua, inicie un proceso que se ajuste a la exigencia de adquirir y mejorar su competencia digital.

En cuanto a entender la complejidad del desarrollo profesional de los docentes Trillo et al. (2017) señalan que este se da bajo la diversidad de tiempos, contextos y experiencias de aprendizaje, así como los contenidos que se tratan y los procesos, todos los cuales son convertidos en aprendizajes por los sujetos en su condición de profesionales, y serán utilizados en su desempeńo, en tiempos y situaciones distintas y cambiantes.

\section{Dimensiones del desarrollo profesional docente.}

A partir de la teoría y la praxis del quehacer educativo, el cual es complejo por naturaleza, es necesario tener un sistema de desarrollo profesional integral y permanente a nivel académico, institucional y personal, ello hace que se formule las siguientes dimensiones:

1. Dimensión Pedagógica, que constituye el núcleo y base fundamental del desenvolvimiento profesional docente. Es un saber específico, construido en la reflexión teórico-práctica, que permite apelar a saberes diversos para cumplir con el rol que tiene este. En los que están incluidos competencias capacidades, actitudes y el compromiso de los estudiantes para aprender y formarse. Ballester \& Sánchez (2011, p. 23) refieren que "La dimensión pedagógica [...] es el conjunto de decisiones articuladas en torno a un modelo educativo basado en competencias básicas y brindan los lineamientos de contexto y contenido en el ámbito pedagógico, en aspectos relacionados a lo organizativo, curricular y didáctico".

Avín et al., (2016, p. 3) hacen mención sobre los aspectos pedagógicos, que son los propósitos y los contenidos de la enseñanza, el entendimiento e identificación del alumno y docente, a la relación pedagógica que se da entre ellos; aunado con el conocimiento, las estrategias didácticas y la evaluación de los aprendi- zajes en todo nivel.

2. Dimensión teleológica, visto a nivel institucional todo docente necesita tener claro su orientación y fin educativo como lo señalan García, Verde et al, (2011, p 57) "La meta social de la docencia consiste en la transmisión de la cultura y la formación de personas críticas", en ese sentido la labor docente tiene un fin inherente a su naturaleza y función, tiene un rol determinado en la línea del cumplimiento de las metas, fines y propósitos educacionales establecidos por el Estado, a través de sus normas y directivas. Montalvo (2012) refiere que esta dimensión, es la lección del profesor, con una visión madura y puesta al día del conocimiento, seleccionando los contenidos posibles y necesarios. Los docentes asumen como reto desarrollar sus competencias como parte de su formación profesional y a los compromisos asumidos con la sociedad, el Estado y el carácter trascedente de ser educador.

3. Dimensión deontológica, que se formula bajo la concepción del desarrollo profesional a partir del respeto y cumplimiento del conjunto de regulaciones, principios y normas que orientan el ejercicio profesional docente, para establecer su línea y orientación. Gonzalo \& Ruiz (2013) mencionan que los principios deontológicos que marcan toda actuación docente, son: Responsabilidad, veracidad, justicia, respeto, empatía, solidaridad, espíritu crítico, desinterés, lo mismos que sirven para que el docente conozca y asuma plenamente sus obligaciones, que la sociedad exige.

Estas dimensiones presentadas por los distintos autores nos ayudaron a sustentar las distintas estrategias de recolección de información y orientar la discusión y conclusiones, para así engranar un plan de trabajo efectivo centrado en el docente como pilar esencial de la educación en nuestro país.

\section{Materiales y Métodos}

\section{Participantes}

La población estuvo constituida por 215 docentes 
Competencia digital y desarrollo profesional de los docentes de dos instituciones de educación básica regular del distrito de Los Olivos, Lima-Perú

de las instituciones educativas públicas "Precursores de la Independencia Nacional" y "Nuestra Señora de Lourdes" distrito de Los Olivos, LimaPerú, considerando como criterios de inclusión, a docentes de educación básica regular, de los niveles primario y secundario, de ambos sexos, de los turnos mañana y tarde. Y como criterios de exclusión a los docentes del nivel inicial, que se encontraban en capacitación y de licencia.

Se aplicó la fórmula de Arkin y Kolton para realizar el análisis de la muestra, dando como resultando 100 docentes. Para la selección de los docentes de la muestra se aplicó la técnica aleatoria simple, ya que todos los participantes del total de ambas instituciones educativas tuvieron la misma probabilidad de ser seleccionados, (Vara, 2015; Hernández, Fernández \& Baptista, (2014). En este estudio no se ha considerado los aspectos sociodemográficos de los docentes, debido a que nuestro interés se centraba en conocer la relación entre competencias digitales y desarrollo profesional docente.

\section{Instrumento}

Para la recolección de los datos se utilizaron dos cuestionarios en escala Likert, para la variable competencias digitales el cuestionario consto de 25 ítems, y tenía un total de tres escalas, desde un buen nivel a un nivel bajo, (Anexo 1) Para la variable Desarrollo profesional docente el cuestionario fue de 20 ítems, baremado con niveles desde alto a bajo. (Anexo 2). En la tabla 3 y 4 se realiza la descripción de ambos cuestionarios.

Tabla 3

Descripción del cuestionario de Competencias digitales

\begin{tabular}{ll}
\hline \multicolumn{2}{c}{ Variable: Competencias digitales } \\
\hline Dimensiones & \multicolumn{1}{c}{ Indicadores } \\
\hline Educativa & $\begin{array}{l}\text { Representa y crea conocimiento en diferentes } \\
\text { lenguajes. }\end{array}$ \\
& $\begin{array}{l}\text { Produce conocimientos y publica información } \\
\text { Lleva a cabo proyectos, resuelve problemas y } \\
\text { toma decisiones en entornos digitales. }\end{array}$ \\
& Trabaja con eficacia con contenidos digitales \\
& Hace uso de las TIC como instrumento del \\
& pensamiento reflexivo y crítico.
\end{tabular}

\begin{tabular}{|c|c|}
\hline & Variable: Competencias digitales \\
\hline Dimensiones & Indicadores \\
\hline Analítica & $\begin{array}{l}\text { Usa sistemas informáticos y navega por Internet } \\
\text { Utiliza diferentes fuentes y motores de búsque- } \\
\text { da } \\
\text { Guarda, archiva y recupera la información } \\
\text { Conoce y utiliza herramientas y recursos } \\
\text { Evalúa la calidad, la pertinencia y la utilidad de } \\
\text { la información. }\end{array}$ \\
\hline $\begin{array}{l}\text { Informacio- } \\
\text { nal y comuni- } \\
\text { cativa }\end{array}$ & $\begin{array}{l}\text { Se comunica mediante dispositivos digitales y } \\
\text { software específico. } \\
\text { Verifica la calidad y el contenido de la comuni- } \\
\text { cación } \\
\text { Emplea herramientas de elaboración colectiva } \\
\text { Participa proactivamente en entornos virtuales. } \\
\text { Colabora y contribuye al aprendizaje mutuo con } \\
\text { herramientas digitales. }\end{array}$ \\
\hline Social y ética & $\begin{array}{l}\text { Gestiona la identidad digital y el grado de priva- } \\
\text { cidad y de seguridad de los datos personales. } \\
\text { Respeta los diferentes ámbitos de propiedad de } \\
\text { los contenidos digitales. } \\
\text { Reflexiona sobre la dimensión social y cultural } \\
\text { de la sociedad del conocimiento. } \\
\text { Propicia el ejercicio responsable de la ciudada- } \\
\text { nía digital. }\end{array}$ \\
\hline Técnica & $\begin{array}{l}\text { Comprende y utiliza con eficacia los dispositivos } \\
\text { Utiliza las funciones de navegación } \\
\text { Determina y configura el software y el entorno } \\
\text { de trabajo. } \\
\text { Instala, actualiza y desinstala software }\end{array}$ \\
\hline
\end{tabular}

Fuente: Prendes et al., (2018)

Tabla 4

Descripción de Desarrollo profesional docente

\begin{tabular}{ll}
\hline \multicolumn{2}{c}{ Variable: Desarrollo profesional docente } \\
\hline Dimensiones & \multicolumn{1}{c}{ Indicadores } \\
\hline Pedagógica & $\begin{array}{l}\text { Demuestra el saber pedagógico construido } \\
\text { en la reflexión teórico-práctica, que le permite } \\
\text { apelar a saberes diversos para cumplir su rol. }\end{array}$ \\
Teleológica & $\begin{array}{l}\text { Reflexiona sobre el objetivo de la educación } \\
\text { basados en el respeto a los principios demo- } \\
\text { cráticos de convivencia y a los derechos y } \\
\text { libertades fundamentales. }\end{array}$ \\
Deontológica & $\begin{array}{l}\text { Conoce y practica los principios y normas } \\
\text { éticas de la profesión docente. }\end{array}$ \\
\hline
\end{tabular}

Fuente: Elaboración propia (2018)

Para ambos instrumentos se procedió a establecer la validez de contenido, mediante el juicio de 7 expertos, quienes concuerdan que los instrumentos presentan un grado mayor al 0.75 , utilizando el método Delphi. (Ver tabla 5 y 6 ) 


\section{Tabla 5}

Validez de contenido por criterio de jueces: Competencias digítales. valor máximo 1 y mínimo 0

\begin{tabular}{|c|c|c|c|c|c|c|c|c|}
\hline \multirow{3}{*}{$\begin{array}{l}\text { Dimen- } \\
\text { siones }\end{array}$} & \multicolumn{7}{|c|}{ Calificación de los jueces } & Índice \\
\hline & J & $\mathrm{J}$ & $\mathrm{J}$ & $\mathrm{J}$ & J & . & J & \\
\hline & 1 & 2 & 3 & 4 & 5 & 6 & 7 & \\
\hline 1 & 0 & 1 & 1 & 1 & 1 & 1 & 1 & 0.86 \\
\hline 2 & 1 & 1 & 1 & 1 & 1 & ( & 1 & 0.86 \\
\hline 3 & 1 & 1 & 1 & 1 & 1 & 1 & 1 & 1.0 \\
\hline 4 & 1 & 1 & 1 & 1 & 1 & 1 & 0 & 0.8 \\
\hline
\end{tabular}

Fuente: Elaboración propia (2018)

\section{Tabla 6}

Validez de contenido por criterio de jueces: Desarrollo profesional docente

\begin{tabular}{|c|c|c|c|c|c|c|c|c|c|}
\hline \multirow{3}{*}{$\begin{array}{l}\text { Dimen- } \\
\text { siones }\end{array}$} & \multicolumn{7}{|c|}{ Calificación de los jueces } & \multirow{3}{*}{$\begin{array}{l}\text { Índice } \\
\text { de eva- } \\
\text { luación }\end{array}$} & \multirow[t]{3}{*}{ Sugerencias } \\
\hline & $\mathrm{J}$ & $\mathrm{J}$ & $\mathrm{J}$ & $J$ & $\mathrm{~J}$ & $\mathrm{~J}$ & $\mathrm{~J}$ & & \\
\hline & 1 & 2 & 3 & 4 & 5 & 6 & 7 & & \\
\hline 1 & 1 & 1 & 1 & 1 & 1 & 1 & 1 & 1.00 & \\
\hline 2 & 1 & 1 & 1 & 1 & 1 & 0 & 1 & 0.86 & $\begin{array}{l}\text { Cambiar en el ítem: Parti- } \\
\text { cipa en las capacitaciones } \\
\text { referidas al manejo de las } \\
\text { nuevas tecnologías por } \\
\text { "Participa en las capacita- } \\
\text { ciones referidas al manejo } \\
\text { de las nuevas tecnologías, } \\
\text { para su desempeño do- } \\
\text { cente" para completar la } \\
\text { información que se busca } \\
\text { recoger del ítem. }\end{array}$ \\
\hline
\end{tabular}

Para la confiabilidad, se empleó el coeficiente Alfa de Cronbach, cuyos resultados fueron 0.77 para Competencias digitales y 0.75 para Desarrollo profesional docente, lo que significa que los dos instrumentos alcanzan una excelente confiabili- dad, previo de la validez de contenido; donde el informante técnico asumió 1 en señal de su conformidad mientras 0 en señal de desconformidad, lo cual se aprecia en la Tabla 7.

Tabla 7

Confiabilidad de los instrumentos

\begin{tabular}{llcc}
\hline \multicolumn{1}{c}{ Cuestionarios } & $\begin{array}{c}\text { Validez de } \\
\text { contenido }\end{array}$ & $\begin{array}{c}\text { Alfa de } \\
\text { Cronbach } \\
\text { (confiabilidad) }\end{array}$ & $\begin{array}{c}\mathrm{N}^{\circ} \text { de } \\
\text { ítems }\end{array}$ \\
\hline $\begin{array}{l}\text { Cuestionario sobre la } \\
\text { Competencia digital }\end{array}$ & Aplicable & 0.77 & 25 \\
\hline $\begin{array}{l}\text { Cuestionario sobre el } \\
\text { Desarrollo profesional } \\
\text { docente }\end{array}$ & Aplicable & 0.75 & 20 \\
\hline
\end{tabular}

Fuente: Elaboración propia (2018)

Tipo y diseño

El tipo de estudio es básico, de acuerdo a Vara (2015) permite generar nuevas formas de interpretar el objeto de estudio y facilita el acercamiento a la realidad de estudio y se asumen teorías que explican las variables analizadas.

El diseño es no experimental, de corte transversal, correlacional causal, de acuerdo a Hernández, et al. (2014), los diseños no experimentales se caracterizan por observar los fenómenos sin intervención del investigador, es transversal al recopilar información en un determinado momento y correlacional causal, al describir una relación de causalidad entre las variables de estudio.

Se empleó el método hipotético deductivo, consiste en partir de afirmaciones o supuestos para refutar o falsear tales hipótesis, infiriendo de ellas conclusiones que se confrontan con los hechos; es decir, comprobar la veracidad o falsedad de los supuestos planteados, que no se pueden demostrar directamente, debido a su carácter de enunciado general. (Bernal et al., 2014).

\section{Procedimiento}

El estudio fue realizado a través de etapas secuenciales:

- Etapa de inicio: La investigación inicio con la formulación del problema a nivel institucio- 
Competencia digital y desarrollo profesional de los docentes de dos instituciones de educación básica regular del distrito de Los Olivos, Lima-Perú

nal, de la cual se tuvo la idea de investigación, lo que finalmente se constituyó en el tema y posterior título de investigación.

- Etapa segunda: La existencia del problema se consultó con la revisión de la literatura especializada, en bases de datos, revistas electrónicas y libros.

- Etapa tercera: Se planteó interrogantes de investigación, objetivos e hipótesis producto de la problemática encontrada.

- Etapa Cuarta: Se desarrolló todo el soporte teórico, lo que permitió la operacionalización de las variables, para la elaboración de los cuestionarios: competencias digitales y desarrollo profesional, pasando los mismos por los procesos de validez de contenido y un proceso estadístico, que se realizó en un grupo piloto, para poder realizar el análisis estadístico y determinar la confiabilidad de los instrumentos. Considerando que cumplía con las condiciones se procedió a recoger los datos de la muestra.

- Etapa quinta: La muestra fue convocada para explicarles el objetivo del estudio y para la firma del consentimiento informado. Posteriormente para la aplicación de los instrumentos, en la que se dio lectura a las instrucciones.

- Etapa sexta: Se procesó los datos recogidos de la muestra de estudio, mediante el programa SPSS, V_24. Para la presentación de los niveles de ambas variables, se utilizó niveles porcentuales. Para determinar la asociación entre variables se utilizó el estadístico Chi cuadrado. Respondiendo al diseño del estudio, correlacional causal, en su primera presentación, la correlación se realizó con los estadísticos ordinales, rho de Spearman, Kendall y Gamma. La relación causal se obtuvo con el coeficiente de determinación Nagelkerke, mostrándose los porcentajes de incidencia

- Etapa de cierre: Finalmente se desarrolló la discusión y conclusiones de la investigación.

\section{Confidencialidad o consentimiento informado}

Se realizó el estudio solicitando la autorización a través de cartas de permiso correspondiente a las instituciones educativas, donde se exponía el porqué de la investigación. Una vez obtenida la aceptación, se convocó a la muestra previamente seleccionada siguiendo rigurosamente los criterios de inclusión, para solicitar el consentimiento informado, a través del cual, eran conscientes que ser parte de un estudio que aporta a la solución del problema y contribuye al conocimiento científico, Anexo 3.

\section{Resultados}

Se obtuvieron y procesaron dos bloques de resultados; en la primera parte se presenta los resultados descriptivos, con los niveles de las variables (nivel alto, regular, etc.), establecidos en el proceso de operacionalización y la aplicación del baremo, según las respuestas de la muestra de estudio en una tabla de contingencia de las frecuencias y porcentajes, (Tabla 8). Y el segundo bloque se presentan los coeficientes de correlación, (Tabla 9).

\section{Tabla 8}

Niveles de la Competencia digital y el Desarrollo profesional docente de EBR de la Red 02 UGEL 02.

\begin{tabular}{|c|c|c|c|c|c|}
\hline & & & \multicolumn{2}{|c|}{$\begin{array}{l}\text { Competencia } \\
\text { digital }\end{array}$} & \multirow[b]{2}{*}{ Total } \\
\hline & & & Regular & Bueno & \\
\hline \multirow{5}{*}{$\begin{array}{l}\text { Desarrollo } \\
\text { profesional }\end{array}$} & \multirow[t]{2}{*}{ Moderado } & $\mathrm{Fi}$ & 51 & 3 & 54 \\
\hline & & pi $\%$ & $51 \%$ & $3 \%$ & $54 \%$ \\
\hline & \multirow[t]{3}{*}{ Alto } & $\mathrm{Fi}$ & 27 & 19 & 46 \\
\hline & & & $27 \%$ & $19 \%$ & $46 \%$ \\
\hline & & $\mathrm{Fi}$ & 78 & 22 & 100 \\
\hline Total & & $\mathrm{Fi} \%$ & $78 \%$ & $22 \%$ & $100 \%$ \\
\hline
\end{tabular}

Chi cuadrado X2 = 18.499; gl=1; sig. asin. bilateral $=0.00$ Fuente: Elaboración propia (2018)

En la Tabla 8 se muestran los resultados por niveles de las competencias digitales y el desarrollo profesional de los docentes; observándose una tendencia de complementariedad entre ellos. Con respecto a las competencias digitales, el 78\% de los docentes presentan un nivel regular, y el 22\% un buen nivel, con respecto al desarrollo profesional; el 54\% de los docentes presentan un nivel moderado y el $46 \%$ alto nivel. Sin embargo, el $51 \%$ de los docentes presentan regular nivel en competencias digitales puesto que muestran moderado nivel en su desarrollo profesional, y 
el 19\% de los docentes muestran buen nivel en competencias digitales y presentan alto nivel de desarrollo profesional, expresado en la Figura 1. Estos resultados permiten afirmar que existe correlación entre las competencias digitales y el desarrollo profesional docente determinado por el Chi cuadrado X2c=18.499 con un 1 grado de libertad y el valor de significación estadística de p_valor 0.00 a un nivel de confianza del $95 \%$.

Niveles de competencia digital y desarrollo profesional docente

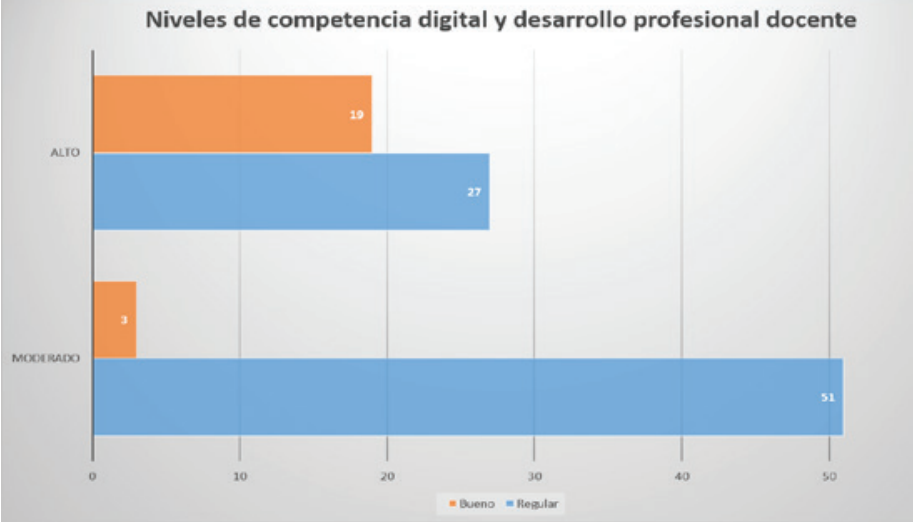

Figura 1

Registros de Educación Básica Regular del distrito de Los Olivos, Lima-Perú.

Las variables de estudio, por su naturaleza son de tipo cualitativa, de escala ordinal; y los coeficientes de correlación reafirman la existencia de concordancia y complementariedad entre ellos. A continuación, se muestra la relación entre las variables de estudio:

Tabla 9

Coeficiente de correlación entre las competencias digitales y el desarrollo profesional.

\begin{tabular}{llcc}
\hline \multicolumn{3}{c}{ Medidas simétricas-Correlaciones } \\
\hline & $\begin{array}{l}\text { Pruebas de } \\
\text { asociación }\end{array}$ & Valor & $\begin{array}{l}\text { Significación } \\
\text { aproximada }\end{array}$ \\
\hline $\begin{array}{l}\text { Ordinal por } \\
\text { ordinal }\end{array}$ & $\begin{array}{l}\text { Rho de } \\
\text { Spearman }\end{array}$ & $.416^{* *}$ & .000 \\
\cline { 2 - 4 } & $\begin{array}{l}\text { Tau-b de } \\
\text { Kendall }\end{array}$ & $.430^{* *}$ & .000 \\
\cline { 2 - 4 } & Gamma & $.846^{* *}$ & .000 \\
\hline $\begin{array}{l}\text { N. }{ }^{\circ} \text { de casos } \\
\text { válidos }\end{array}$ & 100 & \\
\hline
\end{tabular}

Fuente: Elaboración propia (2018)

Los resultados de la tabla 9 permiten reafirmar que existe una relación directa y moderada como se observa mediante el coeficiente de correlación para escala ordinal, Rho de Spearman 0.416, asimismo, el valor de Tau-b de Kendall 0.430; pensando que existieran o no rangos empatados se utilizó el coeficiente de Gamma, con un máximo valor de 0.846; este último estadístico permitió afirmar la correlación entre variables categóricas, (Véliz, 2014). A medida que se incrementa el nivel de las competencias digitales para su labor docente, se manifiesta alto nivel de desarrollo profesional.

Resultados de parámetros y contrastación de hipótesis.

Se tomó de manera porcentual, en referencia al mayor nivel de la variable dependiente, la cual permite determinar el pronóstico porcentual. Sin embargo, para el proceso inferencial con respecto a la contrastación de la hipótesis del estudio, se procedió a analizar con regresión logística ordinal; lo que permitió mostrar la predicción porcentual a partir del Pseudo R cuadrado asociado al estadístico de Wald a un nivel de confianza del 0.05; al respecto la hipótesis del estudio demostró que existe relación de la competencia digital y el desarrollo profesional de los docentes de Educación Básica Regular de la Red 08 de la UGEL 02, de Lima $s$ lo cual fue contrastado con las pruebas estadísticas que a continuación se describen en las Tablas 10 y 11 .

En la Tabla 10 se muestran los coeficientes de la regresión logística ordinal, en el primer bloque, la estimación de la competencia digital frente al desarrollo profesional; al respecto se tiene, el coeficiente de estimación protector de -2.482 , $(\exp -2.482=$ $0.0836)$, implica estadísticamente, que los docentes con nivel regular en el uso de competencia digital, tienen la posibilidad del $8.357 \%$ de mostrar alto nivel en su desarrollo profesional docente, quien es reafirmado por el coeficiente de restricción de Wald, el valor de significación estadística p_valor de 0.000 . Sin embargo, el $24 \%$ del desarrollo profesional se debe o es explicada por las competencias digitales de los docentes, determinado por el coeficiente del seudo R- cuadrado de Nagalkerke. 
Competencia digital y desarrollo profesional de los docentes de dos instituciones de educación básica regular del distrito de Los Olivos, Lima-Perú

\section{Tabla 10}

Estimación de los parámetros logísticos de las competencias digitales y el desarrollo profesional

\begin{tabular}{|c|c|c|c|c|c|c|c|c|}
\hline & & \multirow{2}{*}{$\begin{array}{l}\text { Esti- } \\
\text { ma- } \\
\text { ción }\end{array}$} & \multirow{2}{*}{$\begin{array}{l}\text { Error } \\
\text { están- } \\
\text { dar }\end{array}$} & \multirow[t]{2}{*}{ Wald } & \multirow[t]{2}{*}{$\mathrm{gl}$} & \multirow[t]{2}{*}{ Sig. } & \multicolumn{2}{|c|}{$\begin{array}{c}\text { Intervalo de } \\
\text { confianza al 95\% }\end{array}$} \\
\hline & & & & & & & $\begin{array}{l}\text { Límite } \\
\text { infe- } \\
\text { rior }\end{array}$ & $\begin{array}{l}\text { Límite } \\
\text { supe- } \\
\text { rior }\end{array}$ \\
\hline Umbral & $\begin{array}{l}\text { [Desa } \\
\text { prof = 2] }\end{array}$ & & & & & & -3.063 & -.628 \\
\hline \multirow[t]{2}{*}{$\begin{array}{l}\text { Ubica- } \\
\text { ción }\end{array}$} & $\begin{array}{l}\text { [Comp_ } \\
\text { Dig=2] }\end{array}$ & -2.482 & .665 & 13.916 & 1 & .000 & -3.786 & -1.178 \\
\hline & $\begin{array}{l}\text { [Comp_ } \\
\text { Dig=3] }\end{array}$ & $0^{*}$ & & & 0 & & & \\
\hline \multirow{2}{*}{\multicolumn{2}{|c|}{$\begin{array}{l}\text { Pseudo R } \\
\text { cuadrado }\end{array}$}} & \multicolumn{2}{|c|}{ Cox y Snell } & \multicolumn{3}{|c|}{ Nagelkerke } & \multicolumn{2}{|c|}{ McFadden } \\
\hline & & \multicolumn{2}{|c|}{.180} & \multicolumn{3}{|c|}{.240} & \multicolumn{2}{|c|}{.144} \\
\hline
\end{tabular}

Fuente: Elaboración propia (2018)

* Este parámetro está establecido en cero porque es redundante.

\section{Tabla 11}

Estimación de los parámetros logísticos de las competencias digitales en las dimensiones del desarrollo profesional docente. presentan los docentes, se tiene la probabilidad del buen desarrollo profesional docente, (Hosmer \& Lemeshow, 2000). La significancia individual de cada variable independiente, generalmente, se analiza a través de la prueba de Wald que sigue el comportamiento del Chi cuadrado X2 $(1 ; 0.05)$ y los coeficientes del pseudo $\mathrm{R}$ cuadrado de $\mathrm{Na}$ galkerke para las dimensiones: pedagógica, teleológica y deontológica; esta última presenta mayor incidencia, por cuanto el $52.9 \%$ del comportamiento de la dimensión deontológica es explicada por las competencias digitales durante su desarrollo profesional del docente y el $47.1 \%$ se debe a otros factores. Podemos notar que existe certeza para deducir que existe evidencia estadísticamente significativa para afirmar que los docentes con competencias digitales alcanzan un desarrollo profesional por encima de la media.

\section{Discusión y Conclusiones}

\begin{tabular}{|c|c|c|c|c|c|c|c|c|c|}
\hline \multicolumn{10}{|c|}{ Estimaciones de parámetro } \\
\hline & & \multirow[b]{2}{*}{ Estimación } & \multirow[b]{2}{*}{$\begin{array}{l}\text { Error } \\
\text { estándar }\end{array}$} & \multirow[b]{2}{*}{ Wald } & \multirow[b]{2}{*}{ gl } & \multirow[b]{2}{*}{ Sig. } & \multirow[b]{2}{*}{$\operatorname{Exp}(B)$} & \multicolumn{2}{|c|}{ confianza al $95 \%$} \\
\hline & & & & & & & & $\begin{array}{l}\text { Límite } \\
\text { inferior }\end{array}$ & $\begin{array}{l}\text { Límite } \\
\text { superior }\end{array}$ \\
\hline Umbral & {$[$ Pedag $=2]$} & -3.045 & 1.024 & 8.848 & 1 & .003 & .048 & -5.051 & -1.038 \\
\hline \multirow[t]{2}{*}{ Ubicación } & [Comp_Dig=2] & -2.234 & 1.053 & 4.503 & 1 & .034 & .107 & -4.296 & -.171 \\
\hline & [Comp_Dig=3] & $0^{a}$ & & & 0 & & & & \\
\hline \multirow{2}{*}{\multicolumn{2}{|c|}{ Pseudo R cuadrado }} & \multicolumn{2}{|c|}{ Cox Snell } & \multicolumn{2}{|c|}{ Nagelkerke } & \multicolumn{2}{|c|}{ McFadden } & & \\
\hline & & \multicolumn{2}{|c|}{0.077} & \multicolumn{2}{|c|}{0.114} & \multicolumn{2}{|c|}{0.071} & & \\
\hline Umbral & {$[$ Teleolo = 2] } & -.981 & .479 & 4.198 & 1 & .040 & .375 & -1.919 & -.043 \\
\hline \multirow[t]{2}{*}{ Ubicación } & [Comp_Dig=2] & -3.466 & .640 & 29.316 & 1 & .000 & .031 & -4.720 & -2.211 \\
\hline & [Comp_Dig=3] & $0^{a}$ & & & 0 & & & & \\
\hline \multicolumn{2}{|c|}{ Pseudo $R$ cuadrado } & \multicolumn{2}{|c|}{0.311} & \multicolumn{2}{|c|}{0.478} & \multicolumn{2}{|c|}{0.354} & & \\
\hline Umbral & [Deont = 2] & $-4.523 \mathrm{E}+00$ & .426 & 12.367 & 1 & .000 & .011 & -.836 & .836 \\
\hline \multirow[t]{2}{*}{ Ubicación } & [Comp_Dig=2] & -4.344 & 1.093 & 15.792 & 1 & .000 & .013 & -6.486 & -2.201 \\
\hline & [Comp_Dig=3] & $0^{a}$ & & & 0 & & & & \\
\hline \multicolumn{2}{|c|}{ Pseudo R cuadrado } & \multicolumn{2}{|c|}{0.275} & \multicolumn{2}{|c|}{0.529} & \multicolumn{2}{|c|}{0.439} & & \\
\hline
\end{tabular}

A partir de la obtención de los datos y su procesamiento, se obtuvo el coeficiente del seudo Rcuadrado, de Nagalkerke, donde el $24 \%$ del desarrollo profesional es explicado por las competencias digitales de los docentes y el $76 \%$ se debe a otros factores. Así también en cuanto a los resultados descriptivos, con respecto a las competencias digitales, el $78 \%$ de los docentes presentan un nivel regular Por tanto es estadísticamente sustentable señalar que la mayoría de los docentes Fuente: Elaboración propia (2018)

Los resultados de la Tabla 11 indican que el valor de significación estadística (sig. p_valor) sea menor a 0.05 , es que la ecuación de la regresión logística ordinal alcanza buen ajuste, (Agresti, 1990). Los coeficientes negativos de los estimadores hacen que el Odds Ratio (ExpB) sea menor a uno, y al no estar definida la unidad dentro del intervalo de confianza al 95\%; nos permite estadísticamente afirmar que al mejorar los niveles regulares de las competencias digitales que disponen de un nivel alto de competencia digital concordantes a lo que refiere, Esteve (2015) y el $22 \%$ un buen nivel de competencias digitales, ello permite corroborar la afirmación referida por García (2017) que se promueva el uso de las TIC, en la búsqueda y procesamiento de información, lo que nos indica que los docentes poseen cierto conocimiento en el uso y apropiación de las tecnologías, y por ende haber adquirido un mínimo de competencia digital.

Con respecto al desarrollo profesional, se obtiene 
que un $46 \%$ de los docentes percibe que existe un alto nivel, existe la necesidad de resaltar el uso de las estrategias implementadas en este campo del quehacer educativo teniendo como principal objeto de estudio al docente, por ello se hace necesario apostar por una formación del profesorado que asuma la relevancia de la competencia digital y que tome como punto de partida una adecuada comprensión de lo que supone ser un docente competente digitalmente. Aspecto que Enríquez (2014) precisa en su estudio que el docente está en un continuo desarrollo profesional, al ser este un proceso de crecimiento permanente y dinámico. En tal sentido los resultados de la investigación corroboran nuestro objetivo general, así como los resultados de los trabajos previos. Los datos permiten afirmar que existe correlación entre las competencias digitales docente y el desarrollo profesional, determinado por el Chi cuadrado $\mathrm{X} 2 \mathrm{c}=18.499$ con un 1 grado de libertad y el valor de significación estadística de p_valor 0.00 a un nivel de confianza del $95 \%$, por ende, el mejoramiento de la educación básica y la calidad de esta depende entre otros factores del manejo adecuado de las TIC y las competencias digitales de los profesores, (Vaillant, 2016).

Finalmente, a partir de los hallazgos se recomienda aunar esfuerzos y desde la academia preparar a los docentes en el dominio de herramientas básicas de tecnologías de información y comunicación y así desarrollar sus competencias digitales, logrando asi un impacto mayor en su exitoso desarrollo profesional, lo cual es un desafío constante y un asunto clave, con mayores exigencias y posibilidades de alcanzar niveles de excelencia en este siglo XXI. Así como, incorporar en el plan de estudios de los futuros profesores nuevos perfiles vinculados a la integración, dominio de las TIC y a su utilización en el ámbito educativo, que nos exigen los tiempos actuales; en referencia a lo que precisa el Ministerio de Educación, (2013), a través de talleres y/o formación continua, la misma que redundará en el desarrollo profesional y la mejora de praxis profesional en el aula.

Para futuros estudios se propone incluir aspectos sociodemográficos que verifiquen si estos tienen alguna incidencia en el desarrollo de sus competencias digitales y mejora su desarrollo profesional.

\section{REFERENCIAS BIBLIOGRÁFICAS}

Agresti, A. (1990). Categorical Data Analysis. New York: John Wiley \& Sons.

Almerich, G., Díaz-García, I., Cebrián-Cifuentes, S. \& Suaréz-Rodriguez, J. (2018) Estructura dimensional de las competencias del siglo XXI en alumnado universitario de educación. RELIEVE, 24(1), 1-21. https://doi.org/10.7203/ relieve.24.1.12548

Avín R.; Llanos L, Morales I., Santamarìa B. \& Soto Z. (2016) Dimensión pedagógica de las instituciones educativas. Universidad Pedagógica Nacional, México.

Ballester, M. \& Sánchez, J. (2011) La dimensión pedagógica del enfoque de competencias en educación obligatoria. Ensayos, 26, 17-34.

Bernal, C., Correa, A., Pineda, M.; Lemus, Fonseca, F. \& Muñoz, C. (2014). Fundamentos de la investigación. Primera edición. México: Pearson Educación.

https://doi.org/10.29097/2011-639X.169

Boris, M. (2009) La competencia digital, una propuesta. http://www.xtec.es/-bmir/

Caudillo, Y. (2016). Competencia Digital en el Proceso de Apropiación de las TIC en Jóvenes de Secundaria en el Estado de Sonora, México. Propuesta de Innovación Educativa para la Mejora de las Habilidades Digitales en el Aula. México. Recuperado de http://www.pics.uson.mx/doctorado/ wp-content/uploads/2018/02/Caudillo-Ruiz-Tesis-doctorado.pdf

Chapilliquen, M. (2016) Competencias digitales en estudiantes con diferentes estilos de aprendizaje, del séptimo ciclo de educación secundaria, desarrolladas a través de la red social educativa Edmodo en una institución educativa pública de la Unidad de Gestión Educativa Local Nº3, el año 2015. Pontificia Universidad Católica del Perú, Lima-Perú.

CNE-Consejo Nacional de Educación (2006) Proyecto Educativo Nacional al 2021. La educación que queremos para el Perú. Recuperado de http://repositorio.minedu.gob.pe/ bitstream/handle/123456789/304/166.\%20Proyecto\%20 Educativo\%20Nacional\%20al\%202021.\%20La\%20educaci $\%$ C3\%B3n\%20que\%20queremos\%20para\%20el\%20 Per\%C3\%BA.pdf?sequence $=1$ \&isAllowed $=y$

Colás, M., De Pablos, J. \& Ballesta, J. (2018) Incidencia de las TIC en la enseñanza en el sistema educativo español: una revisión de la investigación. https://doi.org/10.6018/ $\mathrm{red} / 56 / 2$

Colomer, J.; Hernández H. \& Ketil B. (2018) Competencia digital docente Perspectivas y prospectivas para una nueva escuela. Revista Comunicar. España Recuperado de http:// tesis.pucp.edu.pe/repositorio/handle/123456789/6744

Durán, M. C., Prendes, M.P.E. \& Gutiérrez, I. P. (2019). Certificación de la Competencia Digital Docente: propuesta para el profesorado universitario. RIED. Revista Iberoamericana de Educación a Distancia, 22(1), 187-205. https://doi. org/10.5944/ried.22.1.22069 
Competencia digital y desarrollo profesional de los docentes de dos instituciones de educación básica regular del distrito de Los Olivos, Lima-Perú

Elacqua, G., Hincapié, D., Vegas, E., \& Alonso, M. (2018) Profesión: profesor en América Latina. ¿Por qué se perdió el prestigio docente y cómo recuperarlo? Washington, D.C. BID. https://doi.org/10.18235/0001172

Enríquez, L. (2014) Concepciones y factores influyentes en el desarrollo profesional docente en España, Chile y Colombia en los últimos diez años Tesis magistral. Pontificia Universidad Católica del Perú. Recuperado de http://tesis.pucp. edu.pe/repositorio/handle/123456789/6744

Esteve, F. (2015) La competencia digital docente. Italia. Universitat Rovira i Virgili.

Esteve, F. (2016) Bolonia y las TIC: de la docencia $1.0 \mathrm{al}$ aprendizaje 2.0. La cuestión universitaria. Universidad Politécnica de Madrid. Recuperado de http://polired.upm.es/ index.php/lacuestionuniversitaria/article/view/3337

García, F. (2017) Competencias digitales en la docencia universitaria del siglo XXI (Tesis doctoral). España. Universidad Complutense de Madrid

García, R., Verde, I \& Vásquez V. (2011). ¿Por qué es necesario trabajar la dimensión ética en la docencia? Universidad de Barcelona. España.

Gonzalo, J. \& Ruiz, M. (2013) El código deontológico de la profesión docente: evolución y posibilidades. Recuperado de: file://C:/Users/maestria-54/Downloads/Dialnet-ElCodigoDeontologicoDeLaProfesionDocente-4406388.pdf

Hernández, R., Fernández, C. \& Baptista, P. (2014). Metodología de la Investigación. México: Mc Graw Hill Education

Hosmer, D. \& Lemeshow, S. (2000). Applied Logistic Regression. New York: John Wiley \& Sons. https://doi. org/10.1002/0471722146

León, P. (2011). Efectos de la estrategia didáctica funcional basado en las TICS sobre el conocimiento procedimental del trabajo de investigación de los estudiantes de post grado de la Universidad César Vallejo filial Pasco V y Ayacucho VIII. 2009. Tesis de Doctorado en Educación. Universidad César Vallejo, Lima Perú

Lion, C. (2012). Desarrollo de competencias para portales de la región. Buenos Aires: RELPE.

Lizcano, R. et al. (2017) Competencias Digitales, Innovación y Prospectiva Colombia. Editorial CIMTED.

Marc, M. (2015). La competencia digital docente. Análisis de la autopercepción y evaluación del desempeño de los estudiantes universitarios de educación por medio de un entorno 3D, Tesis doctoral. Univertitat Rovira I Virgili

Marcelo, C. (2009). La evaluación del desarrollo profesional docente: de la cantidad a la calidad. Universidad de Sevilla. España

Marqués, P. (2014) Competencias docentes en la Era Internet (v. 6.0) Uruguay DIM-EDU.

Mineduc-Ministerio de educación de Chile. (2016) 10 claves sobre el desarrollo profesional docente. Centro UC. Chile
Minedu-Ministerio de Educación (2013). Marco del buen desempeño docente. Lima Perú.

Minedu-Ministerio de educación del Perú, (2016) El impulso de una carrera. Política de revalorización docente en el Perú. Ministerio de Educación del Perú.

Ministerio de Educación Cultura y Deporte-MECD (2017). Marco común de competencia digital docente V 2.0. INTEF. Gobierno de España.

Ministerio de Educación Nacional (2013) Competencias TIC para el desarrollo profesional docente. Oficina de Innovación Educativa con Uso de Nuevas Tecnologías, Ministerio de Educación Nacional, gobierno de Colombia.

Ministerio de Educación y Cultura - MEC (2013) Desarrollo Profesional Docente y Mejora de la Educación. Informe País Universidad de la República Uruguay. MEC. ANEP. UdelaR

Montalvo, A. (2012) Visión teleológica de la enseñanza. Recuperado de: file://C:/Users/maestria-54/Downloads/Dialnet-VisionTeleologicaDeLaEnsenanza-4679768\%20(1).pdf

Osorio, A. (2016). El desarrollo profesional docente en educación básica primaria. Revista latinoamericana de Estudios Educativos, 12(1).

Prendes, M., Gutiérrez, I. \& Martínez, F. (2018). Competencia digital: una necesidad del profesorado universitario en el siglo XXI. RED. https://doi.org/10.6018/red/56/7

Sámano, G.; Reyes, G. \& Robles, H. (2018) Programa de alfabetización digital para formadores de docentes. Recuperado de http://www.rediech.org/ojs/2017/index.php/recie/ article/view/340/432

Trillo, F; Nieto, J.; Martínez, B. \& Escudero. J. (2017) El Desarrollo Profesional y la Colaboración Docente: Un Análisis Situado en el Contexto Español de las Tensiones y Fracturas Entre la Teoría y la Práctica. https://doi.org/10.14507/ epaa. 25.3316

UNESCO. (2010) Towards Inclusive Knowledge Societies. Recuperado de http://uis.unesco.org/sites/default/files/ documents/towards-inclusive-knowledge-societies-a-review-of-unescos-action-in-implementing-the-wsis-outcomes-inclusive-knowledge-societies-wsis-communicationict-2010-en.pdf

Vaillant, D. (2016) El fortalecimiento del desarrollo profesional docente: una mirada desde Latinoamérica. Journal of supranational policies of education.

Valdivieso T., \& Ángeles M. (2016) Competencia digital docente: ¿¿Dónde estamos? Perfil del docente de educación primaria y secundaria. El caso de Ecuador.

Valdivieso-Guerrero, T. (2013) Modelo de competencias digitales y estándares de formación aplicables a docentes del nivel de educación general básica de Latinoamérica. EDUTEC.

Valencia, T. \& Serna, A. (2016). Competencias y estándares TIC. Dimensión pedagógica. Pontificia Universidad Javeriana - Cali. Colombia

Vara, A (2015). Siete pasos para elaborar una tesis. Perú: 
Editorial Macro.

Vargas-D Uniam, Chumpitaz-Campos, Suárez-Díaz \& Badia (2014) Relación entre las competencias digitales de docentes de educación básica y el uso educativo de las tecnologías en las aulas. Profesorado, 18 (3), 361-376.

Veas, J. (2016) Sistema de desarrollo profesional docente. CPEIP. Chile

Véliz, C. (2014). Estadística para la administración y los negocios. Edit. Pearson, Pontificia Universidad Católica del Perú - CENTRUM. Lima -Perú.

Zavala. D.; Muñoz. K, \& Lozano. E, (2016) Un enfoque de las competencias digitales de los docentes. Revista Publicando, 3(9). 
Competencia digital y desarrollo profesional de los docentes de dos instituciones de educación básica regular del distrito de Los Olivos, Lima-Perú

\section{Anexo I}

\section{CUESTIONARIO SOBRE COMPETENCIA DIGITAL}

\section{Instrucciones:}

Estimado docente, la presente encuesta tiene el propósito de recoger información sobre la competencia digital. Mucho le agradeceré marcar con un aspa "X" en el recuadro que corresponda según su percepción. Esta encuesta tiene el carácter de anónimo, y su procesamiento será reservado, por lo que le solicitamos sinceridad en las respuestas.

\begin{tabular}{cccc}
\hline 1 & 2 & 3 & 4 \\
\hline Nunca & A veces & Muchas veces & Siempre \\
\hline
\end{tabular}

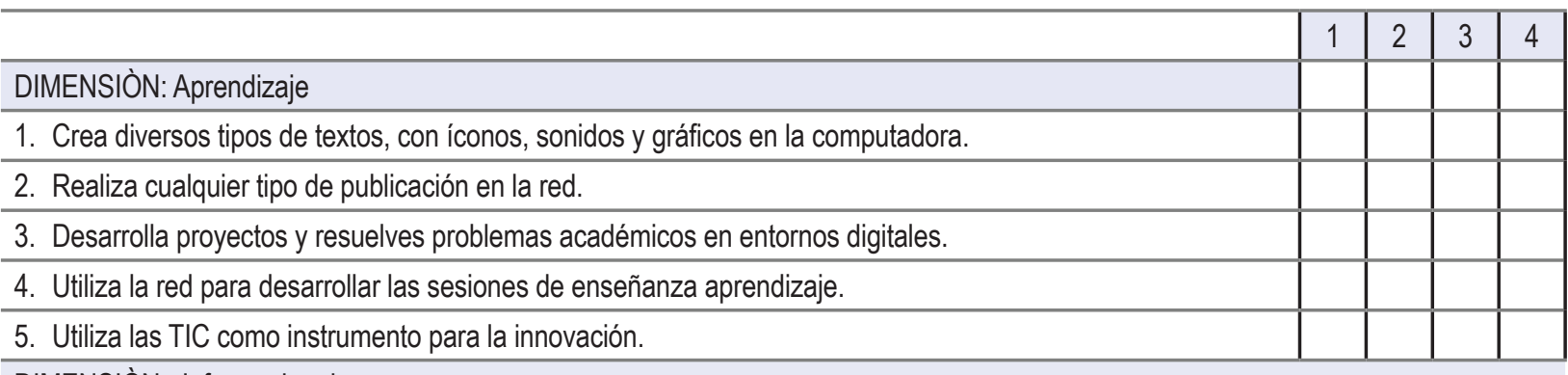

DIMENSIÒN : Informacional

6. Usa sistemas informáticos para acceder a información, recursos y servicios.

7. Utiliza diferentes fuentes de búsqueda según el tipo y el formato de la información: texto, imagen, datos numéricos, mapa, audiovisual y audio

8. Guarda, archiva y recupera la información en Internet.

9. Conoce herramientas y recursos para la buena gestión del conocimiento en ámbitos digitales.

10. Evalúa la utilidad de la información, los recursos y los servicios disponibles

DIMENSIÒN : Comunicativa

11. Se comunica mediante dispositivos digitales.

12. Verifica la calidad y el contenido de la comunicación atendiendo a las necesidades propias y de los demás.

13. Utiliza herramientas de elaboración colectiva de su conocimiento en tareas y proyectos educativos

14.Participa proactivamente en entornos virtuales de aprendizaje, redes sociales y espacios colaborativos.

DIMENSIÒN : Cultura digital

15. Contribuye al aprendizaje mutuo con herramientas digitales.

16. Orienta adecuadamente la identidad digital en Internet.

17. Actúa de forma legal respecto a los derechos de propiedad del software

18. Respeta los diferentes ámbitos de propiedad de los contenidos digitales.

19. Reflexiona sobre la dimensión social y cultural de la sociedad del conocimiento.

20. Propicia el ejercicio responsable de la ciudadanía digital.

DIMENSIÒN : Tecnológica

21. Utiliza con eficacia los dispositivos informáticos propios de las TIC.

22. Utiliza las funciones de navegación en dispositivos informáticos en Internet.

23. Apoya en la configuración del software de la institución educativa.

24. Instala, actualiza y desinstala software o dispositivos informáticos.

25. Cuida de los dispositivos, el software y los contenidos o servicios digitales empleados. 


\section{ANeXo 2}

\section{CUESTIONARIO SOBRE DESARROLLO PROFESIONAL}

\section{Instrucciones:}

Estimado docente, la presente encuesta tiene el propósito de recoger información sobre la el desarrollo profesional. Mucho le agradeceré marcar con un aspa "X" en el recuadro que corresponda según su percepción. Esta encuesta tiene el carácter de anónimo, y su procesamiento será reservado, por lo que le solicitamos sinceridad en las respuestas.

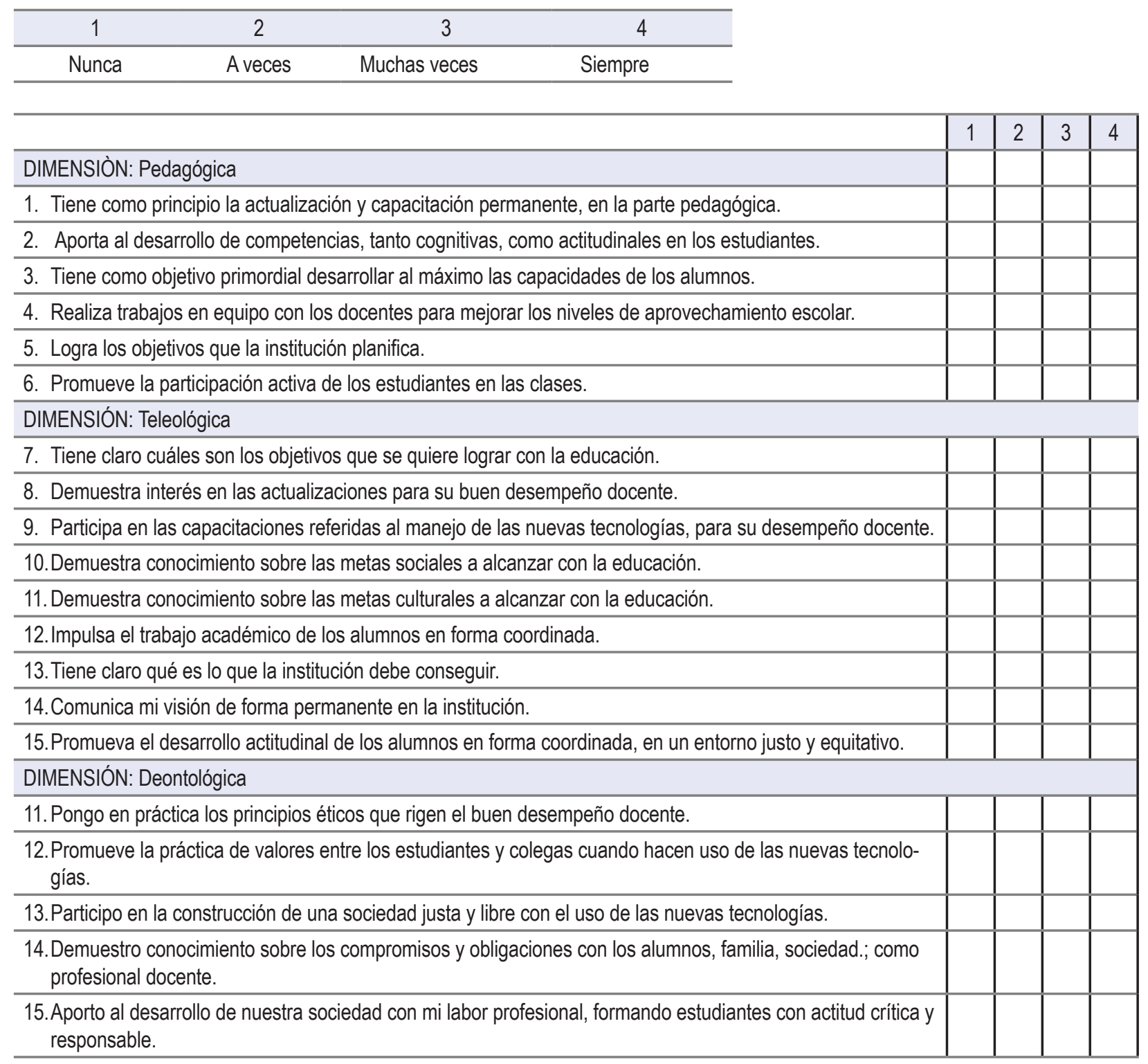


Competencia digital y desarrollo profesional de los docentes de dos instituciones de educación básica regular del distrito de Los Olivos, Lima-Perú

\title{
Anexo 3 \\ TÉRMINO DE CONSENTIMIENTO ÉTICO LIBRE Y CLARO
}

La investigación se titula "Competencias digitales y el desarrollo profesional docente de EBR", de autoría de un equipo de investigadores de la Universidad César Vallejo, Filial Lima, Campus Lima Norte, teniendo como objetivo central: establecer la relación de las variables de estudio.

Los instrumentos a ser aplicados en el estudio cuantitativo permitirán establecer los niveles alcanzados por los docentes en las dimensiones de las variables estudiadas y establecer la relación entre los datos obtenidos de las variables. La información brindada tiene carácter confidencial garantizado; se le pide poner su nombre en cada instrumento para identificar que ambos pertenecen a la misma persona. Además, responder en forma individual y contestar siempre cada ítem.

La evaluación tiene una duración de media a una hora, durante la evaluación se respeta su rechazo en participar o retirar su consentimiento, dado que su participación es voluntaria.

Lima, 15 de abril del 2018

\author{
Evaluado (o) \\ Evaluador (a) \\ Nombre del evaluado (a) \\ Nombres de Investigadores \\ DNI: \\ DNI: \\ Universidad César Vallejo \\ Filial Lima Norte
}




\title{
Plataforma de recursos educativos abiertos para la formación de capital humano en pymes
}

\section{Platform of open educational resources for the training of human capital in SMEs}

\author{
María Dolores Martínez Guzmán ${ }^{1}$ \\ https://orcid.org/ 0000-0003-4523-4655 \\ Dámaris Chávez Maza² \\ http://orcid.org/ \\ Marcela Rojas Ortega ${ }^{3}$ \\ https://orcid.org/0000-0003-1246-5051 \\ Instituto Politécnico Nacional, México
}

Recibido: 10-01-2019

Aceptado: 13-04-2019

\section{Cita Recomendada}

Martinez, M., Chávez, D. \& Rojas, M. (2019) Plataforma de recursos educativos abiertos para la formación de capital humano en pymes. Hamut'ay, 6(1), 71-81.

http://dx.doi.org/10.21503/hamu.v6i1.1575

\section{RESUMEN}

Los cambios que se han ido dando a nivel global en la formación del capital humano en el ámbito laboral ha conllevado a que las empresas utilicen estrategias innovadoras que implican una apropiación de las tecnologías en su recurso humano. Por lo que en este estudio se describe la implementación de los Recursos Educativos Abiertos en una plataforma diseñada para la formación de capital humano de las pymes de la ciudad de México, siendo estas las variables de estudio. Se muestra los resultados del Recurso Educativo Abierto desarrollado en una plataforma tecnológica, en su primera fase.

Se tuvo como objetivo describir la fase diagnóstica de la plataforma, la cual ha permitido realizar las tres etapas posteriores de la misma relacionada: a. Diseño, b. Aplicación y c. Validación de la plataforma REA. El estudio fue de tipo exploratorio, ya que se quería conocer cuál era el interés de los usuarios en el uso de este tipo de recurso y descriptivo al permitir detallar el procedimiento que se realizó antes del desarrollo de la plataforma, utilizando para ello un método cuantitativo de recopilación de datos. La muestra estuvo compuesta por 97 empresarios del sector servicios de la Delegación Tlalpan de la Ciudad de México. Los resultados permitieron obtener información relevante para entender la problemática que expresaron los empresarios, de acuerdo a sus respuestas en la encuesta, y la necesidad de utilizar como herramienta los Recursos Abiertos de la Plataforma Tecnológica REA, para formación de capital humano en temas relacionados con la permanencia de su empresa en el mercado.

1 Docente-investigadora del Instituto Politécnico Nacional (IPN), ESCA Tepepan, México. En la línea de investigación Gestión de Conocimiento y Tecnologías de la Información y comunicación en las organizaciones. E-mail: lolita.martinezg@gmail.com

2 Docente-investigadora del Instituto Politécnico Nacional (IPN), ESCA Tepepan, México. En la línea de investigación de Tecnologías de la Información y comunicación para la formación de recursos humanos. E-mail: damaris.mkt.ipn@gmail.com

3 Docente-investigadora del Instituto Politécnico Nacional (IPN), ESCA Tepepan, México. En la línea de investigación educativa en las carreras de negocios. E-mail: mrojaso7@hotmail.com 
Palabras Clave: Recurso Educativo Abierto, tecnologías, capital humano, formación empresarial, pymes.

\begin{abstract}
The changes that have taken place globally in the training of human capital in the workplace have led companies to use innovative strategies that imply an appropriation of technologies in their human resources. So this study describes the implementation of Open Educational Resources in a platform designed for human capital training of SMEs in Mexico City, being these the study variables. It shows the results of the Open Educational Resources developed in a technological platform, in its first phase.

The aim was to describe the diagnostic phase of the platform, which has enabled its three subsequent stages in relation to: a. Design, b. Application and c. Validation of the REA platform. This was an exploratory study since it aimed to know what was the interest of the users in the use of this type of resources; it was also descriptive, since it allowed to detail the procedure that was carried out before the development of the platform, using a quantitative method of data collection. The sample consisted of 97 entrepreneurs from the services sector of the Tlalpan Delegation of Mexico City. The results allowed to obtain relevant information to understand the problems expressed by the entrepreneurs, according to their responses in the survey; and the need to use the Open Resources of the REA Technology Platform as a tool, to train human capital in topics related to the permanence of their company in the market.
\end{abstract}

Keywords: Open educational resource, technologies, human capital, business training, SMEs.

\section{INTRODUCCIÓN}

La formación de capital humano ha sido una constante en el ámbito empresarial, ya que tener personal reclutado con un alto nivel académico, no solo beneficia al trabajador sino también al sector empresarial, por estar estos capacitados con los últimos avances de la ciencia y las tecnologías. Pero la realidad nos lleva a reflexionar, porque en pleno siglo XXI continuamos con déficit de capital humano formado de manera idónea para afrontar estos retos de este siglo, es una problemática que afecta a la industria y al mundo en general, (Román, 2013, Cámara de Comercio, 2017).

Dentro de este contexto las Pequeñas y Medianas Empresas (pymes) no están exentas, al constituir el sector más dinámico de las economías, incentivan la competencia, la generación de ideas, productos y servicios, en América Latina, consti- tuyen entre $95 \%$ al 99\% de sus economías (C.E. INEGI, 2015, p. 15), las cuales están conformadas por capital humano. Sumado a esto, los escenarios que enfrentan las organizaciones se encuentran llenos de incertidumbre, debido, por un lado, a la competencia directa de las grandes organizaciones y por otro, a la falta de formación del capital humano en aspectos de cultura tecnológica, entre otros aspectos relacionados con la gestión de la organización.

En la Ciudad de México, la problemática de formación de capital humano, es un tema muy complejo y requiere un profundo análisis, debido a que estamos viviendo en una economía llena de incertidumbre donde el conocimiento es la base para realizar los negocios con creatividad e innovación, los conocimientos deben adquirirse más rápido, antes que la competencia para lograr la mayor per- 
manencia en el mercado globalizado. De lo cual no están exentas las pymes en México, ya que estas poseen una limitada cultura en tecnologías, no poseen la cantidad suficiente de personal calificado para gestionar las tecnologías de la información y comunicación (TIC), (Diaz, 2017).

En este orden de ideas, Cueto, 2013; De Marco, 2013, mencionan que para ir incrementando los niveles de productividad del país se requiere incentivar la formación del capital humano con el uso adecuado de las TIC, ya que esta ha generado cambios en los procedimientos de trabajo. Para Mejía (2017) la aplicación de las TIC en el capital humano es uno de los factores que inciden en el crecimiento económico, ya que las tecnologías impactan en todas las actividades humanas, empresariales y en la sociedad en general. Asimismo, el mundo empresarial donde están inmersas las pymes se apoya de las TIC para efectivizar sus procesos productivos, abaratar costos de producción, ampliar su mercado a través de redes sociales para tener un mayor número clientes y proveedores, (Gálvez, Riascos \& Contreras, 2014). Desde esta perspectiva se consideró necesario desarrollar recursos digitales, con la finalidad de impartir contenidos en temáticas que apoyaran a la formación de los empresarios de las pymes de la Delegación Tlalpan; debido a las dificultades de espacio y tiempo que tienen para realizar una actualización continua de manera presencial como lo exige el mercado laboral.

Siendo el objetivo de este estudio el describir los resultados del diagnóstico de necesidades de formación y el uso de herramientas tecnológicas para desarrollar contenidos digitales a través del diseño y desarrollo de la interfaz que integra los Recursos Educativos Abiertos en la plataforma tecnológica REA como soporte en la formación de empresarios de las pymes de la delegación Tlalpan de la Ciudad de México.

Delimitando como nuestras variables Recursos Educativos Abiertos en Plataformas Tecnológicas (Variable independiente), la cual es descrita de manera general, ya que el estudio se centra en presentar la fase diagnóstica, cuyos resultados han servido para el diseño y desarrollo de la plataforma REA. Y formación en capital humano (Variable depen- diente), es en la que se quiere incidir si la Plataforma tiene una influencia en mejorar el perfil de los empresarios de la pyme, lo cual será presentado posteriormente en otra publicación, porque esta fase se encuentra en aplicación.

\section{Recursos Educativos Abiertos en Plataformas Tecnológicas}

La incursión de la TIC en el ámbito empresarial que incluyen desde recursos informáticos hasta plataformas de asistencia y capacitación han ido en aumento, siendo utilizadas por las pymes, pues puede apoyar al aprendizaje, (Hirsch, Almaraz \& Ríos, 2015). Al utilizar las herramientas tecnológicas vinculadas con Recursos Educativos Abiertos (REA) contribuyen a mejorar el proceso de formación, debido a que los REA forman parte del aprendizaje soportados por TIC, ya que brindan la facilidad de ser ensamblados, cambiados y/o adaptados, así como ser reutilizados, embebidos o referenciados en otras plataformas y de acuerdo a las características del usuario, es de acceso público y con una amplitud de contenidos digitales en los que pueden estar inmersos texto, audio, imágenes, juegos educativos, MOOC y una diversidad de materiales, (Reyes, Juárez, Martínez \& Sánchez, 2017; Guzmán \& Motz, 2013)

Tomando como base el contexto actual descrito en el que se desarrollan las pymes en la Ciudad de México, el enfoque teórico en el que se sustenta el desarrollo de la Plataforma REA, se basa en las teorías constructivistas sobre el aprendizaje, a través de dicho enfoque, se fundamenta el diseño de contenidos digitales, así como la selección de herramientas digitales para el diseño instruccional de estos recursos virtuales para impartir cursos de capacitación en el lugar de trabajo para formar al capital humano. La arquitectura e interfaz de la plataforma REA, han sido desarrolladas bajo el enfoque de aprendizaje colaborativo y trabajo colaborativo apoyado en la computadora; el primero está relacionado con el ámbito educativo, el segundo, a ambientes de trabajo profesional que buscan el aprendizaje de técnicas y procedimientos específicos. Ambos están basados en la idea de que los sistemas electrónicos pueden facilitar los procesos y la dinámica de aprendizaje, en formas 
que no son realizables por medios de comunicación presenciales.

Por lo descrito anteriormente, se integran las bases conceptuales del conocimiento distribuido señaladas por Hollan \& Kirsh, 2000; Gibbons, Nelson \& Robert, 1998, dichos autores, proponen aplicar nuevos paradigmas de enseñanza que rompan con los límites impuestos por un enfoque tradicional de obtención de la información y tomar como base de posibilidades que ofrecen los medios electrónicos de comunicación e información. Se consideran como elemento fundamental los desarrollos tecnológicos, como Sistemas de Apoyo Electrónico al Rendimiento (Electronic Performance Support Systems, EPSS por sus siglas en inglés) o como los sistemas de disposición de recursos, pensados como objetos de aprendizaje, para apoyar una gran variedad de necesidades de educación y adiestramiento. Dichos recursos tienen la capacidad de potenciar el rendimiento y el aprendizaje, (texto, vídeo, pictogramas, gráficas, etc.), están organizados en conjuntos de datos, que llevan un mensaje relacionado con un tópico o tarea específicos. Estos sistemas ofrecen situaciones o ambientes flexibles de desarrollo o de creación de productos de enseñanza, en los que el significado de un recurso digital se define continuamente, situándolo en diferentes contextos, para satisfacer las necesidades del individuo que está en proceso de construcción de conocimiento.

\section{Diseño de la Arquitectura de la Plataforma REA para la Formación de Capital Humano en pymes}

Por lo que en este artículo se presenta la primera etapa que comprende la fase diagnóstica de esta tercera versión de la plataforma REA, la cual se ha ido migrando de dos versiones anteriores, iniciándose el proyecto de investigación en el 2015, en el Instituto Politécnico Nacional de México.

Fase diagnóstica, en la cual se hizo un levantamiento de información a 97 empresarios para unificar criterios y estándares, datos que sirvieron para elaborar el diseño y el desarrollo tecnológico REA, que se encuentra en prueba. Los hallazgos encontrados y que permitieron implementar la plataforma REA versión 3, se describen en la sección de resultados.
Fase de diseño y desarrollo de la plataforma, fueron una diversidad de herramientas que se integraron en el diseño, para que este recurso sea dinámico y acorde a las tendencias, como se puede visualizar en la secuencia de figuras tomadas de la plataforma. El menú se construyó para que los usuarios desarrollaran contenidos y posteriormente se muestren en un buscador por categorías, tal como lo muestra la figura 1 . El diseño de esta nueva plataforma REA 2018-2019, ha integrado como propuesta para su diseńo, herramientas digitales para cursos MOOC en una de sus secciones.

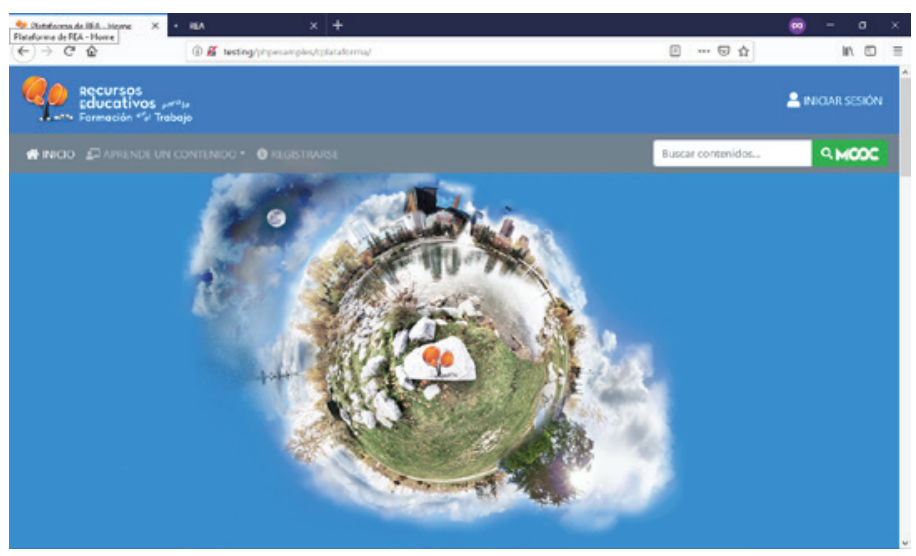

Figura 1

Plataforma REA 2018-2019

Fuente: Elaboración Propia (2018)

Un aspecto importante de esta tercera versión de la plataforma, es que alberga cursos MOOC, cuya característica es que son cursos masivos, el usuario es quien se registra directamente sin necesidad de depender de algún administrador o soporte técnico de alguna plataforma educativa. El registro en plataforma se muestra en la figura 2 .

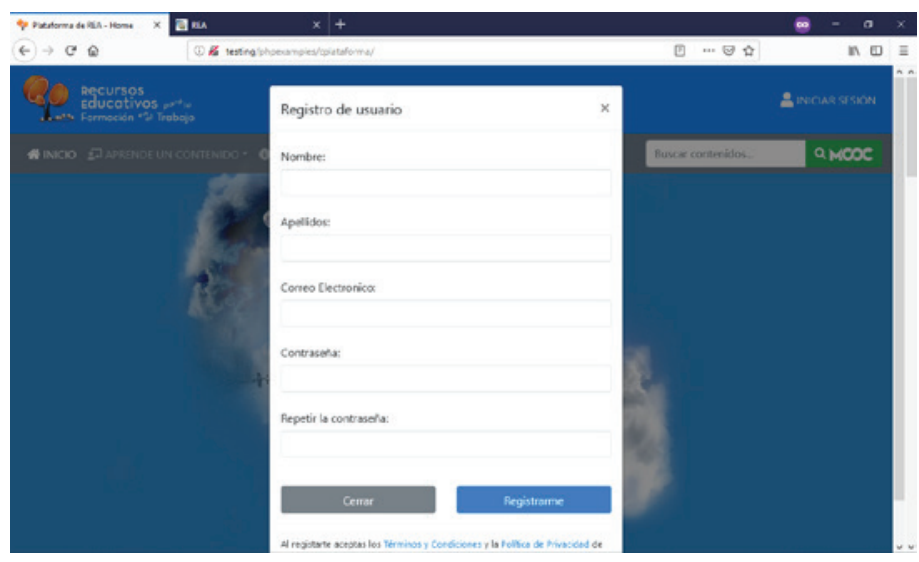

Figura 2

Registro en plataforma REA para cursos masivos MOOC

Fuente: Elaboración Propia (2019) 
Otra de las ventajas de esta tercera versión de la plataforma REA fue diseñada para que el usuario desarrolle de forma autónoma, y que el mismo sea el que haga un auto-monitoreo en el cumplimiento del objetivo planteado para cada tema.

\section{La Formación de capital humano}

En México y en el mundo se está desarrollando la cuarta revolución industrial, que se manifiesta en una gran complejidad e interconexión entre múltiples sectores, los cuales deben trabajar conjuntamente para entender mejor las tendencias emergentes (Schwab, 2016, p. 14). En este contexto, radica la importancia de la creatividad y la capacidad del capital humano para adaptarse y modificar los modelos de negocios y crear nuevos servicios en sus organizaciones para lograr un rendimiento y permanencia en esta nueva economía.

Vivimos en una economía basada en el conocimiento que surgió a partir de la tercera revolución industrial, donde el capital humano es la fuente de la riqueza que tienen las organizaciones. Siendo este capital humano al que debemos dedicar los esfuerzos de formación que garanticen la capacidad de creatividad e innovación continua, para emprender nuevos servicios y nuevos modelos de negocios. (Martínez, 2017, p. 222).

A partir de lo anterior, diversos estudios han permitido conocer la situación por la que atraviesan las pymes en México; Cueto (2013) plantea que entre los aspectos que más se enfrentan son, la preocupante tasa de mortalidad en este sector y el ciclo de vida que no va más allá de cinco años y solo el diez por ciento logran permanecer, es decir, solamente 2 de cada 100 empresas creadas logran mantenerse activas en el mercado. Es en este sentido que, la consolidación y madurez de una empresa sólo se logra a través de establecer estrategias que permitan desarrollar factores internos estratégicos como la administración del conocimiento, la innovación tecnológica en sus procesos y sus productos, el desarrollo del liderazgo en capital humano, la generación de estrategias de calidad y generar valor para ser más competitivas. Esto se fundamenta con datos de México Bursátil, 2013, en el que se muestra que el promedio de vida de las empresas ha aumentado a 7.7 años en prome- dio nacional (C.E. INEGI, 2015), esto se debe a las estrategias que se han seguido para consolidarlas en los mercados globales, sin embargo, aún las micro-empresas siguen siendo el mayor porcentaje de las Mipymes, es decir, las micro-empresas no logran convertirse en pequeñas empresas y posteriormente a medianas organizaciones, debido a los factores antes mencionados.

Padilla, Quintero \& Sales (2015) plantean que la formación del capital humano es un reto ineludible para la innovación empresarial, debido que los constantes cambios y la rapidez en que se modifican los negocios dejan fuera del plano la capacitación, existe una necesidad de formación del capital humano y existe una oportunidad de crear nuevos esquemas que fortalezcan las capacidades de las empresas en diversos ámbitos relacionados a los negocios.

Por otra parte, si tomamos como base los resultados que arroja el quinto informe de las tendencias globales de capital humano publicado por Deloitte, se habla de un panorama enteramente digital en donde se vive la era de la disrupción, esto significa que las organizaciones se ven en la necesidad de reinventar estrategias para mejorar y optimizar los procesos que impacten en mejores productos y servicios. Se trata de una oportunidad para crear plataformas, procesos y herramientas que continúen evolucionando y manteniendo su valor con el tiempo. Deloitte (2017). En dicho estudio se demuestra la brecha tan amplia que existe entre la productividad y el acelerado cambio tecnológico, esto significa que las empresas que no empleen la tecnología en la optimización de sus procesos, están destinadas a desaparecer del mercado.

Por lo anteriormente expuesto, es importante proveer a las pymes de esquemas de formación de capital humano, en el que no lo consideren un gasto, sino una inversión, por esta razón es importante llevar al ámbito del trabajo la actualización del conocimiento, lo cual repercutirá en el aumento de la productividad y por ende el crecimiento económico, (Kido, A. \& Kido, T, 2015; Hirsch, Almaraz $\&$ Ríos, 2015). Una de las estrategias que permite al capital humano a continuar con su formación sin interferir con otras actividades ya programadas y gestionar su tiempo y estilo de aprendizaje en 
los trabajadores, es a través de recursos educativos abiertos implementados en plataformas tecnológicas amigables y que atiendan las necesidades inmediatas para resolver problemas que en el día a día se enfrentan. Esto implica, facilitar la formación atendiendo a necesidades de espacio y tiempo del usuario, es decir, que las personas se sientan con la libertad de llevar su formación, sin necesidad de trasladarse a un espacio específico y con horarios rígidos que no le ayuden a vivir la formación como un proceso de aprendizaje que le beneficie en su desarrollo personal y laboral.

Todos los nuevos desarrollos y tecnologías tienen una característica clave en común: aprovechan el poder de penetración que tienen la digitalización y las tecnologías de la información... La revolución digital está creando enfoques radicalmente nuevos que revolucionan la forma en que los individuos e instituciones participan y colaboran entre sí. (Schwab, 2016. p.21)

\section{Materiales y Métodos}

\section{Participantes}

Los sujetos que participaron en la investigación fueron 97 empresarios, quienes lo hicieron de manera voluntaria, pertenecientes a los diversos sectores de servicios, de la Delegación Tlalpan de la Ciudad de México que constituyen el universo de la población. El tipo de muestreo fue no probabilístico y la selección de la muestra fue por conveniencia, atendiendo a la disponibilidad de los sujetos e interesados en participar en el estudio y su deseo de ser formado a través del uso de los Recursos Educativos Abiertos de la Plataforma.

\section{Instrumento}

Se utilizó el método cuantitativo de recopilación de información para la etapa de diagnóstico a sujetos de estudio, quienes tuvieron un acercamiento al uso de los Recursos Educativos Abiertos de la Plataforma, a través de un cuestionario de respuestas de opción múltiple y de escala Likert, mediante el cual se obtuvo información sobre aspectos sociodemográficos, aspectos de su formación en cuestiones tecnológicas, así como las preferencias sobre el uso de tecnologías para su formación en el trabajo, dicho cuestionario fue validado por la técnica de juicio de expertos en el que se realizó un análisis profundo del contenido de cada uno de los ítems, teniendo una validez en promedio del $90 \%$ por los cinco expertos, con el levantamiento de pequeñas observaciones a los ítems .

Los resultados obtenidos en este estudio sirvieron como base para desarrollar las etapas de diseño y aplicación de la Plataforma REA.

\section{Tipo y diseño}

Se realizó una investigación de campo de tipo cualitativa, exploratoria-descriptiva presentada como diagnóstico, y con la cual se plantea el desarrollo de la Plataforma en Recursos Educativos Abiertos para ser utilizada en la formación de capital humano en pymes del ramo de empresas de servicios de la Delegación Tlalpan de la Ciudad de México, para aumentar su permanencia en el mercado y mejorar sus productos y servicios.

\section{Procedimiento}

A continuación, se describe las dos fases que integra los resultados en este estudio, quedando para estudios subsecuentes la aplicación y validación de la tercera versión en el desarrollo de la Plataforma Tecnológica en cuanto a la Formación de Capital Humano a pyme a través de contenidos digitales, entendidos como Recursos Educativos Abiertos (REA) para la Formación en el Trabajo, son:

\section{Fase Diagnóstico}

- Estudio Diagnóstico de los usuarios de la plataforma. - Participaron 97 sujetos de estudio, identificados como empresarios/directivos de las pymes de la Delegación Tlalpan de la Ciudad de México, lo cual hace una diferenciación con la publicación de estudios de versiones anteriores por el tipo de muestreo utilizado. En este estudio se presenta esta primera fase diagnóstica.

- Fase diseño de la plataforma para integrar MOOC 
1. En el proyecto de la nueva plataforma REA 2018-2019 se diseña en una arquitectura más estable para el desarrollo de contenidos, con la intención de albergar cursos MOOC que permita alojar a más usuarios en corto tiempo.

2. La versión 3 de la plataforma se creó para atender la formación de capital humano en las pymes y su formato se realizó de la misma manera en que se concibió la plataforma REA en sus versiones 1 y 2 .

3. La versión 3 también contiene categorías según la departamentalización clásica de la empresa.

4. Cada Contenido Digital mantiene en su estructura: título del contenido, objetivo de aprendizaje, contenido digital, actividad y evaluación del aprendizaje, al igual que la versión 1 y2.

5. El desarrollo de la Arquitectura de la plataforma tecnológica, se modifica en el diseño de la interfaz, con una estructura de base de datos que permite almacenar, registrar, manipular y editar contenidos digitales de manera más amigable y de fácil acceso, que las versiones anteriores.

6. El desarrollo de los administradores de contenido, conservan la categoría y campos acorde a la estructura de metadatos igual que la versión 1 y 2 de la plataforma, esto con el propósito de controlar y dar seguimiento a la subida de contenidos digitales, empleando estándares SCORM, para organizar y monitorear las actividades.

\section{Consentimiento informado o Confidencialidad}

El consentimiento para la participación de los sujetos participantes, se obtuvo a través de pláticas informativas, asegurando la confidencialidad de su participación al mencionar que la información obtenida es utilizada únicamente para fines de investigación y académicos.

En relación al uso de la Plataforma REA como es de desarrollo propio del equipo de investigación, no hubo necesidad de pedir consentimiento en su uso para fines de investigación.

\section{Resultados}

Fase diagnóstica

A continuación, se muestran los resultados obtenidos al aplicar el cuestionario a los posibles usuarios de la Plataforma REA, en cuanto a aspectos sociodemográficos, su formación en cuestiones tecnológicas, necesidades de capacitación, así como las preferencias sobre el uso de tecnologías para su formación en el trabajo.

\section{Datos Generales}

La evaluación de la fase diagnóstica se realizó con los empresarios del sector servicios, que estaban interesados en formar a su capital humano a través de la Plataforma REA para crear nuevos servicios. En la figura 3 se muestra en porcentajes el género de los empresarios participantes en el estudio.

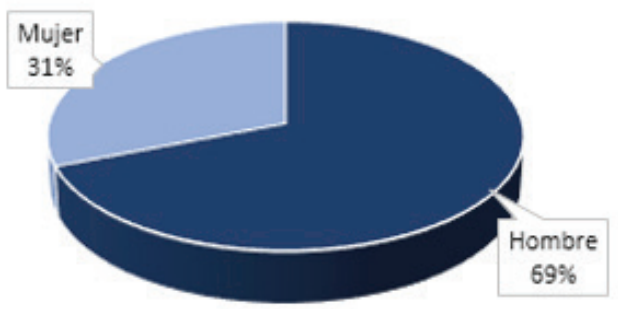

Figura 3

Género de la muestra.

Fuente: Elaboración Propia (2018)

La participación del género masculino (69\%) en la dirección de las organizaciones, sigue siendo mayor, sin embargo, ha existido un aumento en la participación de la mujer (31\%), a diferencia del anterior estudio realizado en el proyecto SIP 20150905, (Martínez \& Chávez, 2016).

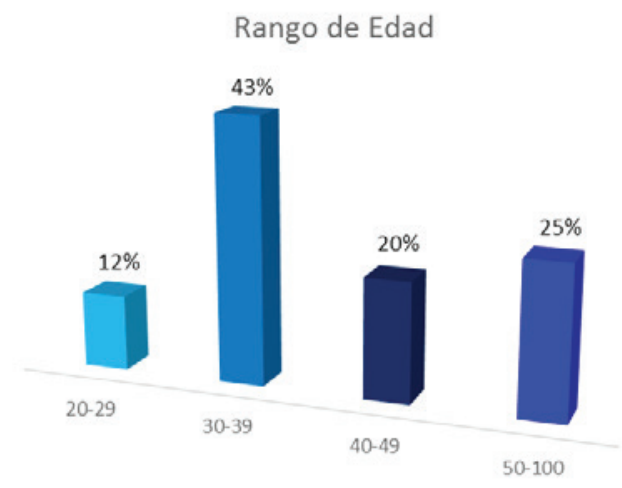

Figura 4

Rango de edades de la muestra.

Fuente: Elaboración Propia (2018) 
Otro factor importante a considerar es la edad de los empresarios, debido a que atraviesan por una etapa de transición, debido a que tienen en promedio entre 30 a 40 años de edad (43\%), como se observa en la figura 4 .

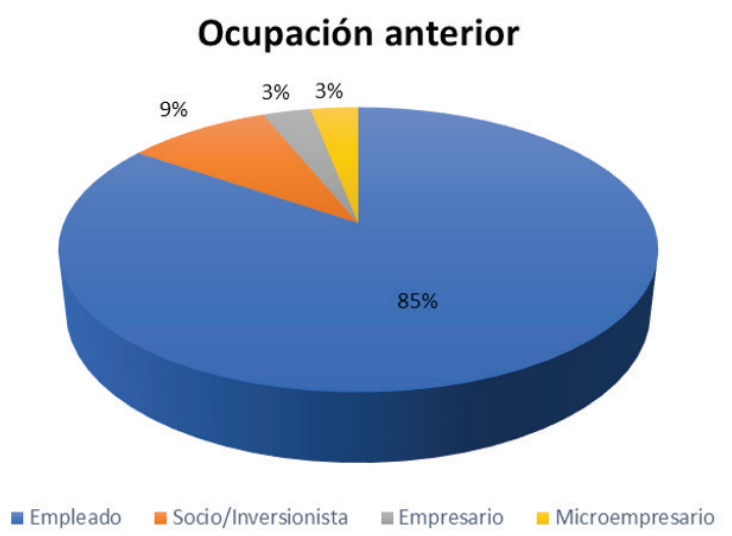

\section{Figura 5}

Ocupación anterior.

Fuente: Elaboración Propia (2018)

Como se describe en la figura 5 , el $85 \%$ de los participantes menciona que fueron empleados en alguna organización antes de ser empresarios y como dato interesante, se encontró que la sucesión de empresas representa solo el 3\%, por otra parte, el crecimiento de microempresarios a empresarios es apenas del 3.\%, lo que nos indica que son pocas las empresas que sobreviven al crecimiento y otras simplemente no pueden crecer, lo que probablemente se relaciona con la falta de capacitación y actualización de los empresarios o quizás a otros factores internos y externos.

En cuanto al uso de las tecnologías y medios digitales para la búsqueda de información, se brindó la alternativa de marcar más de una opción de acuerdo a la prioridad del dispositivo, los datos obtenidos de la investigación muestran que los empresarios emplean con mayor frecuencia en un 96\% el teléfono móvil para buscar información, quizás se deba a que este lo tienen disponible en todo momento. (Ver figura 6).

Es importante destacar que los empresarios, tienen también una preferencia hacia la laptop antes que a una Tablet, probablemente debido a que en una laptop, pueden mantener organizados documentos necesarios para sus actividades operativas
Uso de dispositivos de búsqueda de información

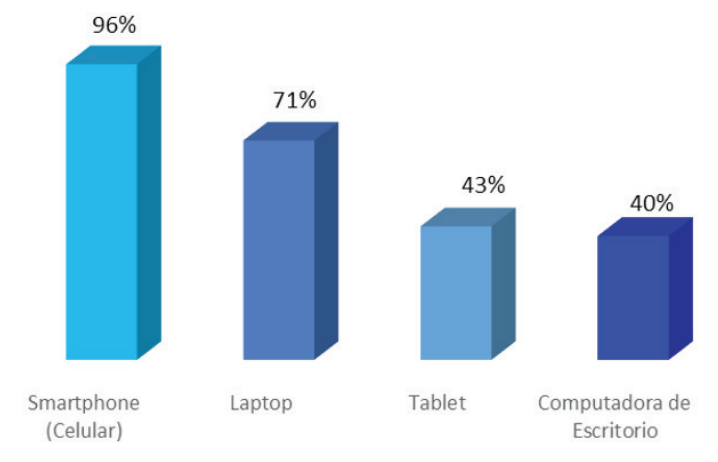

Figura 6

Dispositivos empleados para búsqueda de información. Fuente: Elaboración Propia (2018)

y pueden fácilmente editarlas en una pantalla más amplia, pueden agendar sus citas, revisar expedientes y estas pueden ser transferidas a sus empleados, por otra parte se encuentran los precios de adquisición y la flexibilidad que ofrecen de ser transportadas entre salas de juntas u oficinas de clientes o proveedores, ofrecen una interoperabilidad mayor que aquellos dispositivos que requieren internet para manejar archivos, además su potencia de procesamiento de datos es mayor.

En la Figura 7 se muestra los temas que generan mayor interés en los empresarios, por lo que se tomaron en cuenta para integrarlos en la formación de capital humano en el trabajo a través de la plataforma REA, entre los aspectos más relevantes se observa que el $69 \%$ indicó que le gustaría conocer más sobre el análisis de proyectos de inversión, el $58 \%$ de ellos buscan temas relacionados con la administración financiera, el 53\% propone temas de sustentabilidad y el $44 \%$ se interesa por aspectos relacionados con la toma de decisiones.

Temas prioritarios en Internet para capacitación

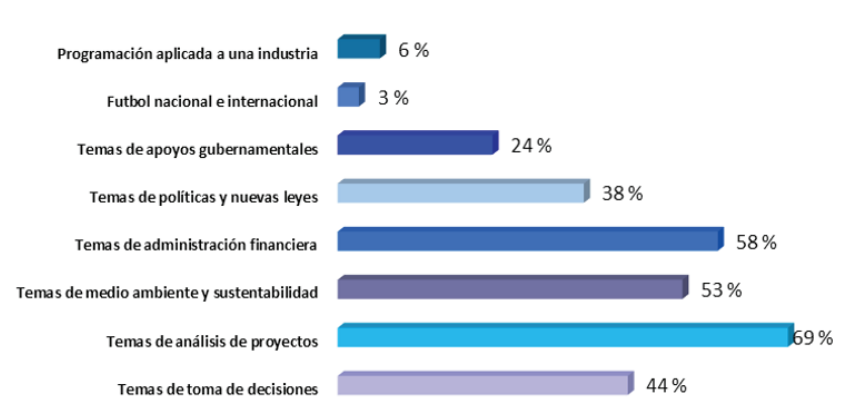

Figura 7

Temas prioridad en internet

Fuente: Elaboración Propia (2018) 
Es evidente que todos los temas seleccionados son fundamentales para las organizaciones, ya que contribuyen a determinar las áreas en que es recomendable la inversión para el desarrollo y formación en talento humano, con la finalidad de permanecer en el mercado y, de ser factible, emprender estrategias de crecimiento.

Respecto a la preferencia del uso de dispositivos para recibir cursos de capacitación, en la Figura 8 se observa que los empresarios prefieren los cursos presenciales (48\%), sin embargo, a diferencia de haber indicado que utilizan más el teléfono móvil para buscar información, en el caso de recibir capacitación el 34\% muestran interés por realizarlo a través de internet mediante el uso de la computadora, lo que indica que es posible generar contenidos digitales que serán aceptados por los empresarios.

\section{Medio por el que recibiría el curso}

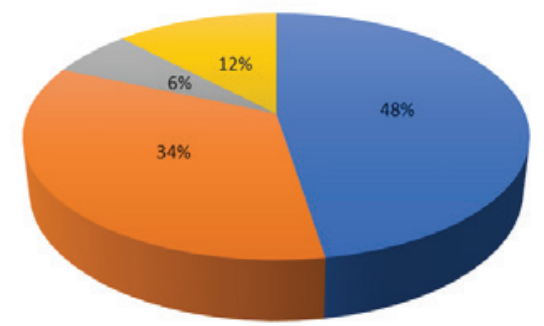

=Curso presencial $\equiv$ Por computadora $=$ En videoconferencia $=$ Por celular/tablet

\section{Figura 8}

Medios para recibir la capacitación.

Fuente: Elaboración Propia (2018)

\section{Discusión y Conclusiones}

Dentro de las problemáticas que presentan las pymes para la formación de su capital humano, destacamos que no existe en ellas una adecuada gestión del conocimiento para su crecimiento constante, es decir además de no tener la capacidad de adquirir capacitación y formación constante por medio de las instituciones educativas, no existen en ellas herramientas que gestionen su información para lograr la adecuada formación del capital humano, generalmente este conocimiento se transmite bajo el esquema de adiestramiento, esto lo confirma Tavera \& Salinas(2011) quienes mencionan que las pymes presentan una serie de problemas relacionados con el desconocimiento en negocios, como la planeación estratégica, el desarrollo de una cultura empresarial, la innovación tecnológica, que limitan la competitividad y la productividad de las mismas, destacando que no existe en ellas un plan de negocios desarrollado.

La formación del capital humano a través de recursos educativos abiertos en las organizaciones, ofrece a los usuarios, elementos muy valiosos en su formación, si se considera su disponibilidad, rapidez de acceso y actualización, así como su bajo costo y adaptabilidad. Lo cual contribuirá a la formación de y fortalecimiento del capital humano de alto nivel, (Romero, López, \& Martínez, 2018).

Los hallazgos encontrados en la presente investigación, cimentan e inciden en la importancia de hacer una reingeniería en la formación del capital humano, en la que las tecnologías formen parte de los recursos que tienen a su alcance y que deben apropiarse de ellas, y que sean integradas como una estrategia en el ámbito organizacional y empresarial, ya que el tema de las tecnologías en el ámbito de la industria para los empresarios todavía en este siglo XXI no está siendo una prioridad según los empresarios encuestados al indicar que solo el $6 \%$ de ellos están de acuerdo en ser necesario la programación aplicada en el sector industrial, lo cual se muestra en la problemática que aún existe en cuanto a la apropiación de las tecnologías en diversos ámbitos empresariales, Padilla, Quintero \& Sales (2015), al respecto plantean que la formación del capital humano es un reto ineludible para la innovación empresarial, debido que los constantes cambios y la rapidez en que se modifican los negocios dejan fuera del plano la formación, existe una necesidad de formación del capital humano y existe una oportunidad de crear nuevos esquemas que fortalezcan las capacidades de las empresas en diversos ámbitos relacionados a los negocios. Además, es una de las capacidades de las organizaciones para lograr una ventaja competitiva y que tiene una relación directa con el conocimiento y habilidades de capital humano, (Páez, 2012).

El 34\% muestran interés por realizarlo a través 
de internet mediante el uso de la computadora, lo que indica que es posible generar contenidos digitales que serán aceptados por los empresarios.

Los resultados mostrados en cuanto a seguir cursos a través de internet mediante el uso de la computadora, (34\%) es un referente para poder realizar plataformas idóneas para la formación de capital humano con contenidos digitales que serán aceptados por los empresarios, por la que en estas se utilicen diversas herramientas o medios digitales tales como el video, gráficos, sonido, presentaciones interactivas, infografías, nubes de tags, etc., que apoyen el diseño y desarrollo de contenidos digitales, entendidos éstos como recursos educativos abiertos, para crear ambientes de aprendizaje virtual más dinámicos, esto contribuye a favorecer en el adulto un aprendizaje más situado a su realidad laboral, permitiendo de manera paralela, aplicarlo a la solución de problemas a los que se enfrenta en su ámbito laboral en el desempeño de sus funciones.

El diagnóstico realizado ha permitido, el diseño y desarrollo de la plataforma REA, en la que se trabaja actualmente con herramientas open source en ambientes virtuales de aprendizaje, esto permite a las empresas, la constante formación en el trabajo del capital humano de manera accesible, a bajo costo, acorde al contexto y a las necesidades del grupo destinatario. Tal es el caso de las plataformas de recursos educativos abiertos que se basan en recursos disponibles para todo el público, generalmente son materiales pedagógicos libres, gratuitos $y$ accesibles en la red, bajo licencias que permiten su reutilización, de acuerdo al consorcio OCW (Open Course Ware Consortium) es un conjunto especifico y estructurado de alta calidad que incluyen generalmente materiales para la planificación, evaluación y estructura de los contenidos.

En este mismo sentido, existen experiencias en universidades públicas en México como la Universidad Nacional Autónoma de México, a través de la Coordinación Universidad Abierta y Educación a Distancia (CUAED) y el IPN (Instituto Politécnico Nacional), que han desarrollado plataformas digitales para lograr satisfacer la necesidad de formación en el ámbito de las organizaciones, sin embargo, la demanda aumenta radicalmente, tanto en sectores productivos como de servicios e incluso el sector privado ha incursionado en el negocio de la formación, generando plataformas con programas y cursos atractivos a un precio considerablemente económico. Butcher (2015) menciona que las oportunidades de aprendizaje se deben proporcionar a todos los individuos a lo largo de la vida y proporcionarles los medios y herramientas tecnológicas para desarrollar competencias digitales que les permita estar integrados en la sociedad de la información y el conocimiento distribuido.

Se considera importante mencionar que para consolidar el diseño y desarrollo de la Plataforma REA en su versión 3 en la integración de cursos MOOC, se pretende, en futuros estudios, integrar herramientas digitales que desarrollen las habilidades del pensamiento estratégico en los empresarios, para favorecer el trabajo en equipo, brindar un conocimiento colectivo enfocado en la solución de problemas, favorecer las redes de negocios para propiciar soluciones a clientes con expertos en los temas, esto con la finalidad de brindar certeza entre los integrantes de las organizaciones y certidumbre en la formación del capital humano en la organización.

Para futuras investigaciones sobre el diseño y desarrollo de plataformas tecnológicas donde se utilicen los Recursos Educativos Abiertos, se debe hacer una batería de instrumentos fiables y confiables para recopilar información de las necesidades que tienen y requieren los usuarios de este tipo de plataforma para su mejora en su formación como capital humano.

\section{Agradecimientos}

Al proyecto SIP 20161051 Instituto Politécnico Nacional: Aplicación de la Metodología para Validar Plataforma Tecnológica Desarrollo de Contenidos Digitales para la Formación en el Trabajo a Empresarios pymes de la Delegación Xochimilco.

\section{REFERENCIAS BIBLIOGRÁFICAS}

Butcher, N. (2015) Guía Básica de Recursos Educativos Abiertos (REA). Place de Fontenoy, 75352 París 07 SP, 
Francia: Organización de las Naciones Unidas para la Educación, la Ciencia y la Cultura.

Cámara de Comercio (2017) Tecnología aplicada al capital humano se enfoca en la evaluación de desempeño. Informe especial Cámara de Comercio de Lima, Perú. La revista de la Cámara de Comercio, No.791, 13-15. Recuperado de https:/www.camaralima.org.pe/repositorioaps/0/0/par/edicion791/edicion\%20791.pdf

Censos Económicos, C.E. INEGI. (2015). Micro, pequeña, mediana y gran empresa estratificación de los establecimientos. INEGI. Aguascalientes, México: Instituto Nacional de Estadística G.

Cueto, A. (2013). Capability Maturity Model (CMM) y la Gerencia. Col. Laboratori de Mitjans Interactius / Publicacions i Edicions de la Universitat de Barcelona. ombia: I Jornadde Gerencia de Proyectos en TI - ACIS 2003.

De Marco, F. (2013) El capital humano como fuente de Innovación en una organización académica. GTEC. Centro -Este. Programa de apoyo al gerenciamiento de las innovaciones tecnológicas.

Deloitte. (2017). 5to Reporte y Encuesta anual de tendencias globales de Capital Humano. México City: Deloitte.

Diaz, H. (2017) Tecnologías de la información y comunicación y crecimiento económico. Economía Informa, 405.

Gálvez, E., Riascos, S. \& Contreras, F. (2014) Influencia de las tecnologías de la información y comunicación en el rendimiento de las micro, peque-as y medianas empresas colombianas. Estudios Gerenciales, 30, 355-364. https://doi. org/10.1016/j.estger.2014.06.006

Gibbons, A., Nelson, J. \& Robert, R. (1998) Learning object design and sequencing theory in David Wiley (Ed.), Designing Instruction with Learning Objects, June.2000

Guzmán, J. \& Motz, R. (2013) Considerando equivalencias pedagógicas para la reutilización de recursos educativos abiertos. Revista Iberoamericana de Educación en Tecnología y Tecnología en Educación, 11, 8-17.

Hill, J. \& Hannafin, M. J. (2000). Teaching and learning in digital environments: The resurgence of resource-based learning. Submitted for publication.

Hirsch, J., Almaraz, I. \& Ríos, M. (2015) La preparación de las empresas manufactureras del Estado de Querétaro, México en el área de las tecnologías de información y comunicación. Suma de Negocios, 6, 166-177. https://doi. org/10.1016/j.sumneg.2015.08.012

Hollann, J., E. \& Kirsh, D. (2000) Distributed Cognition: Toward a new Fundation for Human-Computer Interaction Research. ACM Transaction Computer-Human Interaction 7(2),174-196 https://doi.org/10.1145/353485.353487

Kido, A. \& Kido, T. (2015) Modelos teóricos del capital humano y señalización: un estudio para México. Contaduría y Administración, 60, 723-734. https://doi.org/10.1016/j. cya.2014.06.001

Martínez, F. (2017). Administración Estratégica Inteligente. El pensamiento Estratégico en la 4ta. Revolución Industrial y su economía de Creatividad e Innovación. Ciudad de México: Instituto Mexicano de Innovación y Estrategia, A.C. https://doi.org/10.25100/cdea.v32i56.4284

Martínez, M. \& Chávez, D, (2016) Desarrollo de plataforma tecnológica para la formación de capital humano en PyMES de la ciudad de México. XXI Congreso internacional de contaduría administración e informática. Recuperado de http:// congreso.investiga.fca.unam.mx/docs/xxi/docs/3.03.pdf

Mejía, A. (2017) Personal calificado en la industria de las TICs en México: El caso de las MIPYMES. Gestión de la Innovación para la Competitividad. Altec 2017, XVII Congreso Latino Iberoamericano de Gestión Tecnológica, México.

México Bursátil. (26 de Septiembre de 2013). Los principales problemas de las PyMES. Recuperado de http://www. mexicobursatil.com/los-principales-problemas-de-las-pymes/

Ortega, J. A., Hernández, A. M., Martínez, M. D., Rendón, L. M., Fuentes, J. A., Pérez, A. \& Ortega, A. (2013). La educación a distancia en entornos virtuales hoy. GEU México.

Padilla, S., Quintero, L., \& Sales, J. (2015). Dinámicas grupales en la capacitación empresarial por competencias. Las micro, pequeñas y medianas empresas en el desarrollo económico, cultural y tecnologico de México, 63-74.

Páez, I. (2012) Capital humano, redes externas e innovación en la industria colombiana. Estudios Gerenciales, 28, edición especial, 81-107. https://doi.org/10.18046/j.estger.2012.1480

Reyes, B. Juárez, C., Martínez, M. \& Sánchez, J. (2017) Modelo de propiedad intelectual para recursos educativos abiertos. Campus Virtuales, 6 (2), 107-112. Recuperado de http:// www.uajournals.com/campusvirtuales/journal/11/9.pdf

Román, M. (2013). Crecimiento en un contexto de escasez de capital humano en TIC. Tercera Conferencia en Desarrollo Capital Humano. Universidad Tecnológica de Chile. INACAP.

Romero, J., López, V. \& Martínez, M. (2018) El capital humano en México en el marco de la economía basada en el conocimiento: Una revisión a los indicadores de ciencia y tecnología. Economía coyuntural. Revista de temas de coyuntura y perspectivas, 3 (1) 1-36.

Salomon, E. G. (2005) Distributed Cognition: Psychological and Educational Considerations, Cambridge University Press, Cambridge, United Kingdom.

Schwab, K. (2016). La cuarta revolución industrial. México: Penguin Random House.

Somerville, H. (2018). U.S.News, Technology News. Recuperado de Udacity, With Eye to Eventual IPO, Says Revenue More Than Doubled in 2017: https:/www.usnews.com/ news/technology/articles/2018-02-27/udacity-with-eye-toeventual-ipo-says-revenue-more-than-doubled-in-2017

Tavera, M. E., \& Salinas, E. (2011). Las MIPyME en México. Crecimiento, financiamiento y tecnología. México D.F.: Instituto Politécnico Nacional. 


\title{
Innovación educativa en el aula mediante Design Thinking y Game Thinking
}

\section{Educational innovation in the classroom through Design Thinking and Game Thinking}

\author{
Hugo Arias-Flores ${ }^{1}$ \\ https://orcid.org/0000-0003-0106-6661 \\ Janio Jadán-Guerrero ${ }^{2}$ \\ http://orcid.org/0000-0002-3616-2074 \\ Lucía Gómez-Luna ${ }^{3}$ \\ https://orcid.org/0000-0001-6068-5206 \\ Universidad Tecnológica Indoamérica, Ecuador
}

Recibido: 19-01-2019

Aceptado: 03-04-2019

\section{Cita Recomendada}

Arias-Flores, H., Jadán-Guerrero, j. \& Gómez-Luna, L. (2019). Innovación Educativa en el aula mediante design thinking y game thinking. Hamut'ay, 6(1), 82-95.

http://dx.doi.org/10.21503/hamu.v6i1.1576

\section{RESUMEN}

La tecnología está cambiando los hábitos de las personas y se está insertando con rapidez en la Educación. Cada vez aparecen nuevos recursos educativos apoyados por la tecnología que fomentan la innovación en el aula. En este contexto los maestros afrontan nuevos retos para cambiar rutinas e inercias pedagógicas tradicionales en aulas dinámicas e interactivas. Estos recursos tecnológicos están revolucionando la manera de enseñar en el aula, no solo en el contenido sino también, en la retención del conocimiento y experiencia del estudiante. Este estudio describe una experiencia de innovación educativa en el aula mediante las metodologías Design Thinking y Game Thinking. El objetivo es introducir el uso de tecnologías disruptivas en el aula mediante estrategias lúdicas y pensamiento de diseño para su aplicación didáctica. El estudio se llevó a cabo en un programa de Maestría de Educación, Innovación y Liderazgo en una universidad de Quito, Ecuador. La muestra fue de 120 maestros de educación primaria, secundaria y superior del curso de Infopedagogía Educativa. Estas metodologías permitieron generar resultados innovadores, no sólo en la aplicación sino también en la generación de novedosos recursos educativos tecnológicos. Estos resultados se clasifican en tres categorías: 1. Herramientas de evaluación y coevaluación como Kahoot, Quuizizz y Plickers que generan motivación en el aula; 2. Recursos educativos con códigos QR y realidad aumentada, donde los marcadores y etiquetas NFC proporcionan información adicional para combinar libros interactivos y juegos de mesa con dispositivos móviles; 3 . Recursos educativos tangibles,

\footnotetext{
1 Ingeniero en Marketing y Negociación Comercial Internacional y Maestría en Administración de Empresas y Marketing en la Universidad Tecnológica Indoamérica. Editor asociado de la Revista CienciAmérica, facultad de Ingenierías y Tecnologías de la Información y Comunicación, su línea de investigación es políticas públicas de inserción laboral de personas con discapacidad. E-mail cienciamerica@ uti.edu.ec

2 Doctor en Ciencias de la Computación de la Universidad de Costa Rica. Director de Investigación de la Universidad Tecnológica Indoamérica en Ecuador, su línea de investigación es Interacción Humano-Computador y Tecnologías para la Educación Especial. E-mail janiojadan@uti.edu.ec 3 Licenciada en Restauración de Arte y museología de la Universidad Tecnológica Equinoccial. Analista del Centro de Transferencia y Tecnología. E-mail luciagomez@uti.edu.ec
} 
que integran el dispositivo Makey-Makey y Scratch con materiales tradicionales del aula, tales como frutas, plastilina, papel de aluminio o agua. Como conclusión, se establece que el trabajo en equipo fue una de las características más importantes en el aprendizaje basado en el pensamiento de diseño, que permitió el trabajo en proyectos reales con metodologías de innovación y creatividad..

Palabras Clave: Creatividad, innovación, estrategias lúdicas, pensamiento de diseño, pensamiento de juegos.

\section{Abstract}

Technology is changing the habits of people and it is being inserted quickly in Education. New educational resources supported by technology aimed to encourage innovation in the classroom are increasingly appearing. In this context, teachers face new challenges to change routines and traditional pedagogical habits into dynamic and interactive classrooms. These technological resources are revolutionizing the way of teaching in the classroom, not only in the content but also in the retention of knowledge and experience of the student. This study describes an educational innovation experience in the classroom through the Design Thinking and Game Thinking methodologies. The objective is to introduce the use of disruptive technologies in the classroom through playful strategies and design thinking for its didactic application. The study was carried out in a Master's program in Education, Innovation and Leadership at a university in Quito, Ecuador. The sample was composed of 120 teachers of primary, secondary and higher education of the Educational Infopedagogy course. These methodologies are allowed generating innovative results, not only in the application but also in the generation of new technological educational resources. These results are classified into three categories: 1. Evaluation and co-assessment tools such as Kahoot, Quuizizz and Plickers that generate motivation in the classroom; 2. Educational resources with QR codes and augmented reality, where NFC markers and labels provide additional information to combine interactive books and board games with mobile devices; 3. Tangible educational resources, which integrate the Makey-Makey and Scratch device with traditional classroom materials, such as fruit, plasticine, aluminum foil or water. In conclusion, it is established that teamwork was one of the most important characteristics in learning based on design thinking, which allowed to work on real projects with innovation and creativity methodologies.

Keywords: Creativity, innovation, playful strategies, design thinking, game thinking.

\section{INTRODUCCIÓN}

Hoy en día, el trabajo de la innovación y del cambio digital no es una tarea fácil para muchos maestros. El desconocimiento de la utilidad de la tecnología hace que sea complicado aplicar estrategias innovadoras en el aula. Además, muchos de los proyectos basados en la tecnología tienen un gran enemigo: el tiempo, ya que los maestros necesitan de él para actualizarse, explorar y poner en práctica nuevas estrategias apoyadas con la tecnología (Bautista, Martínez \& Hiracheta, 2014), de ahí nace una pregunta de investigación ¿Cómo fomentar en los maestros el uso y aplicación de tecnologías, para que sus clases sean más dinámicas y participativas?

La innovación educativa no se refiere solo a la tecnología sino también a la pedagogía, la didáctica, las estrategias, los procesos, los recursos, el talento 
humano, el conocimiento, las actitudes y los comportamientos. Para Carbonell, (2002) la innovación educativa es un conjunto de ideas, procesos y estrategias, con las que se trata de iniciar e incentivar cambios en las practicas educativas. Por otro lado, para Llano la innovación educativa se vuelve en el tiempo una educación disruptiva puesto que ésta tiene el potencial de impactar a todo el contexto educativo (Llano, 2015).

La educación disruptiva permite la introducción de avances e innovaciones en los procesos educativos a través de las nuevas tecnologías y los nuevos usos que se abren en el ámbito comunicativo. Por tanto, para llevar a cabo un proceso de educación disruptiva en el aula, la labor docente se centra en propiciar espacios que generen nuevas experiencias a los estudiantes. Es necesario tener claro que los actores del proceso enseńanza y aprendizaje deben estar abiertos constantemente a transformar los espacios, los horarios, la metodología y, en definitiva, la forma de organizar el aprendizaje en clase, para permitir transformaciones importantes y disruptivas que amplíen los conocimientos y se fomente el aprendizaje significativo (Reveles, 2018).

Al hablar de un aprendizaje significativo, se hace referencia a una visión más allá de lo tradicional, en la cual la educación sea innovadora y creativa; ya que los estudiantes aprenden de una manera dinámica, no solo con los materiales comunes, sino con las Tecnologías de la Información y Comunicación (TICs). En la actualidad el uso de las TICs dentro del aula está tomando mayor importancia, los nińos y jóvenes tienen acceso a ella con mayor facilidad y las habilidades de uso son casi innatas. Incluir los recursos tecnológicos en el salón de clase requiere de una presencia docente para que los estudiantes tengan un aprendizaje significativo, mejoren su creatividad, se incremente la motivación hacia el estudio y la clase se vuelva más dinámica y colaborativa.

Lograr una adecuada presencia docente en ambientes de aprendizaje colaborativo mediados por TIC exige apropiarse de los nuevos roles adscritos a ella; teniendo presente que hay distintas etapas de planeación, construcción de recursos, administración e interacción y moderación con quienes participan (Bautista, Martínez \&
Hiracheta, 2014), (Rojas-Montero \& DíazBetter, 2018). Siendo una de las estrategias que el maestro utiliza en clase para enseñar, es despertar la curiosidad del estudiante; a través de nuevas estrategias didácticas y recursos educativos, como la tecnología. Parece entonces oportuno, mezclar los tres elementos para hacer del aula de clase un espacio interactivo cargado de creatividad y que deje huella en los estudiantes. Estos elementos son la educación, la tecnología y la innovación, que guiados a través de novedosas metodologías se generen estrategias para desarrollar la creatividad de los maestros (González, 2015).

El presente trabajo es una secuencia de un estudio realizado anteriormente en el que se aplicó la Metodología de Aprendizaje Basada en Metáforas Narrativas y Gamificación a 62 maestros de educación primaria, secundaria y superior que se están formando en un programa de Maestría de Educación, Innovación y Liderazgo en una universidad de Quito, Ecuador. El objetivo de esta metodología, fue generar interacción en jornadas largas de clase, mediante la aplicación de estrategias didácticas lúdicas para generar interacción y motivación. A través de una plataforma Moodle se diseñó un escenario gamificado, usando la metáfora de la Academia de Magia Hogwartz para resolver retos, con el fin de conocer nuevas herramientas tecnológicas que pueden aplicarse en el aula. En ese estudio los participantes tenían el rol de estudiantes, es decir usaban las herramientas como usuarios finales y no como administradores y diseñadores de las interfaces y contenidos (Jadán-Guerrero \& Ramos-Galarza, 2018). Siguiendo desde esta línea, el objetivo de este nuevo estudio es el de introducir el uso de tecnologías disruptivas en el aula mediante estrategias lúdicas y pensamiento de diseño para su aplicación didáctica. Para ello se aplican las metodologías Design Thinking y Game Thinking, que propician un ambiente de generación de ideas y prototipado rápido mediante actividades lúdicas. Se profundiza el conocimiento en aplicaciones de evaluación en clase, como Kahoot, Quizizz, Plickers y Google Forms. Los participantes aprenden a diseñar cuestionarios y aplican estos a sus estudiantes en un escenario real. Por otro lado, aprenden a generar códigos QR (Quick Response Barcode) y usar etiquetas NFC (Near Field Connection) con el fin de integrar dispositivos móviles a recursos 
tradicionales del aula. Aprenden Realidad Aumentada a través de aplicaciones, como Animal 4D +, Space 4D +, Humanoid 4D + y QuiverVision 3D Augmented Reality. Con las cuales desarrollan cuentos interactivos o juegos de mesa inclusivos. Finalmente, aprenden a usar sensores RFID (Radio Frequency IDentification) y la tarjeta electrónica Makey Makey con la plataforma de programación Scratch para diseñar recursos educativos tangibles, que combinan la información digital con materiales tradicionales del aula, tales como cartulina, colores, papeles brillantes, papel aluminio, plastilina, frutas o agua.

\section{Tendencias en pedagogía y tecnología}

En los últimos años, la presencia de la tecnología está cambiando la manera de enseñar y; una nueva generación de tecnologías disruptivas está ganando popularidad en las aulas. Ya es común ver pizarras digitales, que son superficies aumentadas por computadora con interacción multitáctil; así como tabletas y dispositivos móviles (Martínez, 2017). Este cambio tecnológico está propiciando el desarrollo de nuevas tendencias pedagógicas que van creciendo y no da señales de detenerse, sino que su avance se incrementará con el pasar del tiempo (Adell \& Castańeda, 2012).

Un reporte realizado por el Instituto Tecnológico de Monterrey en el año 2017 presenta un radar de innovación educativa, cuyo objetivo fue determinar las tendencias pedagógicas y las tendencias tecnológicas más relevantes desde la perspectiva de profesores innovadores de la institución. Los resultados mostraron que las tendencias en Pedagogía más utilizadas son: el aprendizaje activo, aprendizaje basado en problemas, aprendizaje basado en proyectos, aprendizaje colaborativo, aprendizaje basado en desafíos, aula invertida, creadores de espacio y gamificación. Por otro lado, las tendencias en tecnología son el aprendizaje adaptativo, aprendizaje en redes sociales y entornos colaborativos, aprendizaje móvil, aprendizaje ubicuo, aprendizaje con asistente virtual, MOOC (Massive Online Open Courses), Big Data y análisis de aprendizaje, laboratorios remotos y virtuales, Internet de las cosas, realidad aumentada y realidad virtual (EduTrends, 2017).
Estas nuevas tendencias, que han surgido en los últimos años, prometen fomentar nuevas formas de enseñanza y, la intención de ellas es que los centros educativos preparen a los estudiantes para un nuevo tipo de sociedad, la sociedad de la información, no solo enseñándoles a usar las TICs, sino también usándolas como herramientas de aprendizaje para enfrentar los nuevos desafíos educativos. Sin embargo, en Ecuador dentro del sistema educativo, el empleo de estas tecnologías se encuentra fragmentado, ya que no todas las instituciones educativas cuentan con los elementos esenciales y necesarios para su correcta aplicación. El uso de las tecnologías no es el adecuado, debido a la falta de capacitación y actualización en este ámbito, o la falta de tiempo para explorar y diseñar nuevas estrategias didácticas, por ende, no se genera una interacción entre docente, estudiante y contenido curricular.

Reconocer la importancia de las tendencias pedagógicas y tecnológicas, es trascendental en la educación actual, ya que es un desafío por su cambio constante, permitiendo a niños y jóvenes a desarrollar habilidades para aprender, desaprender y reaprender durante el transcurso de su vida. En los estudiantes se requiere que se despierte la motivación, que se fomente el trabajo colaborativo. A nivel de las instituciones educativas ecuatorianas, se deben incluir tecnologías educativas que integren el trabajo cotidiano de la institución, contribuyendo al desarrollo de las competencias necesarias en la formación de los futuros ciudadanos, de igual manera es urgente la capacitación de los docentes.

Hoy, no se trata de utilizar las tecnologías digitales para hacer "más" dinámica la clase, replicando prácticas que podrían realizarse sin estas tecnologías, sino que se trata de mirar lo que los estudiantes hacen, cómo se comunican, lo que comparten y crean, para poder recuperar y dar la importancia de acuerdo a la intencionalidad pedagógica a través de propuestas que los ayuden a seguir aprendiendo. En este estudio, se seleccionaron tres tendencias pedagógicas (aprendizaje colaborativo, aprendizaje basado en retos y gamificación) y cuatro tendencias tecnológicas (b-learning, m-learning, realidad aumentada y espacio makers). Aplicando la metodología Design Thinking se identifican necesidades y se abre un espacio de creatividad e innovación. Mientras que con la metodología Game 
Thinking se busca un ambiente competitivo, en el que los participantes mediante actividades lúdicas despierten su interés y motivación al uso de la tecnología. Esta combinación de metodologías facilita la introducción de herramientas tecnológicas que primeramente son evaluadas como usuarios finales y posteriormente como usuarios administradores, con la meta de que los participantes diseñen nuevos recursos educativos y no sólo se queden como prototipos, sino que sean evaluados en un escenario real con sus estudiantes.

\section{Metodología Design Thinking y Game Thin- king como recurso educativo}

La metodología Design Thinking se define como un proceso analítico y creativo que involucra a una persona en oportunidades para la generación de ideas innovadoras y que toma como centro la perspectiva de los usuarios finales para experimentar, modelar y crear prototipos, recopilar comentarios y rediseñar. De esta forma se pueden detectar problemas y necesidades, así como ofrecer soluciones efectivas y en muchos casos, alternativas, para cada una de ellas (Razzouk \& Shute, 2012; González, 2015). La metodología tiene cinco fases, como se muestra en la Figura 1.

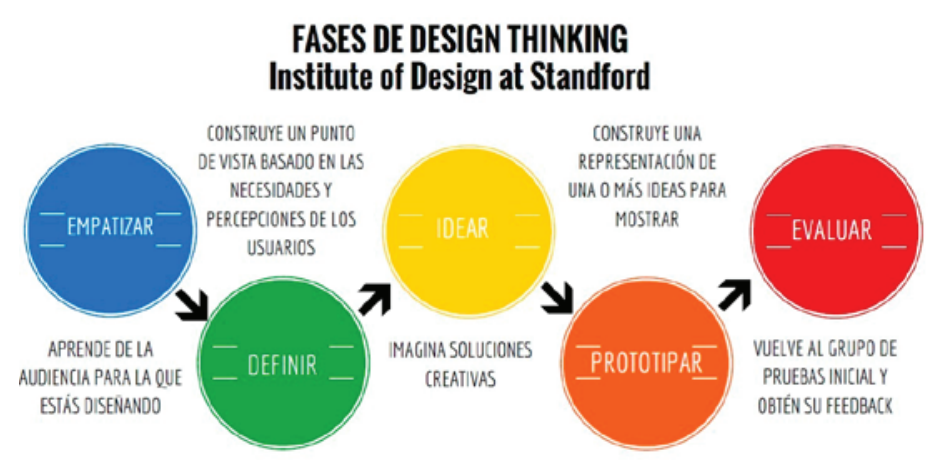

\section{Figura 1}

Fases de la metodología Design Thinking (Insituto de Diseño de Standford)

Elaboración propia (2019)

La fase Empatízar comienza con empatía, con un enfoque humano profundo, para obtener información de la audiencia, conocer sus necesidades y revelar nuevas formas de ver o identificar problemáticas inexploradas. La fase Definir, implica replantear el problema o desafío percibido y obtener perspectivas, lo que permite una visión más integral del camino hacia un punto de vista basado en las necesidades y percepciones de los usuarios, en este caso de los estudiantes. En la fase Idear, se fomenta el trabajo en equipo colaborativo y multidisciplinario para aprovechar las habilidades, personalidades y estilos de pensamiento de los participantes para resolver problemas multifacéticos. En la fase Prototipar se crea un espacio abierto para plasmar las ideas y se construya un prototipo de la solución. En la fase Evaluar se prueba el prototipo en un escenario real. La metodología Game Thinking o pensamiento del juego introduce aproximaciones creativas provenientes de los juegos para convertir actividades a priori complejas en dinámicas que motiven a las personas, invitando a una cooperación lúdica orientada a la innovación. El pensamiento del juego está comenzando a aparecer en una amplia variedad de contextos que no son juegos. El pensamiento del juego se ha descrito como un término general que abarca la gamificación, los juegos serios, el diseño inspirado en el juego y el juego que se puede utilizar para resolver algún tipo de problema. El proceso de usar el pensamiento de juego, consiste en aplicar mecánicas y dinámicas de los juegos para atraer a los usuarios y resolver problemas (Marczewski, 2015; De Puy \& Miguelena, 2017).

Existen algunos estudios que utilizan esta metodología en el ámbito educativo, entre ellas, una llevada a cabo en la Universidad de La Laguna en España en la que desarrolla estrategias para trabajar la creatividad en la Educación Superior. En este trabajo, se describe una experiencia de innovación educativa en la enseńanza de la Ingeniería y el Diseńo, en donde los autores combinan varias estrategias de enseñanza, el aprendizaje basado en proyectos (PBL) y el aprendizaje basado en juegos, así como las técnicas de pensamiento de diseño (Design Thinking), pensamiento visual (Visual Thinking), pensamiento de juegos (Game Thinking) al proceso de enseñanza-aprendizaje. De los resultados encontrados se observó que el trabajo en equipo es una de las cuestiones más importantes que se logró con este tipo de metodologías híbridas. Asimismo, el trabajo en proyectos reales con metodologías de innovación y creatividad, favorecieron la implicación y motivación de los estudiantes en los mismos (González, 2015). 


\section{Materiales y Métodos}

\section{Participantes}

El programa de Maestría en Educación, Innovación y Liderazgo de la universidad en la que se llevó a cabo este estudio cuenta con aproximadamente 600 maestrantes, divididos en el $50 \%$ en la sede Ambato y 50\% la Sede Quito, que corresponde al universo del estudio. Para la muestra se tomaron dos paralelos del módulo de Infopedagogía Educativa, el $51 \%$ de la muestra fue seleccionada de la Sede Ambato y el 49\% restante de la Sede Quito y fue de tipo no probabilística ya que se trabajó con cuatro grupos intactos, siendo un total de 120 maestrantes. Las edades de los maestrantes estaban comprendidas entre 25 y 45 años, de los cuales el $82 \%$ son mujeres y el $18 \%$ varones. En cuanto al nivel de docencia que imparten los maestros de la muestra, se tiene que el $75 \%$ se concentra en la educación básica, seguida del 20\% en la educación secundaria y el $5 \%$ en la educación superior. Los grupos de estudio están conformados por: Grupo 1 de 31 maestrantes, Grupo 2 de 31 estudiantes y Grupo 3 y 4 de 29 maestrantes. El primero y segundo en el período B18 correspondiente a julio-diciembre de 2018 en la sede matriz; mientras que el tercero y cuarto en el período A19 correspondiente a enero-junio de 2019 en la extensión.

\section{Instrumento}

El instrumento para la recolección de evidencias y narraciones fue la plataforma Moodle, en la cual se diseñaron estrategias de juego para desarrollar las actividades. En la Sede Ambato se utilizó la metáfora de la Academia de Magia de Hogwarts, mientras que en la Sede Quito la metáfora del Jurado que está juzgando la educación tradicional. En estos escenarios lúdicos se recogen fotos, videos y comentarios en foros de discusión. Esta información es procesada mediante análisis de contenido. Por otro lado, dentro de este estudio, también se aplicó la técnica de observación, que es un recurso muy útil para analizar el comportamiento de usuarios dependiendo del contexto del estudio. En este caso maestros de educación inicial, secundaria y superior (Hernández-Sampieri \& Mendoza, 2018). También se utilizaron las consultas para determinar la preferencia por determinada herramienta y su nivel de complejidad.

\section{Tipo y diseño}

El estudio es de tipo exploratorio-descriptivo, ya que aborda una temática poco estudiada, relacionada a la experiencia de maestros con tecnologías disruptivas. Asimismo, es de tipo descriptivo, ya que a través de la observación de los fenómenos en su ambiente natural se describen las experiencias innovadoras en el aula y el análisis del desarrollo de la creatividad, desde un punto de vista Psicológico (Ramos, 2019).

\section{Procedimiento}

La asignatura de Infopedagogía Educativa fue organizada siguiendo una modalidad b-learning, es decir un estilo de aprendizaje mediado por una plataforma tecnológica para realizar actividades en el aula y actividades autónomas, las cuales se distribuyeron a lo largo de 5 semanas, destinando 40 horas presenciales, 40 horas de tipo virtual-online y 20 horas al trabajo autónomo. Las actividades de enseñanza-aprendizaje se diseñaron bajo la metodología Game Thinking, es decir basadas en actividades lúdicas. Dichas actividades fueron planteadas en función de la metodología Design Thinking, como se describe a continuación en cada fase.

\section{Empatizar}

Con el fin de conocer a los participantes y comprender de manera más profunda sus problemas y expectativas, se organizó a los participantes en grupos, en el caso de la Academia de Magia Hogwarts los participantes debían inscribirse en una de las 6 casas de confraternidad: Ravenclaw; Hufflepuff; Slytherin; Gryffindor; Slytherpuff y Meilen. En el caso de la metáfora de Jurado, los participantes debían inscribirse en uno de los 6 Bufetes de Abogados: STEM (Science, Technology, Engineering \& Mathematics); Lenguaje y Literatura; Educación Especial e Inclusiva; Estrategias Educativas; Innovación y Emprendimiento; y Liderazgo Educativo. Con el fin de recabar no sólo datos y estadísticas de los participantes, sino de analizar situaciones, comprender su actividad 
académica, así como los diferentes problemas y necesidades que poseen se desarrollaron actividades lúdicas en el aula y en la plataforma, en el primer caso el "El muro de los lamentos" y en el segundo caso "Buscando pistas en la ciudad".

\section{Definir}

En esta fase fue esencial definir los problemas de los participantes según el área de desarrollo laboral y cuál de ellos es más relevante para plantear una solución. En este caso se diseñó un foro de discusión en la plataforma, en el cual los participantes fundamentan su problema mediante fuentes bibliográficas, para ello debían realizar una visita virtual a la "Biblioteca de Hogwarts" o "Biblioteca Cosrpus Lex", respectivamente.

\section{Idear}

Con el problema definido en cada grupo, en esta fase, empieza el proceso de generación de ideas, para ello el "Mago Mayor" o el "Juez" llama a una audiencia y somete a los participantes a un cuestionamiento de los problemas encontrados, para ello se utilizaron las palabras mágicas "Kahoot, Quizizz y Plickers" y la vartita mágica (dispositivo móvil) en el caso de la Academia Hogwarts y en el caso del Jurado los "Clickers (sencillo sistema de respuesta personal remota)" mediante el uso de dispositivos móviles. Kahoot!, Quizizz y son tres herramientas tecnológicas para evaluación, que representan una nueva generación de sistemas de respuesta basadas en un enfoque de la motivación a través de la gamificación (Inge Wang \& Lieberoth, 2016).

\section{Prototipar}

En esta fase, el propósito fue el de convertir la idea o solución en un prototipo digital o físico y esto lo hicieron en un trabajo colaborativo en cada grupo. Para el efecto, se planteó la modalidad Space Makers con los talleres "Taller de Magia" y "Armando el rompecabezas de pistas", respectivamente para cada metáfora narrativa. En estos talleres se utilizaron material tradicional del aula como: papel; cartón; colores; marcadores; acuarelas; plastilina y papel de aluminio, para dar vida a unos personajes mágicos o buscar pistar con la magia de la Realidad Aumentada que proveen las Apps Animal 4D +, Space 4D +, Humanoid 4D + y QuiverVision 3D Augmented Reality. Poste- riormente, se hacía una visita virtual a las "mascotas de Hogwarts" o se invitaba a "los testigos", metáforas de las plataformas web Scratch y MIT AppInventor, que hablan un lenguaje diferente y por ello los participantes debían aprender a programar por bloques e interpretar códigos $\mathrm{QR}$ escondidos. Los miembros de cada grupo debían usar algunas herramientas para presentar un prototipo, entre ellas la App Hi-Q MP3, para grabar sus narraciones o conjuros; así como sensores y etiquetas RFID (Radio Frequency Identification), etiquetas NFC (Near Field Connection) y la placa electrónica Makey-Makey para combinar recursos educativos tradicionales con recursos educativos digitales.

\section{Evaluar}

En esta fase se realizan pruebas de los prototipos realizados, primeramente, una evaluación interna entre los diferentes grupos. Con la retroalimentación de todos los participantes se plantea un reto "challenge" para que este prototipo sea evaluado en un escenario real. Para ello los participantes en el transcurso de una semana debían replicar la evaluación con sus estudiantes y recabar evidencias. Toda esta información debía ser subida en la plataforma Moodle; así como sus opiniones y comentarios de la experiencia.

\section{Resultados}

Los resultados obtenidos en el estudio se enfocan en el uso de las herramientas tecnológicas y el desarrollo de la creatividad para generar nuevos recursos educativos apoyados por la tecnología, en este contexto, los resultados se presentan en tres categorías: 1. Gamificación; 2. Recursos Educativos digitales; y 3. Recursos Educativos híbridos.

\section{Gamificación}

El resultado de la metodología Game Thinking fue muy alentador ya que los participantes descubrieron nuevas formas de aprender, mediante herramientas que ayudan a gamificar el aula. En el estudio se utilizaron Kahoot, Quizizz y Plickers. Gracias a los testimonios de los particpantes fue una experiencia muy enriquecedora. En las narra- 
tivas de los participantes se identificó que gracias a estas herramientas de evaluación y coevaluación disminuyeron considerablemente su ansiedad y miedos a la hora de enfrentarse a nuevos conocimientos. Cada una de las heramientas tiene su particularidad. Kahoot permite la creación de pruebas, debates, encuestas y recolocación de respuestas. En cualquiera de ellas el profesor proyecta un PIN que se genera automáticamente con la prueba seleccionada, se muestra una pregunta con la ayuda de un proyector, mientras que los estudiantes seleccionan una opción en una computadora o en un dispositivo móvil mediante figuras geométricas de colores que representan las opciones de respuesta. En la Figura 2 se muestra un ejemplo de una pregunta.

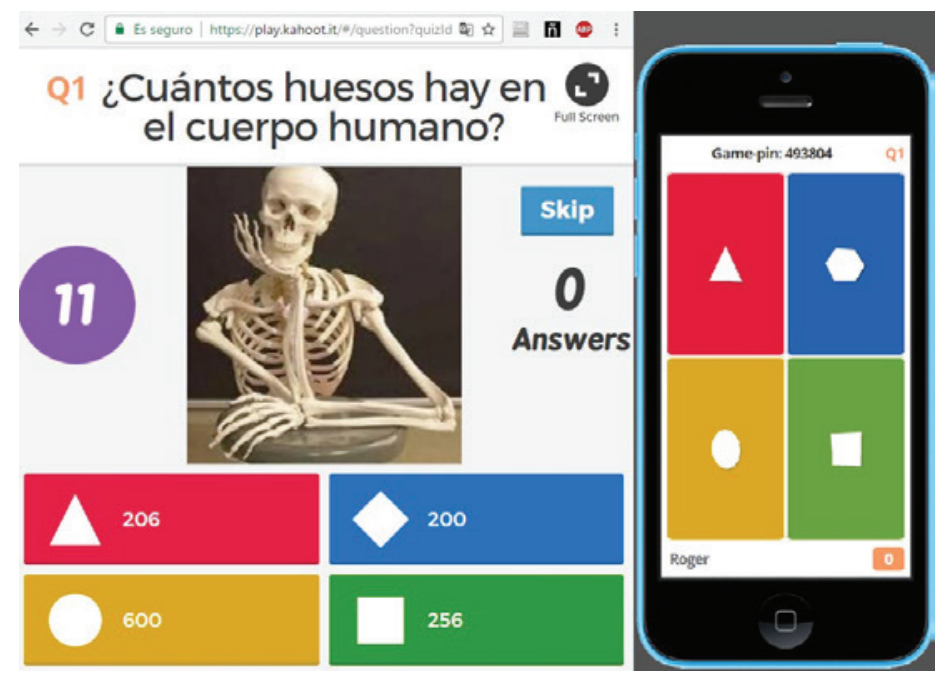

Figura 2

Kahoot muestra en el proyector la pregunta y el dispositivo móvil las opciones

Cuando termina la prueba, los estudiantes se ven reconocidos en un ranking de rapidez y aciertos, lo cual supone gratificación personal y una retroalimentación inmediata sobre sus resultados. De esta manera, son capaces de valorar su puntuación, aprender de sus errores, corregirlos y mejorarlos.

También se hizo uso de la herramienta Quizizz, que a diferencia de la anterior, las preguntas se muestran en la computadora o dispositivo móvil. En el proyector se muestra el progreso de cada estudiante, de color verde las correctas y de color rojo las incorrectas y va generando un ranking.
Los participantes fueron capacitados en el diseño de los cuestionarios para que posteriormente lo pongan en práctica en su aula. Los resultados fueron alentadores, ya que subieron a la plataforma evidencias y comentarios positivos en aspectos de participación y motivación. En la Figura 3 se muestra un ejemplo aplicado en una aula con Quizizz.

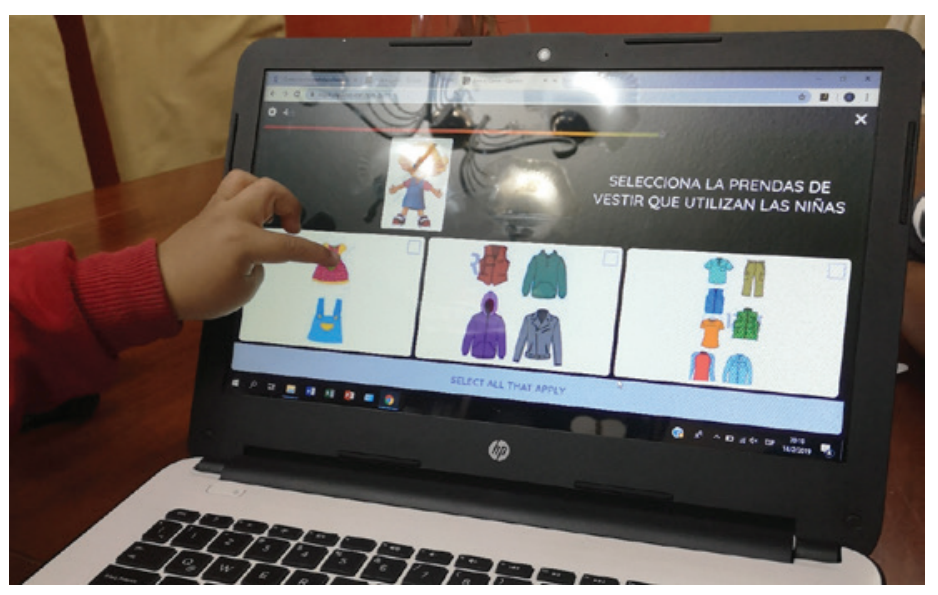

Figura 3

Uso de Quizizz por parte de participantes en una aula

Finalmente, se aplicó Plickers, una herramienta que a diferencia de las anteriores no necesita una computadora o dispositivo móvil para contestar a las preguntas, en su defecto, genera un código QR para cada participante o grupo ingresado en una clase. En Plickers, primero se crea una clase, posteriormente se da de alta a los estudiantes de la clase. Se crean conjuntos de preguntas y de ellos se pueden extraer una o varias para una clase determinada. La ventaja de esta herramienta es que no necesita que los estudiantes cuenten con un dispositivo móvil. En la aplicación se entregó una tarjeta impresa a cada casa de confraternidad o bufete de abogados. Cada código $\mathrm{QR}$ de la tarjeta tenía a cada lado una alternativa A-B-C-D. Después de proyectar una pregunta, el profesor con un dispositivo móvil conectado a Internet pudo leer las respuestas representadas en cada tarjeta. Los participantes ubicaron la tarjeta en una posición de acuerdo a su respuesta, mientras que el profesor escaneaba los resultados, que eran mostrados en pantalla. Esta herramienta resultó más compleja para los participantes porque la interfaz de diseño del cuestionario no fue tan intuitiva como las dos anteriores. Sin embargo, causó motivación y participación de los equipos. En la 
Figura 4 se muestra un ejemplo en un escenario real y se puede observar las expresiones de los participantes.

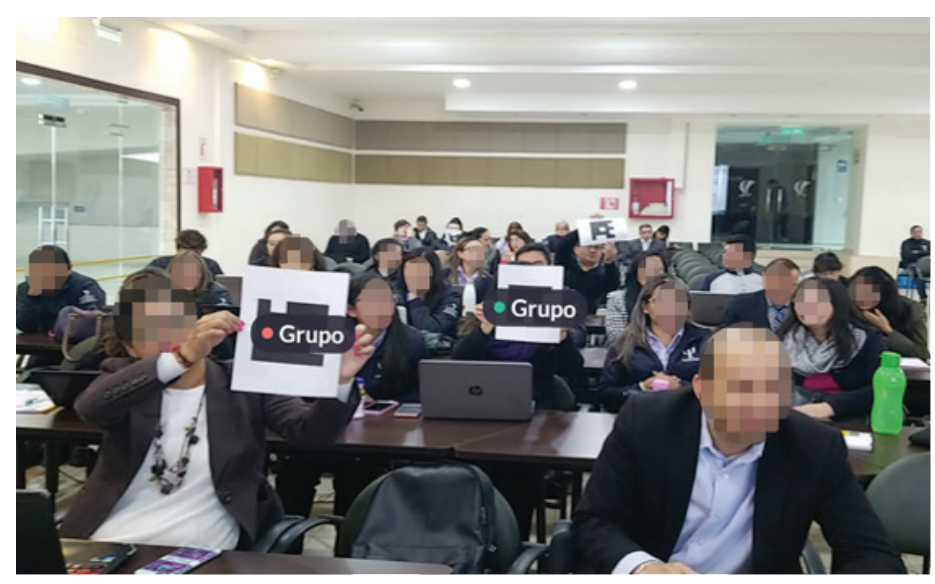

Figura 4

Docentes responden a una pregunta con un código QR en Plickers

En todas las aplicaciones se puso a prueba el número de participantes, logrando obtener hasta 31 usuarios conectados a la vez. En este caso Kahoot y Quizizz si mostraron problemas de conexión en un número mayor a 20 participantes. Ante este problema los maestros diseñaron una estrategia de grupos y dieron solución a este problema de conectividad. A pesar que Plickers no tenía este problema, los maestros prefirieron usar en su fase de evaluación las dos primeras. Estudios similares de gamificación en el aula coinciden en que estas herramientas generan colaboración, participación y motivación, además que permiten llevar un control instantáneo del progreso del alumno de manera individual y de la clase en conjunto (Dellos, 2015; López García, 2016).

Los resultados encontrados con el instrumento de consulta con respecto al uso de estas herramientas en sus aulas en la fase de evaluación, permitieron identificar que Kahoot y Quizizz fueron más intuitivas en el diseño de cuestionarios y más entretenidas a la hora de aplicar en el aula. Mientras que Plickers a pesar que no se requiere que todos los participantes tengan un dispositivo móvil, no fue ampliamente aplicada en la fase de evaluación, como se puede ver en la Figura 5.

Parece ser que el aprendizaje basado en juegos es una buena práctica en educación y encontrar formas de integrar juegos competitivos en el aula ¿que herramienta utilizó en su aula de clase?

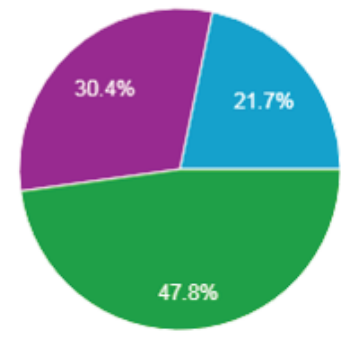

Kahoot !

Quizizz

Plickers

\section{Figura 5}

Estadísticas de uso de las herramientas de evaluación

que promuevan el aprendizaje es esencial para profesores y estudiantes.

Recursos educativos con realidad aumentada y códigos QR

En esta categoría, los equipos diseñaron recursos educativos que combinaron materiales de aula tradicionales con dispositivos móviles. Para ello usaron códigos QR y aplicaciones de realidad aumentada. La inclusión del software que lee códigos $\mathrm{QR}$ en dispositivos móviles permitió darle nuevos usos para compartir información visual dentro del ámbito educativo, pues permite conectar cualquier contenido a un código $\mathrm{QR}$, ya sea un URL o contenido multimedia. Siguiendo las fases de la metodología Design thinking los equipos desarrollaron su creatividad y crearon varios prototipos relacionados al problema que cada uno de ellos tenía en el equipo STEM se dieron cuenta que los estudiantes presentan falencias en el aprendizaje de las Matemáticas, para ello diseñaron el recurso educativo "Twister preguntón, que consistía en un conjunto de códigos QR relacionadas a preguntas de, si un participante contestaba erroneamente a una pregunta, tenía que ejecutar un reto en el tablero del juego. En la figura 7 se muestra la demostración del juego.

Para este tipo de aplicaciones se capacitó a los equipos a programar en MIT App Inventor, en el cual se integraron imágenes y audios en formato MP3 grabados por los mismos participantes con la aplicación Hi-Q MP3. Esta actividad propició el trabajo en equipo y según los comentarios de los particpantes, les permitió descubir nuevos ele- 


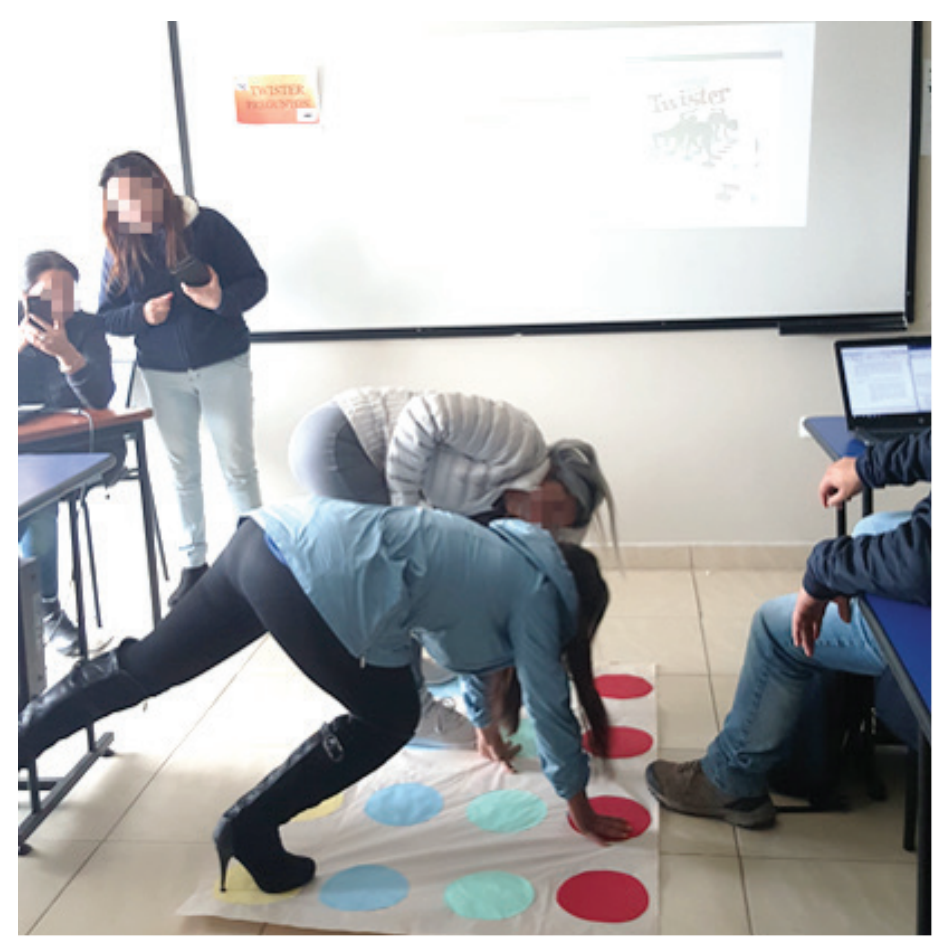

Figura 6

Tablero del Twister preguntón

mentos para ser incorporados en el aula. Uno de los problemas encontrados fue aprender el lenguaje de bloques que porporciona la plataforma MIT App Inventor. En la Figura 7 se muestra la interfaz de la aplicación y el algoritmo utilizado en código de bloques.

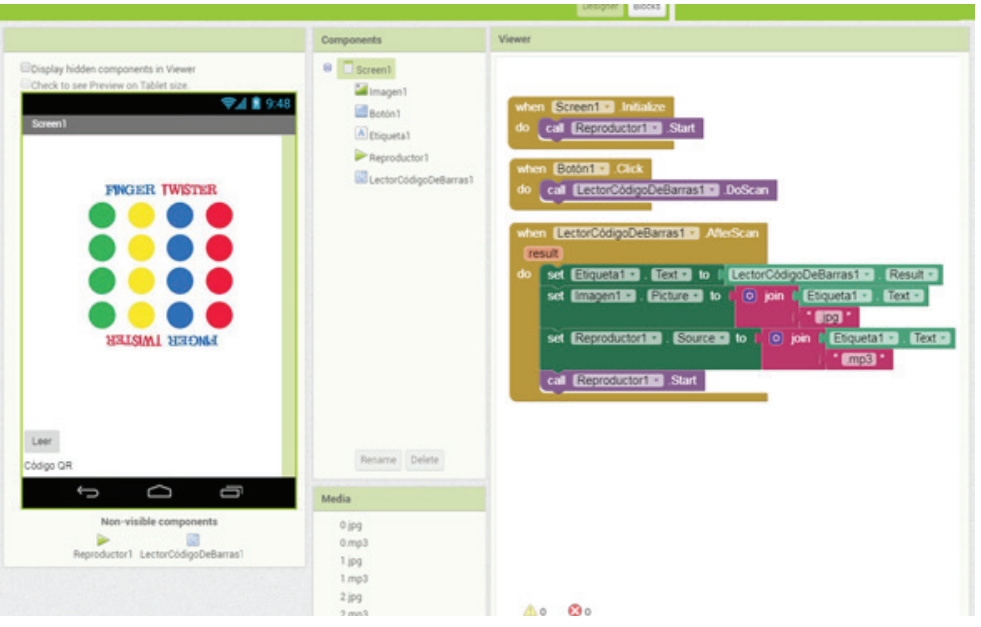

Figura 7

Interfaz y programación del Twister Preguntón en MIT App Inventor

Otro prototipo basado en los juegos interactivos para estudiantes con necesidades educativas especiales, desarrollado en la Universidad Tecnológica Indoamérica (Navas, 2018), fue el "El juego de mesa inclusivo" cuyo objetivo es permitir que los niños con necesidades especiales jueguen con otros miembros de su familia a través de actividades apoyadas por la tecnología. El juego de mesa tiene elementos tradicionales y, en ciertos casos, se integra con una tableta para ver los elementos del juego con realidad aumentada o teléfonos inteligentes que leen etiquetas NFC. Por ejemplo, una tarjeta con códigos Braille vistos a través de una tableta puede generar una realidad aumentada con su significado. Para ello los maestros aprendieron a descifrar el código Braile, para asociarlos con una imagen y letra del abecedario (Arroyo et al., 2019). Otras tarjetas tenían códigos QR que proporcionan información adicional o preguntas sobre el tema del Juego. El equipo de Educación Especial e Inclusiva diseñó el prototipo con tarjetas que contienen código Braile en la que los jugadores no videntes pueden leer las tarjetas por medio de éste código, mientras que los jugadores videntes pueden ver el significado en realidad aumentada, información que ayuda al entretenimiento y al aprendizaje. Los participantes reflexionan "Creemos que es una idea innovadora que utiliza tecnología disruptiva que rara vez se ve en nuestro entorno y se aplica a una población vulnerable y un poco olvidada”. La figura 8 muestra el juego de mesa inclusivo con tarjetas con código Braile y Realidad Aumentada.

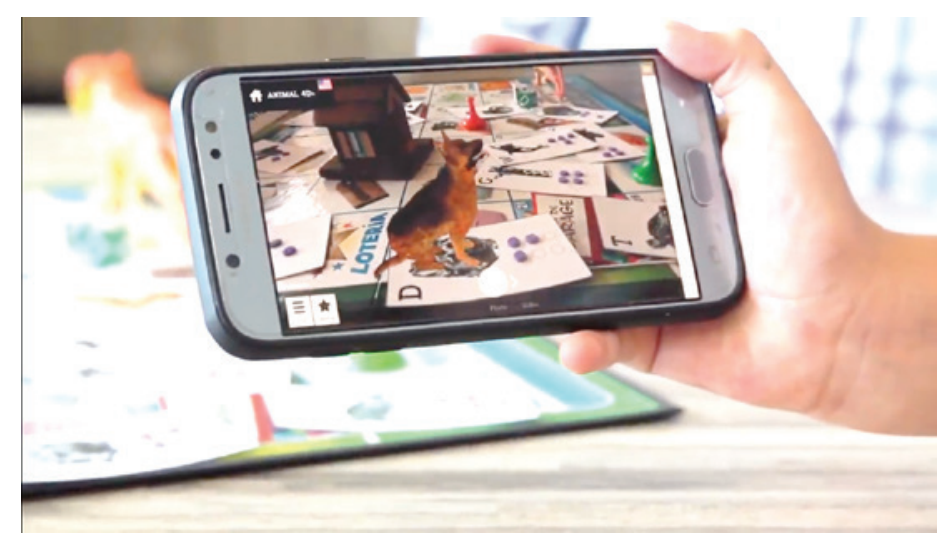

Figura 8

Juego de mesa inclusivo contiene tarjetas con código Braile y Realidad Aumentada

Contrastando los resultados generado y estudios similares, se coincide que la utilización de los códigos QR sin duda son una herramienta tecnológica muy innovadora y de gran ayuda para 
despertar el interés de los estudiantes en el proceso de enseńanza-aprendizaje (Monedero et al., 2017). Por otro lado, la realidad aumentada agrupa aquellas tecnologías que permiten la superposición, en tiempo real, de imágenes, marcadores o información generados virtualmente, sobre imágenes del mundo físico y generan gran interés en los estudiantes (De la Horra Villacé, 2016).

\section{Prototipos de Recursos Educativos híbridos}

Para los recursos educativos híbridos, los equipos fueron capacitados en el uso de Scratch y Makey Makey. Scratch, que es una plataforma diseñada para desarrollar habilidades de pensamiento lógico a través de un lenguaje de programación sencilla, el mismo que en su aplicación se puede interactuar de manera didáctica por medio de piezas (bloques) de rompecabezas. Este conjunto de instrucciones permiten desarrollar la creatividad para escribir historias y juegos interactivos. Makey Makey es una placa electrónica que extiende las funciones del teclado y ratón de la computadora, lo que permite enviar órdenes al computador al que se encuentre conectado por medio de un cable USB. En vez de pulsar las teclas de las flechas o barra espaciadora lo que hace es cerrar el circuito mediante contactos o pinzas de cocodrilo $y$ de esta forma se simula haber pulsado una tecla. Lo cual permite convertir cualquier objeto de la vida diaria en un teclado, un mando o un ratón al brindar a los usuarios conectar objetos cotidianos a programas de computadora o bien programarlos con Scratch (Strawhacker et al., 2015).

Uno de los prototipos híbridos considera el aprendizaje de la lateralidad con la música y el baile. La figura 9 muestra la interfaz híbrida con cartulina y papel de aluminio.

En el área de lenguaje y literatura, los maestros diseñaron un prototipo construido con Scratch y Makey Makey para fortalecer la conciencia fonológica y la asociación. Para ello crearon un cuento digital, en el cual un estudiante después de escucharlo crea elementos o personajes del cuento con plastilina. Estos elementos se conectan a la computadora a través de Makey Makey y Scratch. La estrategia didáctica fue la de asociación de los elementos digitales con los físicos basados en la

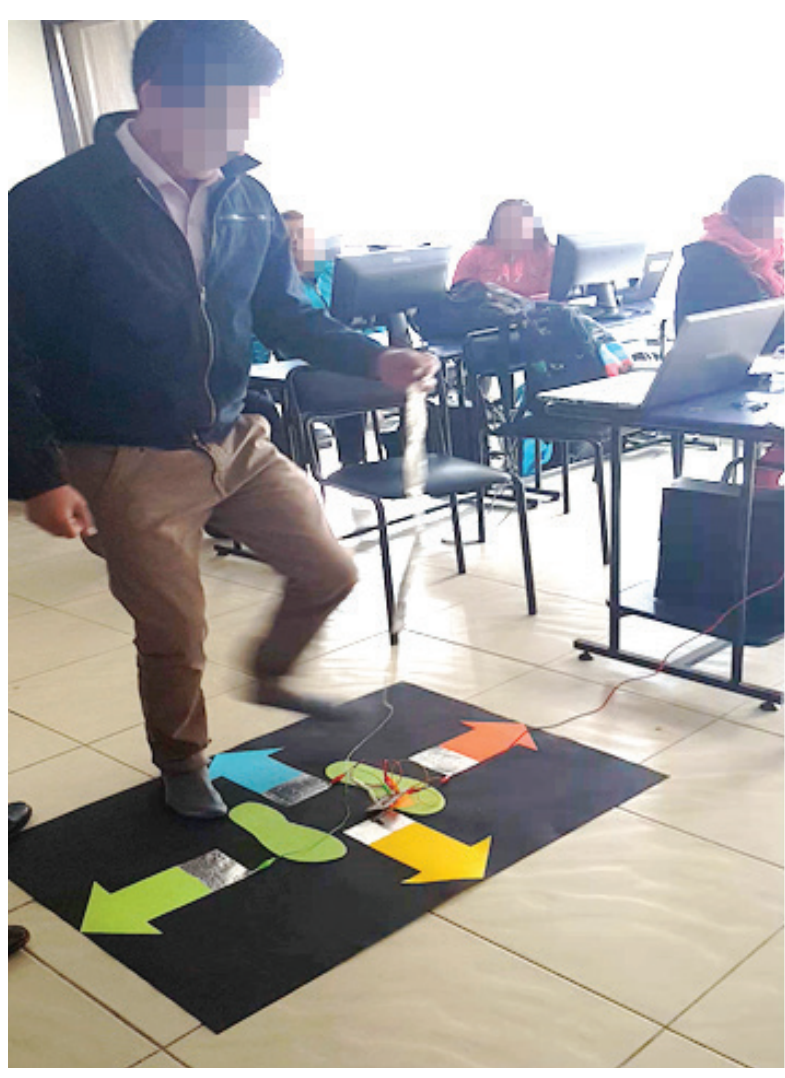

Figura 9

Tablero dance, dance revolution construído con cartulina y papel aluminio

relación pictograma-fonema Esta propuesta esta orientada a niños con necesidades educativas especiales para mejorar su nivel de motricidad fina y lectura. Según un estudio que se hizo con interfaces tangibles, estas favorecen a la estimulación sensorial y al aprenizaje significativo (Fan \& et.al, 2017). En la Figura 10 se muestra el prototipo de conciencia fonológica.

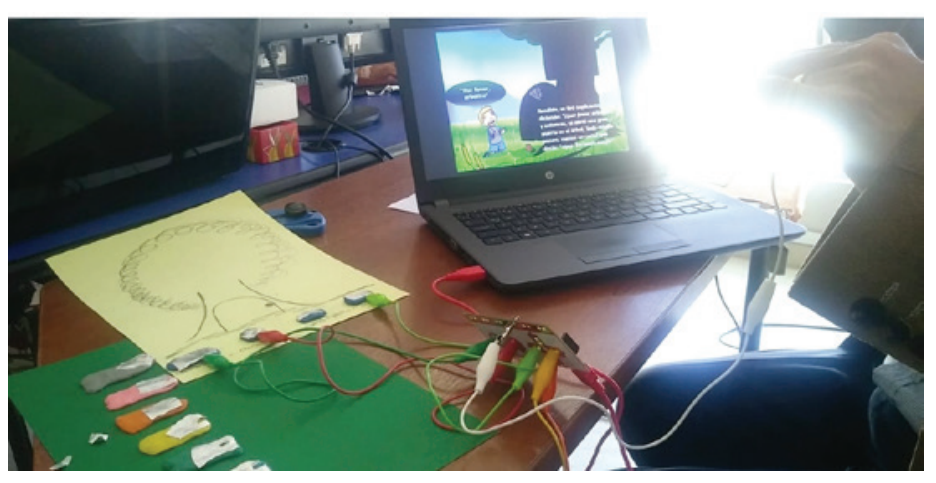

Figura 10

Prototipo de conciencia fonológica construído con cartulina y plastilina

En el área de las ciencias naturales, un grupo diseñó una placa similar a la anterior, pero en lugar 
de letras tenía los órganos del cuerpo humano hechos de plastilina. Explican los maestros que sus estudiantes pueden construir los órganos del cuerpo humano y mediante Makey Makey y un programa en Scratch pueden mostrar información adicional. En la Figura 11 se muestra el tablero del cuerpo humano.

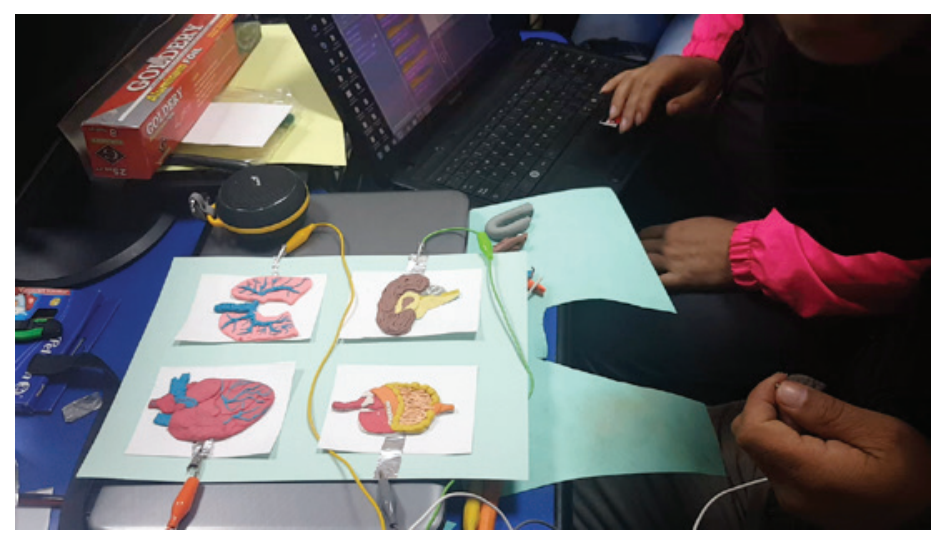

Figura 11

Tablero de órganos del cuerpo humano construído con cartulina y plastilina

\section{Discusión y Conclusiones}

Uno de los problemas a los que se enfrentan los maestros en el aula, es la forma de evaluar los objetivos propuestos en la malla curricular y la forma de controlar el proceso de asimilación de los aprendizajes, así como el grado de dominio de los contenidos por parte de los estudiantes. La tecnología ha permitido poder hacer este proceso de manera inmediata y rápida; sin recurrir a los controles habituales que presionan al alumnado, y siendo copartícipe de estos objetivos el estudiantado; estimulándolos de una forma lúdica y gráfica (Educación 3.0, 2015).

En este trabajo se ha presentado una experiencia de innovación educativa siguiendo una metodología Design Thinking y Game thinking que intenta potenciar la creatividad e innovación de 120 maestros de educación primaria, secundaria y superior a través de un pensamiento lúdico. Para desarrollar esta experiencia se ha seguido la técnica b-learning por medio de una plataforma Moodle, en la cual se planifican las actividades grupales e individuales y se recogen las evidencias y testimonios de los maestros. Asimismo, se trabajó para desarrollar las competencias transversales de los maestros a través del aprendizaje significativo, las actividades se centraron en los problemas mencionados en la fase de empatía. Se ha podido observar que el $100 \%$ de los participantes dispone de un teléfono inteligente, sin embargo, su utilización en el ámbito académico es escaso, pero si se destaca el uso de Whatsapp como herramienta de comunicación y coordinación grupal. De los resultados cualitativos se observó que el trabajo en equipo fue una de las características más importantes en el aprendizaje basado en retos, que permitió el trabajo en proyectos reales con metodologías de innovación y creatividad.

Las estrategias para desarrollar la creatividad y la innovación a través del pensamiento de diseño y aprendizaje basado en retos y juegos permitieron generar prototipos de recursos educativos apoyados por la tecnología. Se observó que la experiencia desarrollada fue muy gratificante, ya que observó a los participantes altamente motivados y desarrollaron prototipos creativos e innovadores, se logró una alta participación en las sesiones presenciales y en las actividades virtuales. Aunque los resultados fueron positivos, es necesario mencionar algunas de las limitaciones que se presentaron en este estudio, una de ellas era la incomodidad que sintieron algunos de los participantes al saber que usarían la tecnología, de antemo existía esa preconcepción de que èsta es compleja y difícil de usar, sin embargo al utilizar la metodología Game Thinking pudieron evidenciar con el juego, que no fue tan compleja como pensaban y fueron capaces de usarla. De igual manera, pasó cuando sabían que serían evaluados o tenían que aprender a programar, tal vez porque se imaginaban evaluaciones tradicionales o lenguajes de programación complejos. Cuando pudieron ver los resulatdos obtenidos reflexionaron que existen herramientas fáciles de usar, como Kahoot, Quizizz y Plickers para evaluación; así como Scratch y MIT App Inventor para programar actividades sin saber programar. Otra limitación fue la capacidad de memoria y la diversidad de los dispositivos móviles de los participantes, que hizo que se desvíe el desarrollo de las estrategias didactica a la limpieza y depuración de los dispositivos. 
Estas vivencias nos anima a continuar trabajando para replicar esta experiencia innovadora en futuras generaciones. Como trabajo futuro se va a profundizar en el desarrollo del prototipo del juego de mesa inclusivo, el cual creemos que tiene un gran potencial para integrar varias de las tecnologías descritas en el estudio, y además que contribuya a la introducción de la tecnología en el aula.

\section{Agradecimientos}

Un agradecimiento especial a los alumnos de la Maestría en Educación, Mención Innovación y Liderazgo Educativo (MEILE-3), por compartir sus vivencias en el módulo de Infopedagogía Educativa.

\section{REFERENCIAS BIBLIOGRÁFICAS}

Adell J. \& Castañeda L. (2012). Tecnologías emergentes, ¿pedagogías emergentes? Asociación Espiral, Educación y Tecnología, pp. 13-32

Arroyo, N., Campos, F., Carballo, M., González, G., Solano, A., Vargas, E., \& Carpio, M. (2019). El Modelo dual de reconocimiento de la palabra en el Sistema Braille. Revista CienciAmérica, 8(1), 90-104. https://doi.org/10.33210/ca. v8i1.194

Bautista M., Martínez A. \& Hiracheta R. (2014). El uso de material didáctico y las tecnologías de información y comunicación (TIC's) para mejorar el alcance académico, Ciencia y Tecnología, 14, 2014, 183-194.

Carbonell, J. (2002). La aventura de innovar. El Cambio en la Escuela, Ediciones Morata

De la Horra Villacé, I. (2016). Realidad aumentada, una revolución educativa. EDMETIC, 6(1), 9-22. https://doi. org/10.21071/edmetic.v6i1.5762

De Puy M. \& Miguelena R. (2017). Importancia de la Gamificación en la Educación Aplicado en Entornos de la Investigación, 15th LACCEI International Multi-Conference for Engineering, Education, and Technology: "Global Partnerships for Development and Engineering Education”, 1921 July 2017, Boca Raton Fl, United States.

Dellos, R. (2015). Kahoot! A digital game resource for learning, International Journal of Instructional Technology and Distance Learning, 12. (4).

Educación 3.0 (2015). Aprendizaje activo con sistemas de respuesta en Infantil y Primaria, Recuperado de https:// www.educaciontrespuntocero.com/experiencias/aprendizaje-activo-infantil-primaria/26144.html.
EduTrends (2017). Observatorio de Innovación Educativa, Reporte Edu Trends. Monterrey, México: Tecnológico de Monterrey

Fan, M., Antle, A. N., Hoskyn, M., Neustaedter, C. \& Cramer, E. S. (2017) Why tangibility matters: A design case study of at-risk children learning to read and spell. Proceedings of the 2017 CHI Conference on Human Factors in Computing Systems, USA, içinde (ss. 1805-1816). https:// doi.org/10.1145/3025453.3026048

González, C. (2015). Estrategias para trabajar la creatividad en la Educación Superior: pensamiento de diseño, aprendizaje basado en juegos y en proyectos. Revista de Educación a Distancia (RED), 40(2), 2-15. Recuperado de: http://www. um.es/ead/red/40

Hernández-Sampieri R. \& Mendoza, C. (2018). Metodología de la Investigación: Las rutas cuantitativa, cualitativa y mixta, Mc Graw Hill. https://doi.org/10.17993/CcyLl.2018.15

Inge Wang A. \& Lieberoth A. (2016). The effect of points and audio on concentration, engagement, enjoyment, learning, motivation, and classroom dynamics using Kahoot!, Academic Conferences and Publishing International Limited

Jadán-Guerrero, J. \& Ramos-Galarza, C. (2018) Metodología de Aprendizaje Basada en Metáforas Narrativas y Gamificación: Un caso de estudio en un Programa de Posgrado Semipresencial. Hamut'ay, 5 (1), 84-104. https:/doi. org/10.21503/hamu.v5i1.1560

Llano, P. (2015). La innovación no es solo cambio de tecnología, AGLALA ISNN 2215-7360; 6 (1): 38-72. https:// doi.org/10.22519/22157360.909

López, N.J. (2016). Evaluación y TIC en Primaria: el uso de Plickers para evaluar habilidades musicales. ENSAYOS, Revista de la Facultad de Educación de Albacete, 31(2). Recuperado de http://www.revista.uclm.es/index.php/ensayos

Marczewski, A. (2015). User Types. In Even Ninja Monkeys Like to Play: Gamification, Game Thinking and Motivational Design. Recuperado de http://www.gamified.uk/usertypes/

Martínez, G. (2017). Tecnologías y nuevas tendencias en educación: aprender jugando. El caso de Kahoot. Revista Opción, 33 (83), 252-277.

Monedero C., Castro A. \& Tomás J. (2017). Videotutoriales y códigos QR: recursos TIC en laboratorios de Ciencias de la Comunicación, INNOEDUCA. International Journal of Technology and Educational Innovation, 3 (2), 137 - 145. https://doi.org/10.24310/innoeduca.2017.v3i2.2046

Navas, E., \& Caisachana, A. (2018). Juego Interactivo para Incrementar la Atención y Retentiva Visual en Niños con Síndrome de Down. Revista CienciAmérica, 7(1), 30-36. Recuperado de http://cienciamerica.uti.edu.ec/openjournal/index.php/uti/article/view/149

Ramos, C. (2019). Fundamentos de investigación para psicólogos: primer round. Quito, Ecuador: Universidad Tecnológica Indoamérica. 
Razzouk, R., \& Shute, V. (2012). What Is Design Thinking and Why Is It Important? Review of Educational Research, 82(3), 330-348. https://doi. org/10.3102/0034654312457429

Reveles J. (2018). La educación disruptiva transforma el aprendizaje, El sol de Zacatecas. Recuperado de https:// www.elsoldezacatecas.com.mx/analisis/la-educacion-disruptiva-transforma-el-aprendizaje-1156622.html

Rojas-Montero, J. \& Díaz-Better, S. (2018) Presencia Docente en Ambientes de Aprendizaje Mediados por Tecnologías de la Información y la Comunicación. Hamut'ay, 5 (1), 53-65. https://doi.org/10.21503/hamu.v5i1.1520

Strawhacker A., Lee M., Caine C. \& Bers, M. U. (2015). ScratchJr Demo: A coding language for kindergarten. Proceedings of the 14th International Conference on Interaction Design and Children (IDC '15). Boston, MA: ACM. https://doi.org/10.1145/2771839.2771867 


\title{
Educomunicación y Buenas Prácticas en los nuevos escenarios tecnológicos: Análisis del Caso Gallego (España)
}

\section{Educommunication and Good Practices in the new technological scenarios: Analysis of the Gallego case (Spain)}

\author{
Mari-Carmen Caldeiro-Pedreira ${ }^{1}$ \\ https://orcid.org/0000-0003-0160-3682 \\ Universidad de Santiago de Compostela, España \\ Ignacio Aguaded ${ }^{2}$ \\ https://orcid.org/0000-0002-0229-1118 \\ Amor Pérez-Rodríguez ${ }^{3}$ \\ https://orcid.org/0000-0001-8312-5412 \\ Universidad de Huelva, España
}

Recibido: 06-02-2019

Aceptado: 28-03-2019

\section{Cita recomendada}

Caldeiro-Pedreira, M.C., Aguaded, I. \& Peréz-Rodríguez, A. (2019) Educomunicación y Buenas Prácticas en los Nuevos Escenarios Tecnológicos: Análisis del Caso Gallego (España) Hamut'ay, 6(1), 96-111.

http://dx.doi.org/10.21503/hamu.v6i1.1577

\section{RESUMEN}

El uso y acceso a las tecnologías de la información y comunicación se ha convertido en una realidad. Actualmente hay casi más teléfonos que personas, además desde edades tempranas se utilizan múltiples pantallas y se accede a Internet. Frente a esta realidad, conviene reflexionar sobre la necesidad de que dos disciplinas de antaño separadas: la educación y la comunicación, aúnen sus esfuerzos para que la totalidad de la ciudadanía esté alfabetizada. En este sentido, resulta fundamental que no solo el profesorado sino también las familias alcancen un mínimo desarrollo de la competencia digital que les permita enseñar a los menores a utilizar adecuadamente los dispositivos digitales. Asimismo, y pese a la inexistencia de políticas educativas claras que amparen la educomunicación como un contenido curricular ni en el contexto español ni en el gallego, se cuenta con iniciativas que responden a los objetivos marcados por el informe DIGCOMP y por el Marco Común de Competencia Digital Docente. Por lo que, en esta investigación con un diseño de estudio analítico-descriptiva documental, se tuvo como objetivos el caracterizar el término educomunicación en relación con el desarrollo de la competencia digital, así como el analizar la legislación educativa, concretamente del

\footnotetext{
1 Doctora en Comunicación y Educación, docente en la Universidad de Santiago de Compostela (España) Docente en universidades latinoamericanas (Chile y Ecuador). Investigador en el Centro de Estudios de Educación Superior (República Checa).Miembro del consejo asesor y revisor científico de revistas nacionales e internacionales. E-mail: mcarmen.caldeiro@usc.es

2 Catedrático de Educación y Comunicación de la Universidad de Huelva. Es presidente del Grupo Comunicar, un colectivo de alfabetización Mediática de larga trayectoria en España. Jefe del equipo de investigación de Ágora que forma parte del Plan de Investigación de Andalucía (HUM-648), director del Máster Internacional de Comunicación y Educación (UNIA, UHU) y Coordinador del Programa Interuniversitario de Doctorado en Comunicación (UHU, UMA, UCA, UHU). E-mail: aguaded@uhu.es

3 Profesor del Departamento de Filología de la Universidad de Huelva. Miembro del Grupo de Investigación Agora, Grupo Comunicar y Alfamed. Editor asistente de Comunicar Journal y editor de Universitas Journal of Social and Human Sciences (Universidad Politécnica Salesiana, Ecuador). (h-index, 16). Lidera proyectos de investigación nacional e internacional sobre alfabetización mediática y narrativas digitales. E-mail: amor@uhu.es
} 
contexto gallego en España y revisar buenas prácticas existentes para desarrollar la conciencia crítica, autónoma y responsable a edades tempranas.

Una formación que no está regulada como tal ni en el contexto español ni en el gallego. Pese a todo, existen buenas prácticas que, desde el ámbito educativo se están llevando a cabo. Las conclusiones apuestan por una tarea conjunta entre el trabajo de la escuela y la familia que han de favorecer la alfabetización de los menores.

Palabras Clave: Escenarios tecnológicos, educomunicación, educación infantil, buenas prácticas

\begin{abstract}
The use and access to information and communication technologies have become a reality. Currently, there are almost more phones than people. Multiple screens are used and the Internet is accessed from an early age. Faced with this reality, it is convenient to reflect on the need for two formerly separate disciplines: education and communication, to combine their efforts so that the entire citizenship is literate. In this sense, it is essential that not only teachers but also families achieve a minimum development of digital competence that allows them to teach children to properly use digital devices. Likewise, and despite the lack of clear educational policies that assure educommunication as a curricular content neither in the Spanish nor in the Galician context; there are still initiatives that respond to the objectives set by the DIGCOMP report and the Common Digital Competence Framework for Teachers. For this reason, in this research with a documentary descriptive analytical study design, the objectives were to characterize the term educommunication in relation to the development of digital competence, as well as to analyze educational legislation, specifically in the Galician context in Spain and to review existing good practices to develop critical, autonomous and responsible awareness at an early age. An area that is not regulated as such neither in the Spanish nor in the Galician context. In spite of everything, there are good practices that are being executed from the educational field. The conclusions convey a joint task between school and family that benefit the literacy of children.
\end{abstract}

Keywords: Technological scenarios, educommunication, children education, good practices

\section{INTRODUCCIÓN}

La ciudadanía en general y, de forma concreta los menores utilizan los medios de comunicación para entender el mundo, y buscar modelos con los que se identifiquen (Sahuquillo, 2007; Caridad-Sebastián \& Ayuso-García, 2011). Una realidad que, pese a la existencia de desigualdades a nivel planetario en el acceso a Internet, conforme avanza el tiempo, comienza a disiparse (Pérez-Gutiérrez \& Florido-Bacallao, 2011).
Además de la brecha de acceso, la de uso y la de calidad de uso (Mendoza-Ruano \& Caldera-Serrano, 2014) focalizan la atención dado que no sólo impiden la inclusión digital, sino que favorecen la discriminación socio-cognitiva al tiempo que interfieren en el desarrollo de relaciones tanto horizontales como verticales. Tales desigualdades permiten que se ignoren gran parte de las posibilidades que ofrecen los medios (Carlsson, 2013). Especialmente en el caso de Internet, se obvian potencialidades como son la adquisición y crea- 
ción de conocimiento o la posibilidad de que se comparta con fines no lúdicos ni perniciosos. En este sentido, resulta clave una implicación marcada por parte de la familia y de los educadores, agentes básicos que, de forma marcada a edades tempranas, han de responsabilizarse y promover una educación mediática que permita a los menores a mantener un rol participativo, reflexivo y comprometido ante los medios.

En esta línea, deben primar y fortalecer el desarrollo de la competencia mediática, una tarea que compete no solo a las familias sino además a los docentes; en este sentido, resulta fundamental conocer factores tan relevantes como: la necesidad de poder acceder a los recursos, tecnologías y materiales audiovisuales; el desarrollo profesional de manera continuada que permite abordar los cambios y tener respuestas adecuadas a las nuevas demandas; la colaboración entre familias, estudiantes, docentes, administradores y profesionales de los medios, para compartir conocimientos y experiencias; y por último, la necesidad de investigar sobre alfabetización mediática e informacional. La totalidad de elementos harán posible la continuidad y el avance alrededor de las mejores prácticas de alfabetización, entendida esta última como la disciplina que ofrece conocimientos no solo instrumentales sino también axiológicos y críticos que empoderan al sujeto para actuar de forma responsable en la sociedad digital.

En este contexto, conviene señalar que la presencia de los medios no conlleva la adquisición de la competencia mediática, entendida esta última como la habilidad que contribuye a la alfabetización digital, es decir, la formación necesaria para afrontar los cambios que suponen el uso masivo en las diferentes facetas de la vida de las tecnologías de la información y la comunicación, (Hobbs \& Coiro, 2019). Esta competencia resulta imprescindible en el ecosistema mediático más reciente, y está referida a la habilidad que prepara a la ciudadanía para ser crítica, activa y responsable ante los contenidos audiovisuales que recibe (Aguirre-Sala, 2013; Ballesteros-Velázquez, 2010)

En esta línea, resulta clave apelar a la responsabilidad de la institución educativa y la sociedad tecnológica, una necesidad que se acrecienta cuando las redes y la tecnología están avanzando de forma continua y constante. Este avance lleva intrínseca una complejización de la totalidad de aspectos derivados de la era digital (Ranzólin, 2018) y demanda la conversión del usuario en "prosumidor" de contenidos (Carrero \& Contreras, 2014). En este contexto sociocomunicativo resulta imprescindible el alcance de conductas responsables que se desarrollen con base en las competencias digitales y mediáticas que capacitan al usuario para la adecuada creación de contenidos críticos, responsables y creativos. La tarea de producción constructiva y autónoma inicialmente se consideraba propia de emisores críticos (Aguaded, 2012; Gozálvez \& Contreras, 2014) si bien no es exclusiva de los emisores, sino que corresponde también a los productores, es decir el conjunto de usuarios digitales que deben convertirse en prodiseñadores de contenidos (Hernández-Serrano, Renés-Arellano, Graham \& Greenhill, 2017).

Con el fin de alcanzar este objetivo resulta fundamental la integración de los medios en la enseñanza, una inmersión que ha de producirse desde edades tempranas y que debe realizarse desde una doble óptica: como recurso e instrumento del aprendizaje, ya que se relaciona no solo con el alumnado sino también con su forma de aprender,-semejante a la que se produce fuera del ámbito escolar- y por otra parte, como objetivo mismo del aprendizaje, al ofrecer instrumentos que posibiliten la interpretación y procesamiento de los contenidos que reciben a través de los medios. Con todo ello se auspicia favorecer el desarrollo del pensamiento reflexivo tan necesario en la sociedad de la información y del conocimiento (Ortega-Ruiz, Casas \& Del Rey, 2014). Por todo ello, resulta fundamental considerar nuevos retos culturales, sociales y educativos que permitan la introducción de formas de enseñanza que capaciten al usuario, desde edades tempranas para enfrentarse a la comprensión, creación, gestión y distribución de contenidos, una formación que ha de conducir a la convivencia tanto en el ambiente presencial como en el virtual. (Sánchez-Teruel \& Robles-Bello, 2016).

En este contexto, la educación se enfrenta a nuevos retos adquiriendo un papel clave como mediadora, para ello debe apoyarse en el uso de las nuevas técnicas y estrategias metodológicas, sin 
dejar de lado la adquisición de conocimientos. En definitiva, ha de superarse la mera transmisión vertical central y unidireccional de contenidos; en el contexto audiovisual y digital más reciente, la educación debe cumplir una función comunicativa, horizontal, descentralizada, multidireccional e interactiva. Este cambio define la necesidad de reflexión sobre la transformación de la educación, en general y de forma particular la educación mediática que se propone como resorte para empoderar, no solo al alumnado sino además al profesorado. Asimismo, tal necesidad justifica el hecho de que antes de entrar en la escuela, los menores toman contacto con los medios adquiriendo de este modo, una alfabetización informal básica. Teniendo presente estos hechos, la educación formal no debe alejarse de la realidad y que el profesorado ha de contar con las habilidades necesarias para no incurrir en acrecentar la brecha digital que puede establecerse entre el ambiente escolar y el social de donde proviene el alumnado (Chamorro-Crisaldo, 2018). Para ello, se propone que desde la escuela se apueste por la educación que tiene como centro el aprendizaje significativo que se construye sobre destrezas ya adquiridas y la alfabetización mediática del alumnado que subraya el potencial educativo de las TIC en los contextos intra y extra escolares.

La realidad justifica que la investigación que se presenta se apela al uso de buenas prácticas como forma de desarrollo de la expresión crítica desde edades tempranas. Una expresión que se va cimentando durante toda su vida y que permitirá el alcance de la competencia critica, necesaria en una sociedad hipercomunicada, (García-Avila, 2017; Johnson et al, 2016). Este desarrollo se prevé creciente y continuo a lo largo de la vida de los más pequeños, por ende, se apela al "life long learning» (Longworth, 2005) que permitirá el alcance de la competencia crítica (Caldeiro \& Aguaded, 2015; Tirado \& Ventura, 2009) propia de la ciudadanía que convive en la sociedad hipercomunicada (Regil, 2014) y propia de quienes deben desarrollar nuevas miradas (Cabero \& Marín, 2014).

En la sociedad líquida (Bauman, 2004) el conocimiento se ha vuelto inestable y dinámico (Cabero, 2018) por tanto resulta necesario el desarrollo de nuevas formas de aprendizaje y es imprescindible disminuir la brecha de conocimiento que irremediablemente se establece entre la educación formal que se imparte en las instituciones educativas y la informal a la que, desde edades tempranas estamos expuestos. La realidad justifica el interés por caracterizar el término educomunicación en relación con el desarrollo de la competencia mediática que ha de alcanzarse mediante la adecuada alfabetización digital y cognitiva.

Además, centra el interés el análisis de la legislación educativa, concretamente del contexto gallego en España y revisar buenas prácticas existentes para desarrollar la conciencia crítica, autónoma y responsable a edades tempranas.

\section{Educomunicación y alfabetización en el contex- to digital actual}

Educación y comunicación son dos disciplinas que inicialmente discurrían de manera independiente si bien, conforme se ha ido complejizando el entramado socio-comunicativo, la situación se ha visto modificada de forma determinante. Para (Barbas, 2012; Gregorio-Chaviano, 2018) es un campo interdisciplinar y transdisciplinar que integra dos disciplinas la educación y comunicación. En este sentido, desde finales de la década de los ochenta del pasado siglo la UNESCO ha comenzado a preocuparse por políticas de comunicación en diferentes países. Asimismo, pedagogos como Freinet a comienzos del siglo pasado han apostado por la enseñanza de forma activa. En este sentido, el autor ha sido pionero al sugerir la introducción de la comunicación en el ámbito educativo con el fin de transformar el método memorístico. De esta forma, se ha situado como uno de los precursores a la hora de proponer una nueva forma de enseñar similar a la que hoy en día se demanda. Posteriormente, continuando con esta misma filosofía Freire (1997) se ha referido a la post-alfabetización, un aspecto destacado puesto que, según indica, más allá de la transmisión de conocimientos y la acumulación de los mismos, es necesaria su comprensión.

En este sentido, es posible afirmar de forma rotunda que estos objetivos se adelantaban a aquellos propios de la sociedad digital en el sentido de 
que demandaban un cambio hacia un rol activo del alumnado. Asimismo, apuntaban una necesidad que a lo largo de los años se confirma, el hecho de que el profesorado se convierta en un guía, un mentor que ayuda al discente a construir su propio conocimiento y a crecer en el mismo. Un hito que requiere de nuevas formas de enseñanza, aplicación de estrategias y metodologías que sirvan para poner en marcha buenas prácticas en las cuales la tecnología y el trabajo activo, colaborativo y participativo alcanzan un peso fundamental.

En esta línea, diferentes organizaciones de carácter internacional como es el caso de la UNESCO establecen, según puede leerse en su página web (https://bit.ly/2TKTTzP), la necesidad de empoderar a la ciudadanía a través de diferentes alfabetizaciones que han sido definidas, en diversas ocasiones, como múltiples (Area M. \& Ribeiro P., 2012; Tyner, Gutiérrez \& Torrego, 2015). Se trata de conocimientos que permitan avanzar de lo sólido a lo líquido. Una necesidad de la que debe hacerse eco, de forma indiscutible, la educación, tanto del alumnado como la del propio profesorado (Bergomás, 2019; Fernández, 2015). Sin duda alguna, el profesorado no puede permanecer ajeno a los cambios derivados de la ingente cantidad de tecnología que, de manera exponencial, prolifera en el ecosistema audiovisual más reciente.

Actualmente, la mayor parte de las comunicaciones son mediadas por tecnologías, por ello la educación mediática adquiere un valor clave en el contexto académico y el social en general. Esta necesidad se acentúa en un momento en el cual asistimos al "desarrollo de procesos educativos, mediante los cuales las personas se dotan de herramientas básicas para manejar automáticamente y con consciencia crítica la información y la cultura de la sociedad en la que se encuentran inmersos" (Rodríguez-Fueyo, 2008). En este contexto, resulta necesario focalizar las energías en la formación ciudadana en materia mediática y evitar así, caer en la bruma de la ambigüedad extrema y generalizada Buckingham (2005). Además de ello, "La educación mediática es necesaria para alfabetizarse y dialogar con los medios para que los discentes interaccionen entre sí y también con el profesorado" (Hergueta, 2017, p.21). Esta alfabetización corresponde por partida igual a la edu- cación y la comunicación que existen de forma indisoluble. Ambas disciplinas y sus profesionales han de favorecer y promover el alcance de "visiones más amplias y reflexivas y trazar recorridos complejos es tarea de educadores, con una mirada democrática y un espíritu de aprendizaje y de innovación que nos acerque y no nos aleje" (Quiroz, 2010 , p. 202). En definitiva, la educación mediática y la alfabetización digital deben auspiciar el desarrollo de personalidades autónomas, responsables y críticas. Sujetos capaces de comprender y diseñar contenidos audiovisuales que subrayen el valor de la interrelación social y cívica.

Competencia digital y formación docente para el alcance de "prosumers" críticos

Con el fin de que la ciudadanía en general y los más jóvenes en particular superen la "infoxicación”- sobrecarga informativa que está expuesto el usuario-, (Aguaded, 2014) y, se comuniquen e interrelacionen en el contexto digital surge la necesidad de alcance de la competencia digital. De forma general se entiende esta como una habilidad de carácter teórico-práctico que busca no solo capacitar para localizar información y seleccionarla, sino además para comunicarla de modo adecuado. Esta competencia pretende además que quienes la desarrollen sean capaces de producir contenidos audiovisuales de forma segura y han de saber resolver algún problema con tal difusión y producción. En definitiva, siguiendo el Marco de Competencia Digital Docente (INTEF, 2017), un ciudadano competente digitalmente debe desarrollar los conocimientos que le acreditan para estar al menos en el nivel básico de cada una de las 5 áreas que la componen. Esta acreditación de conocimientos permitirá, no solo a nivel español sino también europeo, contar con las políticas necesarias para, según señala el Informe DigCompedu (2018), "implementar herramientas regionales y nacionales y programas de capacitación» adaptadas a los diferentes niveles de desarrollo».

De este modo, y teniendo en cuenta que los nativos e inmigrantes digitales (Prensky 2001, 2005) deben abandonar el papel de consumidores pasivos y ser capaces de afrontar la recepción de contenidos audiovisuales de forma crítica se propone 
su empoderamiento con el fin de que se conviertan en "prosumidores" activos (Sachez-Carrero \& Contreras, 2012) o más bien en "prodiseñadores de contenido" (Hernández-Serrano, Renés-Arellano, Graham \& Greenhill, 2017).

Para que este objetivo se alcance resulta clave el papel de las familias como agentes formativos fundamentales en la sociedad digital. Desde esta perspectiva, tan importante es la labor de la escuela, como lo es la de las familias, pues en ausencia de pautas educativas, constructivas y orientadoras, surgen situaciones indeseadas que perjudican el bienestar emocional de los más jóvenes y las relaciones con sus iguales. Por tanto, se hace imprescindible alcanzar un equilibrio que además de tratar de evitar los riesgos busque apoyar actuaciones que supongan compartir tiempos y criterios en los ámbitos familiar y escolar "para hacer más potentes las relaciones, más intensos los conocimientos y más adecuadas las comunicaciones, para construir la ciberconvivencia en la red» (Avilés-Martínez \& García-Barreiro, 2018, p.6)

A la luz de los hechos, la legislación educativa contempla la participación familiar como un elemento fundamental en el proceso de aprendizaje. Concretamente en el ámbito gallego, al que nos referimos en esta investigación, en el decreto 330/2009, de 4 de junio, por el que se establece el currículo de la educación infantil en la Comunidad Autónoma de Galicia se hace referencia al proceso educativo de esta etapa y a la participación y colaboración familiar. En este contexto conviene hacer hincapié en uno de los factores más influyentes en las relaciones interfamiliares, la presencia y el uso de los medios de comunicación y las nuevas tecnologías de la información, ya que "la convergencia ha dado pie a un enriquecimiento progresivo en cuanto a la cantidad de dispositivos, mecanismos y formas de expresión que acaban estando a disposición de los ciudadanos y ciudadanas" (Ferrés, 2008, p.66).

La nueva generación de niños y jóvenes, no posee los mismos lenguajes de comunicación que sus progenitores, ya que viven y se comunican chateando, descargando canciones, compartiendo información, navegando por Internet, entre otros, mientras que sus padres/madres aprenden de una manera más paulatina a conocer las nuevas tecnologías y posteriormente a emplearlas. Por cuestiones económicas en gran parte de los casos y de poco conocimiento en otros. De forma general los adultos quedan desvinculados de las apetencias y necesidades de los menores, esto, causa en la educación familiar inquietudes, desequilibrios y problemas, ya que los adultos no conocen las verdaderas necesidades de sus hijos e hijas, y de este modo, es más complicado poder ayudarles o apoyarles en su aprendizaje. En este contexto se justifica la falta de comprensión de los mayores hacia la afición que sus hijos demuestran por determinados modos de estudiar o divertirse.

En esta línea resulta importante destacar que, en la mayor parte de los casos, las personas adultas no están preparadas para leer, entender, comprender, utilizar y cuestionar el lenguaje icónico, lo que dificulta la enseñanza de sus menores a encarar el mundo de las nuevas tecnologías de la educación.

Por todo ello, se infiere básico e imprescindible que los padres y madres tomen conciencia y busquen subsanar sus carencias formativas. Carencias derivadas del hecho de que las familias no se involucran en el acercamiento por parte de sus hijos a las nuevas tecnologías convirtiéndolos de este modo en huérfanos digitales (Junta de Andalucía, 1987, p.3). A la luz de estos hechos resulta preocupante la situación ya que, sin un referente de comportamiento claro, los menores no sabrán enfrentarse a los dilemas que se les planteen. Además de ello, serán más propensos a desarrollar hábitos de convivencia digital poco saludables $y$, estarán más expuestos a potenciales riesgos que no favorecen la e-inclusión.

Con el fin de frenar, en la medida de lo posible, tales riesgos y dificultades se propone la implicación de las familias, ya que, es en este contexto donde el aprender tiene un significado importante y especial que hay que entender muy bien para darse cuenta del valioso papel que desempeña en la vida digital. En este sentido no se puede olvidar que en el contexto social más reciente la mayor parte de los niños y adolescentes, pasan más tiempo con el profesorado y con los medios de comunicación que con su familia, por lo que es importante que el tiempo que estén con la familia, ésta, pueda 
educarles mediáticamente, ya que su responsabilidad es en primer lugar la aceptación de los medios y seguidamente la utilización que se hace en ellos con finalidad de ser un soporte para el cambio social. En cualquier caso, se trata de una tarea múltiple donde la familia educa para la participación, siendo los medios de comunicación y las nuevas tecnologías de la información apoyos clave para alcanzarlo, ya que, "la socialización de los jóvenes por los medios sociales de comunicación es un fenómeno irreversible“ (Frau-Meigs 2011).

Por todo esto, el alcance de niveles elevados de competencia digital se erige como una necesidad clave que deben asumir los diferentes agentes formativos sean o no académicos. Esta realidad certifica el hecho de que "los adultos juegan un papel muy importante en tres aspectos principales: como formadores o responsables directos de su alfabetización digital; como acompañantes o referentes a los que los niños pueden pedir ayuda; y como ejemplo de modelos de comportamiento» (Vélez, Napal \& Mendioroz, 2018). Por tanto, el desarrollo de la competencia digital por parte de los agentes de referencia contribuirá de forma clave al empoderamiento y alcance de la ciudadanía mediática prosumidora (García-Ruiz, Ramírez \& Rodríguez, 2014). Asimismo, permitirá, aprovechar la tecnología disponible con el fin de abrir la mente y aprender cosas nuevas (especialmente en un momento en el que la red nos acerca a diferentes herramientas y recursos, por ejemplo, hobbies. Por tanto, puede afirmarse que, la totalidad de materiales disponibles han de ser utilizados como herramienta para enseñar a los menores y para ayudarlos a sobrevivir y desarrollarse en la sociedad digital.

Teniendo como referente el título de este epígrafe no se puede dejar de lado el papel del profesorado y la imperante necesidad de que desarrollen niveles óptimos de competencia digital que les permita enfrentarse a los retos de la sociedad digital. En definitiva, la tarea formativa corresponde en primera instancia a las familias seguido de los educadores, es por esto que, "Tanto las familias como los educadores precisan ser competentes mediáticamente para poder ser un modelo personal, profesional y social ante los menores sobre cómo acceder reflexiva y constructivamente a la información y el conocimiento a través de los medios» (González-Fernández, Ramírez-García \& Salcines-Talledo, 2018, p. 301).

De lo normativo a lo práctico: ¿contamos con experiencias reales?

Realizada la justificación y argumentación que certifica la necesidad de intervención educativa y formación integral por parte de la ciudadanía en general conviene revisar aquellas prácticas que, pese a no estar regulado en la legislación educativa de forma explícita, se están desarrollando en pro de la alfabetización mediática de los menores. Un alcance que se realiza teniendo en cuenta las propias necesidades de los menores.

Entre otras experiencias en el contexto español se cuenta con diferentes Blogs y actividades tales que se enmarcan en el contexto socio-digital al que se ha hecho referencia a lo largo del estudio. En este contexto, a la institución educativa le corresponde educar a un alumnado eminentemente digital para formar una ciudadanía prosumidora. Todo ello en un contexto donde adquieren gran importancia las experiencias mediáticas que, a edades tempranas, ya han experimentado previamente dado que, "el aprendizaje se logra de forma tanto explícita como implícita, gracias a un proceso en el que los aprendices son capaces de relacionar conocimientos previos con la experiencia en la resolución de problemas reales» (De la Fuente, 2014, p.454). En este contexto, resulta imprescindible la práctica de la educación mediática en las aulas, estando ésta más próximo al desarrollo de un currículo bimodal (Marqués, 2016).

En este ambiente y pese a las marcadas carencias existen algunas experiencias que pueden verse en la selección de recursos presentes en la Tabla 1.

Tabla 1

Selección de recursos y actividades

\begin{tabular}{ll}
\hline \multicolumn{1}{c}{ Recursos } & \multicolumn{1}{c}{ Actividades } \\
\hline Web o blog & - EvoluTICvos \\
Proyectos & - El gran libro viajero \\
& - Robot Cubetto \\
Propuesta Metodológica & - Eu cociño, ti cociñas \\
\hline
\end{tabular}

Fuente: elaboración propia 2019 
Para conseguir una formación integral acorde a los intereses y necesidades de los más jóvenes, resulta clave introducir la educación mediática en la etapa de educación Infantil, esta introducción se realiza, como puede apreciarse en la tabla 1 , de diversas formas.

En primer lugar, se pueden diferenciar varios ejemplos de diversos tipos de prácticas educativas para el nivel de Educación Infantil. Las prácticas educativas se entienden como experiencias cuyo nombre surge en el contexto de la política y se vincula al ámbito educativo y en concreto a las prácticas docentes que integran recursos digitales en software libre y redes de comunicación para crear nuevos contenidos y formas de organización escolar. Las buenas prácticas "buscan además promocionar otros tipos de actividades educativas y fomentar estrategias de trabajo colaborativo (De Pablos, \& Jiménez, 2007, p.18), y se entienden como diferentes recursos que no necesariamente tienen que identificarse con actividades a realizar en el aula con los niños y niñas, sino que son proyectos en los que el uso de la tecnología es la materia dominante.

En este sentido la revisión nos muestra diferentes prácticas que se están desarrollando en el contexto espańol y también en el gallego, describiendo a continuación estos recursos.

\section{Blog EvoluTICvos}

Proyecto integral, integrado e integrador, del CEIP Pasico Campillo, en Lorca Murcia. En el que se busca integrar las TIC en el aula de una manera creativa, competencial, funcional y significativa en todas las áreas curriculares. A través de este blog (https://bit.ly/2SIdFet) se muestran las distintas actividades que en esta escuela se realizan con TIC, utilizándolo así, como método de formación para el profesorado.

Esta iniciativa busca sumistrar ayuda tanto a los niños y niñas como a los maestros y maestras, proporcionando así toda la información necesaria para ambos.

Además de los Blog existen a nivel nacional, en el contexto español, diferentes proyectos que persiguen el mismo objetivo, entre otros destacan:

\section{Proyectos}

\section{a. El gran libro viajero}

Iniciativa que surge del blog La Eduteca, un proyecto en el que participan varios colegios de diferentes ciudades de España, recogiendo la riqueza cultural, artística y patrimonial. El principal objetivo de "El Gran Libro Viajero" (https:// bit.ly/2HbtlpA) es potenciar la creatividad y favorecer que el alumnado se familiarice con el conocimiento y la importancia de la cultura o la tradición oral. Se trata de estimular a jóvenes para que participen como gestores de ideas para de este modo, desarrollar un proyecto que pretende, por un lado, enriquecer la cultura y su vocabulario, y por otro, que descubran y conozcan nuevas formas de aprender.

Cada uno de los centros que participa en este proyecto, recibe el libro para trabajar con el alumnado de su clase, a través de la presentación del mismo y seguidamente de la escritura de unas 3 páginas en las que discentes y profesorado tendrán que describir su colegio, su ciudad, o su cultura y que podrán realizarlo de manera libre, es decir, usando pictogramas, dibujos, textos o fotografías.

La estancia del libro en el colegio, junto con las actividades realizadas, es grabada y fotografiada, ya que en el momento en el que el libro se va del colegio, los profesores son entrevistados para conocer la experiencia. El seguimiento y conocimiento de la experiencia de cada uno de los colegios, está en el blog del propio libro, haciendo así que tanto alumnos como profesores sean autores y participantes de un proyecto en el que sin duda la inclusión de las TIC es relevante.

\section{b. Experiencias con el robot Cubetto}

Proyecto que surge de la mano del Colegio Base de San Sebastián de los Reyes (Madrid), ya que en él se trabaja la programación y la robótica dentro de la etapa de educación infantil.

Este proyecto, consiste en la utilización de un pequeño robot de madera que se mueve por medio de unas piezas de plástico de colores en un tablero de control separado.

Con este planteamiento, el alumnado de educa- 
ción infantil aprende a trabajar de forma colaborativa, conoce y desempeña diferentes roles dentro del grupo, aprendiendo así, cuáles son las funciones de un diseñador, un programador y un depurador.

La introducción de la tecnología con esta iniciativa ha generado múltiples y diversas actividades en las que se pueden trabajar diversos temas, favoreciendo así la educación en medios basada en el control únicamente del alumnado.

Además de las prácticas a nivel nacional, en el contexto autonómico, concretamente en la Comunidad de Galicia, se están llevando a cabo iniciativas centradas en el aprendizaje teórico-práctico y su aplicación a la vida diaria.

Propuesta metodológica "Eu cocińo, ti cocińas" alimentación saludable y currículo

Llevada a cabo en un aula del $2^{\circ}$ ciclo de educación infantil del CEIP Sigueiro de Oroso (A Coruña) en la que, no solo el alumnado se dedica a aprender de manera descontextualizada las distintas destrezas y contenidos, si no que a través de los alimentos y la elaboración de recetas se desarrollan los distintos aspectos del Decreto 330/2009, de 4 de junio, por el que se establece el currículo de la educación infantil en la Comunidad Autónoma de Galicia. (https://bit.ly/2kcUVVM).

La propuesta metodológica "Eu cociño, ti cociñas" alimentación saludable y currículo, se describe en la Tabla 2 se centra en varias actividades divididas en bloques:

\section{Tabla 2}

Contenidos y actividades que se llevan a cabo con la práctica "Eu cociño ti cociñas"

\begin{tabular}{ll}
\hline \multicolumn{1}{c}{ Contenidos } & \multicolumn{1}{c}{ Actividades } \\
\hline $\begin{array}{l}\text { Recogida, escucha y/o } \\
\text { transmisión de informa- } \\
\text { ción }\end{array}$ & $\begin{array}{l}\text { Cuentos, adivinanzas, poesías, } \\
\text { imágenes, juegos, videollamadas, } \\
\text { escucha de canciones }\end{array}$ \\
$\begin{array}{l}\text { Análisis e interpretación } \\
\text { de datos }\end{array}$ & $\begin{array}{l}\text { Manipulación, degustación, repre- } \\
\text { sentaciones gráficas, entre otras } \\
\text { actividades. }\end{array}$
\end{tabular}

\begin{tabular}{ll}
\hline \multicolumn{1}{c}{ Contenidos } & \multicolumn{1}{c}{ Actividades } \\
\hline $\begin{array}{l}\text { Memorización y aplica- } \\
\text { ción de contenidos }\end{array}$ & $\begin{array}{l}\text { Recetario, dónde recogen recetas, } \\
\text { las estudian y con las selecciona- } \\
\text { das, después escriben las suyas } \\
\text { propias para escribir su "libro de } \\
\text { recetas" }\end{array}$ \\
Puesta en práctica de lo & $\begin{array}{l}\text { Cocinamos, a través de la elabora- } \\
\text { ción de las recetas seleccionadas } \\
\text { aprendido }\end{array}$ \\
$\begin{array}{l}\text { Explicación y puesta en aula. } \\
\text { común (Programa: Eu } \\
\text { cociño, ¿ti cociñas?,) }\end{array}$ & $\begin{array}{l}\text { Elaboración de las recetas se gra- } \\
\text { bará en vídeo, elaborarán un pro- } \\
\text { grama de cocina en el que explica- } \\
\text { rán el proceso de elaboración }\end{array}$ \\
\hline
\end{tabular}

Jornadas de Puertas Abiertas, en la que realizarán las recetas a invitados especiales y todo el proceso es grabado en vídeo.

Fuente: Elaboración propia partiendo de la Buena Práctica "Eu cociño ti cociñas" (2019)

Este planteamiento sigue la filosofía del aprendizaje por competencias, entendidas como habilidades teórico-prácticas (OCDE, 1997), habilidades cuya base se sitúa sobre la construcción significativa del conocimiento que proporciona al alumnado un nuevo modo de aprender que no se limite a recordar nociones, sino se comprendan y apliquen. Esta aplicación se vincula con todo tipo de experiencias, recursos y herramientas para facilitar la comprensión de los diferentes núcleos temáticos propuestos en el currículo Una necesidad que resulta relevante, de forma especial en la etapa de educación infantil, cuando se sientan las bases de los futuros conocimientos en la edad adulta.

\section{Materiales y Métodos}

\section{Participantes}

La población de estudio es el análisis documental basada en una revisión bibliográfica a través de bases de datos tales como: Dialnet, Scielo, WOS, SCOPUS, haciendo un total de artículos 95 encontrados que formaron parte de la población. Los artículos seleccionados han sido mayoritariamente en español si bien se han consultado algunos en lengua inglesa. La selección de la muestra se realizó considerando los siguientes criterios:

1. Aplicación de los descriptores: sociedad digital, educación, educación infantil, legislación, 
buenas prácticas, como criterio de inclusión.

2. Criterio de exclusión de los años 2013-2018, es decir, desde la implantación en España de la LOMCE (Ley Orgánica de Mejora de la Calidad Educativa) hasta la actualidad. Pese a todo, en las referencias figuran materiales anteriores dada la necesidad de justificar la continuidad y origen de los modelos pedagógicos que demanda la sociedad digital.

Una vez realizado el análisis de la población $(\mathrm{N}=95)$ se obtuvo un muestreo no probabilístico, por conveniencia, teniendo en consideración los criterios de inclusión y exclusión, obteniéndose como muestra 54 artículos.

\section{Instrumento}

La recolección de datos se hizo con una rejilla de indicadores, (López, 2016) en el que se seleccionaron tres criterios:

1. Indicadores bibliométricos: publicación por año, base de datos, país de estudio.

2. Términos de búsqueda: Descriptores de la temática a analizar

3. Selección de los documentos: Criterios inclusión y exclusión

Tipo y diseño

La investigación es de tipo descriptiva, ya que se busca caracterizar el término educomunicación en relación con el desarrollo de la competencia mediática que ha de alcanzarse mediante la adecuada alfabetización digital y cognitiva. (Hernández, Fernández \& Baptista, 2014)

Además, centra el interés en analizar la legislación educativa, concretamente del contexto gallego en España y revisar buenas prácticas existentes para desarrollar la conciencia crítica, autónoma y responsable a edades tempranas.

La metodología hace referencia a aspectos de diferente nivel de concreción dentro del proceso de investigación (Montero \& León, 2005), en este estudio se realiza una revisión documental y posterior reflexión sobre los aspectos clave mencionados.

\section{Procedimiento}

El estudio se realizó de una manera secuencial y organizada por etapas. Como se puede observar en la Figura 1.

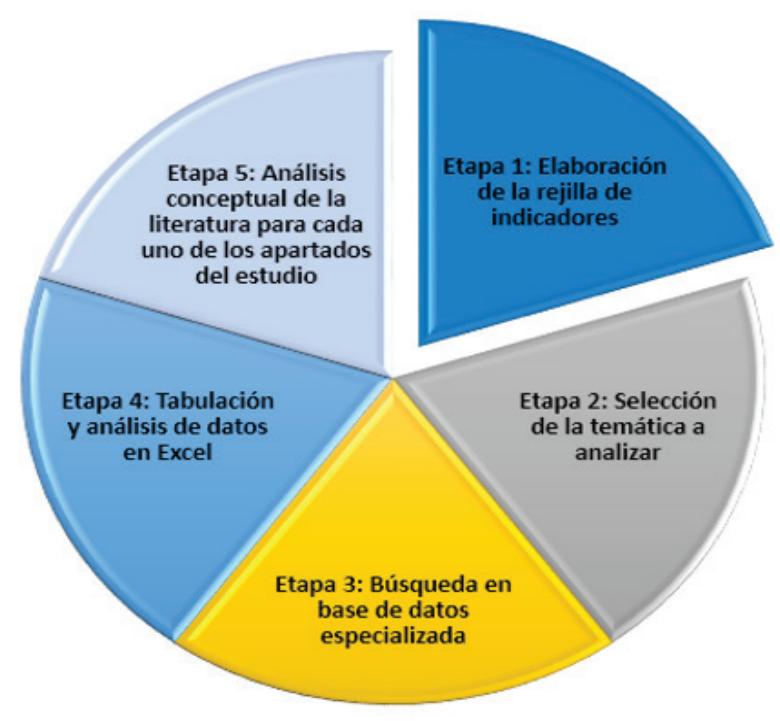

Figura 1

Procedimiento de analisis de la revisión del estudio.

Fuente: Elaboración propia 2019

\section{Resultados}

El análisis de resultados se hizo desde dos vertientes: a) Desde un carácter descriptivo bibliométrico y b) Desde el aspecto conceptual y teórico, como se muestra en la Figura 2.

Las experiencias descritas en los apartados anteriores se realizan en un marco normativo donde la educación mediática queda relegada a la transversalidad y la interdisciplinariedad, especialmente en la legislación educativa de la etapa de Infantil. A Grosso modo puede afirmarse que esta situación se repite tanto en el contexto español, con la entrada en vigor de la LOMCE, como en el gallego puesto que la legislación de la etapa de educación infantil no recoge el término "educomunicación" en ningún caso. En este sentido, conviene señalar que La ley Educativa vigente hasta el año 2013, Ley Orgánica 2/2006 de 3 de mayo de Educación, define en su artículo 6, el currículo entendido como el conjunto de competencias básicas, contenidos, métodos pedagógicos 

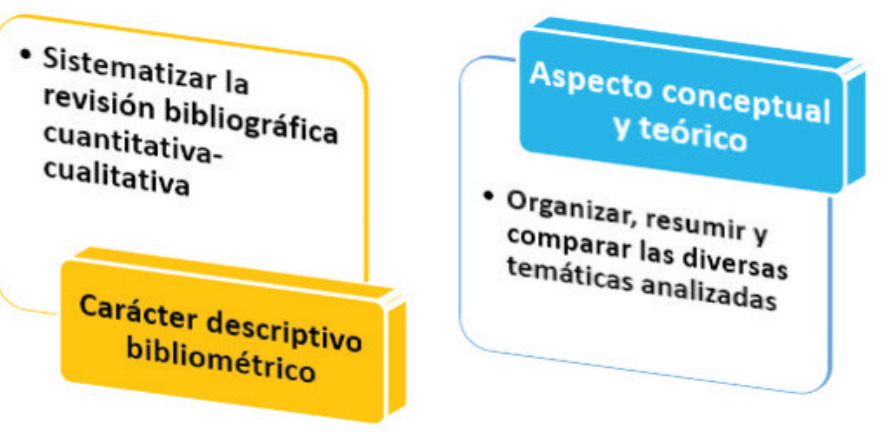

\section{Figura 2}

Análisis de los resultados.

Fuente: Elaboración propia 2019

y criterios de evaluación. Sin embargo, no hace mención a la educación mediática ni en medios ni a la alfabetización tecnológica. Pese a las diferentes modificaciones no se aprecian, en esta línea, cambios notables. La modificación de 2013 afecta únicamente a un artículo que cambia varios artículos de la antigua LOE. Una situación que conduce al desarrollo de la Ley Orgánica 8/2013, 9 de diciembre, para la Mejora de la Calidad Educativa, es decir, la LOMCE. En ésta el currículo de Educación Infantil, está comprendido concretamente por tres áreas de conocimiento: conocimiento de sí mismo y autonomía personal; conocimiento del entorno y el área de lenguajes: comunicación y representación. Se trata de áreas en las que se subraya la necesidad de que, desde el primer ciclo, se haga hincapié en el desarrollo de la autonomía de los niños y niñas, y la creación de los primeros vínculos sociales junto con la conquista del lenguaje, aspectos que adquieren un valor relevante en la sociedad digital donde es necesario desarrollar las competencias necesarias para comprender los contenidos y producirlos de forma responsable y autónoma. En este sentido, además de fomentar una primera toma de contacto con la lectura, la escritura y con experiencias de iniciación temprana en habilidades numéricas básicas, se requiere de un contacto marcado con las tecnologías de la información y la comunicación y la expresión visual y musical. Objetivos que pueden alcanzarse a través del desarrollo de las estrategias y metodologías que recoge la (Tabla 1). Actividades a través de las cuales es posible introducir la alfabetización mediática en la primera infancia de forma divertida a la par que efectiva.
En definitiva, puede afirmarse que, las buenas prácticas educativas, lo son si forman parte de ellas alumnos, profesores y familias, unos y otros han de conseguir desarrollar un nivel adecuado de competencia mediática. Una tarea que, dado su carácter transversal debe desarrollarse entre los ámbitos familiar y escolar puesto que, alfabetizar corresponde en primer lugar a la familia y la tarea debe continuarse en la escuela.

Esa situación no es exclusiva de España, según nuestros datos en Latinoamérica también es preocupación de los investigadores la relación efectiva de la tecnología y la familia en relación con la educación, es así como mostramos en la Tabla 3 las investigaciones orientadas en el tema, cosa que nos invita a seguir impulsando este tipo de iniciativas. Se puede notar en España se realizan aproximadamente $62 \%$ de trabajos de investigación en el tema en estudio en comparación con Latinoamérica en ese año.

Tabla 3

Distribución de publicaciones sobre el tema según la región entre 2015

\begin{tabular}{lcc}
\hline \multicolumn{1}{c}{ Region } & Cantidad de investigaciones 2015 & $\%$ \\
\hline España & 10 & 62 \\
America Latina & 6 & 38 \\
\hline
\end{tabular}

Fuente: Elaboración propia, 2019

En la Tabla 4 se constatan los tipos de trabajos y la cantidad de ellos que realizan en Espańa y latinoamericano. Se aprecia la diferencia en los tipos de trabajos que se desarrollan en cada uno y en cual base de datos fue publicada, tal es el caso de España donde podemos encontrar artículos Latindex, capítulos de libro, acta de congreso y tesis doctoral. A diferencia de los artículos publicados en las bases de datos Scielo y Scopus fueron desarrollados con más éxito en Latinoamérica que España.

La Tabla 4 refleja los tipos de trabajos y la cantidad de ellos que realizan en España y latinoamericano. Se puede notar la diferencia en los tipos de trabajos que se desarrollan en cada uno y en cual base de datos fue publicada, tal es el caso de España donde podemos encontrar artículos Latindex, capítulos de libro, acta de congreso y tesis docto- 
ral. A diferencia de los artículos publicados en las bases de datos Scielo y Scopus fueron desarrollados con más éxito en Latinoamérica que España.

Tabla 4

Porcentajes del número de publicación según país y tipo de trabajo de las variables de estudio 2017

\begin{tabular}{lclr}
\hline $\begin{array}{c}\text { País de la } \\
\text { publicación }\end{array}$ & $\begin{array}{c}\text { Cantidad } \\
\text { de publica- } \\
\text { ciones }\end{array}$ & $\begin{array}{l}\text { Tipo de trabajo y/o base } \\
\text { de datos }\end{array}$ & $\%$ \\
\hline México & 3 & $\begin{array}{l}\text { Artículo WOS+Scie- } \\
\text { lo+ESCl }\end{array}$ & 18.75 \\
Argentina & 1 & $\begin{array}{l}\text { Artículo WOS+Scie- } \\
\text { lo+ESCl }\end{array}$ & 6.25 \\
Colombia & 1 & Articulo Scopus & 6.25 \\
España & 1 & Artículo WOS & 6.25 \\
España & 3 & Artículo ESCl & 18.75 \\
España & 2 & Artículo Latindex & 12.5 \\
España & 1 & Capítulo de Libro & 6.25 \\
España & 1 & Actas congreso & 6.25 \\
España & 2 & Tesis doctoral & 12.5 \\
Ecuador & 1 & Artículo ESCl & 6.25 \\
\hline
\end{tabular}

Fuente: Elaboración propia, 2019

En la Figura 3 se observa cantidad de los proyectos de investigación relacionado educomunicación y buenas prácticas, los temas de revisión y los reportes de caso que se han desarrollado entre los años 2010 y 2015. Es notable como en el año 2013 los proyectos originales de investigación tuvieron una caída de 11 proyectos en el año 2012 a 8 proyectos en el ańo 2013. En los siguientes dos años hubo en aumento considerable hasta llegar en el 2015 a 14 proyectos. Los temas de revisión en los ańos 2010 y 2011 fueron 3 proyectos por año, un aumento significativo en el año 2012 y 2013 donde duplicaron su cantidad desarrollados y finalizando en los años 2014 y 2015 con 4 proyectos. Los reportes de caso como se puede notar no son muy comunes, en el periodo de 6 años se realizaron solo 4 proyectos.

Se aprecia en la tabla 5 un incremento de aproximadamente un $28 \%$ en cantidad de proyectos que se realizaron desde el año 2010 al año 2015 sin tomar en cuenta el tipo de proyecto. Empezando en el año 2010 con 13 proyectos realizados, al paso de 5 años en el año 2015 se llegaron a desarrollar 18 proyectos.
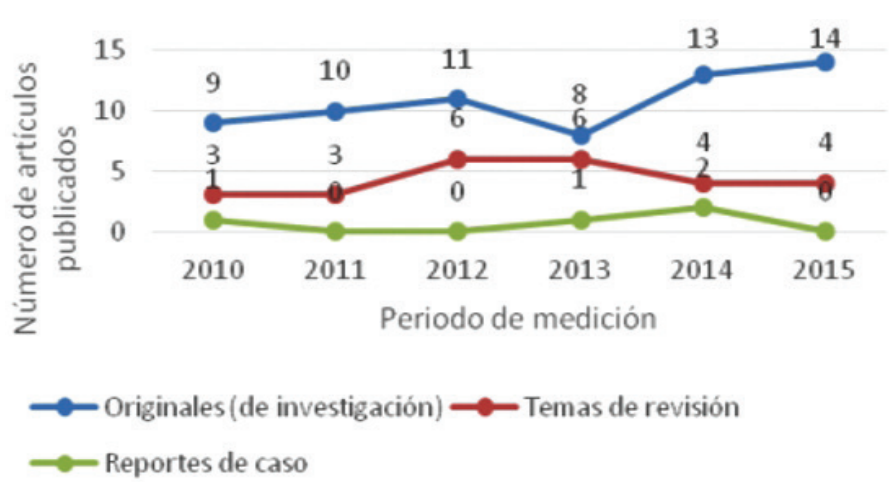

Figura 3

Número de articulos publicados 2010-2015

Fuente: Elaboración propia 2019

Tabla 5

Cantidad de publicaciones por año 2010-2015

\begin{tabular}{cc}
\hline Año & Investigaciones \\
\hline 2010 & 13 \\
2011 & 13 \\
2012 & 17 \\
2013 & 15 \\
2014 & 19 \\
2015 & 18 \\
\hline
\end{tabular}

Fuente: Base de datos Scielo, Scopus, Latindex, WOS.

\section{Discusión y Conclusiones}

Es de resaltar, de acuerdo a lo analizado en la revisión bibliográfica, que la educomunicación se erige como una nueva vertiente en la educación de los niños y jóvenes al ser esta integradora de diversas competencias. Habilidades que los jóvenes han tenido que desarrollar de forma inexcusable. Esta realidad implica el fomento de nuevas políticas públicas acordes con los múltiples cambios generados en este siglo. Un hecho que constata Aparici (2010) al mencionar que la educomunicación contempla múltiples lenguajes y medios, al permitir realizar una comunicación personal, grupal y social que integra una formación con sentido crítico e inteligente frente a los procesos comunicativos y sus mensajes.

En otro orden de hechos y, según se desprende de la legislación educativa vigente en Espańa y en Galicia, hoy en día no existen directrices curriculares concretas ni políticas educativas claras que 
amparen la educación mediática como una disciplina con entidad propia. Tanto en el contexto nacional como en el autonómico, como ha podido apreciarse anteriormente, se están llevando a cabo experiencias que sirven de modelo y que ejemplifican el interés y necesidad de alfabetización por parte de los menores al tiempo que certifican la necesaria formación de los docentes, especialmente los de edades tempranas.

Por otra parte, la escasa cantidad de prácticas educativas que se desarrollan no solo en estos dos ámbitos sino también en los contextos europeo e incluso en el latinoamericano, se requiere de un cambio pedagógico por parte del profesorado que, además de adquirir niveles óptimos de competencia digital ha de enseñar según el modelo de competencias que proponía la OCDE (1997), en este sentido el profesorado debería utilizar, por ejemplo, la gamificación de los contenidos para, por ejemplo, favorecer "el desarrollo de la lectura dentro del entorno mediático y digital» (Torres, Romero, Pérez \& Björk, 2016, p. 37) y para alfabetizar a los discentes según sus necesidades (Peñalva \& De-Casas, 2018). En este contexto el docente ha de modificar su rol de transmisor de contenidos para trabajar con nuevas metodologías, estrategias que contribuyen a reducir la posible brecha digital y por otro lado preparan al alumnado para que pueda enfrentarse a la sociedad donde tendrá que desarrollarse, donde tendrá que ser capaz de encarar situaciones derivadas de un irregular uso de la tecnología tales como diferentes tipos de acoso; así como los diversos tipos de lenguajes y formas de comunicación y aprendizaje que se están dando con el advenimiento de las tecnologías (Fernández, 2015)

Para finalizar, la realización de esta investigación permite señalar, de forma general, las características de las prácticas educativas que están vinculadas con el fin o propósito, "en la acción intencional", el "saber qué hacer". Un hecho que debe tener en cuenta que se convierte en "saber cómo" de forma más directa, es decir, el tener en mente lo que se quiere conseguir estará íntimamente unido al cómo lograr lo que se desea obtener" (Ospina \& Montoya, 2017). Asimismo, se constata la importancia de llevar a cabo prácticas educativas en las que los niños y niñas, no sólo las ejecuten, sino que han de interiorizarlas de modo que la formación en medios no solo sea completa sino también eficaz.

Para ello resulta clave el trabajo conjunto de la escuela y la familia para favorecer una adecuada alfabetización y desarrollo de la competencia digital que capacita, en este caso, al menor para su adecuado desarrollo.

Con el fin de alcanzar este objetivo sería deseable el trabajo conjunto entre ambos agentes educativos y se considera deseable que, por ejemplo, la escuela pudiese proporcionarles a las familias, además de materiales didácticos, un seguimiento detallado de sus hijos acorde a su formación y al alcance y desarrollo de sus conocimientos. Con esta iniciativa se contribuiría a favorecer la conexión y fluidez entre ambas partes y contribuiría además al mejor aprendizaje de los menores. Es también sensible la necesidad de incrementar las iniciativas de investigación en esta área para incrementar la cobertura de esta información y así reconocer y aplicar métodos y herramientas en lengua española, favoreciendo así a España y Latinoamérica. El crecimiento sostenido desde 2015 al 2017 debería continuar influenciado con la masificación de herramientas y equipos portátiles como teléfonos inteligentes y tablets que facilitar el desarrollo de proyectos de investigación orientados a develar el importante número de interrogantes presentes en este nuevo escenario educativo.

En síntesis y como última reflexión, se considera imprescindible un cambio en la metodología, que consiga que la inclusión de las TIC sea completa y absoluta.

\section{Agradecimientos}

Este trabajo se ha elaborado en el marco de Alfamed (Red Interuniversitaria Euroamericana de Investigación en Competencias Mediáticas para la Ciudadanía), con el apoyo del Proyecto $\mathrm{I}+\mathrm{D}+\mathrm{I}$ Coordinado "Competencias mediáticas de la ciudadanía en medios digitales emergentes (smartphones y tablets): practicas innovadoras y estrategias educomunicativas en contextos múltiples"(EDU2015-64015-C3-1-R) (MINECO/ FEDER), la "Red de Educación Mediática" del 
Programa Estatal de Investigación Científica-Técnica de Excelencia, Subprograma Estatal de Generación de Conocimiento (EDU2016-81772REDT), financiados por el Fondo Europeo de Desarrollo Regional (FEDER) y Ministerio de Economía y Competitividad de España. Y en el Marco del $\mathrm{I}+\mathrm{D}$ de la Universidad de Cantabria "Competencia mediática en la sociedad digital para la participación crítica de la ciudadanía (UC2016-GRE-01)".

\section{REFERENCIAS BIBLIOGRÁFICAS}

Aguaded, I. (2014). From Infoxication to the Right to Communicate. Comunicar, 42, 07-08. https://doi.org/10.3916/ C42-2014-a1

Aguirre-Sala, J. (2013). Nuevos alcances de la participación ciudadana a través de las redes sociales. Culturales, 1(2), 119-150. Recuperado de https://bit.ly/2IOeHG9

Apararici, R. (2010) Educomunicación: Más allá del 2.0., Barcelona, Gedisa.

Area, M. \& Ribeiro, M.T. (2012). From Solid to Liquid: New Literacies to the Cultural Changes of Web 2.0. Comunicar, 38, 13-20. https://doi.org/10.3916/C38-2012-02-01

Avilés-Martínez, J. \& García-Barreiro, J. (2018). Ciberconvivencia y ciudadanía digital. Revista digital de la Asociación CONVIVES. 22.

Ballesteros Velázquez, B. (2010): “Educación y medios”. In Aguado, T. (Coord.): Diversidad e igualdad en educación, pp. 277-316, UNED, Madrid

Barbas, A. (2012) Educomunicación: desarrollo, enfoques y desafíos en un mundo internconectado. Foro de Educación, 10 (14), 157-175.

Bauman, Z. (2004). Modernidad líquida. FCE: Argentina. Recuperado de https://goo.gl/zQL632

Bergomás, G. (2019). Las alfabetizaciones múltiples como eje de la formación docente. Razón y Palabra, 63. Recuperado de https://bit.ly/2tCqwoz

Buckingham, D. (2005). Educación en medios: alfabetización, aprendizaje y cultura contemporánea. Barcelona: Paidós.

Cabero, J. (2018). Tic y educación en la sociedad del conocimiento. In Ortiz-Colón, A. \& Ortega-Tudela, J.M.(cords) (2018). Tecnologías en entornos educativos. Madrid: Paraninfo. PMCid:PMC5920066

Cabero-Almenara, J. \& Marín-Díaz V. (2014). Miradas sobre la formación del profesorado en TIC, Enl@ce. Revista Venezolana de Información, Tecnología y Conocimiento, 11(2). 11-24. Recuperado de https://bit.ly/1G09Ber

Caldeiro, MC. \& Aguaded-Gómez, J. (2015). «Estoy aprendiendo, no me molestes» la competencia mediática como forma de expresión crítica de nativos e inmigrantes digitales. Redes.com, 12. Recuperado de http://goo.gl/2ORkf1

Caridad-Sebastián, M. \& Ayuso-García, M. (2011). Situación de la brecha digital de género y medidas de inclusión en Espa-a. Investigación bibliotecológica, 25(55), 227-252. https://doi.org/10.22201/iibi.0187358xp.2011.55.32973

Carlsson, U. (2013). Los jóvenes en la cultura digital y mediática: perspectivas globales y escandinavas. Analisí Monogràfic 2013. 77-94. Recuperado de https://goo.gl/xnKjoH

CEIP Pasico Campillo, en Lorca Murcia. https://bit. ly/2Opj2Pm

CEIP Sigueiro de Oroso (A Coruña). Recuperado de https://bit.ly/2Tstbvk

Chamorro-Cristaldo, M. (2018). Digital divide, factors affecting your appearance: internet access in Paraguay. Población y Desarrollo, 24(47), 58-67. https://doi.org/10.18004/ pdfce/2076-054x/2018.024(47)058-067

Colegio Base de San Sebastián de los Reyes (Madrid). Recuperado de https://bit.ly/2VCaAyy

Commision European (2018). DigCompEdu. Recuperado de https://bit.ly/2BRoeGD-De la Fuente, J. (2014). Alfabetización mediática: del prosumidor al profesional. Historia y Comunicación Social, 19. pp. 451-464. https://doi. org/10.5209/rev_HICS.2014.v19.45041

De Pablos-Pons, J. \& Jiménez-Cortés, R. (2007). Buenas prácticas con TIC apoyadas en las Políticas Educativas: claves conceptuales y derivaciones para la formación en competencias ECTS, Revista Latinoamericana de Tecnología Educativa, 6 (2), 15-28. Recuperado de https://bit.ly/2w9hkZD

Díaz-Lazo, J. Pérez-Gutiérrez, A. \& Florido-Bacallao, R. (2011). Impacto de las tecnologías de la información y las comunicaciones (Tic) para disminuir la brecha digital en la sociedad actual. Cultivos Tropicales, 32(1), 81-90. Recuperado de https://bit.ly/2tQ3iet

DOG 121. DECRETO 330/2009, de 4 de junio, por el que se establece el currículo de la educación infantil en la Comunidad Autónoma de Galicia. Recuperado de https:// bit.ly/2kcUVVM

Fernández, E. (2015) Educomunicación: Las tecnologías de la información y la comunicación, en la educación. (Tesis de grado), Facultad de Publicidad y RR.PP. Universidad de Valladolid, España.

Ferrés, J. (2008). La educación como industria del deseo. Un nuevo deseo comunicativo. Gedisa: Barcelona. PMCid:PMC2648280

Frau-Meigs, D. (2011). Socialisation des jeunes et éducation aux médias. Toulouse, France: Eres. https://doi. org/10.3917/eres.fraum.2011.01

Freire, P. (1973) ¿Extensión o comunicación? la concientización en el medio rural. México. Siglo veintiuno editores.

García-Ávila, S. (2017). Alfabetización Digital. Razón y Palabra, 21 (98), 66-81. Recuperado de https://bit.ly/2MbFNbj 
García-Ruiz, R., Ramírez, A. \& Rodríguez, M. (2014). Media Literacy Education for a New Prosumer Citizenship. Comunicar, 43, 15-23. https://doi.org/10.3916/C43-201

González-Fernández, N., Ramírez-García, A. \& Salcines-Talledo, I. (2018). Competencia mediática y necesidades de alfabetización audiovisual de docentes y familias españolas. Educación XX1, 21(2), 301-321, https://doi.org/10.5944/ educxx 1.16384

Gozálvez, V. \& Contreras, P. (2014): Empoderar a la ciudadanía mediática desde la educomunicación. Comunicar, 42, 129-136. https://doi.org/10.3916/C42-2014-12

Gregorio-Chaviano, O. (2018) Análisis de la educomunicación como campo de investigación en desarrollo: una aproximación bibliométrica. Paper, III Congreso Internacional, Competencias Mediáticas, Medellín, Colombia.

Hergueta Covacho, E. (2017) Educación mediática. Propuesta metodológica para el desarrollo de la competencia mediática en la práctica educativa. Programa de doctorado en comunicación y educación en entornos digitales.

Hernández, R., Fernández, C. \& Baptista, P. (2014). Metodología de la Investigación. México: McGraw-Hill.

Hernández-Serrano, M., Renés-Arellano, P., Graham, G. \& Greenhill, A. (2017). From Prosumer to Prodesigner: Participatory News Consumption. Comunicar, 50, 77-88. https://doi.org/10.3916/C50-2017-07

Hobbs, R. \& Coiro, J. (2019). Design Features of a Professional Development Program in Digital Literacy. Journal 1 of Adolescent \& Adult Literacy, 62 (4). 401-409. https://doi. org/10.1002/jaal.907

INTEF (2017). Marco Común de Competencia Digital Docente. Recuperado de https://bit.ly/2EwAu0O

Johnson, L., Adams Becker, S., Cummins, M., Estrada, V., Freeman, A. \& Hall, C. (2016). NMC Informe Horizon 2016 Edición Superior de Educación. Austin, Texas: The New Media Consortium.Recuperado de https://bit.ly/2H$\mathrm{dbWcW}$

Junta de Andalucía (1978). Educar para proteger. Guía de formación TIC para padres y madres de menores de 3 a 11 ańos. Recuperado de https://bit.ly/2TkzFQQ

Ley Orgánica 2/2006, de 3 de mayo, de Educación. Recuperado de https://bit.ly/2tE8hPC

Ley Orgánica 8/2013, 9 de diciembre, para la Mejora de la Calidad Educativa, LOMCE. Recuperado de https://bit. ly/2hnUxTt

Longworth, N. (2005). El aprendizaje a lo largo de la vida en la práctica. Barcelona: Paidós.

López, A. (2016) Tesis de la actividad científica de la técnica psicológica de rejilla a través de indicadores bibliométricos. (Tesis doctoral). Universidad Nacional de Educación a Distancia, España. Recuperado de https://bit.ly/2WITuW3

Marqués, P. (2016). Síntesis de las investigaciones realizadas entre 2011 y 2016: ¿por qué conviene aplicar el CURRÍCULUM BIMODAL? Recuperado de https://bit.ly/2TfeSye
Mendoza-Ruano, J., \& Caldera-Serrano, J. (2014). Umbrales para la determinación de la brecha digital: comparativa entre regiones desarrolladas. Transinformação, 26(2), 125132. https://doi.org/10.1590/0103-37862014000200002

Montero, I., \& León, O. (2005). Sistema de clasificación del método en los informes de investigación en Psicología. International Journal of Clinical and Health Psychology, 5 (1), 115-127.

OCDE. (1997). La definición y selección de competencias clave. Recuperado de https://bit.ly/2eILmLD

Ortega-Ruiz, R., Casas, J.A. \& Del Rey, R. (2014). Hacia el constructo de ciberconvivencia. Infancia y Aprendizaje, 37 (3), 602-628. https://doi.org/10.1080/02103702.2014. 957537

Ospina Botero, M. \& Montoya Pavas, E. (2017). Las prácticas educativas con familia desde la escuela. Revista del Instituto de Estudios en Educación y del Instituto de Idiomas Universidad del norte. pp. 31-43

Peñalva, S. \& De Casas, P. (2018). El uso de la gamificación como metodología educomunicativa en el contexto universitario. In Torres, A. \& Romero, LM. (ed.) (2018). Gamificación en Iberoamérica. Experiencias desde la comunicación y la educación. Recuperado de https://bit.ly/2HecqBE-Pe-alva-Vélez.

Peñalva, A., Napal, M. \& Medioroz, A.M. (2018). Competencia digital y alfabetización digital de los adultos (profesorado y familias). International Journal of New Education, 1, 1-13. https://doi.org/10.24310/IJNE1.1.2018.4892

Prensky, M. (2001). Digital Natives, Digital Immigrants. New York: MCB University Press. PMid:11282041

Prensky, M. (2005). Teaching digital natives: partnering for real learning. Recuperado de https://goo.gl/opELD9

Quiroz Velasco, T. (2010). Educar en otros tiempos. El valor de la comunicación. En R. Aparici (Ed.), Educomunicación: más allá del 2.0 (pp.187-203)

Ranzólin, A. (2018). Educomunicación y ciudadanía: Reflexiones sobre responsabilidades compartidas en un mundo digital. Aularia 7 (1), pp. 11-16. Recuperado de https://bit. ly/2UlHhQi

Regil, L. (2014). Cultura digital universitaria. Tesis doctoral. Recuperado de https://bit.ly/2Ulamvc

Rodríguez- Hoyos, C. \& Fueyo, A. (2011). La alfabetización audiovisual crítica en la sociedad de la información. Una experiencia de formación continua. Pixel Bit. Revista de Medios y educación, 39. Pp. 95-107. Recuperado de https://bit.ly/2EapUv7

Sahuquillo, P. (2009). Algunas aportaciones teóricas a la influencia de la televisión en el proceso de socialización de la infancia. Teoría De La Educación. Revista Interuniversitaria, 19(1). Recuperado de https://goo.gl/HDRSuW

Sánchez-Carrero, J. \& Contreras, P. (2012). De cara al prosumidor: producción y consumo empoderando a la ciudadanía 3.0. 14, 10 (3); 62-84. https://doi.org/10.7195/ri14. v10i3.210 
Sánchez-Teruel, D. \& Robles-Bello, M. A. (2016). Riesgos y potencialidades de la era digital para la infancia y la adolescencia. Revista Educación y Humanismo, 18(31), 186-204. http://dx.doi.org/10.17081/eduhum.18.31.1374

Tirado, M.A. \& Ventura, C. (2009) Proposals for the development of critical competence in Physical Education, Cultura y Educación, 21:1, 55-66. https://doi. org/10.1174/113564009787531181

Torres-Toukoumidis, A., Romero-Rodríguez, L., Pérez-Rodríguez, M. A., \& Björk, S. (2016). Development of reading skills through video games: state of the art. Ocnos, 15 (2), 37-49. https://doi.org/10.18239/ocnos_2016.15.2.1124

Tyner, K., Gutiérrez, A. \& Torrego, A. (2015). "Multialfabetización" Sin muros en la era de la convergencia. La competencia digital y "la cultura del hacer" como revulsivos para una educación continua. Revista de currículum y formación del profesorado, 19(2), 41-56. https://bit.ly/2CyLQzS 


\title{
La escuela en la sociedad red: Un espacio de encuentro con los valores
}

\author{
Paula Renés-Arellano ${ }^{1}$ \\ https://orcid.org/0000-0003-0932-7694 \\ Universidad de Cantabria, España
}

Schools in the network society: A meeting place with values

Recibido: 08-01-2019

Aceptado: 23-03-2019

\section{Cita Recomendada}

Renés-Arellano, P. (2019). La Escuela en la Sociedad Red: Un Espacio de Encuentro con los Valores. Hamut'ay, 6(1), 112-123.

http://dx.doi.org/10.21503/hamu.v6i1.1578

\section{RESUMEN}

La influencia de los medios de comunicación, de Internet y de las tecnologías en general, es una realidad innegable que requiere de nuevos replanteamientos éticos personales, sociales, políticos, económicos, culturales y educativos, que preserven los auténticos principios democráticos en las sociedades actuales. La Sociedad Red como estructura social de la era de la información es uno de los pilares que fundamentan el trabajo presentado, a través de esta el objetivo es realizar un acercamiento teórico hacia su definición y la relación existente con los efectos de la presencia de Internet y los nuevos medios tecnológicos y audiovisuales que evidencian una realidad social en continua transformación que requiere de agentes educativos comprometidos con la misma. El método aplicado ha sido descriptivo a través de una búsqueda bibliográfica que apoya la reflexión-teórica de la misma. Los resultados se dirigen hacia propuestas de cómo se otorga a la escuela y a la sociedad, la oportunidad de promover los valores sociales y personales albergados con la corresponsabilidad, la justicia con baluartes de los procesos educativos de los más jóvenes. Desde este planteamiento, se avanza hacia la relación existente entre la Sociedad Red y los valores como elementos fraguadores de las sociedades democráticas, finalizando con las conclusiones y propuesta de retos, oportunidades y ventajas que supone educar en valores en las escuelas en la sociedad actual.

Palabras Clave: Valores, Internet, escuela, democracia, alumnos, profesores, tecnologías.

\section{Abstract}

The influence of the media, the Internet and technologies in general, is an undeniable reality that requires new ethical, personal, social, political, economic, cultural and educational rethinking that

1 Doctora y profesora en la Facultad de Educación, adscrita al área de Teoría e Historia de la Educación de la Universidad de Cantabria (España). Las líneas de investigación se vinculan a la educación mediática, TIC y valores. Miembro de la Red Interuniversitaria Euroamericana de Investigación sobre Competencias Mediáticas para la Ciudadanía (ALFAMED). E-mail: paula.renes@unican.es 
preserves the authentic democratic principles in current societies. The Network Society as a social structure of the information age is one of the pillars that underlie the work presented. Through it, the objective is to make a theoretical approach to its definition and the existing relationship with the effects of the presence of the Internet and the new technological and audiovisual media that demonstrate a social reality in continuous transformation that requires educational agents committed to it. The applied method has been descriptive through a bibliographic search that supports the theoretical-reflection of it. The results lead to proposals for how the school and society are given the opportunity to promote the social and personal values hosted by co-responsibility, justice with bastions of the educational processes of the youngest. From this approach, progress is made towards the relationship between the Network Society and the values as fragmenting elements of democratic societies, ending with the conclusions and proposals of challenges, opportunities and advantages that involves educating in values at schools in today's society.

Keywords: Values, Internet, school, democracy, students, teachers, technologies.

\section{INTRODUCCIÓN}

El actual epicentro de la sociedad se enmarca en las Tecnologías de la Información y la Comunicación (TIC), la presencia de Internet y los nuevos modelos de comunicación social y ciudadana, llevando a reconocer la era de la información como una sociedad caracterizada por la inmediatez, la fragilidad o la facilidad del acceso a la información; pero también, una sociedad cargada de valores, retos y proyectos humanizadores. Internet $y$ en concreto, las posibilidades que se ofrecen a través de los móviles o dispositivos inteligentes, las ventanas abiertas al mundo, han llevado a una clara "conectividad total" o, lo que es lo mismo "Internet del todo". Este influjo de los medios de comunicación, de Internet o de las tecnologías en general, es innegable; se considera un proceso dinámico en el que la escuela, como institución socializadora, se ha visto enmarcada. Algunos autores como Castells (2003), ya definieron la sociedad actual como la Sociedad Red: «la nueva estructura social de la Era de la Información, basada en redes de producción, poder y experiencia» ( $\mathrm{p}$. 350). Esta descripción ha sido confirmada, y permanece aún vigente con autores como Medina $\&$ Ballano (2015), quienes también la denominan "sociedad mediatizada", en la que los medios y las tecnologías se convierten en posibles agentes educativos. En esta línea Jiménez (2002) conduce su aportación hacia el concepto de "techné", aquello que permite a la persona designar algo que no es capaz de describirse por cualidades de su propia naturaleza (physis), sino que es considerado elaborado, producido o creado por el individuo (Cabrera, 2004), y, por tanto, es "constitutivo de lo humano” (Fernández \& López, 2018, p.138). Si las tecnologías, los medios de comunicación o Internet son consideradas un producto social y cultural inherente al propio individuo, la educación se convierte en el baluarte necesario para entender, comprender y reflexionar sobre la influencia de las mismas en el desarrollo personal e interpersonal de cada sujeto.

En este contexto, parece necesario plantearse realmente qué papel juega la Sociedad Red en el mundo globalizado y por tanto, cómo se puede conseguir que los ciudadanos se empoderen de las capacidades, destrezas y habilidades necesarias que les permitan ser críticos, activos y comprometidos con las decisiones y acciones que toman en relación con las situaciones en las que se desenvuelven; cómo la escuela, queda más que justificada en la necesidad de experimentar estos avances en sus tareas educativas.

Es asumible, pero a veces, complejo, entender que el acceso a la información es un derecho y una vía fundamental para conocer el mundo e interaccionar con él. Sin embargo, el consumo pasivo de 
esta información no garantiza la adquisición de competencias éticas, críticas y responsables sobre el uso de los medios de comunicación, de Internet o de las tecnologías en general. La "sociedad líquida" (Bauman, 2007) en la que la celeridad marca muchas de las relaciones sociales, no garantiza el aprendizaje de destrezas, valores, conocimientos $y$ actitudes que requieren ser asimilados en este nuevo contexto. Es necesario seguir favoreciendo desde las escuelas procesos educativos que permitan a los niños, ir progresivamente adquiriendo las habilidades necesarias que les conviertan en verdaderos consumidores con miradas críticas ante, para y por lo que ven, escuchan y asimilan.

Investigaciones como las de Ruiz, Bernal, Gil \& Escámez, 2012; Martínez 2015, recogen la necesidad de desarrollar una educación en valores dentro de la escuela. Según Bindé (2004), plantearse y reflexionar sobre los valores, es el resultado de analizar y ser consciente de que las sociedades cambian, se transforman, y ello deriva en determinados efectos en la manera de relacionarnos socialmente ante las tecnologías. En este sentido, una de las responsabilidades sociales y ciudadanas es formar a niños y jóvenes, especialmente si el foco de atención es la escuela, esta como "prodiseñadores de contenido” (Hernández-Serrano, Renés-Arellano, Graham, \& Greenhill, 2017).

Por lo que, el objetivo de este estudio es realizar un acercamiento teórico-reflexivo sobre la Sociedad Red, una realidad en la que Internet y sus efectos, así como los nuevos medios tecnológicos y audiovisuales, evidencian un contexto social en continua transformación que requiere de agentes educativos comprometidos con la misma.

\section{MÉTodo}

Se realizó una búsqueda bibliográfica para el análisis de la revisión de la literatura que apoya la reflexión-teórica de la misma durante el primer trienio de 2019. Se empleó un diseño de tipo descriptivo (Day, 2005), lo cual sirvió para seguir los pasos y procedimientos para la redacción final del estudio, identificando documentos bibliográficos en diversas bases de datos como son; ESCI, WOS y Scopus y otras fuentes como las publicaciones en libros impresos y digitales (Tabla 1). Los descriptores empleados (tanto en castellano como en inglés) fueron: valores, alumnos, profesores, sociedad, Internet, medios de comunicación, democracia, tecnologías y escuela. Se seleccionaron aquellos documentos que informaron de los aspectos formales que debía recoger la revisión y la lectura crítica de los mismos. Los objetivos de esta primera fase fueron: resumir la información sobre el tema, identificar aspectos conocidos o controvertidos, identificar aproximaciones teóricas ya elaboradas sobre la temática, proporcionar información vinculada a esta revisión, reflexionar sobre los temas abordados tomando en consideración la Sociedad Red, los valores y la educación como focos de interés, mostrar evidencias de esta y ofrecer retos, oportunidades y propuestas finales que ayuden a mejorar avanzar hacia la relación existente entre la Sociedad Red y los valores como elementos fraguadores de las sociedades democráticas y en la escuela.

Tabla 1

Bases de datos y artículos seleccionados

\begin{tabular}{lll}
\hline \multicolumn{1}{c}{ Bases de datos } & tipo de documento & $\begin{array}{l}\text { Artículos se- } \\
\text { leccionados }\end{array}$ \\
\hline Wos & & 16 \\
Scopus & & 10 \\
Esci & Revistas científicas & 3 \\
Latindex & & 10 \\
Otras & & 4 \\
Libros y Documen- & Libros editoriales es- & 15 \\
tos Internacionales & pañolas en SPI & \\
& Libros internacionales & 7 \\
& (inglés) & 2 \\
& Otros & \\
\hline
\end{tabular}

Fuente: elaboración propia 2019

La estrategia de búsqueda, una vez seleccionadas las bases de datos, y fijados los descriptores, fue seguir los pasos que plantea Maeda (2006): ordenar, rotular, integrar y priorizar la información recogida para lo que se inició el planteamiento y estructura del trabajo siguiendo los recursos documentales obtenidos y llevando el hilo conductor del objetivo del trabajo iniciando la reflexión teórico-descriptiva desde la Sociedad Red, los valores, la democracia y la escuela. Para ello, en el apartado de conclusiones, que es la segunda fase, 
se indican estos temas.

Un acercamiento a los valores en la escuela desde la educación en la Sociedad Red

A menudo se escucha en prensa y en los medios de comunicación que los nuevos modelos de globalización están acusando las diferencias entre pueblos y culturas, y aumentando la brecha de la fragmentación social; una preocupación que ha sido abordada en diferentes espacios de debate y reflexión como son los organismos internacionales. En la actualidad, existen grandes y diversas tensiones suscitadas por los cambios tecnológicos, así como sociales y económicos, que plantean cómo afrontar e integrar elementos cercanos y lejanos, tradicionales, actuales, particulares y universales, o materiales y espirituales, $y$, por tanto, cómo las personas son capaces de asumirlo y adaptarlo a sus realidades desde una visión personal y grupal (UNESCO, 2015). Estos elementos descritos son los que alimentan las transformaciones actuales a nivel social y marcan los patrones culturales y comunicativos de todos los grupos sociales. En este contexto aparecen también los valores, relacionados con la cultura de sociedad. Es la cultura y los valores, los que permiten, entre otros aspectos, comprender de forma global las capacidades, conocimientos y moralidad de determinados grupos sociales (Arribas \& Torrego, 2008).

La adquisición de valores es un proceso dinámico y permanente que permite asumir las normas sociales, convivir en comunidad, desarrollarse integralmente y respetar a los demás. Actualmente, se habla de una crisis de valores (Buxarrais, 1997); como señala Tornero $(2017$, p.5), "por el simple hecho de habernos trasladado a la red, de vivir de modo virtual, hemos puesto en crisis algunos de los valores que imperan en nuestro día a día". Es el resultado de las sociedades globales actuales, caracterizadas por su heterogeneidad, y cada vez más acusadas por los nuevos registros comunicativos que exige la Sociedad Red. En palabras de Mínguez (2014), existe una fractura de criterios y referencias de convivencia social que pueden afectar a las relaciones interpersonales y es resultado del modo de vida de las personas desde comienzos de este siglo. Es por ello, que se requiere una educación reformulada, un pilar fundamental que vele por la búsqueda de la responsabilidad de todos los que formamos parte de la sociedad, en el que la escuela juega un papel primordial (Mayor, 2007).

Este progreso tecnológico en el que los medios de comunicación, Internet o las tecnologías están presentan en nuestra cotidianeidad genera el surgimiento de cuestiones éticas que pueden ser complejas de afrontar, pero necesarias (Albizuri, Samaniego \& Torrientes, 2001). La multiculturalidad actual es a su vez, junto con estos elementos, un reto educativo fundamental, porque se presenta como la oportunidad de poder desarrollar una ciudadanía democrática y dialógica, que favorezca el intercambio cultural y la comprensión social. La escuela, en este sentido, se puede convertir en el espacio de reflexión y acción que favorezca el desarrollo de identidades personales, culturales y sociales que permitan participar a las personas bajo principios de libertad (Besalú, 2002).

El cuidado y la preservación de valores universales como la libertad han sido y siguen siendo, objeto de análisis, reflexión y defensa desde diversos organismos, más concretamente y realizando un acercamiento a documentos internacionales, parece necesario detenerse en la Declaración Universal de Derechos Humanos de diciembre de 1948, que ya en su artículo 26 promulgó que toda persona tiene derecho a su pleno desarrollo:

La educación tendrá por objeto el pleno desarrollo de la personalidad humana y el fortalecimiento del respeto a los derechos humanos y a las libertades fundamentales; favorecerá la comprensión, la tolerancia y la amistad entre todas las naciones y todos los grupos étnicos o religiosos; y promoverá el desarrollo de las actividades de las Naciones Unidas para el mantenimiento de la paz (ONU, Asamblea General, Declaración Universal de los Derechos Humanos. Art.26. p.8).

También otras instituciones han dejado patente esa necesidad de luchar no solo por los derechos humanos, sino también por las libertades. Valores y derechos que la educación puede promulgar y que son propios de las sociedades contemporáneas, tal y como reflejan las diferentes Decla- 
raciones de Derechos Humanos, en las que se han reconocido el derecho a la educación como el instrumento base para el pleno desarrollo de la persona. También la UNESCO en 1960 y el Convenio para la protección de los derechos humanos y de las libertades fundamentales, aprobado en Roma el 4 de noviembre de 1950 hacen eco de esa realidad.

Entender la autonomía del sujeto es respetar la autonomía personal, la libertad individual, de creencias, expresión y educación, aspectos que se recogen, en el artículo 27 de la Constitución Española:

1. Todos tienen el derecho a la educación. Se reconoce la libertad de enseñanza.

2. La educación tendrá por objeto el pleno desarrollo de la personalidad humana en el respeto a los principios democráticos de convivencia y a los derechos y libertades fundamentales.

Actualmente, ya se recoge desde organismos internacionales como la UNESCO, el Parlamento Europeo, la Comisión Europea y la ONU a través de su programa de la alianza para las civilizaciones, la importancia y necesidad de una educación en valores actualizada, en la que las personas logren ser críticas y activas ante las realidades sociales, culturales, económicas, tecnológicas o mediáticas.

Parece imprescindible plantearse y reflexionar sobre cómo y de qué manera desde la escuela se cuida y se capacita a los nińos para que sean conscientes de los valores y contravalores que se transmiten en las redes. Según Garitaonandia \& Garmendia (2007) los jóvenes con mayores problemas en Internet lo ocultan a los padres, por lo que la necesidad de conocer, analizar e investigar realmente qué tipo de valores o contravalores adquieren los niños a través de Internet, parece necesaria, porque promueve valores morales e influye en el desarrollo moral (Koh, 2014) y en la construcción de su identidad digital y personal (Zhao, Grasmuck, \& Martin, 2008). Si la Convención de las Naciones Unidas sobre los derechos del niño habla de la necesidad de preservar los datos personales de los nińos; la escuela, como institución socializadora, debe ser sensible y estar preparada para afrontar esta realidad a través de intervenciones educativas ajustadas a estas necesi- dades propias de la interconexión, el acceso libre a la información y la celeridad para compartir información.

Los valores de una sociedad: del pensamiento a la acción para comprender las realidades actuales en educación

$\mathrm{Si}$ entre las funciones fundamentales de la escuela prima la educación, es ahora el momento de explicar cómo es entendida: como un proceso intencional que debe favorecer el pleno desarrollo de la persona es uno de los estandartes de las sociedades democráticas, tal y como defendió Bernardini (2010). Porque ofrece el marco ideal para adquirir las habilidades y destrezas necesarias que permiten a cada individuo pensar y tomar decisiones adecuadas y ajustadas a las realidades. La educación, en este sentido, se convierte en un factor determinante para la promoción de valores universales aceptados y respetados por todos, y, en consecuencia, compartidos socialmente.

Desde esta perspectiva, y siguiendo a los autores García Aretio, Ruíz \& García Blanco, (2010), la educación promoverá la adquisición y la asimilación de valores propios en cada individuo, y deberá favorecer el desarrollo de una ciudadanía crítica, participativa y activa. En este sentido, Hernández \& Eyeang (2017) afirman que los valores propios de una sociedad o comunidad son aquellas pautas de actuación individual y social que son aceptadas para la adecuada convivencia y que de forma transgeneracional serán respetadas por todos los miembros de la comunidad o grupo social. Por ende, los valores de una sociedad son aquellos que además de ser adquiridos, necesarios y observados, también son estimados como válidos. En este contexto, la educación cobra sentido, porque es a través de ella como cada persona logra ese proceso de adquisición de valores, los dota de significado y los transfiere al ámbito individual (Martínez, Esteban \& Buxarrais, 2011).

Es por ello, que surge la incertidumbre de cómo esta nueva cultura mediática que está patente actualmente en la Sociedad Red, ejerce efectos en las actuaciones de las personas (Colom \& Melich, 1993). Y cómo pueden influir en la construcción de una moral adecuada, de valores racionales que 
permitan ser integrados en la cotidianeidad personal y social. Esta reflexión requiere de un análisis pormenorizado de estos interrogantes desde una óptica responsable y comprometida de aquellos que ofrecen los medios en el desarrollo de la persona (García-Ruíz, Ramírez, \& Rodríguez, 2014).

El panorama actual de Internet está generando formas diferentes de interaccionar, comunicarnos y dar sentido a las realidades en las que se vive, está generando nuevos hábitos derivados del papel de agentes socioeducativos que han adoptado estas tecnologías. Y es que "somos partícipes y espectadores de una época en donde los nuevos canales de comunicación, especialmente Internet, se han convertido en noticias recurrentes" (Garrido-Cabezas, 2011, p.1376).

Internet, así como los medios de comunicación y las tecnologías están promoviendo nuevos hábitos, y un mundo de valores nuevos, con una moral diferente y adaptada a estas realidades.

El problema surge cuando el anonimato que se mantiene en la Red hace que se pierdan los valores realmente importantes, como son el respeto a otra persona o la responsabilidad de las acciones que tomamos en los procesos comunicativos en Internet. Internet ofrece un gran potencial, tal y como afirman autores como, Agarwal, 2000; Agarwal \& Venkatesh, 2002; Carmel \& Agarwal, 2002; Briñol., et al., 2004; Reig, 2018, quienes estudian la relación de la cognición humana, los valores y el uso de Internet. En concreto, comparten la idea de que existen diferentes variables que influyen, desde perspectivas exógenas, en las actitudes y usos de Internet entre las personas, más específicamente, afirman que las habilidades y las motivaciones están estrechamente relacionadas con la interacción que se establece en la Red en la que la persona es capaz de diversificar la comunicación a través de diferentes canales online y requiriendo por su parte, la puesta en marcha de mecanismos cognitivos y habilidades que le permitan establecer, iniciar o mantener una relación interactiva a través de Internet. A ello hay que sumar, que las personas buscan en las comunicaciones online las finalidades actitudinales, eso significa que necesitan conocer y controlar esos procesos de interrela- ción porque puede ser que esa relación estableci$\mathrm{da}$, coincida con las creencias o valores personales, pero se precisa conocer realmente qué significado cobran esas relaciones y las acciones derivadas de las mismas (Orantes, 2011).

Es en este contexto desde donde se precisa una educación en valores, que prepare y forme integralmente a los niños para su desarrollo y para una adecuada adquisición de valores necesarios en los nuevos entornos mediáticos y tecnologizados. Internet se ha convertido hoy en día en un instrumento fundamental para la construcción de valores socialmente compartidos porque en su utilización diaria los valores afloran constantemente, las decisiones responsables o irresponsables se relacionan con esta, y las conductas éticas suelen estar pautadas por los aprendizajes que se derivan de la interrelación. En concreto, Tornero (2017, p.15) afirma que "en la actualidad existen ciertos vacíos éticos en el mundo digital, lo que puede dar lugar a problemas y malentendidos-que provocan que muchas personas teman usar las TIC". En este sentido, es cierto que el acceso a la información no supone haber adquirido las capacidades, habilidades y actitudes que permitan a la persona, niño, joven o adulto, a ser competente ante el contenido que se muestra en las redes, y menos aún, que se participe de forma crítica y responsable ante el uso de Internet. Es por ello, que desde este trabajo se aboga por realizar procesos de reflexión crítica, responsable y ética sobre la sociedad digital actual (Buxarrais, Martínez, Puig \& Trilla, 1990; Aparici, 2010; Caldeiro \& Aguaded, 2015), que permitan adquirir ciertos valores universalmente compartidos y rechazando aquellos contravalores que, desde la óptica de la Red, no favorecen la construcción de una adecuada moral en los más jóvenes.

Transformaciones sociales y escuela: hacia una ciudadanía democrática en un mundo tecnologizado

La pluralidad de concepciones e ideas que supone la existencia de los cambios de las sociedades hace que las personas se enfrenten diariamente a conflictos de valores y tomen decisiones siguiendo sus propios patrones de escala de valores e interpreta- 
ción de las realidades. Ante este planteamiento, se hace necesaria una educación que mire el plano axiológico como un todo indiscutible; una escuela que promueva hábitos de convivencia sustentados en valores democráticos en los que el diálogo, la escucha o la participación de todo el alumnado sea tomado en cuenta (Abad, 2018). Y es que los hábitos personales forman parte de la cultura de una escuela, de su forma de entender las realidades e interacciones humanas $y$, además, se precisa realizar prácticas coherentes que consigan efectos positivos en las propuestas y toma de decisiones diarias (Martínez, Puig \& Trilla, 2003).

La escuela se convierte en el espacio a través del cual se producen procesos de socialización y transmisión de ideologías, promoviendo el desarrollo de la personalidad de cada niño (Deval, 2002; Martínez, Esteban \& Buxarrais, 2011). Es por ello, por lo que normalmente la sociedad confía en que, desde su posición institucional, socializadora y educadora, se fomente la transmisión de valores democráticos, siendo fundamentales los roles que ejercen todos los miembros de la comunidad educativa, en especial el profesorado y las familias, como agentes más cercanos a los niños, ya que ejercen una influencia fundamental en la educación en valores.

No se puede seguir avanzando en el camino de la justificación de los valores en la sociedad tecnologizada actual, sin detenerse en las palabras que pronunciaron Ortega \& Mínguez (2004) sobre la familia y su función como transmisora de valores:

El cambio profundo producido en la sociedad postindustrial sociológicamente laica, incorporada a los avances tecnológicos de la información, ha llevado consigo el debilitamiento de la institución familiar como ámbito autosuficiente y mecanismo básico de transmisión de valores; pero también ha supuesto la recuperación de un nuevo discurso sobre la familia (p. 37).

Es la familia, junto con el profesorado y la escuela quienes deben primar una educación por, para y ante valores promotores de principios democráticos. $\mathrm{Y}$ es que convictos de realismo, lo cierto es que es evidente el inexorable funcionamiento de la ciudadanía hacia un cosmopolitismo que avanza por la tecnociencia, tal y como defiende Maceiras (2015), un camino en el que la familia promueva principios y prácticas educativas coherentes con las realidades tecnológicas y digitales existentes, que busquen el desarrollo de hábitos éticos e intelectuales con la formación de los niños. La identidad personal se fragua en consonancia con la singularidad propia, pero también, en relación con los otros y el contexto en el que se vive, aspectos que ya defendieron en su momento autores de gran relevancia como fueron Hegel y Ortega.

$\mathrm{Si}$ se toman estas afirmaciones como ciertas, la esencia educativa en la escuela y la ética, estará cargada de compromisos y deberes que ha de asumir cada agente educativo y alumnado, en su acción diaria. Porque la construcción de la moral, el desarrollo de principios éticos y la asunción de valores democráticos en el proceso educativo de los niños, favorecerá la adquisición de hábitos, acciones y conductas responsables y éticamente correctas. En este sentido y siguiendo a Maceiras (2015), se comparten los valores, que aún discutibles por la permeabilidad e intangibilidad de las sociedades digitalizadas en continua transformación, se hacen necesarios para solventar esa crisis de valores sobre la que se reflexiona habitualmente. Se precisan referencias axiológicas seguras que permitan a niños y jóvenes construir sus propios juicios morales desde pilares sólidos y coherentes con los retos que surjan en las sociedades. Es por ello, que a pesar de la complejidad de las sociedades y de los valores que en ellas se transmiten, se hace necesario plantearse los siguientes principios y valores que guíen los procesos educativos en las escuelas, las instituciones educativas y el quehacer diario de la sociedad: igualdad, solidaridad, la fidelidad a la palabra, el respeto al otro y la convivencia, el esfuerzo, la paz, el amor, el perdón y la información o el conocimiento frente a la ignorancia.

Las sociedades democráticas precisan de procesos educativos que vertebren sus políticas y acciones en los valores mencionados, sin olvidar que la igualdad, la solidaridad o la fraternidad favorecerán la consecución de las mismas. En palabras de Salazar \& Woldenberg (2016, p.43): "A fin de cuentas, aun si la democracia es esencialmente 
política, sólo la generalización de los valores democráticos en el conjunto de la sociedad permite un ejercicio pleno y funcional de la misma”. Es por ello, por lo que la escuela, su profesorado $y$ las familias, se pueden convertir en los mejores promotores de los principios democráticos.

La escuela: su compromiso en la educación en valores ante los retos de la Sociedad Red

Ante el planteamiento mostrado anteriormente, la actual "crisis de valores" y la ausencia de valores (Morín 1999; Bernardini, 2010; Mínguez, 2012; Piña, 2012; Berríos \& Buxarrais, 2013; Torrego \& Martínez, 2014; Arenas, 2015), en ocasiones de referentes universales, hace que la construcción de la personalidad de niños y jóvenes se vea mediatizada por el consumo de medios de comunicación, Internet o tecnologías. Ante este panorama, se hace preciso una educación en valores por parte de la escuela, buscando formas correlacionadas en las que se priorice la formación integral del niño, atendiendo a sus necesidades académicas, formativas y morales. Lo cierto, es que, en este sentido, los nińos se enfrentan continuamente a experiencias moralmente controvertidas, resolviendo conflictos de valor día a día, porque como individuos, los valores se van adquiriendo de forma progresiva desde los primeros ańos.

Educar en valores, más aún en la Sociedad Red, supone emplear la inteligencia moral de forma adecuada porque en las soluciones a conflictos individuales, cada persona pone en marcha sus competencias y habilidades, sus propias capacidades individuales y sus guías de valor (Martínez, Puig \& Trilla, 2003). Los valores morales que desde la escuela se desean desarrollar y proyectar en la ciudadanía se entienden en las prácticas diarias sirviendo de retroalimento de las guías de valor en los niños y niñas.

Actualmente, la familia y la escuela siguen siendo dos de las instituciones socializadoras más importantes, pero no se debe menospreciar la influencia que ejercen los medios de comunicación, Internet o las tecnologías en la vida de los niños y jóvenes, porque comparten la tarea de formación de estos (Martín \& Tyner, 2012; Cuervo, Medrano $\&$ Aierbe, 2016). La escuela, en este caso, se ve influenciada por la cultura de Internet, por los estilos de vida y comportamientos que aparecen en esta y por la formación en valores que invita a interiorizar, una nueva perspectiva que es importante cuidar, observar, reflexionar y tomar conciencia de los efectos que puede generar, porque la educación en valores y los procesos de alfabetización en todos los registros comunicativos permitirán a las personas ser críticas y responsables en la Sociedad Red que les ha tocado vivir (Ambrós \& Breu, 2007; García-Ruíz, Ramírez \& Rodríguez, 2014).

\section{Discusión y Conclusiones}

Una vez que se analizó toda la información documental de las diferentes bases de datos y el análisis de la literatura para la introducción y el apartado de revisión de la literatura, se llegó a las siguientes conclusiones, las cuales se enmarcan dentro de criterios de autores que aseveran la relevancia de los retos, oportunidades y ventajas de educar en valores hoy en día: una ética educativa comprometida con la escuela. Dentro de este contexto, hasta este momento se ha realizado un recorrido sobre Internet, los valores que precisa la sociedad actual y la finalidad de la educación en valores en este entramado. $Y$ es que el acceso solamente no garantiza un uso adecuado de Internet, ni una adecuada adquisición de valores porque:

Para que la Sociedad del Conocimiento sea una realidad y continúe contribuyendo al progreso mundial es necesario que los ciudadanos puedan acceder a las TIC de modo normalizado en las respectivas facetas de la vida. Reto que no solo está supeditado al propio conocimiento, sino que, además, se encuentra condicionado por las posibilidades de acceso y el uso que se hace de las herramientas digitales con toda la repercusión que esto conlleva para las personas (Rico, Sevillano \& Feliz, 2011, p.504).

Es, desde la reflexión, donde se exponen las siguientes pautas orientativas con la finalidad de arrojar luces a los nuevos procesos comunicativos a través de Internet, otorgando a los valores, su 
espacio para lograr una verdadera integración en la cotidianeidad de la escuela y en la búsqueda de una ciudadanía democrática, respetuosa y justa. Una sociedad desde la que se promuevan valores sociales y personales sustentados en la corresponsabilidad social, con implicación de todos los agentes educativos y buscando que niños y jóvenes encuentren a lo largo de su proceso formativo, las herramientas y orientaciones que les permitan ser libres, respetuosos y conscientes de sus acciones en la Red, (Figura 1).

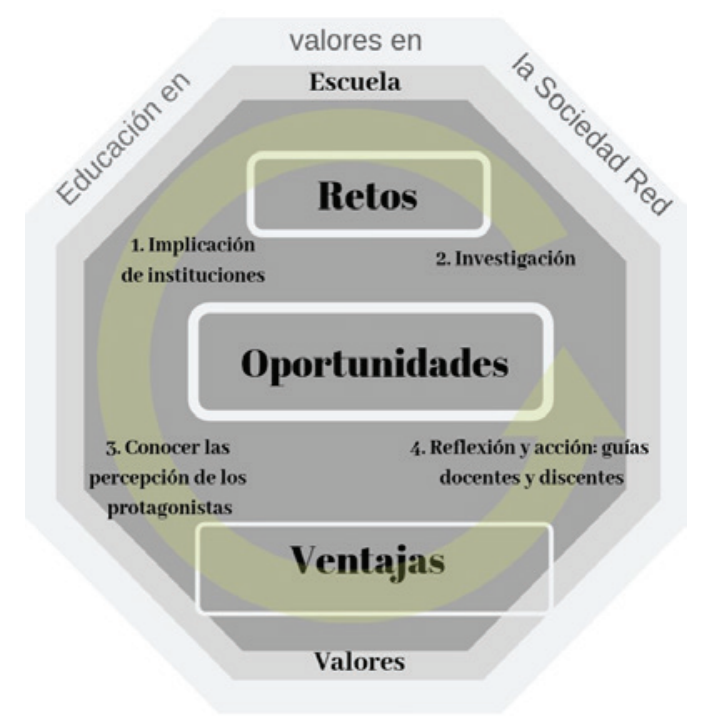

\section{Figura 1}

Retos, oportunidades y ventajas de la educación en valores en la Sociedad Red.

Fuente: Elaboración propia 2019

Otro aspecto relevante dentro de la promoción de valores es el trinomio escuela-familia-profesores, quienes deben promover el por, para y ante valores como principios democráticos, lo cual lo asevera también Reverter, 2004, p.109, al referir que la promoción de valores globales que exijan y construyan "modelos sociales y pautas de vida que respondan al mínimo establecido por una ética cívica transnacional”.

Dentro de este análisis se ha podido ver que sería interesante apelar a las instituciones políticas para que promuevan entre la ciudadanía una "ética cívica transnacional" (Cortina, 2003, p.133). Que cada país no solamente descubra por sí mismo los valores y principios que son compartidos por los ciudadanos, sino que ese diálogo y esa mirada se realice desde la ruptura de las fronteras, desde el inicio de los procesos transnacionales para que realmente se configure una ética cívica común y compartida. En palabras de Nussbaum (1999, p.51), "la educación es para las personas. Antes de poder elaborar un plan para el futuro de la educación, necesitamos entender los problemas que afrontamos en el proceso de transformación de los estudiantes en ciudadanos de la democracia, capaces de efectuar buenas reflexiones y elecciones sobre una gran variedad de temas de importancia nacional y mundial". Es decir, las instituciones políticas, sociales y educativas requieren plantearse el compromiso y la preservación de una ética cívica común y respetuosa con todas las personas en la sociedad global y tecnológica actual.

No se puede dejar de lado el rol importante que tienen las diversas instituciones públicas, sobre todo el invitar a controlar a las empresas para evitar la corrupción de tecnologías potencialmente peligrosas. Como diría Gee \& Esteban-Guitart (2019), algunas tecnologías permiten posibilidades de interacción, activismo y aprendizaje que en ocasiones se emplea inadecuadamente y es que el contexto en el que se utiliza la tecnología "tiene más peso en la hora de determinar sus efectos que la propia tecnología” (p.12).

Es importante también investigar sobre las percepciones de niños y jóvenes sobre los valores culturales y sociales que adquieren en su cotidianeidad a través del influjo de la Red, respetando su propia perspectiva (Pereira, 2013) y no la que se considera que deben tener (Livingstone $\&$ Sefton-Green, 2016); buceando hacia el verdadero significado de las ideologías que suponen los efectos de las tecnologías y los medios (Erstad \& Sefton-Green, 2013; Pereira, S., Fillol \& Moura, 2019).

Desde una mirada más amplia, se hace necesario promover pautas educativas que tengan en cuenta la perspectiva de los diferentes agentes educativos, teniendo en cuenta sus miradas, percepciones y consideraciones, porque las tecnologías, Internet o los medios de comunicación cobran diferente sentido en función de la interpretación de cada individuo o grupo social (Hoffman, 2017; Yudes-Gómez, Baridon-Chauvie, \& González-Cabrera, 2018). 
Conocer de primera mano las verdaderas causas por las cuales los nińos y jóvenes buscan en Internet o en las redes sociales el espacio para divertirse, relacionarse o comunicarse. No hay que olvidar que estos suelen buscar espacios online para establecer relaciones sociales (Ochaíta, Espinosa \& Gutiérrez, 2011) y, por tanto, como adultos tenemos el deber y la obligación moral de atender adecuadamente a estas necesidades y demandas, otorgándoles las herramientas suficientes que les permitan ser, estar y permanecer seguros, respetuosos y tolerantes en los espacios virtuales.

A futuro, hay que considerar favorecer iniciativas vinculadas a programas de formación infantojuvenil, así como a la elaboración de guías didácticas destinadas a profesionales de la educación en relación a cómo Internet o el mundo digitalizado en el que se enmarcan los nińos y jóvenes con los que trabajan, influye en las relaciones inter e intrapersonales, en la adquisición de valores y en la construcción del juicio moral. La finalidad sería favorecer encuentros y espacios abiertos al diálogo, la participación y la escucha. Otro elemento sería la reflexión sobre la continua trasformación social y sus efectos en el desarrollo de la personalidad moral (Anaya, 2013, UNESCO, 2015) con la finalidad de promover la autonomía y la adquisición responsable de valores. Y promover el "aprendizaje profundo" (Gee, 2017), en el que se planteen objetivos claros de debate y diálogo sobre la influencia que ejerce algún contenido como aquellos que son objeto de análisis en este trabajo, que son los medios de comunicación, Internet o las tecnologías en la vida cotidiana, sus efectos en el desarrollo emocional y el descubrir cuáles son los valores y juicios de valor que intervienen en la toma de decisiones y en internacionalizar las normas.

\section{Agradecimientos}

Este trabajo se ha elaborado en el marco de Alfamed (Red Interuniversitaria Euroamericana de Investigación en Competencias Mediáticas para la Ciudadanía), con el apoyo del Proyecto $\mathrm{I}+\mathrm{D}+\mathrm{I}$ Coordinado "Competencias mediáticas de la ciudadanía en medios digitales emergentes (smartphones y tablets): prácticas innovadoras y estrategias educomunicativas en contextos múltiples" (EDU2015-64015-C3-1-R) (MINECO/ FEDER), y de la "Red de Educación Mediática" del Programa Estatal de Investigación Científica-Técnica de Excelencia, Subprograma Estatal de Generación de Conocimiento (EDU201681772-REDT), financiados por el Fondo Europeo de Desarrollo Regional (FEDER) y Ministerio de Economía y Competitividad de Espańa. Y también del Proyecto I+D de la Universidad de Cantabria "Competencia mediática en la sociedad digital para la participación crítica de la ciudadanía (UC2016-GRE-01)”.

\section{REFERENCIAS BIBLIOGRÁFICAS}

Abad, J.V. (2018). Promover la equidad en la escuela. Aula de innovación educativa, 275, 67.

Agarwal, R. \& Venkatesh, V. (2002). Assessing a firm`s web presence: A heuristic evaluation procedure for the measurement of usability. Information System Research, 13, 168225. https://doi.org/10.1287/isre.13.2.168.84

Agarwal, R. (2000). Individual acceptance of information technologies. In R. W. Zmud (Ed.), Framing the domains of it management research: glimpsing the future to the past. Pinnaflex, 85-104.

Albizuri I.E., Samaniego C.M. \& Torrientes, E.Q. (2001). Desarrollo de los valores en las instituciones educativas. Madrid: Mensajero.

Ambrós, A. \& Breu, R. (2007). Cine y educación. El cine en el aula de primaria y secundaria. Barcelona: Grao.

Anaya, R. (2013). El programa de Educación en Valores y su relación con el razonamiento moral, ideología educativa y liderazgo del Centro Docente. Nóesis: Revista de Ciencias Sociales y Humanidades, 22(44), 90-119. https://doi. org/10.20983/noesis.2013.3.4

Aparici, R (Coord.) (2010). Educomunicación: más allá del 2.0. Barcelona: Gedisa.

Arenas, A. (2015). Crisis del estado democrático: un acercamiento teórico y ético. Revista educación y desarrollo social, 10(1) 214-229.

Arribas, J. M. \& Torrego, J. C. (2008). Cómo elaborar y desarrollar el plan de convivencia. En J. C. Torrego (coord.) El plan de convivencia: Fundamentos y recursos para su elaboración y desarrollo (pp. 95-166). Madrid: Alianza Editorial.

Bauman, Z. (2007). Los retos de la educación en la modernidad líquida. Barcelona: Gedisa.

Bernardini, A. (2010). La educación en valores hoy en día: entre conciencia crítica y respuestas constructivas. Innovaciones Educativas, 17, 11-22. 
Berríos, Ll. \& Buxarrais Estrada, M. R. (2013). Educación en valores: análisis sobre las expectativas y los valores de los adolescentes. Educación y educadores, 16(2), 244-264. https://doi.org/10.5294/edu.2013.16.2.3

Besalú, X. (2002). Diversidad cultural y educación. Madrid: Síntesis Educación.

Bindé, J. (2004). Introdução geral. In J. Bindé (Ed.), Para onde vão os valores? Lisboa: Instituto Piaget.

Briñol, P., Horcajo, J., De la Corte, L., Valle, C., Gallardo, I. \& Díaz, D. (2004). Efecto de la ambivalencia evaluativa sobre el cambio de actitudes. Psicothema. 16, 373-377

Buxarrais, M., Martínez, M., Puig, J. \& Trilla, J. (1990). La educación moral en primaria y secundaria. Madrid: Edelvives.

Buxarrais, R.M. (1997). La formación del profesorado en educación en valores. Bilbao: Desclée de Brouwer.

Cabrera, D. (2004). La matriz imaginaria de las nuevas tecnologías. Comunicación y Sociedad, 17 (1), 9-45.

Caldeiro, MC. \& Aguaded, J. (2015). «Estoy aprendiendo, no me molestes» la competencia mediática como forma de expresión crítica de nativos e inmigrantes digitales. Redes. com, 12. Recuperado de http://goo.gl/2ORkf1

Carmel, E. \& Agarwal, R. (2002). The maturation of offshore sourcing of information technology work. MIS Quarterly Executive, 1, 65-77

Castells, M. (2003). La era de la información. Economía, sociedad y cultura: 2. El poder de la identidad. Madrid: Alianza.

Colom, T., \& Melich, J. C. (1993). Postmodernidad y educación. La teoría de Toffler y la práctica de la C. M. U. Teoría de la Educación. Revista Interuniversitaria, 5, 97-110.

Cortina, A. (2003). Ética Cívica Transnacional: Fundamentación y Aplicación. Seminarios de filosofía, 16, 119-134. Recuperado de https://goo.gl/FtLkki

Cuervo, S. L., Medrano, C. \& Aierbe, A. (2016). Values perceived by adolescents on television: cross-cultural and gender differences. Educación XX1, 19(2), 383-404.

Day, R. A. (2005). Cómo escribir y publicar trabajos científicos ( $3^{\mathrm{a}}$ ed.). Washington, DC: Organización Panamericana de Salud.

Deval J., 2002. La escuela posible. Barcelona: Ariel.

Erstad, O., \& Sefton-Green, J. (2013). Digital disconect? The 'digital learner' and the school. In O. Erstad, \& J. Sefton-Green (Eds.), Identity, community, and learning lives in the digital age (pp. 87-104). New York: Cambridge University Press. https://doi.org/10.3726/978-1-4539-1019-1

Fernández, S., \& López, C. (2018). La sociedad en red y el cambio de nuestra percepción. Hologramatica, 28 (1), 135 153.

García Aretio, L., Ruíz, M., \& García Blanco, M. (2010). Claves para la Educación. Madrid: Narcea.
García-Ruíz, R., Ramírez, A. \& Rodríguez, M. M. (2014). Media Literacy Education for a New Prosumer Citizenship. Comunicar, 22, (43), 15 - 23.https://doi.org/10.3916/C432014-01

García-Ruiz, R., Ramírez-García, A \& Rodríguez, M.M. (2014). Educación en alfabetización mediática para una nueva ciudadanía prosumidora. Comunicar, 43, 15-23. https://doi.org/10.3916/C43-2014-01

Garitaonandia \& Garmendia (2007). Cómo usan Internet los jóvenes: hábitos, riesgos y control parental [Proyecto Eukids online]. Vizcaya: Universidad del País Vasco, Facultad de Ciencias Sociales y de la Comunicación [Documento en línea]. Recuperado de http://www.anobium.es/docs/gc_fichas/doc/01237BEXqx.pdf

Garrido-Cabezas, N. (2011). Internet como un nuevo medio social para la comunicación y la participación ciudadana. Revista de comunicación Vivat Academia, 117E, 13751390. https://doi.org/10.15178/va.2011.117E.1375-1390

Gee, J.P. (2017). Teaching, learning, literacy in our high-risk high-tech world: A framework for becoming human. New York: Teachers College Press.

Hernández, J.M. \& Eyeang, E. (2017). Los valores en la educación de África. De ayer a hoy. Salamanca: Ediciones Universidad de Salamanca.

Hernández-Serrano, M., Renés-Arellano, P., Graham, G. \& Greenhill, A. (2017). From Prosumer to Prodesigner: Participatory News Consumption. Comunicar, 50, 77-88. https://doi.org/10.3916/C50-2017-07

Hoffmann, A.L. (2017). Breaking bad algorithms. Science, 358, 310-311. https://doi.org/10.1126/science.aao4414

Jiménez, J. (2002). La invención del arte. El término Techné. Teoría del arte; Tecnos-Alianza, Madrid.

Koh, C. (2014). Exploring the use of Web 2.0 technology to promote moral and psychosocial development: Can YouTube work? British Journal of Educational Technology, 45 (4), pp. 619-635. https://doi.org/10.1111/bjet.12071

Livingstone, S. \& Sefton-Green, J. (2016). The class: living and learning in the digital age. New York: New York University Press. https://doi.org/10.18574/ nyu/9781479884575.001.0001

Maceiras, M. (2015). Una aproximación filosófica. La herencia de la filosofía clásica y su vigencia en la actualidad. Revista del consejo escolar del estado, 4(6), 7-17. https:// doi.org/10.4438/1886-5097-PE

Maeda, J. (2006). Laws of Simplicity. U.S.A: M.I.T Press.

Martín, A. G. \& Tyner, K. (2012). Media Literacy in Multiple Contexts. Comunicar, 19 (38), 10-12. https://doi. org/10.3916/C38-2012-02-00

Martínez, J. M. (2015). La participación de los padres en la educación. Un análisis crítico. Participación educativa, 4(7), 65-70.

Martínez, M., Esteban, F., \& Buxarrais, M.R. (2011). Escuela, profesorado y valores, Revista de educación, N. ${ }^{\circ}$ Extra. 1, 95-113. 
Martínez, M., Puig, J. M. \& Trilla, J. (2003). Escuela, profesorado y educación moral. Teoría de la educación, 15, 57-94.

Mayor, J. (2007). La educación en valores, una apuesta de la sociedad. Idea La Mancha. Revista de Educación de Castilla-La Mancha, 271-274. Recuperado de http://redined.mecd.gob.es/xmlui/bitstream/ handle/11162/93584/00620073000950.pdf?sequence $=1$

Medina, A \& Ballano, S. (2015). Retos y problemáticas de la introducción de la educación mediática en los centros de secundaria. Revista de Educación, 369, 135-158. https://doi. org/10.4438/1988-592\#-RE-2015-369-293.

Mínguez, R. (2012). La responsabilidad educativa en tiempo de crisis. Edetania, 42, 107-125.

Mínguez, R. (2014). Ética de la vida familiar y transmisión de valores morales. Revista de educación, 363, 2010-229.

Morín, E. (1999). Los siete saberes necesarios a la educación del futuro. París: UNESCO.

Nussbaum, M. (1999). Sin fines de lucro. Por qué la democracia necesita de las humanidades. Madrid: Katz Ediciones.

Ochaíta, E., Espinosa, M.A. \& Gutiérrez, H. (2011). Las necesidades adolescentes y las nuevas tecnologías de la información y la comunicación. Revista de Estudios de Juventud, 92, 87-110.

ONU, Asamblea General, Declaración Universal de los Derechos Humanos. Recuperado de http://www.un.org/es/ universal-declaration-human-rights/

Orantes, S. (2011). Viabilidad del Modelo de la Aceptación de la Tecnología en las empresas mexicanas. Una aproximación a las actitudes y percepciones de los usuarios de las tecnologías de la información. Revista Digital Universitaria, $12,1-15$.

Ortega, P. \& Minguez, R. (2004). familia y transmisión de valores. Teoría de la Educación. Revista interuniversitaria, 15, 33-56. https://goo.gl/y762Fp

Pereira, S. (2013). More Technology, Better Childhoods? The Case of the Portuguese 'One Laptop per Child' Programme. CM: Communication Management Quarterly, 29, 171-198. https://doi.org/10.5937/comman1329171P

Pereira, S., Fillol, J. \& Moura, P. (2019). Young people learning from digital media outside of school: The informal meets the formal. [El aprendizaje de los jóvenes con medios digitales fuera de la escuela: De lo informal a lo formal]. Comunicar, 58, 41-50. https://doi.org/10.3916/C58-2019-04

Piña, E. (2012). Aprender en el vivir. Revista educare, 16, 2, 138-158.

Reig, D. (2018). Jóvenes de un nuevo mundo: cambios cognitivos, sociales, en valores, de la Generación conectada. Revista de estudios de juventud, 108, 21-32. Recuperado de https://goo.gl/nmueBQ

Reverter, J. (2004). Valores básicos de la identidad europea. Castellón de la Plana: Universitas.

Rico, MC., Sevillano, ML. \& Feliz, T. (2011). Competencias necesarias para la utilización de las principa- les herramientas de Internet en la educación. Revista de educación, 356, 483-507. https://doi.org/10-4438/1988592X-RE-2010-356-048

Ruiz, M., Bernal, A., Gil, F., \& Escámez Sánchez, J. (2012). Ser uno mismo. Repensando la autonomía y la responsabilidad como coordenadas de la educación actual. Teoría de la Educación. Revista Interuniversitaria, 24(2), 59-81.

Salazar, L. \& Woldenberg, J. (2016). Principios y valores de la democracia. Cuadernos de Divulgación de la Cultura Democrática, Instituto Nacional Electoral: México. Recuperado de http://biblio.ine.mx/janium/Documentos/cuaderno_01.pdf

Tornero, J.M. (2017). Aprender a ser con Internet. Barcelona: Octaedro.

Torrego, J. C., \& Martínez, C. (2014). Claves para el Desarrollo del Plan de Convivencia en los Centros Educativos desde una Perspectiva Integral. Qualitative Research in Education, 3 (1), 83-113.

UNESCO. (2015). Replantear la educación. ¿Hacia un bien común mundial? Recuperado de http://unesdoc.unesco. org/images/0023/002326/232697s.pdf

Yudes-Gómez, C., Baridon-Chauvie, D. \& González-Cabrera, J.M. (2018). Cyberbylling and problematic Internet use in Colombia, Uruguay and Spain: Cross-cultural study. [Ciberacoso y uso problemático de Internet en Colombia, Uruguay y España: Un estudio transcultural]. Comunicar, 56, 49-58. https://doi.org/10.3916/C56-2018-05

Zhao, S., Grasmuck, S. \& Martin, J. (2008). Identity construction on Facebook: Digital empowerment in anchored relationships. Computers in Human Behavior, 24, 18161836. https://doi.org/10.1016/j.chb.2008.02.012 


\title{
La Tablet en la escuela: Revisión bibliográfica en Scopus
}

\author{
The Tablet in schools: A bibliographic review from Scopus \\ María Montserrat Castro Rodríguez ${ }^{1}$ \\ https://orcid.org/0000-0002-5544-4421 \\ Óscar Mallón Suárez ${ }^{2}$ \\ https://orcid.org/0000-0002-8090-7715 \\ Universidade da Coruña, España
}

Vol. 6(1). Enero-abril. Hamut'ay 2019. Lima-Perú

\section{Cita recomendada}

Castro, M. \& Mallón, O. (2019). La Tablet en la escuela: Revisión bibliográfica en Scopus.

Hamut'ay, 124-139.

http://dx.doi.org/10.21503/hamu.v6i1.1579

\section{RESUMEN}

La incorporación de las tabletas en muchas escuelas a lo largo del mundo, ha despertado la curiosidad de la comunidad científica, justificando el auge de reseñas, noticias, publicaciones derivadas de la investigación, la celebración de congresos y exposiciones o la proliferación de libros. En este contexto surge la necesidad de conocer y analizar aquello que sea de interés. El presente artículo recoge los resultados de una revisión bibliográfica a partir de las publicaciones localizadas en la base de datos de Scopus, del periodo del 2016 al 2019. El objetivo principal fue identificar y analizar las 50 publicaciones seleccionadas como muestra, recogidas de revistas, libros y libros de actas en la base de datos Scopus cuya temática abordase la investigación y uso de la Tablet en la escuela en los últimos cuatro años. En lo metodológico se ha optado por el análisis documental, que permite extraer datos de índole cuantitativa y cualitativa.

Los resultados reflejan la importante presencia de la Tablet en las escuelas, aunque se sigue percibiendo una gran brecha digital entre países. En general, la mayoría de las investigaciones reflejan un impacto positivo en los sistemas educativos analizados, repercutiendo de manera eficiente en la motivación del alumnado y su adquisición de competencias. Sin embargo, para que el resultado de su uso sea exitoso es necesaria la introducción de metodologías pedagógicas que favorezcan el aprendizaje interdisciplinar y cooperativo.

Palabras Clave: Tablet, revisión bibliográfica, Scopus, recurso, tecnología

\footnotetext{
1 Doctora en CC. De la Educación. Licenciada en CC. De la Educación y Diplomada en Educación primaria por la Universidad de Santiago de Compostela. http://www.researcherid.com/rid/H-6108-2015 Profesora en la Facultad de CC. Educación de la Universidade da Coruña (A Coruña, España). Investigador en diversos proyectos nacionales e internacionales de educación. E-mail: maria.castror@ udc.es

2 Graduado en Educación Primaria en la Universidad de la Coruña. Ha realizado su trabajo de graduación sobre el uso de cortometrajes en las aulas de Educación Primaria para desarrollar la inteligencia emocional dentro de dinámicas de flippedClassroom. E-mail: oscarmalln@yahoo.es
} 


\section{Abstract}

The incorporation of tablets in many schools throughout the world, has aroused curiosity in the scientific community, justifying the growth of reviews, news, publications derived from research, the launch of conferences and exhibitions and the proliferation of books. Within this context, there is a need to know and analyze what is in the public interest. The present article collects the results of a bibliographic review from the publications in the Scopus database, from the period of 2016 to 2019. The main objective was to identify and analyze the 50 selected publications as a sample, collected from magazines, books and minute books in the Scopus database whose subject matter covered the research and use of tablets in schools in the last four years. Methodologically, we have opted for a documentary analysis, which allows us to extract quantitative and qualitative data.

The results reflect the important presence of tablets in schools, although there is still a large digital divide among countries. In general, most of the research reflects a positive impact on the analyzed educational systems, efficiently impacting the motivation of students and their acquisition of competences. However, for a successful result of its use, it is necessary to introduce pedagogical methodologies that favor interdisciplinary and cooperative learning.

Keywords: Tablet, bibliographical review, Scopus, resource, technology.

\section{INTRODUCCIÓN}

La eclosión de la tecnología en la sociedad y en el ámbito educativo se cuenta por décadas, estando presentes en las aulas desde el pasado siglo XX, aunque su desarrollo no ha parado de crecer, debido a la continua aparición de nuevos dispositivos y software simultáneamente, abriendo inmensas posibilidades de aplicación. Desde empresas productoras, la administración y el campo de la investigación ratifican su enorme potencialidad en el proceso de enseñanza-aprendizaje, destacando su carácter innovador, motivador y de adaptación a los contextos individuales y colectivos de la escuela. A las tecnologías digitales se les atribuye un rol clave en una sociedad hipercomunicada, donde es esencial la cooperación, la participación y la ayuda a la hora de completar una determinada actividad o tarea, convirtiéndose en competencias fundamentales tanto para el desarrollo personal, social como profesional. Esta consideración justifica las millonarias inversiones económicas en muchas partes del mundo (Ferri \& Moriggi, 2017). Las TIC son recursos didácticos, herramientas que posibilitan una comunicación alternativa, la intervención y fundamentación del saber (Salmerón, Rodríguez \& Gutiérrez, 2010); facilitan una nueva estructura educativa, al vencer las fronteras espacio-tiempo habituales, gracias a los nuevos entornos y redes sociales que transforman la docencia y el aprendizaje (Maraza, 2016), permitiendo compartir experiencias educativas a distancia.

Uno de los recursos TIC que ha supuesto una revolución en el sistema educativo es, sin duda, la Tablet o iPad. Su aparición a inicios del siglo XXI, aunque más efectiva en las escuelas en la actual segunda década, supone un innegable avance en cuanto a su versatilidad de uso y funcionamiento (Hassan \& Geys, 2016), a las posibilidades de manipulación, de movilidad, de adaptación a las características de cada contexto, de variedad, funcionalidad y accesibilidad de software no sólo para la adquisición del conocimiento y la comunicación, sino también a la hora de transferir conocimientos en una doble dirección entre escuela y sociedad. Todo ello asociado a sus características técnicas de fácil manejo, abaratamiento de costos, la implicación con programas de gobiernos $\mathrm{y}$ algunas instituciones supranacionales que han promovido la dotación de las tablets en muchos 
lugares imposibles para el ordenador, explican su expansión a nivel mundial. Surgen algunas interrogantes: ¿qué aporta el uso de la tablet al aula?, ¿cómo se utiliza?, ¿̇realmente el uso de la tablet está ligado al uso de metodologías innovadoras que faciliten la accesibilidad al conocimiento a todo el alumnado de un aula?, ¿están contribuyendo a la calidad en la escuela? ¿El iPad accesible a todo el alumnado o es un nuevo recurso que ahonda aún más la brecha digital entre estudiantes?

De toda esta situación se ha hecho una mayor divulgación en revistas, congresos y libros a nivel internacional (Zydney \& Warner, 2016) que presentan resultados de investigación, experiencias, reflexiones sobre la implantación de estos dispositivos digitales y del software que ha ido apareciendo. En este contexto, surge la presente investigación que tuvo como objetivo la identificación, selección y análisis de las publicaciones acerca del uso de la tablet y la escuela, especialmente relacionado con la escuela elemental o primaria y sus posibilidades de atención a la diversidad del alumnado que en ellas participa. En este trabajo se analizaron 50 artículos de revistas indexadas en la base de datos Scopus.

\section{La tablet en la escuela}

Una parte considerable de los trabajos publicados en revistas indexadas en las bases internacionales hablan de un movimiento mundial en el uso de estos dispositivos en diferentes escuelas de Canadá, USA, Brasil, Túnez, México, Reino Unido, Turquía, Costa Rica Dinamarca, Francia, España, Suecia, Alemania, Guatemala, Croacia, Australia, Nueva Zelanda y en otros países, que visibilizan, además, la existencia de una enorme brecha digital entre unos países y otros. La mayoría de las conclusiones extraídas conducen a interesantes aportaciones del uso de la tablet, por ejemplo, en la adquisición de conocimientos lingüísticos, matemáticos, geográficos, además de competencias inter e intrapersonales, en todos los ciclos educativos, pero también en el ámbito familiar o de ocio. Según el informe Ditrendia, en el año 2015 se vendieron en el mundo 206,8 millones de tablets y aun detectando un importante descenso en los últimos años, en el año 2016 se vendieron cerca de 174,8 millones (Ditrendia, 2017). A priori, las características de la tablet, permiten introducir en el aula una serie de posibilidades pedagógicas, que pueden facilitar la accesibilidad del alumnado a las distintas dimensiones de la sociedad actual, donde la tecnología es un elemento clave para su desarrollo personal, social, académico e incluso económico. Se le asigna a este dispositivo las posibilidades de promover un rol innovador en la escuela, fundamentalmente, porque facilita la adquisición de nuevos contenidos, nuevas competencias, exigiendo apostar por metodologías innovadoras para aprender (Javorcik, 2017; Young, 2016), aunque no existe unanimidad acerca de sus potencialidades o sobre la idoneidad de su uso en la escuela (Bodsworth \& Goodyear, 2017). Numerosas publicaciones destacan los beneficios y los riesgos (Haßler, Major \& Hennessy, 2016; De La Serna-Tuya, González-Calleros \& Rangel, 2018; Altan \& Karalar, 2018) que conlleva el utilizar dispositivos móviles desde edades muy tempranas en los niños, sobre todo, en la etapa en la que todavía están aprendiendo a leer y escribir y se encuentran inmersos en su desarrollo intelectual y psicomotriz. Su uso intuitivo y sencillo, moviendo sólo un dedo para poder interactuar, ver imágenes, escuchar distintos idiomas, etc. lo hace útil para todo tipo de alumnado, sea cual sea su edad. Su inclusión en las aulas, ha obligado a definir nuevos términos pedagógicos, ya que introducen elementos sustanciales de uso que permite de acuerdo con los principios que sintetiza inspira TICs: Ubicuidad, Trabajo por proyectos, Currículum bimodal, Enfoque multidisciplinar.

La motivación del alumnado es el argumento principal para su uso en el aula en muchos de los trabajos publicados, junto al soporte visual y auditivo y una inabarcable oferta de apps educativas o de uso general (Kolas, Nordseth \& Munkvold, 2016), y gran utilidad en el aula, para adaptarse a la diversidad de estudiantes de la misma (Campos, 2015). Se recomienda su uso en las escuelas porque supone una herramienta más, un apoyo para la labor docente, sin que los alumnos tengan que aprender nuevas metodologías o procesos complicados para su utilización. Algunas investigaciones realizadas en entornos escolares que usan tablets, atribuyen un incremento del rendimiento académico de los alumnos, al mejorar su 
capacidad visual-espacial, fomentar la imaginación, aumentar su productividad y su inteligencia emocional (Shamir-Inbal \& Blau, 2016; Villányi, Martin, Sonnleitner, Siry, Fischbach, 2018; Van Deur, 2017). Son interesantes las numerosas investigaciones realizadas en las distintas etapas educativas en diferentes áreas de conocimiento (lengua, matemáticas) y con respecto a la atención a la diversidad.

Las implicaciones metodológicas que aporta el uso de los dispositivos móviles afectan también al rol del docente, como refleja el artículo de Suárez-Guerrero, Lloret-Catalá \& Mengual-Andrés (2016) cuyos resultados destacan la tendencia del profesorado de $5^{\circ}$ y $6^{\circ}$ de Educación Primaria a usar las tablets para la adquisición de competencias. Las apps ayudan a centrarse más en las actividades que en los contenidos, a incorporar el juego como estrategia de aprendizaje, al mismo tiempo que parece relacionar modelos pedagógicos basados en proyectos educativos. También destaca la importancia de la infraestructura e instalación en el aula: buena conexión a Internet (Bin Tuwaym \& Berry, 2018); el importante número de apps educativas como Kahoot, Duolingo o plataformas educativas como Edmodo para enseñar contenidos (Correa, De Biase, Lotto \& Lopes, 2018); organización en las aulas, fomentando el trabajo cooperativo (Suárez-Guerrero, Lloret-Catalá, \& Mengual-Andrés, 2016; ) y el rol que desempeña el profesorado: uso del iPad, los docentes como guías, desarrolladores del currículo y coach que fomentan la búsqueda del conocimiento en el alumnado a través de una mayor participación y cooperación en su instrucción (Cakir \& Rorkmaz, 2018).

De los inconvenientes destacables a la hora de disponer de estos dispositivos, las investigaciones revisadas hacen especial hincapié en la formación del profesorado (Bin Tuwaym \& Berry, 2018) o (Bluestein \& Kim, 2017) y la necesidad de que los docentes sean conscientes de las barreras o las exigencias con las que se puede encontrar el uso de iPad o tablet en el aula (Walsh \& Farren, 2010).

Parejo al uso de la tablet, aparece el término complementariedad; la necesidad de hacer usos de distintos materiales y recursos educativos para trabajar en el aula.

El uso de tablets en la escuela elemental y primaria está muy presente en las publicaciones, ligado en gran medida a su aplicación en áreas de aprendizaje específicas como matemáticas y especialmente en el proceso de aprendizaje de la lectoescritura. Distintos trabajos que destacan la importancia del uso de la tablet en los primeros años de escolarización por las posibilidades que ofrecen en el aprendizaje cooperativo (Ortega \& Febles, 2016). Castro, Cedillo \& Valenzuela (2016) resaltan que el éxito del uso de las tablets en Educación Primaria se basa en su amplia aceptación por el alumnado, debido a que desde edades muy tempranas tienen accesibilidad a recursos digitales fácilmente manipulables.

\section{Materiales y Métodos}

\section{Participantes}

Siendo un estudio bibliométrico la población estuvo conformada por la revisión documental en revistas indexadas en la base de datos de Scopus haciendo un total de 203 publicaciones, extraídos a partir de los descriptores tablet+school, tablet+elementary school, tablet+primary school, tablet+school+disabilities, teniendo como criterio de inclusión todos los artículos publicados entre el 2016 al 2019, ámbito de las ciencias sociales, con textos escritos en inglés, español o portugués.

Para la selección de la muestra, se establecieron varios criterios, extraídos a partir de las dimensiones identificadas en la población general y son los siguientes: índice de citación, diversidad de países, etapa educativa y otros que, siendo publicados en el 2018 y 2019, todavía no aparecen en citas y referencias bibliográficas, pero introducen distintos contenidos que pueden ser innovadores, bien por originalidad o por resultados de investigación, lo cual nos permitió tener una muestra de 50 publicaciones.

Para la selección de las 50 publicaciones se realizó el siguiente procedimiento: 
1. Teniendo en cuenta como población los 203 artículos, en función año de publicación, etapa educativa, país, tipología de publicación y revistas, se ha mantenido su proporcionalidad al inicio.

2. De esta distribución y organización, se procede a la selección de los artículos en función del número de citas.

3. Se han incorporado algunos artículos que, no teniendo citas, porque su publicación fue en el 2018 o 2019, resultaban interesantes por los resultados, la innovación en la temática, etc

Tabla 1

Porcentajes de representación de los artículos en la muestra extraída a partir de la población general

\begin{tabular}{|c|c|c|}
\hline \multicolumn{2}{|c|}{ Criterios para el filtrado de documentos } & $\begin{array}{l}\text { Represen- } \\
\text { tación }\end{array}$ \\
\hline \multirow{4}{*}{$\begin{array}{l}\text { Año de publi- } \\
\text { cación }\end{array}$} & 2016 & $15.5 \%$ \\
\hline & 2017 & $38 \%$ \\
\hline & 2018 & $36 \%$ \\
\hline & 2019 & $9.5 \%$ \\
\hline \multirow{5}{*}{$\begin{array}{l}\text { País de proce- } \\
\text { dencia }\end{array}$} & USA & $26.7 \%$ \\
\hline & Turquía & $6.7 \%$ \\
\hline & España & $5 \%$ \\
\hline & $\begin{array}{l}\text { Brasil, UK, China y Grecia con } \\
\text { dos publicaciones }\end{array}$ & $13,3 \%$ \\
\hline & Países con una publicación & $51 \%$ \\
\hline \multirow{7}{*}{$\begin{array}{l}\text { Etapa educa- } \\
\text { tiva }\end{array}$} & Educación Infantil & $8 \%$ \\
\hline & Educación primaria & $60 \%$ \\
\hline & Educación Secundaria & $4 \%$ \\
\hline & Educación Superior & $2 \%$ \\
\hline & $\mathrm{Fp}$ & $8 \%$ \\
\hline & Profesorado & $6 \%$ \\
\hline & Interetapas & $12 \%$ \\
\hline \multirow{3}{*}{$\begin{array}{l}\text { Tipología de } \\
\text { publicaciones }\end{array}$} & Artículos & $94 \%$ \\
\hline & Capítulos de libro & $4 \%$ \\
\hline & Libros de actas & $2 \%$ \\
\hline \multirow{2}{*}{$\begin{array}{l}\text { Tipo de } \\
\text { estudio }\end{array}$} & Investigación & $57 \%$ \\
\hline & Experiencia & $43 \%$ \\
\hline Citas & $\mathrm{N}^{0}$ de citas & 213 \\
\hline
\end{tabular}

\begin{tabular}{|c|c|c|}
\hline & Revistas seleccionadas & $\begin{array}{l}\mathrm{N}^{0} \text { de artí- } \\
\text { culos de la } \\
\text { muestra }\end{array}$ \\
\hline \multirow[t]{11}{*}{ Revistas } & Education and Information & 5 \\
\hline & Technologies & 4 \\
\hline & Computers and Education & 3 \\
\hline & $\begin{array}{l}\text { International Journal of Emer- } \\
\text { ging Technologies in Learning }\end{array}$ & 2 \\
\hline & $\begin{array}{l}\text { Journal of Information Techno- } \\
\text { logy Education: Innovations in } \\
\text { Practice }\end{array}$ & 2 \\
\hline & $\begin{array}{l}\text { Journal of Computer Assisted } \\
\text { Learning }\end{array}$ & 2 \\
\hline & $\begin{array}{l}\text { Education and Training in } \\
\text { Autism and Developmental } \\
\text { Disabilities }\end{array}$ & 2 \\
\hline & Comunicar & 2 \\
\hline & Campus Virtuales & 2 \\
\hline & $\begin{array}{l}\text { British Journal of Educational } \\
\text { Technology }\end{array}$ & 1 \\
\hline & $\begin{array}{l}25 \text { revistas, } 2 \text { libros de actas y } \\
\text { un capítulo de un libro capítulo } \\
\text { de libro }\end{array}$ & \\
\hline
\end{tabular}

Fuente: elaboración propia 2019

\section{Instrumento}

Para la recolección de datos e información se procedió a la elaboración de una guía de análisis, a cumplimentar por cada una de las publicaciones seleccionadas. Las dimensiones de investigación se identificaron a partir de las extraídas en la población general. (Anexo I)

\section{Tipo y Diseño}

La investigación es de corte cualitativo, y de diseño descriptivo al realizar un análisis de contenido, dado que, además de datos de carácter cuantitativo, aporta un proceso riguroso de análisis cualitativo (Bardin, 1986; Sayago, 2014). Se utilizó un diseño cuantitativo no experimental, de tipo exploratorio, cuyos estadísticos reflejan la frecuencia y uso de distintos vocablos. El diseño cualitativo empleado es emergente, realizado a partir de una serie estrategias de búsqueda de palabras clave y nexos semánticos, que permitieron identificar temáticas de análisis, que facilita la interpretación de los textos. 


\section{Procedimiento}

Como fase preparatoria de la investigación, se procedió a un estudio aleatorio en Web of Science donde se identificaron palabras claves y revistas, con el objetivo de delimitar los criterios de la posterior búsqueda bibliográfica. A continuación, se realizaron las búsquedas de las publicaciones en la base de datos Scopus, de las que se extrajeron 203 publicaciones. Teniendo en cuenta la amplitud del estudio y para la gestión de la información se decide realizar el análisis de 50 trabajos, que constituye la muestra del presente artículo. Seleccionada la muestra final se procedió a una lectura exhaustiva por parte de las dos personas investigadoras, cumplimentando la guía de análisis. Ambas personas leen los mismos artículos y registran los datos y la información en la guía de análisis. Una vez analizados todos los documentos, se contrastan los análisis realizados para cada una de las publicaciones, en caso de no haber consenso se procede a un análisis conjunto y a la discusión para la toma de decisiones finales.

\section{Resultados}

Para la exposición de los resultados, se ha procedido a una organización en torno a cinco núcleos de análisis: etapa educativa, países de procedencia de las experiencias e investigaciones, tipología de publicaciones, tipología de estudios y análisis de contenido: temáticas y resultados de investigación.

\section{Etapa educativa}

Como se puede observar en la tabla 2, en todas las etapas educativas el uso de la tablet en la escuela es objeto de estudio y reflexión, lo que evidencia su carácter transversal en el sistema educativo. La etapa educativa más representada es la Educación Elemental o Primaria que asciende a un 60\% de los trabajos analizados. Las temáticas abordadas en todas las etapas son muy diversas, pero abundan las que investigan la aplicación de las herramientas TIC en al aula (Ale, Loh \& Chib,2017; Al-Mashaqbeh, 2016; Altan \& Karalar, 2018; Avidov-Ungar \& Shamir-Inbal, 2017), en general o en las distintas áreas de conocimiento (Chen,
Chiu, Lin \& Chou, 2017; Dahan, Barzillai \& Katzir, 2018; Falloon, 2017), en muchas ocasiones, con el objetivo de responder a la atención a la diversidad dentro del aula (Fleisch, Schoer, Roberts, Thornton, 2016; Fletcher-Watson, Pain, Hammond, Humphry, McConachie, 2016) o con estudiantes que presentan capacidades diferentes (Barrientos, 2017).

Las publicaciones centradas en la etapa de Educación Inicial (EI), pre-school o kindergarten corresponden al $8 \%$ y muestran conclusiones y análisis de investigación vinculados al uso de las pantallas táctiles en distintas situaciones: Fletcher Watson et al. (2016) diseñaron una app para alumnado afectado por el Trastorno Autista (TEA); Al-Mashaqbeh, (2016) expone los resultados de aprendizaje de las matemáticas a través del IPAD en una escuela privada; Ferri \& Moriggi, (2017) analizaron el uso que hacen los estudiantes desde 0 a 10 ańos; Altan \& Karalar (2018) por su parte reflexionan sobre el impacto de los recursos TIC en áreas urbanas y rurales de Turquía.

El 4\% proceden de la Educación Secundaria, High School, Middle School. Ferguson \& Oigara, 2017; Ferguson, 2017 presentan resultados en aulas de Educación Secundaria de USA.

En el ámbito universitario, representando el 8\%, destacan los trabajos de Fujita, Todo, Sugawara, Kageura \& Arai, 2017; Castillo-Manzano et al.,2017; Attia, Ben Fadhel \& Bettaieb, 2016; Bluestein \& Kim, 2017; todos ellos inciden en el uso de dispositivos móviles (tablets o iPad) como recurso que mejora la didáctica y el estudio.

Cavkaytar, Acungil \& Tomris, (2017) explican cómo hacer uso de las TIC para ayudar a personas con discapacidad intelectual a adquirir las destrezas necesarias para ser camarero Formación Profesional. Es una investigación muy interesante sobre una aplicación real, que permite a personas afectadas por una discapacidad, adquirir competencias de autonomía personal, profesional e inserción laboral.

El 12\% de los artículos restantes no especifican o no se centran en una etapa educativa concreta o en algunos casos integran distintas etapas educativas. Como los trabajos de Baglama et al (2018) 
que realizan un análisis bibliográfico sobre el uso de TIC con niños sordos; Clements \& Sarama (2017) publicaron una reseńa para la mejora de las matemáticas entre el alumnado con pocos recursos, Dolan (2016) que realiza un análisis sobre la brecha digital, Emiroğlu \& Kurt (2017) publicaron un trabajo a través de una aplicación virtual, Cole, Cohen, Wilhelm \& Lindell, (2018) realizaron una investigación para el desarrollo de la inteligencia espacial en el marco de la astronomía, el trabajo de Azigwe et al., (2016) consistió en encuestar al alumnado de escuelas de Ghana acerca de la calidad de la enseñanza de las Matemáticas por parte de sus profesores, Barzillai \& Thomson (2017) que dedicaron un capítulo de un libro al uso de ebooks para la alfabetización de nińos. Otro 6\%, corresponde a encuestas y proyectos que tienen al profesorado como protagonista al implantar o cubrir las aulas con recursos TIC. Son los trabajos de Caldwel, 2018; Chambers et al,.2018; Cherner, Fegerly \& Lee, 2016; Darling-Aduana \& Heinrich, 2018; en los que se estudia el rol o la opinión de los profesores ante el uso de tablets en el aula para la mejora del aprendizaje.

\section{Tabla 2}

Distribución de la muestra en función de las etapas educativa en el uso de las tablet

\begin{tabular}{lc}
\hline Etapa educativa & $\begin{array}{c}\text { Uso de las Tablet } \\
\text { en la muestra (\%) }\end{array}$ \\
\hline Educación Infantil (EI) & 15.5 \\
EP & 38.0 \\
Educación Secundaria & 36.0 \\
FP & 9.5 \\
Universidad & 26.7 \\
Profesorado & 6.7 \\
Interetapa la etapa & 5.0 \\
\hline
\end{tabular}

Fuente: elaboración propia 2019

Países de procedencia de las investigaciones y experiencias.

Los datos relativos al país de procedencia donde se lleva a cabo la investigación o experimentación (Tabla 3), reflejan la existencia de una gran brecha digital, donde USA sigue teniendo una posición hegemónica a nivel mundial en un gran porcentaje de todas las búsquedas realizadas. Paulatina- mente, a medida que van pasando los ańos, cada vez son más los trabajos de países procedentes de África, América o Asia que llegan a las revistas indexadas en bases de datos como Scopus, y así se refleja que un país como Turquía se sitúa en el segundo puesto de la presente muestra, aunque en los valores absolutos de Scopus de publicaciones sobre la tablet en cualquier ámbito de conocimiento, no tiene tanto protagonismo, pero si se sitúa entre los 10 primeros productores junto a USA, Australia y Reino Unido. Este aumento se produce no tanto por la incorporación de revistas indexadas, sino porque las investigaciones llegan a revistas europeas y especialmente estadounidenses. El inglés es la lengua más usada y escasamente representados están el español y el portugués, que no llegan al 5\%.

Tabla 3

Países según la procedencia de las investigaciones

\begin{tabular}{lc}
\hline País & $\begin{array}{c}\text { Número de publicaciones } \\
(\%)\end{array}$ \\
\hline USA & 26.7 \\
Turquía & 6.7 \\
España & 5.0 \\
Brasil, UK, China y Grecia con & 13.3 \\
dos publicaciones & \\
Países con una publicación & 51.0 \\
\hline
\end{tabular}

Fuente: elaboración propia 2019

\section{Tipología de publicaciones}

Tabla 4

Distribución de los artículos analizados según la tipología de publicaciones que las editan

\begin{tabular}{lcc}
\hline $\begin{array}{l}\text { Tipología de publi- } \\
\text { caciones }\end{array}$ & $\begin{array}{c}\text { Revistas especiali- } \\
\text { zadas en tecnología } \\
(\%)\end{array}$ & $\begin{array}{c}\text { Revistas no } \\
\text { vinculadas a las } \\
\text { tecnologías (\%) }\end{array}$ \\
\hline Artículos & 54 & 40 \\
Libros de Actas & 4 & \\
Capítulos de libro & 2 & \\
\hline
\end{tabular}

Fuente: elaboración propia 2019

En cuanto a la tipología de revistas que publican los artículos, es evidente el predominio de aquellas que tienen como temática vincular la tecnología: 27 artículos y 2 capítulos de libro y libros de actas están en revistas y libros especializados en tecnología. Los 20 restantes se publican en re- 
vistas específicas de otras áreas: destacan aquellas relacionadas con publicaciones centradas en la diversidad funcional o capacidades diferentes. Resultan interesantes estos resultados en tanto que evidencia el carácter interdisciplinar que puede y deben conllevar el uso de un dispositivo electrónico, que debería estar en relación con las áreas de conocimiento en las que se utiliza y los destinatarios, sin olvidar la necesidad de su relación con una metodología.

\section{Tipología de estudio}

En el análisis documental realizado, se constata que los textos mayoritarios son los procedentes de investigaciones (57\%) y de experiencias (43\%) basadas en el desarrollo y/o uso de las pantallas táctiles en contextos escolares, que, con frecuencia, generan investigaciones que analizan el proceso de implementación y los resultados obtenidos.

1. Las investigaciones llevadas a cabo en cada uno de los artículos tienen como eje principal reflexiones, opiniones y valoraciones empleo de tablet en el aula y su impacto en la educación (Attia, Fadhel \& Bettaieb, 2016; Accardo, Costa \& Perrone, 2017; Altan \& Karalar, 2018; Avidov-Ungar, \& Shamir-Inbal, 2017; Bagon, Gačnik, \& Starčič, 2017; Dahlström \& Boström, 2017, Accardo, Costa \& Perrone, 2017, defienden una metodología interdisciplinar para mejorar la escritura en nińos con necesidades educativas especiales de EP, que reflejan el incremento de la velocidad de escritura y la caligrafía con resultados favorables en el test de movimiento $\mathrm{ABC}$ o la prueba del desarrollo de la integración visual-motriz.

2. Artículos basados en experiencias que analizan y evalúan el uso de las tablet en el aula. Ale, Loh \& Chib (2017) llevaron a cabo un trabajo de campo en escuelas rurales de la India, donde propusieron utilizar una laptop por alumno, con el fin de mejorar su rendimiento académico. Demostraron que el uso de estas herramientas se asociaba positivamente con una alfabetización funcional, teniendo un gran impacto en su aprendizaje. Avidov-Ungar \& Shamir-Inbal, (2017), por su parte, reflejaron la experiencia de aplicar un programa de colaboración entre el profesorado, utilizando herramientas digitales con recogida de muestras en el aula, para fomentar la educación artística entre los alumnos. Barrientos (2017) realizó diversos trabajos de campo, experimentando con niños cuatro formas de adquirir la escritura. Cakir \& Korkmaz (2018) especificaron el estudio experimental de 61 niños de $5^{\circ}$ de EP a la hora de adquirir vocabulario y mejorar en la materia de Lengua y Literatura. Cordero, Nussbaum, Ibaseta, Otaíza \& Chiuminatto (2018), pusieron en marcha una herramienta multimodal para ayudar a los niños a construir su conocimiento. Fletcher-Watson, Pain, Hammond, Humphry \& McConachie (2016) estudiaron, diseñaron y pusieron en marcha gracias a la experimentación, una aplicación móvil para tratar a 51 nińos con TEA en EP.

Análisis de contenido: temáticas y resultados de investigación

Teniendo en cuenta las temáticas abordadas en las diferentes publicaciones, se identificaron cuatro dimensiones de análisis: mejoras/barreras en el desarrollo del proceso educativo, implicaciones metodológicas dentro del aula, respuestas a la diversidad del aula y ámbito sociocultural. (Ver figura 1)

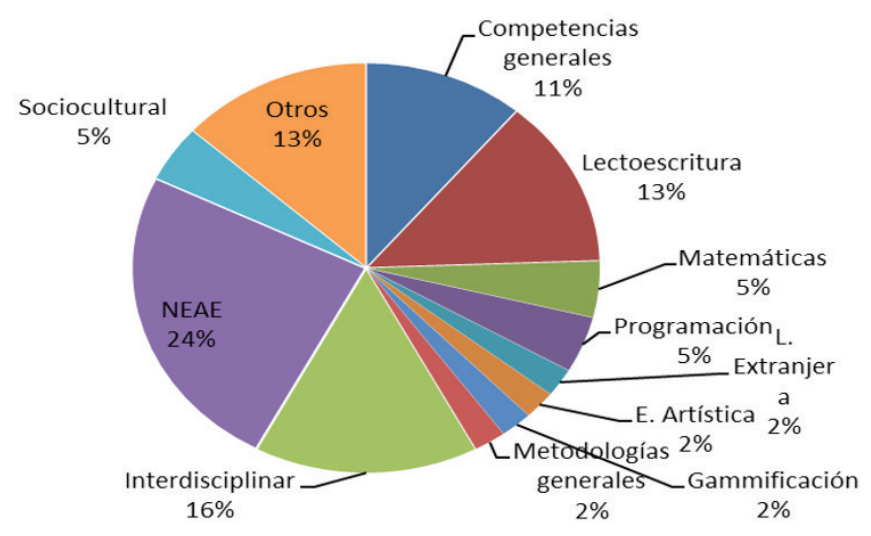

Figura 1

Distribución de las temáticas en la muestra analizada. Fuente: Elaboración propia 2019 


\section{Mejoras/barreras en el desarrollo del proceso educati- vo: competencias y rendimiento}

- Competencias generales. Los trabajos dedicados al ámbito universitario, Fujita, Todo, Sugawara, Kageura \& Arai, 2017; Castillo-Manzano et al.,2017; Attia, Ben Fadhel \& Bettaieb, 2016; Bluestein \& Kim, 2017, se orientan a mejorar y perfilar la evaluación continua del alumnado, estudiar el uso que hacen los estudiantes de sus tablet o laptop, estableciendo una relación entre el uso de estos dispositivos con el acceso a redes sociales, así como, evaluar y comparar resultados de la lectura, tanto en soporte digital como en papel. Bluestein \& Kim (2017) mostraron diferentes resultados en el tiempo, al utilizar un cuestionario a principio y final de un semestre mostrando que, para una mayoría de estudiantes, incumpliéndose las expectativas puestas en el uso de la tablet más que al usar el libro de texto u otros recursos. Sin embargo, su uso se incrementó exponencialmente en las redes sociales.

- Competencias específicas en distintas áreas de conocimiento. El uso de la tablet u otros dispositivos móviles en EP sirve como herramienta de apoyo en la adquisición de la lectoescritura, durante los primeros ańos como demuestran los trabajos de Dahan Golan, Barzillai \& Katzir, 2018; Baglama, Haksiz \& Uzunboylu, 2018; Bara, et al., 2016; Cordero et al., 2018; Beers, Mickail, Abbott \& Berninger, 2016. Sus propuestas mostraron errores en la pronunciación de algunas palabras, pero no en la escritura en sus dos vertientes: a través de la mano y en un teclado digital. El uso de estos dispositivos mejoró la composición de las palabras y el proceso de lectoescritura, favoreciendo la escritura a mano. Connor et al., (2019) aplicaron un programa con varios recursos TIC, permitiendo al alumno entender sus errores al leer y escribir, recibiendo un feedback que motivaba su mejora en el aprendizaje; también se aplica como herramienta útil para el desarrollo de diferentes materias: matemáticas, Al-Mashaqbeh, 2016; Chen, Chiu, Lin \& Chou, 2017, conceptos básicos de programación Fokides, (2018), ciencias, Falloon
(2017) y Fokides (2017), lenguas extranjeras, Darling-Aduana \& Heinrich (2018) o educación artística Avidov-Ungar \& Shamir-Inbal (2017) o aplicaciones didácticas a través de la gamificación (García-Sanjuan et al., 2018; El Kah \& Lakhouaja, 2018).

- El rendimiento académico en EI, se ha visto mejorado a partir del uso de la aplicación de la tablet en matemáticas o adquirir mayores destrezas en los procesos de lectoescritura según los resultados de investigación de Al-Mashaqbeh (2016). Chen, Gu \& Wong (2019) estudian el rendimiento del alumnado usando la Tablet y la mejora del comportamiento en un aula de EP.

\section{Implicaciones metodológicas en el aula: enfoque in- terdisciplinar y nuevas metodologías.}

Los dos trabajos analizados para la Educación Secundaria, Ferguson, 2017; Ferguson \& Oigara, 2017, buscan analizar el impacto del iPad desde la visión del alumnado y del docente, incidiendo en la motivación que supone para ambos grupos su utilización en las aulas. El resto de las investigaciones identifican la necesidad de un uso interdisciplinar, que se debe complementar con otros recursos, conscientes de la importancia social de la tecnología en la sociedad, pero advirtiendo de su manejo, ya que, debe ser empleado como una herramienta más, sin convertirse exclusivamente en la "herramienta" (Geer, White, Zeegers \& Barnes, 2017; Ferri \& Morigi, 2017; Falloon, 2017; Accardo, Costa \& Perrone, 2017). Sánchez \& Ricoy (2018), por su parte, hablan de la necesidad de implicar activamente la familia en el proceso de adquisición de las competencias digitales. Algunos trabajos analizados destacan dicha participación como una variable de éxito en el desarrollo de sus experiencias. Bin Tuwaym \& Berry (2018) así lo constatan cuando trabajan con alumnado con diversidad funcional visual en Brasil. Camacho \& Esteve (2018) subrayan la sencillez de incorporar este recurso a las aulas, por su potencial educativo, interactivo, las exigencias de un trabajo colaborativo e interdisciplinar, así como su huella en el interés, la atención y motivación y en el ambiente de trabajo del aula y en desarrollo de las competencias clave de los alumnos. Daya $\&$ 
Laher (2019) también hablan de las diferencias que se establecen en el éxito del uso de las tabletas y las actitudes del profesorado.

Atención a la diversidad, inclusión educativa y social: necesidades especificas de apoyo educativo (NEAE) y ámbito sociocultural

NEAE. Una amplia mayoría de los trabajos analizados en esta revisión bibliográfica concluyen la riqueza de las herramientas digitales en el proceso de atención a toda persona que asiste al aula, por su versatilidad para adaptar los procesos de enseñanza-aprendizaje a las necesidades individuales y colectivas de todo el alumnado, con o sin NEAE. Ale, Loh \& Chib, 2017; Bagon, Gačnik \& Starčič, 2018 mostraron cómo estudiantes con NEAE y el resto de la clase usan las tablets y ordenadores con fines más lúdicos que académicos, aunque los primeros eran más reacios a su utilización. Su mismo estudio demostró que los niños tienen una mayor predisposición a utilizar estos dispositivos para mejorar en su aprendizaje que las nińas. El Kah \& Lakhouaja (2018) diseñaron un programa lúdico en soporte digital para la atención de niños disléxicos. Fage et al., (2019) por su parte, elaboraron una app que regula el comportamiento de niños con TEA. Barrientos, 2017; Beers, Mickail , Abbott \& Berninger, 2016; Cakir \& Korkmaz, 2018; Correa, De Biase, Lotto \& Lopes, 2017, a su vez, soslayaron en sus investigaciones los beneficios que tienen las tablet en diferentes aspectos educativos, bien sea la adquisición de la lectoescritura en el caso de Barrientos (2017), la escritura y su transcripción (Beers et al., 2016), la aplicación de la realidad virtual para la adquisición del lenguaje según Cakir \& Korkmarz (2018) o la mejora del aprendizaje en niños con diversidad funcional visual (Correa et al., 2017). Bin Tuwaym \& Berry (2018), que también presentan un trabajo en el que usa las TIC con niños con diversidad funcional visual en Brasil, extraen como conclusión la necesidad de formación del docente, así como una mayor dotación en infraestructura escolar. El trabajo de Fletcher-Watson, Pain, Hammond, Humphry \& McConachie (2016) refleja los resultados positivos en la potenciación de la atención en niños afectados por TEA. Cavkaytar, Acungil \& Tomris (2017) buscaron la utilidad de la tablet y otros dispositivos audiovisuales para ayudar a personas con capacidades intelectuales diferentes a aprender una profesión.

Rol de las tablet según el ámbito sociocultural. Varias de las publicaciones introducen en sus variables de análisis el ámbito sociocultural. Altan \& Karalar (2018), un estudio acerca del impacto de las herramientas TIC en una provincia de Turquía, distinguiendo entre ámbito rural y urbano. Los resultados reflejan diferencias entre el alumnado de las escuelas rurales y el urbano: el primero tenía carencias sociales para poder llevar a cabo proyectos de forma cooperativa usando las TIC en el aula, mientras que, los segundos carecían de habilidades académicas para trabajar en el aula, dada su predisposición a utilizar las tablet/iPad $\mathrm{u}$ ordenadores con fines lúdicos. Bin, Tuwaym $\&$ Berry (2018) analizaron el uso con alumnado escolarizado en escuelas rurales de Brasil donde aquellos niños/as con capacidades visuales diferentes podían participar activamente en un gran número de actividades de las que, anteriormente, no habían sido capaces de realizar; se tuvo en cuenta su motivación y predisposición al uso de estos dispositivos, así como, la participación de familias y docentes en la educación del alumnado, mostrando resultados muy favorecedores. La investigación llevada a cabo por Ale, Loh, \& Chib, 2017 fue un programa de aplicación en nueve escuelas rurales de la India, que estudiaron el impacto provocado por el uso de laptop de bajo coste, gracias a un programa de ayuda gubernamental OLPC-one laptop per child, asistiendo al impacto educacional en "términos de mejora significativa del aprendizaje”; Daya \& Laher (2019) estudiaron la opinión de 119 profesores de varias escuelas de Johannesburgo y enfatizan la relación que se produce entre percepción y la actitud hacia la utilización de recursos tecnológicos como pieza fundamental en el nuevo paradigma educativo.

\section{Discusión y Conclusiones}

Analizada la muestra de los 50 trabajos publicados en los últimos cuatro ańos, que tienen como centro de estudio la incorporación de las pantallas digitales en el ámbito escolar, se puede concluir 
que se ha producido una importante expansión a nivel mundial. Sin embargo, es necesario destacar la existencia de una gran brecha digital entre países, dado que, los trabajos siguen procediendo en su mayoría de naciones hegemónicas en el uso de las TIC. Esta situación puede tener distintas explicaciones: por una parte, la posible desigualdad derivada de la gran diferencia de dotación de estos recursos en los centros educativos de los distintos países, así como, las desiguales oportunidades a la hora de investigar, publicar o llevar a cabo experimentaciones en las distintas partes del mundo; otro factor podría ser la accesibilidad a la publicación de trabajos en revistas de ámbito internacional, en muchas ocasiones, derivadas del uso casi exclusivo como lengua de investigación. USA, Europa y Australia siguen aglutinando la mayoría de las publicaciones sobre el uso de la tablet en el sistema educativo. Según los datos extraídos de Scopus, de Europa proceden el 42,5 \% de los trabajos recopilados sobre la tablet en la escuela, el $22,7 \%$ de Asia, el 21,3\% de de USA, el 6,7\% de Australia, con un 6,5\% del resto de América frente a los procedentes de todo el continente africano que no alcanza el $0,3 \%$ de lo publicado. Datos que son coherentes con los proporcionados por investigaciones como la realizada por Arellano, Cámara, Pérez \& Tuesta (2016), Cabero (2004).

El uso de la tablet está presente, en mayor o menor medida, en todas las etapas del sistema educativo de casi todos los países. Esta confirmación no es contundente con la muestra analizada y sí podrá ser testada en la investigación global de los 203 documentos. En la muestra analizada, la mayoría de los textos explican resultados de trabajos realizados en la EP o elemental (60\%) de acuerdo con las distintas organizaciones de los sistemas escolares mundiales. El origen de los resultados de las publicaciones refleja una predominancia de aquellas que presentan investigaciones o el desarrollo de experiencias, siendo menos numerosas aquellos que optan por la modalidad de la reflexión teórica y epistemológicas. Casi todas ellas apoyadas en metodologías de investigación de corte cuantitativo o mixto. Posiblemente, esta situación se puede deber a los criterios establecidos por las revistas.

Desde el punto de vista de las temáticas y resul- tados de investigación, en general, destaca la presentación de una visión positiva y optimista del impacto del uso de la tablet en la mejora de la competencia en lectoescritura, cálculo, habilidades sociales y para el trabajo cooperativo.

El uso de las pantallas en muchas ocasiones aparece asociado al trabajo con personas con capacidades diferentes, trastornos y/o dificultades de aprendizaje. El 26\% de las investigaciones y experiencias analizadas están relacionadas con el uso de la tablet, en especial, personas con capacidades diversas en la dimensión auditiva (4\%) o visual (4\%) o intelectual (4\%), o con TEA y sobre todo en las dificultades asociadas a la lectoescritura (4\%), especialmente derivadas de la dislexia; TEA (4\%); el $8 \%$ integra distintas diversidades y trastornos. No obstante, cada vez son más los trabajos que van encaminados a analizar o desarrollar propuestas y experiencias en las aulas ordinarias en las que coexisten estudiantes con necesidades y potencialidades muy diversas, en todas las áreas del currículum, aunque, con especial protagonismo, en el aprendizaje de la lectoescritura, de las matemáticas y las materias del ámbito artístico. El 99\% de las investigaciones analizadas coinciden en destacar las posibilidades que ofrece la tablet para la atención a la diversidad de alumnado, aunque numerosos autores y autoras hacen hincapié en la importancia de considerar la relación de este dispositivo y las metodologías derivadas de su uso en las aulas. Un importante número de artículos consideran que el uso de la tablet conlleva el uso de metodologías basadas en el desarrollo de proyectos de aprendizaje que, a través del trabajo cooperativo, permiten visibilizar y ahondar en el conocimiento de la realidad que les circunda, pero también la apertura a nuevos horizontes y nuevos conocimientos. Si no existe esa coherencia entre metodología y uso de las pantallas, los efectos pueden ser negativos. Así mismo ensalzan la figura de liderazgo pedagógico del profesional de la educación para el desarrollo de prácticas educativas exitosas.

Es necesaria la convivencia de este tipo de publicaciones con otras más contextualizadas en las culturas educativas y profesionales de cada país. En algunas de estas publicaciones queda escaso margen para la introducción de información que 
permita una más sólida contextualización, especialmente de aquellos elementos singulares de cada país, de cada sistema educativo.

Con el objetivo de promover una proyección de las publicaciones más equitativa parece necesario realizar un ejercicio de reflexión, en el que participen todos los sectores sociales implicados, para diseñar estrategias de publicaciones que permitan difundir trabajos rigurosos desde el punto de vista científico, que además se adecúen a las circunstancias contextuales, evitando la hegemonía de unas tendencias metodológicas sobre otras. La primacía de publicaciones con metodologías cuantitativas debe complementarse con la publicación de trabajos que utilizan metodologías cualitativas, que introduzcan criterios contextualizadores y explicativos, que posiblemente, faciliten las posibilidades de adaptación y desarrollo de iniciativas y experiencias. Por otra parte, dada la ingente cantidad de publicaciones existentes resulta imprescindible aumentar las investigaciones que ayuden a profundizar en el análisis y organización de los documentos.

\section{REFERENCIAS BIBLIOGRÁFICAS}

Accardo, A., Costa, F., \& Perrone, I. (2017) The Influence of the Spatio-Temporal Terzi Treatment on the Kinematics of Cursive Writin gof Dysgraphic Subjects. IEEE Transactions on Human-MachineSystems, 47 (2), 249-258. https://doi. org/10.1109/THMS.2017.2658445

Ale, K., Loh, Y.A. \& Chib, A. (2017) Contextualized-OLPC education project in rural India: measuring learning impact and mediation of computer self-efficacy. Educational Technology Research and Development, 65 (3), 769-794. https://doi.org/10.1007/s11423-017-9517-2

Al-Mashaqbeh, I.F. (2016) IPad in elementary school math learning setting. International Journal of Emerging Technologies in Learning, 11 (2), 48-52. https://doi.org/10.3991/ ijet.v11i02.5053

Altan, B.A. \& Karalar, H. (2018) How students digitally age: By gaining or losing? [Article@Öğrenciler teknoloji ile nasıl büyüyor: Kazanarak mı kaybederek mi?. Elementary Education Online, 17 (2), 738-749.

Arellano, A., Cámara, N., Pérez, D. (2016). Brecha digital y desarrollo. BBVA. Research Observatorio Digital. Recuperado de https://www.bbvaresearch.com/wp-content/ uploads/2016/07/TICs_Brecha-Digital.pdf

Attia, M., Ben Fadhel, S. \& Bettaieb, L. (2016) Impact of tablet based learning on continuous assessment (ESPRIT smart school framework). IEEE Global Engineering Education Conference, EDUCON. https://doi.org/10.1109/ EDUCON.2016.7474569

Avidov-Ungar, O. \& Shamir-Inbal, T. (2017) ICT coordinators' TPACK-based leadership knowledge in their roles as agents of change. Journal of Information Technology Education: Research, 16 (1), 169-188. https://doi.org/10.20849/ jed.v2i1.306

Azigwe, J.B. \& Kyriakides, L., Panayiotou, A., Creemers, B.P.M. (2016) The impact of effective teaching characteristics in promoting student achievement in Ghana. International Journal of Educational Development, 51, 51-61. https://doi.org/10.1016/j.ijedudev.2016.07.004

Baglama, B., Haksiz, M. \& Uzunboylu, H. (2018) Technologies used in education of hearing impaired individuals. International Journal of Emerging Technologies in Learning, 13 (9), 53-63. https://doi.org/10.3991/ijet.v13i09.8303

Bagon, S., Gačnik, M. \& Starčič, A.I. (2018) Information communication technology use among students in inclusive classrooms. International Journal of Emerging Technologies in Learning, 13 (6), 56-72. https://doi.org/10.3991/ijet. v13i06.8051

Bara, F., Morin, M.F., Alamargot, D. \& Bosse, M. (2016) Learning different allographs through handwriting: The impact on letter knowledge and reading acquisition. Learning and Individual Differences, 45, 88-94. https://doi.org/10.1016/j.lindif.2015.11.020

Bardin, L. (1986). El análisis de contenido. Madrid: Akal

Barrientos, P. (2017) Handwriting Development in Spanish Children with and Without Learning Disabilities: A Graphonomic Approach. Journal of Learning Disabilities, 50 (5), 552-563. https://doi.org/10.1177/0022219416633866

Barzillai, M., Thomson, J.M. \& Mangen, A. (2017) The influence of e-books on language and literacy development .Education and New Technologies: Perils and Promises for Learners, 33-47. https://doi.org/10.4324/9781315644851

Beers, S.F., Mickail, T., Abbott, R. \& Berninger, V. (2016) Effects of transcription ability and transcription mode on translation: Evidence from written compositions, language bursts and pauses when students in grades 4 to 9 , with and without persisting dyslexia or dysgraphia, compose by pen or by keyboard. Journal of Writing Research, 9 (1), 1-25 https://doi.org/10.17239/jowr-2017.09.01.01

Bin Tuwaym, S.T. \& Berry, A.B (2018). Assistive Technology for Students With Visual Impairments: A Resource for Teachers, Parents, and Students. Rural Special Education Quarterly, 37 (4), 219-227. https://doi. org/10.1177/8756870518773397

Bluestein, S.A. \& Kim, T. (2017) Expectations and fulfilment of course engagement, gained skills, and non-academic usage of college students utilizing tablets in an undergraduate skills course. Education and Information Technologies, 22 (4), 1757-1770. https://doi.org/10.1007/s10639-0169515-8 
Bodsworth, H. \& Goodyear, V.A. (2017) Barriers and facilitators to using digital technologies in the Cooperative Learning model in physical education. Physical Education and Sport Pedagogy, 22 (6), 563-579. https://doi.org/10.1080/1 7408989.2017 .1294672

Almenara, J. C. (2004). Reflexiones sobre la brecha digital y la educación. Soto, F. \& Rodríguez, J.(coords.): Tecnología, educación y diversidad: retos y realidades de la inclusión social. Murcia, Consejería de Educacióny Cultura, 23-42.

Cakir, R. \& Korkmaz, O. (2018) The effectiveness of augmented reality environments on individuals with special education needs. Education and Information Technologies, Article in Press. https://doi.org/10.1007/s10639-018-98486

Caldwell, H. (2018) Mobile technologies as a catalyst for pedagogic innovation within teacher education International. Journal of Mobile and Blended Learning, 10 (2), 50-65. https://doi.org/10.4018/IJMBL.2018040105

Camacho, M. \& Esteve, F. (2018). El uso de las tabletas y su impacto en el aprendizaje. Una investigación nacional en centros de EP. Revista de Educación, 379, 212-4068, https:/ doi.org/10.4438/1988-592X-RE-2017-379-366

Campos, J. A. (2015). El uso de las TIC, dispositivos móviles y redes sociales en un aula de la educación secundaria obligatoria. (Tesis doctoral) Granada: Universidad de Granada.

Castillo-Manzano, J.I., Castro-Nuño, M.,López-Valpuesta, L., Sanz-Díaz, M.T. \& Yñiguez, R. (2017) To take or not to take the laptop or tablet to classes, that is the question. Computers in Human Behavior, 68, 326-333. https://doi. org/10.1016/j.chb.2016.11.017

Castro, Cedillo \& Valenzuela (2016) Apropiación de las competencias digitales mediante el uso de tabletas iPads en alumnos de sexto grado de primaria. Revista ibero-americana de educação, 68(2), 123-140. Recuperado de https:// rieoei.org/historico/documentos/RIE_68_2.pdf\#page=123

Cavkaytar, A., Acungil, A.T. \& Tomris, G. (2017) Effectiveness of teaching café waitering to adults with intellectual disability through audio-visual technologies. Education and Training in Autism and Developmental Disabilities, 52 (1), 77-90.

Chambers, D., Jones, P., McGhie-Richmond, D., Riley, M., May-Poole, S., Orlando, A.M., Simsek, O. \& Wilcox, C. (2018) An exploration of teacher's use of iPads for students with learning support needs. Journal of Research in Special Educational Needs, 18 (2), 73-82. https://doi. org/10.1111/1471-3802.12394

Chen, C.H., Chiu, C.-H., Lin, C.P. \& Chou, Y.C. (2017) Students' attention when using touchscreens and pen tablets in a mathematics classroom. Journal of Information Technology Education: Innovations in Practice, 16 (1), 91-106.

Chen, W., Gu, X. \& Wong, L.-H. (2019) To click or not to click: Effectiveness of rating classroom behaviours on academic achievement with tablets. British Journal of Educational Technology, 50 (1), 440-455. https://doi.org/10.1111/ bjet. 12593

Cherner, T., Fegerly, A., Lee, C.-Y. \& Santaniello, L. A (2016) A detailed rubric for assessing the quality of teacher resource apps .Journal of Information Technology Education: Innovations in Practice, 15 (1), 117-143. https:/doi. org/10.28945/3527

Clements, D.H. \& Sarama, J. (2017) Valid issues but limited scope: A response to Kitchen and Berk's research commentary on educational technology. Journal for Research in Mathematics Education, 48 (5), 474-482. https://doi. org/10.5951/jresematheduc.48.5.0474

Cole, M., Cohen, C., Wilhelm, J. \& Lindell, R. (2018) Spatial thinking in astronomy education research Physical. Review Physics Education Research, 14 (1). https://doi. org/10.1103/PhysRevPhysEducRes.14.010139

Connor, C.M., Day, S.L., Zargar, E., Wood, T.S., Taylor, K.S., Jones, M.R. \& Hwang, J.K. (2019) Building word knowledge, learning strategies, and metacognition with the Word-Knowledge e-Book. Computers and Education, 128, 284-311. https://doi.org/10.1016/j.compedu.2018.09.016

Cordero, K., Nussbaum, M., Ibaseta, V., Otaíza, M.J. \& Chiuminatto, P. (2018) Read, write, touch: Co-construction and multi-literacies in a third-grade digital writing exercise. Journal of Computer Assisted Learning, 34 (2), 162-173. https://doi.org/10.1111/jcal.12224

Correa, A.G.D., De Biase, L.C.C., Lotto, E.P. \& Lopes, R.D. (2018) Development and Usability Evaluation of a Configurable Educational Game for the Visually Impaired. IEEE Games, Entertainment, Media Conference, GEM 2018, 173-180. https://doi.org/10.1109/GEM.2018.8516472

Da Fonte, M.A. \& Boesch, M.C. (2018) Effective augmentative and alternative communication practices: A handbook for school-based practitioners Effective Augmentative and Alternative Practices: A Handbook for School-Based Practitioners, 1-322. https://doi.org/10.4324/9781315200750

Dahan Golan, D., Barzillai, M. \& Katzir, T.(2018) The effect of presentation mode on children's reading preferences, performance, and self-evaluations Computers and Education, 126, 346-358. https://doi.org/10.1016/j.compedu.2018.08.001

Dahlström, H. \& Boström, L. (2017) Pros and Cons: Handwriting versus digital writing. Nordic Journal of Digital Literacy, 12 (4), 143-161. https://doi.org/10.18261/ issn.1891-943x-2017-04-04

Darling-Aduana, J. \& Heinrich, C.J. (2018) The role of teacher capacity and instructional practice in the integration of educational technology for emergent bilingual students Computers\&Education, 126, 417-432. https://doi.org/10.1016/j.compedu.2018.08.002

Daya, A. \& Laher, S. (2019) Exploring the Influence of Educators' Access to and Attitudes towards Educational technology on the Use of Educational Technology in Johannesburg School Africa Education Review, Article in Press. https://doi.org/10.1080/18146627.2018.1490154

De La Serna-Tuya, A.S., González-Calleros, J.M. \& Rangel, 
Y.N. (2018). App design for tablet use on preschool teaching (Diseño de App para el uso de la tablet en la enseńanza de preescolares Campus Virtuales, 7 (1), 111-123. https://doi. org/10.2478/dfl-2014-0009

Ditrendia (2017). Informe Mobile en España y en el Mundo 2017. Recuperado de https://www.amic.media/media/ files/file_352_1289.pdf

Dolan, J.E. (2016) Splicing the divide: A review of research on the evolving digital divide among K-12 students. Journal of Research on Technology in Education, 48 (1), 16-37. https://doi.org/10.1080/15391523.2015.1103147

El Kah, A. \& Lakhouaja, A. (2018) Developing effective educative games for Arabic children primarily dyslexics. Education and Information Technologies, 23 (6), 29112930. https://doi.org/10.1007/s10639-018-9750-2

Emiroğlu, B.G. \& Kurt, A.A. (2017) Use of augmented reality in mobile devices for educational purposes. Mobile Technologies and Augmented Reality in Open Education, 95117. https://doi.org/10.4018/978-1-5225-2110-5.ch005

Fage, C., Consel, C., Etchegoyhen, K., Amestoy, A.,Bouvard, M., Mazon, C. \& Sauzéon, H.(2019) An emotion regulation app for school inclusion of children with ASD: Design principles and evaluation. Computers and Education, 131, 11- 21. https://doi.org/10.1016/j.compedu.2018.12.003

Falloon, G (2017). Mobile Devices and Apps as Scaffolds to Science Learning in the Primary Classroom. Journal of Science Education and Technology, 26 (6), 613-628. https://doi.org/10.1007/s10956-017-9702-4

Ferguson, J.M.(2017) Middle school students' reactions to a 1:1 iPad initiative and a paperless curriculum Education and Information Technologies, 22 (3), 1149-1162. https:// doi.org/10.1007/s10639-016-9480-2

Ferguson, J.M. \& Oigara, J.N. (2017) iPads in the classroom: What do teachers think? International Journal of Information and Communication Technology Education, 13 (4), 74-86. https://doi.org/10.4018/IJICTE.2017100106

Ferri, P. \& Moriggi, S.(2017) «Children go touch»: Notes on the way young children's ( $0-10$ years) appropriation of new (touchscreen) technologies is leading us to revisit our teaching strategies and vision of learning [Article@«Children go touch»: Note sulle pratiche di appropriazione delle tecnologie («touch») dei più piccoli (0-10 anni) e sulla necessità di una didattica digitalmente aumentata]. Journal of Educational, Cultural and Psychological Studies, (15), 185-197. https://doi.org/10.7358/ecps-2017-015-ferr

Fleisch, B., Schöer, V., Roberts, G. \& Thornton, A.(2016) System-wide improvement of early-grade mathematics: New evidence from the Gauteng Primary Language and Mathematics. Strategy International Journal of Educational Development, 49, 157-174. https://doi.org/10.1016/j. ijedudev.2016.02.006

Fletcher-Watson, S., Pain, H., Hammond, S., Humphry, A. \& McConachie, H. (2016) Designing for young children with autism spectrum disorder: A case study of an iPad app.
International Journal of Child-Computer Interaction, 7, 1-14. https://doi.org/10.1016/j.ijcci.2016.03.002

Fokides, E. (2018) Teaching basic programming concepts to young primary school students using tablets: Results of a pilot project. International Journal of Mobile and Blended Learning, 10 (1), 34-47. https://doi.org/10.4018/IJMBL.2018010103

Fokides, E. \& Atsikpasi, P. (2017) Tablets in education. Results from the initiative ETiE, for teaching plants to primary school students Education and Information Technologies, 22 (5), 2545-2563. https://doi.org/10.1007/s10639-0169560-3

Fujita, A., Todo, N., Sugawara, S., Kageura, \& K., Arai, N.H. (2017) Development of a Reading Skill Test to Measure Basic Language Skills Proceedings - IEEE 8th International Conference on Technology for Education, T4E 2016, 156-159. https://doi.org/10.1109/T4E.2016.040

Garcia-Sanjuan, F., Jurdi, S., Jaen, J., \& Nacher, V. (2018) Evaluating a tactile and a tangible multi-tablet gamified quiz system for collaborative learning in primary education Computers and Education, 123, 65-84. https://doi. org/10.1016/j.compedu.2018.04.011

Geer, R., White, B., Zeegers, Y., Au, W. \& Barnes, A. (2017) Emerging pedagogies for the use of iPads in schools. British Journal of Educational Technology, 48 (2), 490-498. https://doi.org/10.1111/bjet.12381

Hassan, M. \& Geys, B. (2016) Expectations, realizations, and approval of tablet computers in an educational setting, Journal of Educational Change, 17 (2), 171-190. https:// doi.org/10.1007/s10833-015-9270-4

Haßler, B., Major, L. \& Hennessy, S. (2016) Tablet use in schools: A critical review of the evidence for learning outcomes. Journal of Computer Assisted Learning, 32 (2), 139156. https://doi.org/10.1111/jcal.12123

inspiraTICs .Recuperado de https://www.inspiratics.org/es/ inspiratics

Javorcik, T. (2017) PLE as a tool for the development of the learning to learn competence. Proceedings of the European Conference on e-Learning, ECEL, 2010-October, 211-220.

Kolas, L., Nordseth, H. \& Munkvold, R. (2016) Learning with educational apps: A qualitative study of the most popular free apps in Norway. 15th International Conference on Information Technology Based Higher Education and Training, ITHET 2016. https://doi.org/10.1109/ ITHET.2016.7760701

Maraza, B. (2016) Hacia un aprendizaje personalizado en ambientes virtuales. Campus Virtuales, 5(1), 20-29. Recuperado de http://goo.gl./nwu8Ra

Ortega, C. \& Febles, J P., (2016) Modelo Conceptual Para La Introducción De Las Tabletas Digitales En La Enseñanza Primaria (Conceptual Model for the Introduction of Digital Tablets in Primary Education). GECONTEC: Revista Internacional de Gestión del Conocimiento y la Tecnología, Vol. 4(2). Recuperado de https://ssrn.com/abstract=2876107 
Salmerón, H., Gutiérrez, C. \& Rodríguez, S. (2010) Metodologías que optimizan la comunicación en entornos de aprendizaje virtual. Comunicar, 34(17), 163-171. https:// doi.org/10.3916/C34-2010-03-16

Sánchez Martínez, C. \& Ricoy, M.C. (2018). Posicionamiento de la familia ante el uso de la tableta en el aprendizaje del alumnado de EP. Digital Education review- 33. Recuperado de http:// greav.ub.edu/der

Sayago, S. (2014). Discourse analysis as a qualitative and quantitative technique in the social sciences. Cinta de moebio, (49), 1-10. https://doi.org/10.4067/S0717554X2014000100001

Shamir-Inbal, T. \& Blau, I. (2016) Developing Digital Wisdom by Students and Teachers: The Impact of Integrating Tablet Computers on Learning and Pedagogy in an Elementary School. Journal of Educational Computing Research, 54 (7), 967-996.. https://doi.org/10.1177/073563311664937

Suárez-Guerrero, C., Lloret-Catalá, C. \& Mengual Andrés, S. (2016) Percepción docente sobre la transformación digital del aula a través de tabletas: un estudio en el contexto español. Comunicar, 49, v. XXIV. http://dx.doi.org/10.3916/ C49-2016-08

Van Deur, P. (2017) Managing self-directed learning in primary school education: Emerging research and opportunities Managing Self-Directed Learning in Primary School Education: Emerging Research and Opportunities, 1-147. https://doi.org/10.4018/978-1-5225-2613-1

Villányi, D., Martin, R., Sonnleitner, P., Siry, C. \& Fischbach, A. (2018) A tablet-computer-based tool to facilitate accurate self-assessments in third- and fourth-graders. International Journal of Emerging Technologies in Learning, 13 (10), 225-251. https://doi.org/10.3991/ijet.v13i10.8876

Walsh, V.\& Farren, M. (2018) Teacher Attitudes Regarding Barriers to Meaningfully Implementing iPads in a Primary School Setting Computers in the Schools, 35 (2), pp. $152-$ 170. DOI: $10.1080 / 07380569.2018 .1462674$

Young, K. (2016) Teachers' Attitudes to using iPads or Tablet Computers; Implications for Developing New Skills, Pedagogies and School-Provided Support. TechTrends, 60 (2), 183-189. https://doi.org/10.1007/s11528-016-0024-9 Zydney, J.M. \& Warner, Z. (2016) Mobile apps for science learning: Review of research Computers and Education, 94, 1-17. https://doi.org/10.1016/j.compedu.2015.11.001 


\section{Anexo I}

\begin{tabular}{|c|c|}
\hline Guía de análisis & $\begin{array}{l}\text { Revistas especializadas en tecnología } \\
\qquad \%)\end{array}$ \\
\hline \multicolumn{2}{|l|}{ Citas } \\
\hline \multicolumn{2}{|l|}{ Palabras clave } \\
\hline \multicolumn{2}{|l|}{ Revista } \\
\hline \multicolumn{2}{|l|}{ Año de publicación } \\
\hline \multicolumn{2}{|l|}{ País de procedencia } \\
\hline \multicolumn{2}{|l|}{ Lengua } \\
\hline \multirow[t]{7}{*}{ Etapa educativa } & Educación Infantil \\
\hline & Educación primaria \\
\hline & Educación Secundaria \\
\hline & Educación Superior \\
\hline & $\mathrm{Fp}$ \\
\hline & Profesorado \\
\hline & Interetapa \\
\hline \multirow[t]{3}{*}{ Tipología de publicaciones } & Artículos \\
\hline & Capítulos de libro \\
\hline & Libros de actas \\
\hline \multirow[t]{2}{*}{ Tipo de estudio } & Investigación \\
\hline & Experiencia \\
\hline \multirow[t]{14}{*}{ Análisis de contenido } & Temáticas \\
\hline & Mejoras/barreras.... \\
\hline & Compentencias generales \\
\hline & Competencias específicas \\
\hline & Rendimiento académico \\
\hline & Barreras en el proceso \\
\hline & Implicaciones metodológicas \\
\hline & Interdisciplinariedad \\
\hline & Nuevas metodologías \\
\hline & Efectos en el alumno (motivación) \\
\hline & Atención a la diversidad \\
\hline & Neae \\
\hline & Ámbito sociocultural \\
\hline & Otros \\
\hline Resultados & \\
\hline
\end{tabular}




\section{PARES REVISORES}

Hamut'ay 6(1). Enero-abril 2019

Dr. Joan Marc Ramos Sabaté

Docente investigador.

Universidad de Barcelona, España

Dr. Javier Fombona Cadavieco

Facultad de Formación del Profesorado y Educación.

Docente investigador. Universidad de Oviedo, España.

Dra. Mercedes Ahumada Torres

Profesora del Departamento de Educación.

Universidad Internacional de Valencia, España

Dr. Rafael Morales Gamboa

Profesor Investigador en el Instituto de Gestión del Conocimiento y del Aprendizaje en Ambientes Virtuales -

Sistema de Universidad Virtual.

Universidad de Guadalajara, México

Dra. Mercedes Sánchez Ambriz

Coordinadora académica del módulo de Educación a distancia, Instituto Latinoamericano de la Comunicación Educativa (ILCE). Miembro del Consejo Editorial de la Revista de la Academia de Educación abierta y a distancia. México.

\section{Dra. Gema Paramio Pérez}

Docente investigador.

Universidad de Cádiz, España

\section{Dra. Paloma Contreras Pulido}

Docente investigador.

Universidad Internacional de La Rioja, Espańa

Dra. Patricia de Casas Moreno

Profesora Asociada.

Universidad Antonio de Nebrija, España

Dr. Angel Luis Torres Toukoumidis

Docente tiempo completo.

Universidad Politécnica Salesiana, Ecuador

Adriana Huertas PhD.

Directora Investigación - UDCII. Facultad de Educación.

Universidad Antonio Narińo, Bogotá, Colombia

Dra. María Santamarina Sancho

Docente investigador.

Universidad de Granada, España
Dr. Jesús Valverde Berrocoso

Director Revista Latinoamericana de Tecnología Educativa, RELATEC. Investigador especialista en TIC y Educación. Director del grupo de investigación NODO Educativo.

Universidad de Extremadura, España

\section{Dr. Marcos Cabezas Gonzáles}

Investigador en la Facultad de Educación y miembro del Grupo de Investigación-Innovación en Tecnología

Educativa (GITE-USAL)

Universidad de Salamanca, España

\section{Dr. Jesús Rodríguez Rodríguez.}

Presidente de Lartem. Director de la Revista Galega de Educación. Miembro del equipo de investigación Stellae

(USC). Universidade de Santiago, España

Dra. Silvia López Gómez

Docente investigadora. Miembro del equipo de investigación Stellae (USC)Universidade de Vigo, España

Dr. Juan Antonio Fuentes Esparrell Docente investigador.

Universidad de Granada, España

Dra. Belinda Izquierdo García Investigadora.

Universidad Veracruzana, México

Carlos Alberto Ramos, $\mathrm{PhD}$

Profesor Principal de la Facultad de Psicología. Pontificia Universidad Católica del Ecuador

Sandra Sánchez Gordón, Phd

Docente e investigadora en Informática Aplicada y Ciencias de la computación. Escuela Politécnica Nacional, Ecuador 


\section{INSTRUCCIONES PARA AUTORES}

La revista electrónica "HAMUT'AY" es una publicación científica cuatrimestral de la Coordinación de Investigación y Extensión Científica Tecnológica de la Dirección de Educación a Distancia de la Universidad Alas Peruanas.

Su objetivo es divulgar artículos científicos a texto completo sobre tecnologías y virtualidad en los diferentes ámbitos profesionales y académicos dirigido a toda la comunidad universitaria del nivel de pregrado y posgrado nacional e internacional.

\section{Periodicidad}

La revista publica un volumen al año conformado por tres números cuatrimestrales publicados en los meses de abril, agosto y diciembre.

\section{Tipos de ARTí́culos a PUBlicar}

La revista científica HAMUT'AY acepta dos categorías de artículos a publicar:

- Artículos de investigación científica y tecnológica: (López, 2013, Publindex, 2010) son investigaciones originales, que presentan resultados de proyectos de investigación académicas y/o tecnológicas concluidas o en proceso.

- Artículo de revisión: (Fernández-Ríos \& Buela-Casal 2009) Es la síntesis de estudios bibliográficos de un tema determinado, en el que se analiza, sintetiza y discute la revisión de la literatura y/o análisis de información publicada de una manera integrada.

\section{EstruCtura de los TIPOS DE ARTí́culos}

Los artículos deberán ser redactados con el software Microsoft Word, siguiendo las normas de estilo APA (American Psychological Association) Sexta edición, como se describe: tamaño de papel A4, con márgenes $2.5 \mathrm{~cm}$.; fuente Times New Román, tamaño 12 e interlineado a doble espacio.

En el encabezado deberá ir el título del artículo y los nombres completos de los autores, según el orden de participación. Un resumen que no exceda de 250 palabras y como máximo 5 palabras claves

Cada una de las páginas del artículo debe estar numerada consecutivamente.

La fuente de datos para la revisión de la literatura será de fuentes confiables como Scopus, Wos y/o repositorios institucionales, y debe tener, en lo posible, su identificador digital permanente (DOI) y con 5 años de antiguedad como máximo.

\section{COMPOSICIÓN DE LOS TIPOS DE ARTí́culos}

- Los artículos de investigación científica y tecnológica: (López, 2013; Bobenrieth, 2002) está compuesta por título, autor(es), resumen (abstract), palabras claves (keywords), introducción (antecedentes, objetivos), revisión de la literatura (fundamentos teóricos del estudio) materiales y método (participantes, instrumento, diseño, procedimiento) resultados (interpretación tablas y figuras), discusión y conclusiones, referencias bibliográficas, agradecimientos (opcional) y anexos. Esquema y formato de artículo Científico y/o tecnológico original (EFACYT). 30 páginas y máximo 4 autores.

- Los artículos de revisión: (Fernández-Ríos \& Buela-Casal 2009, p.332) están compuestos del título, autor(es), resumen (abstract), palabras claves (keywords), introducción, método (criterios de selección de la literatura) revisión de la literatura (Marco teórico del tema de revisión), conclusiones, (aspectos relevantes de la revisión de la literatura y sugerencias o recomendaciones a futuro) referencias bibliográficas, agradecimientos (opcional) y anexos. Esquema y Formato de Artículo de Revisión (EFAR) 25 páginas, hasta tres autores. 


\section{ORIGINALIDAD DE LOS MANUSCRITOS}

Siendo la originalidad una de las políticas editoriales de la revista Hamut'ay, se realiza de la siguiente manera:

1. Una primera revisión por el comité editorial, de que se cumpla con citar y referenciar todas las fuentes que se mencionan en el manuscrito.

2. Posteriormente, para verificar que no existe plagio se analiza con software especializado de antiplagio, (Turnitín).

3. Una vez realizado el análisis el software arroja un informe, en el que se describe detalladamente, si existe plagio o no, mostrando un porcentaje de $0-100 \%$. Si hubiera plagio indica el porcentaje y las citas y referencias originales de donde se tomaron los contenidos o datos, lo cual se informa al autor en la primera fase del sistema de arbitraje del artículo. Para que realice los cambios que correspondan y pueda continuar con el segundo proceso editorial, que es la revisión a doble ciego.

\section{RESPONSABILIDAD ÉTICA}

El autor o autores que envíen sus manuscritos a publicación en la revista Hamut'ay, (COPE, 2011), debe considerar lo siguiente:

1. Garantizar que el artículo es un documento original e inédito y no ha sido publicado, total ni parcialmente, en otra revista y no está siendo considerado simultáneamente para publicación y se compromete a no presentar este trabajo a otra revista para su publicación, hasta recibir la decisión editorial de la Revista Científica Hamut'ay sobre su publicación.

2. Certificar que han contribuido directamente al contenido intelectual del manuscrito, a la génesis y análisis de los datos, haciéndose responsable de éste.

3. Dejar constancia que se ha respetado los criterios éticos en la investigación y el cumpliendo de la obtención del consentimiento informado de los participantes y/o instituciones sujetas a investigación.

4. Garantizar no haber copiado sin citar o referenciar o sin solicitar permiso de otras inves- tigaciones; plagio o autoplagio, ni la creación de datos falsos.

Los cuatro criterios descritos están refrendados por el autor o autores con su firma en la Declaración Jurada de Autoría y Autorización para publicación de trabajo científico en la Revista Hamut'ay, (DEJA), el cual es enviado conjuntamente con el artículo aceptado a publicación.

\section{Sistema de Arbitraje de los artículos}

Los artículos enviados a la revista Hamut 'ay son sometidos a un proceso de evaluación, considerando los estándares y normas establecidos.

Primera fase: El comité editorial verifica el cumplimiento de los siguientes criterios:

1. Los de estructura y de forma según las instrucciones para autores, redactado en el esquema y formato normado por la revista según tipo de artículo (EFACYT o EFAR).

2. Coherencia y claridad en la redacción de contenidos y secuencialidad con lo propuesto en el manuscrito, normas de ortografía, citación adecuada según normas de estilo APA Sexta edición, entre otros aspectos.

3. Se evalúa si cumple con las normas éticas establecidas por la revista.

4. Verificación de originalidad del manuscrito, a través de la revisión de software antiplagio especializado, (Turnitín).

En el caso que el manuscrito en esta primera fase cumpla con los cuatro criterios descritos, este será aceptado para seguir la revisión y evaluación en la segunda fase con los pares evaluadores externos.

Segunda fase: Para la segunda fase la revista cuenta con un staff de pares evaluadores externos a nivel internacional y nacional, con grado académico de magíster y doctor, expertos en el tema a revisar, miembros de grupos de investigación y con experiencia en publicaciones científicas.

La revisión y evaluación de los manuscritos son bajo el sistema a doble ciego, ni los pares revisores ni los autores conocen sus identidades, siendo el proceso el siguiente: 
1. Los pares evaluadores determinan el valor del contenido del artículo y sus aspectos metodológicos, evaluando la calidad científica del mismo, para lo cual se le hará entrega de manera anónima los manuscritos al correo asignado por ellos, cuando aceptaron la invitación de formar parte del staff de pares evaluadores de la revista.

2. Para la evaluación y calificación del manuscrito se le entregará el Protocolo de Artículo original (PEAO) o el Protocolo de artículo de revisión (PEAR) incluyendo en el mismo una hoja con sugerencias $y / u$ observaciones a ser levantadas por lo(s) autor(es).

3. Los pares evaluadores emiten uno de los siguientes criterios: No publica, Publica con condición y publica.

4. Si se da el criterio de Publica con condición se remitirá al autor(es) de manera anónima la calificación, para que levante las observaciones, luego éste devolverá al editor el manuscrito corregido, para que se envíe nuevamente al par revisor para su decisión final.

5. En el caso de que un manuscrito tenga la aceptación de un par evaluador y del otro no, para dirimir se remitirá a un tercer evaluador, quien definirá uno de los tres criterios de publicación para la aceptación o rechazo del mismo.

El editor y consejo editorial considerando la calificación de "publica" de los pares evaluadores y luego que el manuscrito cumpla con el objetivo de la revista, se procederá a notificar vía correo electrónico la aceptación a publicación del manuscrito, el cual se envía en su versión final con la corrección de estilo y traducción, para la verificación del autor, quien devolverá a la revista el manuscrito y el consentimiento de publicación firmado (DEJA).

\section{Envío de Manuscritos}

Los autores deberán enviar al Editor jefe de la revista, Dra. Cleofé Alvites Huamaní, el manuscrito a someter a publicación, vía correo electrónico a revistahamutay@uap.edu.pe. Al recibir la misiva se les confirmará la recepción del manuscrito, que también puede realizarse a través de la web de la revista, previa inscripción. La recepción está abierta durante todo el año.

\section{Políticas de Derechos de Autor}

Para preservar los derechos de autor se ha considerado lo siguiente:

1. Los autores conceden el permiso para que su manuscrito al haber sido aceptado a publicación se divulgue en la revista Hamut'ay bajo Licencia Creative Commons Attribution (CC BY: https://creativecommons.org/licenses/by/4.0/).

2. Los autores aceptan que siendo la revista Hamut'ay de acceso abierto al conocimiento científico, comprenden que no se le otorgará regalías ni otra compensación monetaria.

3. Aceptan el permitir la copia y distribución por cualquier medio de su manuscrito, siempre que se mantenga el reconocimiento de los autores y no se realice modificaciones.

4. Los archivos de los manuscritos aceptados o no, no serán compartidos con terceros ni durante ni después de la realización del proceso editorial, excepto se tenga una autorización escrita por el autor.

Los cuatro criterios descritos estarán refrendados por los autores con su firma en la Declaración Jurada de Autoría y Autorización para publicación de trabajo científico en la Revista Hamut'ay, (DEJA), el cual es enviado conjuntamente con el artículo aceptado a publicación y con la licencia Creative Commons Attribution.

\section{RefERENCIAS BibliográficAs}

Las referencias y citas bibliográficas deberán considerar las Normas de estilo APA, sexta edición.

\section{Libros:}

Cabello, R. \& Levis, D. (2007), Medios informáticos en la educación a principios del siglo XXI, (pp.107) 1era. Edición. Argentina: Publicaciones Prometeo Libros.

\section{Capítulos de libros:}

García, A., Cocero, D., Velázquez, J., Blanco, E., 
Grande, M., Núñez, M.V. \& Tejera, R. (2006) Aplicación de la teledetección a la gestión silvopastoral. En Camacho Olmedo, M., Cañete, J. \& Lara, J. (ed.) El acceso a la información espacial y las tecnologías geográficas. (pp.831-842). España Granada: Editorial universidad de Granada.

\section{Artículos publicados en revistas:}

Padilla, J., Rincón, D., \& Buitrago, L. (2015) La investigación formativa desde la teoría de las representaciones sociales en la Facultad de Estudios a Distancia de la Universidad Militar Nueva Granada. Revista Academia y Virtualidad, 8 (1), 21-34.

\section{Artículos publicados en revistas con DOI:}

Alcalde-Alvites, M.A. (2016) Software libre enfocados en diversos campos de las ciencias biológicas. Revista Hamut ay, 3 (1) 59-70. https://doi. org/10.21503/hamu.v3i1.1000

\section{Tesis:}

Carmona, J. (2012) Aplicaciones de la simulación tridimensional para la detección precoz de consumo de sustancias y violencia escolar en ámbitos educativos entre los años 2011 y 2012. (Tesis doctoral). Universidad de Almería, España.

\section{Tablas:}

El título será claro, conciso y descriptivo del contenido de la tabla. Solo la palabra inicial lleva mayúsculas y no se coloca punto al final del título. Véase modelo siguiente:

Tabla X

Proporción de errores en grupos de jóvenes y adultos

\begin{tabular}{|c|c|c|c|c|c|c|}
\hline \multirow{2}{*}{$\begin{array}{l}\text { Nivel de } \\
\text { dificultad }\end{array}$} & \multicolumn{3}{|c|}{ Jóvenes } & \multicolumn{3}{|c|}{ Jóvenes } \\
\hline & $n$ & $M(D E)$ & $95 \%$ IC & $n$ & $M(D E)$ & $95 \%$ IC \\
\hline Bajo & 12 & $.05(.08)$ & {$[.02, .11]$} & 18 & $.01(.15)$ & {$[.08, .22]$} \\
\hline Moderado & 15 & $.05(.07)$ & {$[.02, .10]$} & 12 & $.17(.15)$ & {$[.08, .28]$} \\
\hline Alto & 16 & $.11(.10)$ & {$[.07, .17]$} & 14 & $.26(.21)$ & {$[.15, .39]$} \\
\hline
\end{tabular}

Nota: IC = Intérvalo de confianza

Fuente: APA (2010, p.157)

\section{Figuras:}

Son gráficas, fotografías, diagramas y dibujos en formato JPG de calidad alta. El título será breve y conciso. Véase el siguiente ejemplo.

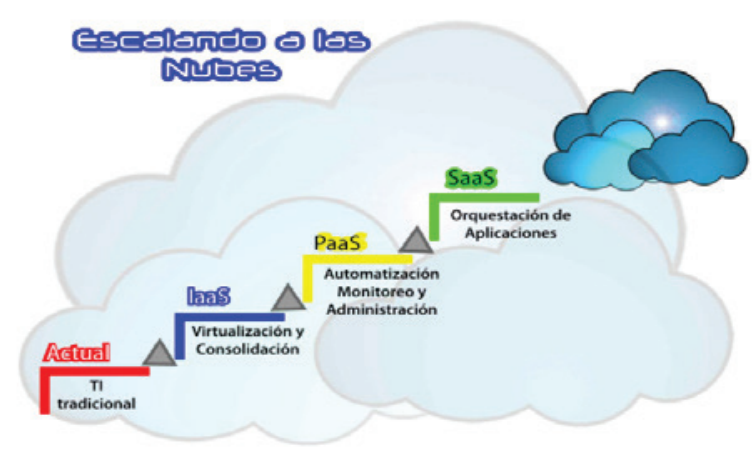

Figura X. Proporción de errores en grupos de jóvenes y adultos (De acuerdo con Baron \& Kenny, 1996) Adaptado de "Preschool Home Literacy Practices and Children's Literacy Department: A Longitudidal Analysis" por M. Hood, E. Conlon \& G. Andrews, 2008, Journal of Education Psychology, 100, p.259. Copyright 2008 por la American Psychological Association.

Fuente: APA (2010, p.170)

\section{Referencias Bibliográficas}

APA - American Psycgological Association (2010). Manual de Publicaciones de la American Psychological Association. (3ra. Ed.) México: El Manual Moderno.

Bobenrieth, M. (2002) Normas para revisión de artículos originales en Ciencias de la Salud. Revista Internacional de Psicología Clínica y de la Salud, 2 (4) 509-523.

COPE (2011) Code of conduct and best practice guidelines for journal editor. Committee on publication ethics-COPE. Version 4, Publicationethics.org.

Fernandez-Ríos, L. \& Buela-Casal, G. (2009) Standards for the preparation and writin of Psychology review articles. Revista International Journal of Clinical and Health Psychology, 9 (2) 329-344

López, S. (2013) El proceso de escritura y publicación de un artículo científico. Revista Electrónica Educare, 17 (1), 5-27. Recuperado de http://www.revistas.una.ac.cr/index. php/EDUCARE/issue/current

Publindex (2010) Documento Guía, servicio permanente de indexación de Revistas de Ciencia, Tecnología e innovación colombianas, Base Bibliográfica Nacional-BBN, Índice bibliográfico nacional Publindex-IBN. 